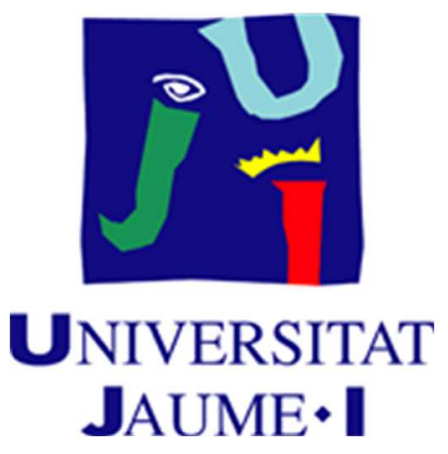

UNIVERSITAT JAUME I DE CASTELLÓ

ESCUELA SUPERIOR DE TECNOLOGÍA Y CIENCIAS EXPERIMENTALES

Departamento de Ingeniería Química

\title{
METODOLOGÍAS PARA LA CUANTIFICACIÓN DE LAS EMISIONES DIFUSAS DE MATERIAL PARTICULADO EN ENTORNOS INDUSTRIALES
}

\author{
MEMORIA \\ que para optar al grado de \\ Doctora en Ingeniería Química presenta \\ VICENTA SANFÉLIX FORNER \\ Castellón, 2017
}



ELISEO MONFORT GIMENO, CATEDRÁTICO DE INGENIERÍA QUÍMICA DE LA UNIVERSITAT JAUME I, E IRINA CELADES LÓPEZ, DOCTORA EN INGENIERÍA QUÍMICA

CERTIFICAN: Que Dña. Vicenta Sanfélix Forner ha realizado bajo su dirección, en los laboratorios del Instituto de Tecnología Cerámica, dentro del programa de doctorado «Tecnologías industriales, materiales y edificación» de la Universitat Jaume I de Castellón, el trabajo que bajo el título «Metodologías para la cuantificación de las emisiones difusas de material particulado en entornos industriales» presenta en esta memoria y que constituye su tesis para optar al grado de Doctora en Ingeniería Química.

Y para que conste a los efectos oportunos, firman el presente certificado en Castellón, a 14 de junio de 2017.

Eliseo Monfort Gimeno

Catedrático de Ingeniería Química
Irina Celades López

Doctora en Ingeniería Química 

Este estudio ha sido financiado a través de tres proyectos de investigación:

1) Emisiones de material particulado en focos canalizados y difusos de la industria cerámica. Caracterización y modelización (REN2003-08916-C02-01). Ministerio de Economía y Competitividad.

2) Cuantificación y caracterización de emisiones difusas de partículas en la gestión y transporte de materiales pulverulentos (CGL2009-14680-C02-01). Ministerio de Ciencia y Tecnología.

3) Control de las emisiones difusas de material particulado: Propuesta de medidas correctoras. Ministerio de Agricultura, Alimentación y Medio Ambiente, a través de la Fundación Biodiversidad. 

A mis padres, Antonio y Tica 



\section{Agradecimientos}

La consecución del trabajo presentado en esta tesis ha sido posible gracias al trabajo en equipo de un grupo de personas del que me siento muy afortunada de pertenecer, tanto por su calidad humana como técnica. Muchas gracias a todos.

Gracias a mis directores de tesis por haberme ofrecido la oportunidad de realizar esta tesis doctoral, y por la confianza mostrada en mí en todo momento. Eliseo e Irina sois los autores de mi trayectoria en el mundo de las emisiones industriales, gracias por aportarme tantos conocimientos y por ofrecerme vuestras sugerencias para mejorar el contenido y comprensión de la tesis. Estos años con vosotros me han ayudado a crecer profesional y personalmente, os estoy muy agradecida.

Gracias Alberto por estar siempre disponible cuando te he necesitado, que no ha sido poco. Este trabajo no hubiera sido posible sin tus magníficas aportaciones científicas en el campo de la modelización. Gracias por tu paciencia durante las explicaciones. Eres un «crack» (en comillas francesas) en todos los sentidos, a nivel personal eres excepcional y profesionalmente un fuera de serie.

Gracias David por tu gran ayuda con los problemillas informáticos. Me has demostrado que aun eres mejor persona de lo que sabía, siempre con soluciones para mejorar el formato de la tesis.

A mis compañeros de unidad: Salva, Raúl, Alicia, Fernando y Teresa, gracias por la buena armonía que compartimos y por darme muchos ánimos en los momentos de bajón y de lágrima fácil. Raúl hemos conseguido que nos conocieran todos los guardias de seguridad, gracias por las gratas conversaciones que hemos tenido en nuestras largas tardes de trabajo. Sois unos excelentes compañeros.

A mis compañeros de tesis: Ana, Raúl y Alberto, con los que he compartido muchas preocupaciones y algunas alegrías, gracias por hacer este viaje más llevadero. Gracias Ana por tu ayuda, nuestras tesis inician una colección sobre el estudio de las emisiones difusas.

Gracias al ITC por ofrecerme la posibilidad y facilitarme la realización del presente trabajo.

Gracias al IDAEA por los análisis químicos realizados.

Gracias a Silvia y Encarna por las fotografías del MEB.

Gracias a las empresas que nos han permitido realizar las campañas experimentales para la consecución de los resultados del presente trabajo, sin su colaboración no hubiera sido posible alcanzarlos.

Gracias a mi maravillosa familia, Edu y Sofía, que han contribuido a mejorar enormemente mi vida personal. Gracias por animarme y comprender todo el tiempo que he tenido que dedicar a esta nueva meta y por recibirme siempre con una sonrisa.

Gracias a mis padres por estar siempre ahí, en todos los momentos de mi vida, sé que mi padre se siente muy orgulloso de su niña. Gracias mamá por quererme y ayudarme tanto. Gracias a mis hermanos, Toni, Javi, Alberto y Pablo por animarme y mostrarme siempre vuestro apoyo. Gracias a Eduardo y Palmira por vuestro ánimo y ayuda.

Gracias a todos por permitirme realizar el trabajo en un ambiente de confianza, afecto y amistad. 



\section{Resumen}

El transporte, almacenamiento y manipulación al aire libre de materiales sólidos pulverulentos conlleva frecuentes episodios de contaminación atmosférica por emisiones difusas de material particulado (PM), cuyo impacto sobre la calidad del aire y el medio ambiente puede llegar a ser significativo.

Este tipo de emisiones tienen mayor relevancia en determinados entornos geográficos con presencia de actividades industriales tales como cerámicas, cementeras, plantas de hormigón, canteras, fundiciones de acero, centros logísticos de biomasa, muelles de graneles sólidos en puertos, entre otras. Asimismo, en zonas donde se estén ejecutando trabajos de construcción o demolición, estas emisiones también pueden llegar a ser importantes.

Desde un punto de vista técnico y legislativo, a la gestión y control de las emisiones difusas de PM se les ha prestado tradicionalmente una atención limitada. Este hecho se refleja claramente en las metodologías de control establecidas actualmente, en las que se detectan una serie de limitaciones: aplicación de valores límites propios de legislación de calidad del aire, y por tanto, desarrollados para núcleos urbanos con una casuística y problemática diferente a la de los entornos mencionados; desconocimiento de la eficacia de las Mejores Técnicas Disponibles (MTD) propuestas en las Autorizaciones Ambientales Integradas (AAl); y falta de información sobre factores de emisión (FE) para inventarios de detalle.

Esta situación probablemente pueda deberse a la complejidad inherente que conlleva la cuantificación y control de las emisiones difusas de PM, influida por diferentes factores como: su naturaleza discontinua y corta duración; la dependencia de las condiciones meteorológicas; la variabilidad de la posición de determinadas fuentes con el tiempo; la presencia simultánea de diferentes fuentes emisoras; y la influencia de las propiedades del material manipulado y de las medidas correctoras implementadas.

En este contexto y con el objeto de conocer con mayor detalle el alcance de las emisiones difusas de PM10 e identificar las necesidades para su control, se ha realizado un estudio exhaustivo en el sector cerámico, por ser uno de los sectores donde este tipo de emisiones son habituales. En una primera fase, se ha procedido a su cuantificación en distintos tipos de escenarios tecnológicos (parques de almacenamiento de materias primas cerrados, semicerrados y abiertos). Con este fin se ha aplicado una metodología analítica, basada en realizar un inventario de detalle de todas las operaciones generadoras de emisiones difusas de PM. Asimismo, se han estimado los rendimientos de mejora alcanzados cuando se implementan un conjunto de MTD recogidas en las AAI otorgadas a empresas del sector cerámico. El estudio se ha completado mediante una caracterización química y morfológica del PM emitido, la cual ha permitido identificar la contribución de fuentes externas (fondo local, regional y focos de emisión colindantes) en el perfil químico y morfológico obtenido.

Los resultados alcanzados muestran que las emisiones difusas de PM10 en el sector cerámico pueden deteriorar significativamente la calidad del aire si no se aplican medidas correctoras de elevada eficacia, tales como el cerramiento parcial o total de los parques de almacenamiento y gestión de materias primas.

En general, la metodología aplicada ha permitido obtener FE globales por tipo de instalación, lo que se considera de enorme interés práctico, ya que permite simplificar la cuantificación de las emisiones difusas para dar respuesta a determinados requisitos legislativos, como, por ejemplo, la cumplimentación del Registro Estatal de Emisiones. Sin embargo, estos FE globales no permiten identificar las operaciones más problemáticas de un proceso, situación que dificulta la determinación 
de medidas correctoras específicas para cada operación. Esta información sería de gran interés para la optimización del diseño de las instalaciones, por lo que para un mayor control operacional e inventarios de detalle este tipo de FE puede no ser suficiente.

Por las razones comentadas y, con el objetivo de disponer de información real y precisa sobre las emisiones difusas de PM, se ha desarrollado una metodología experimental para la determinación de FE específicos, para operaciones y materiales de interés, y de la eficacia de MTD concretas. Esta metodología, ha requerido tanto del desarrollo de un modelo de dispersión de contaminantes acorde a las peculiaridades de las emisiones difusas de PM, como de un protocolo de ejecución de las campañas experimentales, el cual permite introducir de forma apropiada en el modelo propuesto las condiciones atmosféricas y las características de la emisión de la forma más realista posible.

Concretamente, el modelo de dispersión desarrollado es un modelo no estacionario que incorpora todas las particularidades con relevancia en los procesos de emisión y dispersión. En consecuencia, permite determinar el campo de velocidades y la dispersión vertical considerando la estructura de la capa límite planetaria, simular los meandros descritos por la pluma resultante de la emisión y tratar fuentes de geometría arbitraria e intermitentes.

La aplicación de dicha metodología a escenarios industriales reales ha permitido obtener de forma satisfactoria FE específicos, tanto para fuentes simples como complejas, debido a la flexibilidad del modelo de dispersión de contaminantes desarrollado y a la parametrización exhaustiva de las fuentes de emisión.

En concreto, se han determinado FE específicos para operaciones y materiales habituales en cerámicas, en plantas de fabricación de hormigón prefabricado, en canteras de áridos, en cementeras y en muelles de graneles sólidos en puertos.

Los FE específicos obtenidos evidencian diferencias significativas en la emisión de PM10 que se genera cuando un mismo material se somete a diferentes operaciones. Estos resultados permiten obtener un escenario más realista en materia de impacto ambiental, dado que estas diferencias no pueden apreciarse si se aplican los FE propuestos en las principales guías utilizadas para la realización de inventarios de PM.

La metodología experimental desarrollada también permite cuantificar la eficacia de medidas correctoras concretas. En este sentido, se ha determinado la eficacia del riego con agua y con aditivos químicos (CMA, acetato de $\mathrm{Ca}$ y $\mathrm{Mg}$ ) en viales no pavimentados. Si bien, la duración de la eficacia de estas medidas se encuentra muy influenciada por factores meteorológicos, así como por la propia frecuencia de paso de vehículos, se considera muy importante haber establecido una correspondencia entre la cantidad de agua y CMA aplicada y la duración temporal del efecto. De hecho, la información actual disponible proporciona la eficacia de la medida en función de la cantidad de agua aplicada, sin detallar el tiempo durante el que persiste el efecto.

De forma general, se considera que el estudio en detalle de las emisiones difusas de PM10 en entornos industriales, así como las metodologías propuestas, resultan ser muy novedosas y de enorme interés por su aplicabilidad para mitigar el impacto ambiental que generan.

En este sentido, tanto las autoridades públicas como los gestores de las actividades afectadas pueden utilizar la información obtenida para definir estrategias de mitigación más acordes a las necesidades reales requeridas, adoptando MTD con una eficacia reconocida y cuantificada, de modo que permita alcanzar los estándares medioambientales establecidos. 


\section{Resum}

El transport, emmagatzematge i manipulació a l'aire lliure de materials sòlids pulverulents comporta freqüents episodis de contaminació atmosfèrica per emissions difuses de material particulat (PM), l'impacte sobre la qualitat de l'aire i el medi ambient de la qual pot arribar a ser significatiu.

Aquest tipus d'emissions tenen major rellevància en determinats entorns geogràfics amb presència d'activitats industrials com ara ceràmiques, cimenteres, plantes de formigó, pedreres, foses d'acer, centres logístics de biomassa, molls de granels sòlids en ports, entre altres. Així mateix, en zones on s'estiguen executant treballs de construcció i demolició, aquestes emissions també poden arribar a ser importants.

Des d'un punt de vista tècnic i legislatiu, a la gestió i control de les emissions difuses de PM se'ls ha parat tradicionalment una atenció limitada. Aquest fet es reflecteix clarament en les metodologies de control establides actualment, en les quals es detecten una sèrie de limitacions: aplicació de valors límits propis de legislació de qualitat de l'aire i, per tant, desenvolupats per a nuclis urbans amb una casuística i problemàtica diferent de la dels entorns mencionats; desconeixement de l'eficàcia de les millors tècniques disponibles (MTD) proposades en les autoritzacions ambientals integrades (AAI); i falta d'informació sobre factors d'emissió (FE) per a inventaris de detall.

Aquesta situació probablement es produïsca per la complexitat inherent que comporta la quantificació i control de les emissions difuses de PM, influïda per diferents factors com ara: la seua naturalesa discontínua i durada curta; la dependència de les condicions meteorològiques; la variabilitat de la posició de determinades fonts amb el temps; la presència simultània de diferents fonts emissores; i la influència de les propietats del material manipulat i de les mesures correctores implementades.

En aquest context, i amb l'objecte de conèixer amb major detall l'abast de les emissions difuses de PM10 i identificar les necessitats per al seu control, s'ha realitzat un estudi exhaustiu en el sector ceràmic, per ser un dels sectors en els quals aquest tipus d'emissions són habituals. En una primera fase, s'ha procedit a la seua quantificació en distints tipus d'escenaris tecnològics (parcs d'emmagatzematge de matèries primes tancats, semitancats i oberts). Amb aquest fi s'ha aplicat una metodologia analítica, basada en realitzar un inventari de detall de totes les operacions generadores d'emissions difuses de PM. Així mateix, s'han estimat els rendiments de millora aconseguits quan s'implementen un conjunt de MTD recollides en les AAI atorgades a empreses del sector ceràmic. L'estudi s'ha completat mitjançant una caracterització química i morfològica del $\mathrm{PM}$ emès, la qual ha permès identificar la contribució de fonts externes (fons local, regional i fonts pròximes) en el perfil químic i morfològic obtingut.

Els resultats aconseguits mostren que les emissions difuses de PM10 en el sector ceràmic poden deteriorar significativament la qualitat de l'aire si no s'apliquen mesures correctores d'eficàcia elevada, com ara el tancament parcial o total dels parcs d'emmagatzematge i gestió de matèries primeres.

En general, la metodologia aplicada ha permès obtenir FE globals per tipus d'instal·lació, la qual cosa es considera d'enorme interès pràctic, ja que permet simplificar la quantificació de les emissions difuses per a donar resposta a determinats requisits legislatius, com, per exemple, l'emplenament del Registre Estatal d'Emissions. No obstant això, aquests FE globals no permeten identificar les operacions més problemàtiques d'un procés, situació que dificulta la determinació de mesures correctores específiques per a cada operació. Aquesta informació seria de gran interès per 
a l'optimització del disseny de les instal-lacions, per la qual cosa per a un major control operacional i inventaris de detall aquest tipus de FE pot no ser prou.

Per les raons comentades i, amb l'objectiu de disposar d'informació real i precisa sobre les emissions difuses de PM, s'ha desenvolupat una metodologia experimental per a la determinació de FE específics, per a operacions i materials d'interès, i de l'eficàcia de MTD concretes. Aquesta metodologia ha requerit tant del desenvolupament d'un model de dispersió de contaminants d'acord amb les peculiaritats de les emissions difuses de PM, com d'un protocol d'execució de les campanyes experimentals, el qual permet introduir de forma apropiada en el model proposat les condicions atmosfèriques i les característiques de l'emissió de la manera més realista possible.

Concretament, el model de dispersió desenvolupat és un model no estacionari que incorpora totes les particularitats amb rellevància en els processos d'emissió i dispersió. En conseqüència, permet determinar el camp de velocitats i la dispersió vertical considerant l'estructura de la capa límit planetària, simular els meandres descrits per la ploma resultant de l'emissió i tractar fonts de geometria arbitrària i intermitents.

L'aplicació d'aquesta metodologia a escenaris industrials reals ha permès obtenir de forma satisfactòria FE específics, tant per a fonts simples com per a complexes, degut a la flexibilitat del model de dispersió de contaminants desenvolupat i a la parametrització exhaustiva de les fonts d'emissió.

En concret, s'han determinat FE específics per a operacions i materials habituals en ceràmiques, en plantes de fabricació de formigó prefabricat, en pedreres d'àrids, en cimenteres i en molls de granels sòlids en ports.

Els FE específics obtinguts evidencien diferències significatives en l'emissió de PM10 que es genera quan un mateix material se sotmet a diferents operacions. Aquests resultats permeten obtenir un escenari més realista en matèria d'impacte ambiental, atès que aquestes diferències no poden apreciar-se si s'apliquen els FE proposats en les principals guies utilitzades per a la realització d'inventaris de PM.

La metodologia experimental desenvolupada també permet quantificar l'eficàcia de mesures correctores concretes. En aquest sentit, s'ha determinat l'eficàcia del reg amb aigua i amb additius químics (CMA, acetat de $\mathrm{Ca}$ i $\mathrm{Mg}$ ) en vials no pavimentats. Tot i que la durada de l'eficàcia d'aquestes mesures es troba molt influenciada per factors meteorològics, així com per la pròpia freqüència de pas de vehicles, es considera molt important haver establert una correspondència entre la quantitat d'aigua i CMA aplicada i la durada temporal de l'efecte. De fet, la informació actual disponible proporciona l'eficàcia de la mesura en funció de la quantitat d'aigua aplicada, sense detallar el temps durant el qual persisteix l'efecte.

De forma general, es considera que l'estudi en detall de les emissions difuses de PM10 en entorns industrials, així com les metodologies proposades, resulten ser molt noves i d'enorme interès per la seua aplicabilitat per a mitigar l'impacte ambiental que generen.

En aquest sentit, tant les autoritats públiques com els gestors de les activitats afectades poden utilitzar la informació obtinguda per a definir estratègies de mitigació adaptades a les necessitats reals requerides, amb l'adopció de MTD amb una eficàcia reconeguda i quantificada, de manera que permeta aconseguir els estàndards mediambientals establerts. 


\section{Abstract}

The transport, storage, and handling in the open air of dusty solids entail frequent episodes of air pollution by fugitive emissions of particulate matter (PM), which can, in certain cases, significantly affect the environment and human health.

This type of emissions is greater in geographic contexts with industrial activities such as ceramic manufacturing facilities, cement factories, concrete works, quarries, steel foundries, biomass logistics centres, and bulk solids wharves in ports. Such emissions may also become significant in areas where construction works are being carried out.

From a technical and regulatory viewpoint, management and control of fugitive PM emissions have traditionally drawn little attention. This is clearly reflected in current control methodologies, which exhibit a series of limitations: application of limit values stemming from air quality legislation developed for urban settings with features and problems that differ from those of industrial environments; unacquaintance with the efficiency of the best available technologies (BAT) described in integrated environmental authorisations (IEA); and lack of information regarding emission factors (EF) for detailed inventories.

This situation is likely due to the inherent complexity involved in quantifying and controlling PM fugitive emissions, owing to factors such as their discontinuous nature and short duration; dependence on weather conditions; variability of source positions in time; simultaneous presence of different emitting sources; influence of the properties of the material handled; and corrective measures implemented.

With a view to determining in greater detail the extent of PM10 fugitive emissions and to identifying how best to control these, a thorough study was conducted in the ceramic sector, in which this type of emissions is widespread. These emissions were first quantified in different types of technology scenarios (closed, semi-closed and open managing area), applying a methodology based on a detailed inventory of all the PM fugitive emissions-generating operations. The improvement efficiencies achieved on implementing a set of BAT described in the IEA awarded to ceramic sector companies were estimated. The study was rounded off with a chemical and morphological characterisation of the emitted PM, which enabled identification of the contribution of external sources (local and regional background and adjacent plumes) to the resulting chemical and morphological profile.

The results obtained show that PM10 fugitive emissions in the ceramic sector can significantly affect air quality unless highly efficient corrective measures are applied, such as the partial or total enclosure of raw materials handling and storage areas.

In general, the applied methodology has allowed overall EF per type of facility to be obtained, this being deemed of great practical interest as it simplifies quantification of fugitive emissions in response to legislative requirements such as compliance with the State Emissions Registry. However, these EF do not allow the more problematic operations of a process to be identified, which makes it difficult to determine specific operation-based corrective measures to optimise the design of facilities, so that the EF may not suffice for greater operational control and/or detailed inventories.

For the reasons mentioned above, and to have real, precise information on PM fugitive emissions, an experimental methodology was developed to determine specific EF for the operations and materials of interest and to establish the efficiency of particular BAT. This methodology required development of a pollutant dispersion model consistent with the peculiarities of PM fugitive 
emissions, as well as an execution protocol for the experimental campaigns, enabling atmospheric conditions and emission characteristics to be introduced in the most realistic possible form into the proposed model.

The developed dispersion model is a non-steady-state model that incorporates all the significant singularities in the emission and dispersion processes. It thus allows determination of the field of velocities and the vertical dispersion considering the structure of the planetary boundary layer, simulation of plume meandering, and treatment of intermittent sources of arbitrary geometry.

The application of this methodology to actual industrial scenarios has allowed specific EF for both simple and complex sources to be satisfactorily obtained owing to the flexibility of the developed pollutant dispersion model, in addition to extensive parameterisation of the emission sources.

Specific EF were determined for typical operations and materials in ceramic manufacturing facilities, prefabricated concrete works, aggregate quarries, cement factories, and bulk solids wharves in ports.

The specific EF obtained exhibited significant differences in the arising PM10 emission when the same material was subjected to different operations, yielding a more realistic scenario with regard to environmental impact. However, these differences cannot be observed when the EF proposed in the main guides used for carrying out PM inventories are applied.

The experimental methodology developed has also allowed the efficiency of specific corrective measures to be determined. The efficiency of spraying water and chemical additives (CMA, Ca and $\mathrm{Mg}$ acetate) on unpaved roads was thus determined. Although the duration of the efficiency of such measures is highly influenced by meteorological factors and vehicle traffic frequency, it is deemed very important to have established a relationship between the amount of applied water and CMA and the duration of the effect. In fact, though the information currently available provides the efficiency of the measure as a function of the amount of applied water, it does not specify how long the effect will last.

The detailed study of PM10 fugitive emissions in industrial settings and the proposed methodologies are considered highly innovative and of great interest, owing to their applicability in mitigating the environmental impact of such emissions.

In this sense, the information obtained can be used both by public authorities and managers of the activities at issue to define mitigation strategies more in line with actual needs, implementing BAT with recognised, quantified efficiency in the more problematic operations, in order thus to attain the set environmental standards. 


\section{Índice}

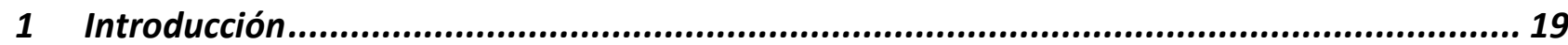

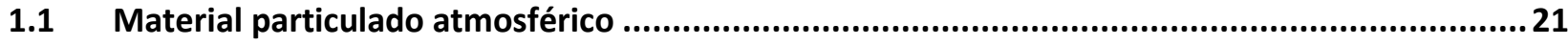

1.1.1 Distribución granulométrica y fracciones del PM atmosférico ...............................................................22

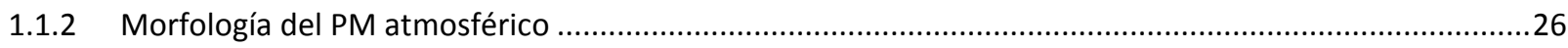

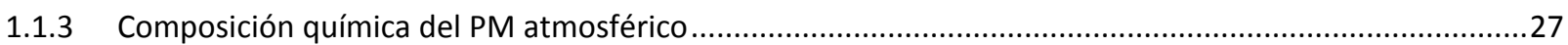

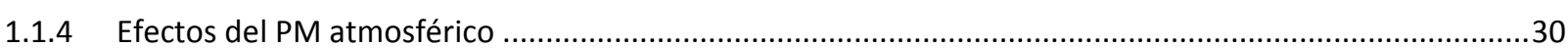

1.2 Emisiones difusas de PM en entornos industriales ............................................................... 34

1.2.1 Características y contribución de las emisiones difusas de PM ....................................................34

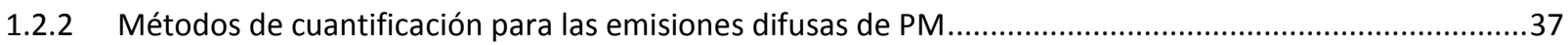

1.2.3 Actividades industriales potencialmente generadoras de emisiones difusas de PM ...............................38

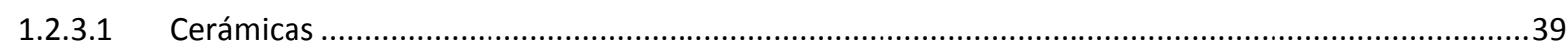

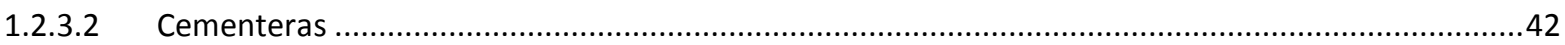

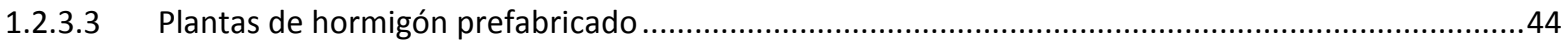

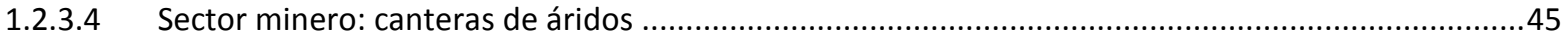

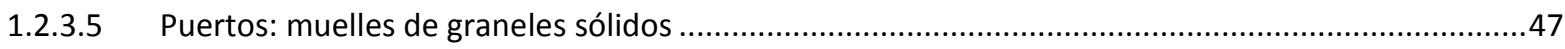

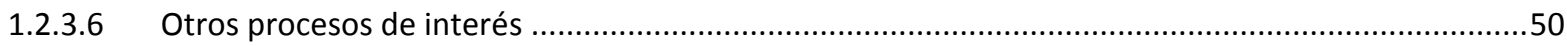

1.2.4 Medidas correctoras para las emisiones difusas de PM .............................................................51

1.2.4.1 Medidas correctoras para el almacenamiento, transferencia y manipulación de sólidos .................51

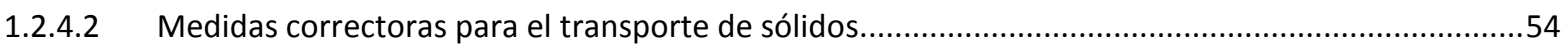

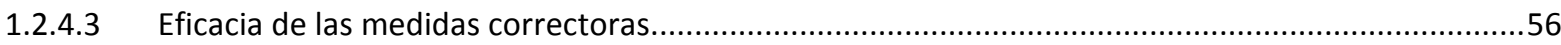

1.3 Instrumentos normativos aplicables a las emisiones difusas de PM ...................................57

1.3.1 Legislación ambiental en materia de calidad del aire para PM.........................................................57

1.3.2 Legislación ambiental en materia de emisiones industriales .............................................................58

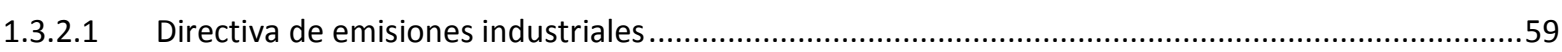

1.3.2.2 Catálogo de actividades potencialmente contaminadoras de la atmósfera ..................................61

1.3.3 Metodologías de control de las emisiones difusas de PM recogidas en la normativa actual ...................62

1.3.3.1 Implementación de una serie de medidas correctoras .....................................................63

1.3.3.2 Establecimiento de valores límite en el perímetro de la instalación............................................63

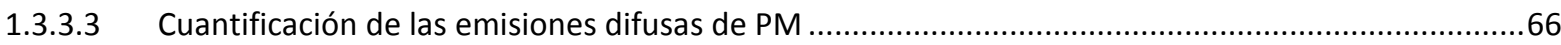

1.3.4 Recomendaciones del Plan Aire para las emisiones difusas de PM ...............................................73

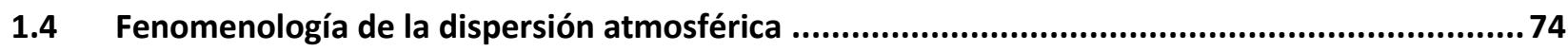

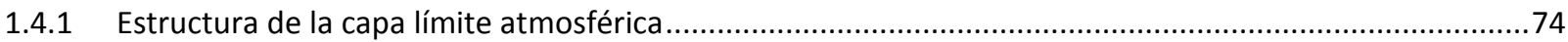


1.4.2 Teoría de semejanza de Monin Obukhov........................................................................................ 76

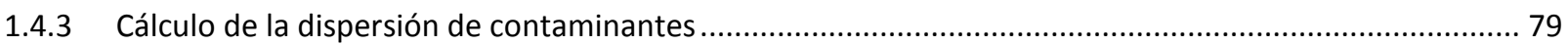

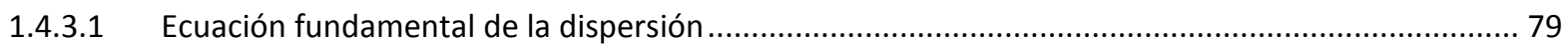

1.4.3.2 Modelos de cálculo de la dispersión de contaminantes atmosféricos ........................................ 81

1.4.3.3 Soluciones analíticas: modelos gaussianos y no gaussianos .................................................... 82

1.4.3.4 Métodos para la estimación de los parámetros de dispersión.................................................. 84

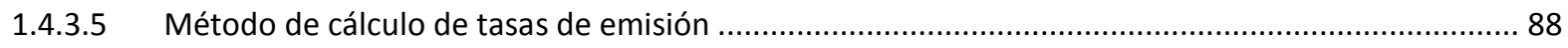

2 Estado del arte, motivaciones, objetivos y alcance.....................................................91

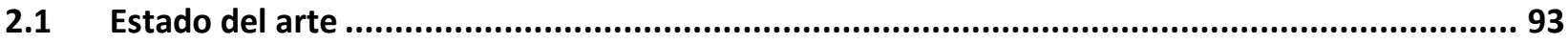

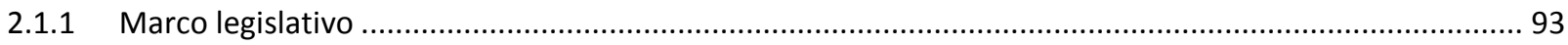

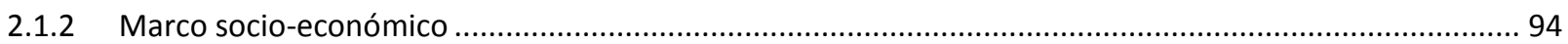

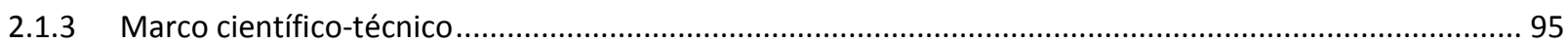

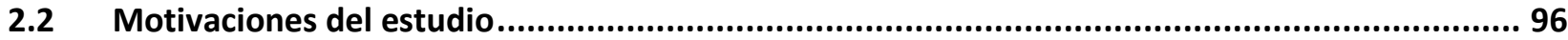

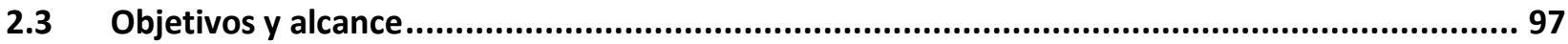

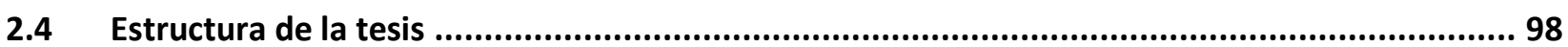

3 Metodología................................................................................................99

3.1 Metodologías para la cuantificación de las emisiones difusas de PM...................................101

3.1.1 Determinación de FE globales en el sector cerámico .............................................................. 101

3.1.1.1 Equipamiento requerido para la ejecución de las campañas experimentales .............................. 101

3.1.1.2 Determinación de parámetros para la aplicación de los FE del AP-42 …................................. 102

3.1.2 Determinación de FE específicos por operación y/o material ....................................................... 102

3.1.2.1 Equipamiento requerido para la ejecución de las campañas experimentales ............................. 102

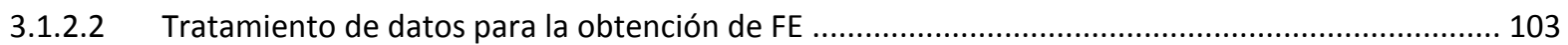

3.2 Metodologías para la caracterización del PM y de los materiales manipulados.....................105

3.2.1 Caracterización química y morfológica del PM ......................................................................... 105

3.2.2 Caracterización física de los materiales manipulados .............................................................. 106

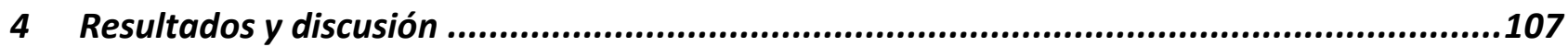

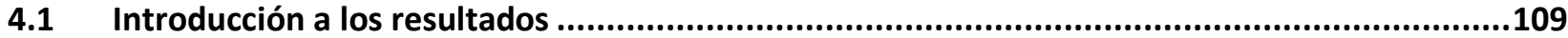

4.2 Determinación de factores de emisión y de eficacias de medidas correctoras en la industria

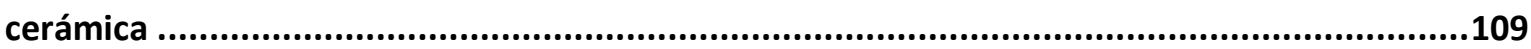

4.2.1 Estimación de emisiones difusas de PM10 y de eficacias de MTD en el sector cerámico ...................... 110

4.2.2 Determinación de factores de emisión de PM10 y de eficacias de medidas correctoras globales por tipo de instalación en el sector cerámico

4.2.3 Resultados adicionales: Caracterización química y morfológica de las emisiones difusas de PM10 en la industria cerámica 
4.3 Determinación de factores de emisión y de eficacias de medidas correctoras específicas

4.3.1 Metodología propuesta para la determinación de factores de emisión específicos de PM.....

4.3.2 Resultados adicionales al artículo no3: refinamiento de la metodología experimental propuesta......

4.3.2.1 Ensayos preliminares para refinar la metodología experimental ..........................................125

4.3.2.2 Protocolo de ejecución de las campañas experimentales....................................................128

4.3.2.3 Importancia del protocolo experimental en la bondad de los ajustes .........................................129

4.3.3 Determinación de factores de emisión específicos de PM10 para fuentes difusas de interés.

4.3.5 Resultados adicionales al artículo $\mathrm{n}$ 4: Determinación de la eficacia del riego con agua y aditivos en viales no pavimentados.

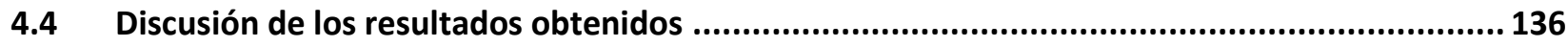

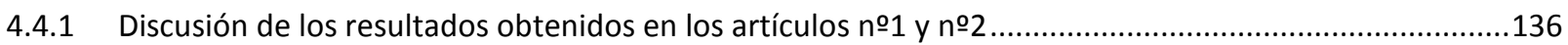

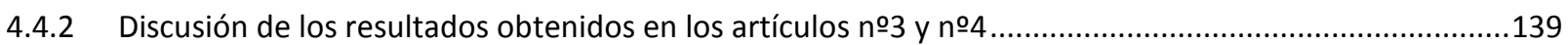

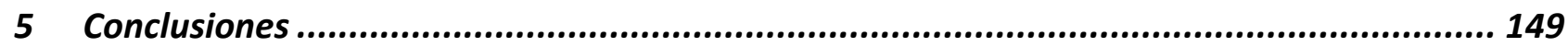

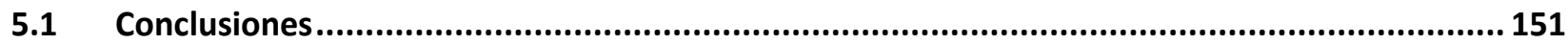

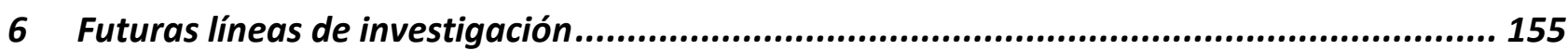

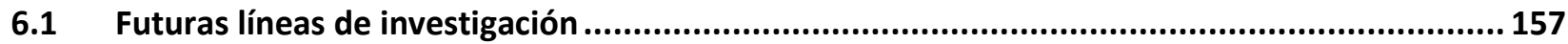

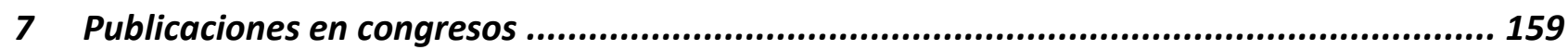

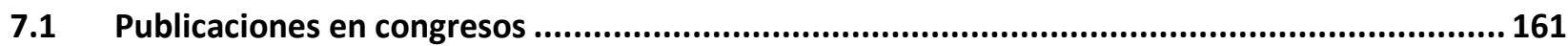

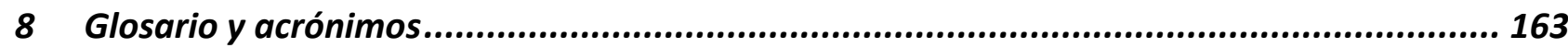

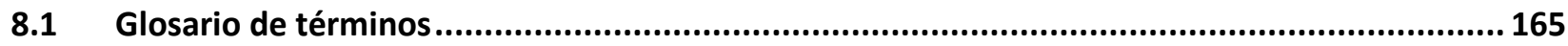

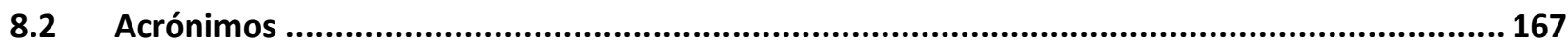

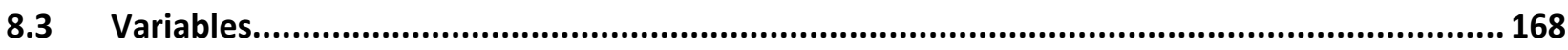

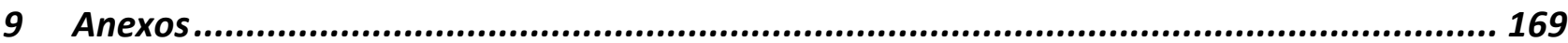

9.1 Anexo I. Determinación de la densidad de flujo de calor sensible para la reconstrucción del perfil vertical de la velocidad ......................................................................... 171

9.2 Anexo II. Perfiles químicos individuales de las emisiones difusas de PM10...................... 173

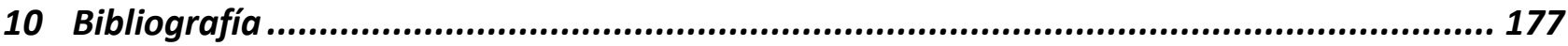



1. Introducción 



\subsection{Material particulado atmosférico}

El material particulado atmosférico ( $\mathrm{PM}$, del inglés particulate matter) es un constituyente habitual de la atmósfera terrestre y se define como un conjunto de partículas sólidas y/o líquidas presentes en suspensión en la atmósfera (Mészáros, 1999). Generalmente, el término aerosol atmosférico se utiliza como sinónimo de partículas atmosféricas, aunque los dos términos no son estrictamente equivalentes, ya que el primero incluye las partículas (sólidas y/o líquidas) y el gas sobre el que éstas se encuentran suspendidas (Mészáros, 1999).

EI PM atmosférico engloba una gran variedad de compuestos que varían ampliamente en su origen y vías de formación y, por tanto, en sus características físico-químicas y en sus efectos sobre la salud y el medio ambiente.

A este respecto, el PM puede ser clasificado en función de su origen (natural y antrópico), atendiendo a su mecanismo de formación (primario y secundario), en base a su composición química (materia mineral, aerosol marino, partículas carbonosas, especies inorgánicas secundarias y metales), o según su tamaño (nanopartículas, partículas ultrafinas, partículas finas y partículas gruesas).

Existen numerosas fuentes de emisión de PM antrópicas (emisiones residenciales, tráfico rodado, procesos industriales, generación de energía, actividades de construcción y demolición, procesos extractivos, agricultura, ganadería, quemas al aire libre de biomasa, entre otros) que contribuyen a incrementar los niveles de PM. Si bien las fuentes naturales (materia mineral resuspendida, aerosol marino, actividad volcánica, algunos incendios forestales, emisiones biogénicas, entre otros) contribuyen de forma dominante a las emisiones a escala global (IPCC, 2007), las emisiones antropogénicas pueden ser muy intensas en zonas de alta densidad de población y regiones industrializadas (Querol et al., 2004; Putaud et al., 2004).

Respecto a las fuentes antrópicas, el sector industrial se identificó en la Unión Europea (UE) como la segunda fuente emisora más importante de PM primario (definiéndose primario como el PM emitido directamente en forma sólida/líquida desde la fuente de emisión), contribuyendo en un $22 \%$ y un 17\% a las emisiones de PM10 y PM2.5 respectivamente en 2014 (EEA, 2016).

En cuanto al mecanismo de formación, las partículas secundarias, a diferencia de las primarias que se emiten directamente a la atmósfera, se originan a partir de precursores gaseosos $\left(\mathrm{SO}_{\mathrm{x}}, \mathrm{NO}_{\mathrm{x}}\right.$, $\mathrm{COV}, \mathrm{NH}_{3}$, entre otros), ya procedan de fuentes naturales o antrópicas. Los principales procesos de transformación que generan este tipo de partículas son la interacción entre gases precursores en la atmósfera para formar una nueva partícula dando lugar a la nucleación, la condensación de un gas sobre una partícula existente, o la reacción entre un gas y una partícula para dar lugar a un nuevo aerosol por adsorción o coagulación (Seinfeld y Pandis, 2006).

Las propiedades del PM son temporal y espacialmente muy variables debido a los cambios que sufren en la atmósfera. Su tiempo de residencia en la atmósfera varía de minutos a semanas, dependiendo fundamentalmente de su tamaño, sus características físico-químicas y de factores meteorológicos (Seinfeld y Pandis, 2006).

La alteración de la composición natural de la atmósfera como consecuencia de la presencia en suspensión de partículas, ya sea por causas naturales o antropogénicas, se conoce como contaminación atmosférica por PM. Los efectos de este tipo de contaminación se han identificado 
en diferentes ámbitos, entre los cuales destacan la salud humana, el clima, los ecosistemas, y la conservación de edificios (EEA, 2016). La definición de estrategias de mitigación apropiadas, para reducir los impactos de la contaminación por PM requieren conocer en detalle tanto su origen, como los fenómenos de transporte y transformación que sufre el PM en la atmósfera (EEA, 2016).

En este sentido, las características del PM que mejor definen los posibles impactos de la contaminación atmosférica sobre el medio son: el tamaño de sus partículas, la morfología y la composición química (Hinds, 1999; McKenna et al., 2008; Kulkarni et al., 2011). A continuación, se comentan en detalle estas características.

\subsubsection{Distribución granulométrica y fracciones del PM atmosférico}

La forma más habitual de presentar los distintos rangos de tamaños de partículas es en términos de "modas", debido al amplio rango de tamaños que presentan las partículas, el cual abarca cinco ordenes de magnitud (de 1 a $10^{5} \mathrm{~nm}$ ). Estas modas son: nucleación, Aitken, acumulación y gruesa, cuyos mecanismos de formación se detallan seguidamente (Warneck, 1988; EPA, 1996; Hinds, 1999; Seinfeld y Pandis, 2006).

Las partículas ultrafinas presentan un tamaño inferior a $100 \mathrm{~nm}$ y pertenecen a las modas de nucleación $(<20 \mathrm{~nm})$ y de Aitken $(20-100 \mathrm{~nm})$. Generalmente, son partículas procedentes de procesos de combustión, así como partículas de origen secundario, formadas por procesos denominados de nucleación o condensación homogénea (un estado físico) o heterogénea (varios estados físicos). Estas partículas son muy abundantes en número, sin embargo, suponen una parte mínima de la concentración en términos de masa.

Las partículas de tamaños comprendidos entre 100 nm y $1 \mu \mathrm{m}$, denominada moda de acumulación, se forman a partir de la moda Aitken como consecuencia de procesos de aglomeración, condensación y de reacciones en fase líquida.

Las partículas pertenecientes a la moda gruesa $(1-10 \mu \mathrm{m})$ son mayoritariamente de origen primario y tienen su origen en procesos mecánicos. Así, pueden proceder de emisiones biogénicas, de la erosión de la superficie terrestre (materia mineral o crustal) o de otros materiales, o de las superficies de mares y océanos (aerosol marino). Las partículas de origen secundario presentes en esta moda se forman por reacciones químicas entre las partículas primarias de origen crustal y marino y gases presentes en la atmósfera. Las partículas incluidas en esta moda tienden a depositarse gravitacionalmente. A diferencia de las partículas ultrafinas, la concentración de partículas gruesas es muy reducida o despreciable, si se considera el número de partículas, mientras que es muy elevada si el parámetro considerado es la masa.

La transferencia de las partículas entre lo que se denomina PM fino y grueso se encuentra con un límite situado alrededor de $1 \mu \mathrm{m}$, debido a que el crecimiento de las partículas de tamaño $<1 \mu \mathrm{m}$ no suelen dar lugar a partículas de tamaño $>1 \mu \mathrm{m}$, y a que los procesos mecánicos que generan partículas primarias no producen normalmente partículas de diámetro $<1 \mu \mathrm{m}$ debido a limitaciones energéticas.

En relación a su tamaño, las partículas presentan un tiempo de residencia en la atmósfera distinto (Seinfeld y Pandis, 2006). Las partículas pertenecientes a las modas de Aitken y acumulación (20$1000 \mathrm{~nm}$ ) tienen una larga vida en la atmósfera, manteniéndose suspendidas desde una a varias semanas. Sin embargo, las partículas de la moda nucleación $(<20 \mathrm{~nm})$ presentan una corta duración 
en la misma, de minutos a horas, debido a que tienden a aglomerarse. Por otro lado, las partículas de la moda gruesa $(>1000 \mathrm{~nm}$ ) tienden a depositarse y por tanto también presentan una corta duración de vida en la atmósfera.

En el caso de partículas esféricas de densidad uno, el tamaño se puede caracterizar a través del diámetro geométrico, para el estudio de partículas de densidad y tamaño arbitrario se propone el uso de un diámetro equivalente. En este sentido, la bibliografía consultada propone otros diámetros como: diámetro aerodinámico, diámetro equivalente de Stokes y diámetro óptico, entre otros. La selección de un tipo de diámetro u otro va a depender principalmente del tipo de medida realizada. Los diámetros más utilizados en estudios de contaminación atmosférica son: el diámetro equivalente de Stokes y el diámetro aerodinámico (Hinds, 1999; Ehrlich et al., 2007; McKenna et al., 2008; Kulkarni et al., 2011).

El diámetro aerodinámico es muy útil cuando estamos en un rango de tamaño de partículas donde la inercia de las mismas es significativa, lo que ocurre para tamaños de partículas mayores de $0.5 \mu \mathrm{m}$. Por debajo de ese tamaño, tienen mucha importancia la difusión browniana de las partículas y, el diámetro utilizado es el diámetro difusivo (Hinds, 1999).

Para mejorar la comprensión de estos conceptos, en la Figura 1.1, se compara una partícula irregular y sus equivalentes esferas aerodinámicas y de Stokes, cada una de ellas tiene la misma velocidad de sedimentación, pero con una densidad y una forma diferente. Tanto el diámetro aerodinámico como el diámetro de Stokes, se definen en base al comportamiento aerodinámico de la partícula sin considerar su geometría.

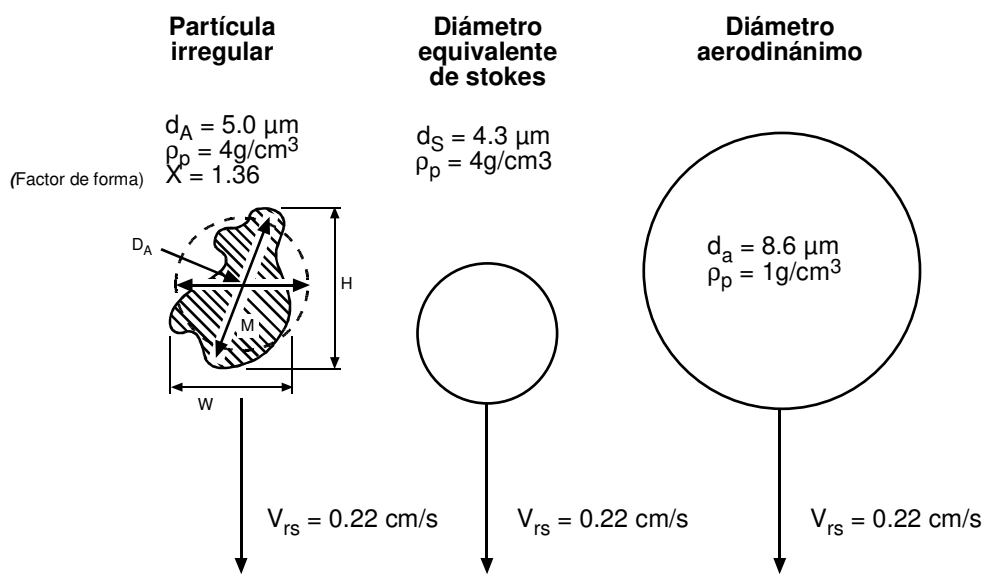

Figura 1. 1. Comparación de diferentes tipos de diámetros considerados (Hinds, 1999).

De estos dos parámetros citados, el más común y el que se va a utilizar en este trabajo para determinar o definir el tamaño de las partículas, es el diámetro aerodinámico. Este diámetro es el de una partícula ficticia esférica de densidad $1 \mathrm{~g} / \mathrm{cm}^{3}$, que tiene el mismo comportamiento aerodinámico (misma velocidad terminal en régimen estacionario en el aire), que la partícula real.

La velocidad terminal es una característica aerodinámica de las partículas $y$, se obtiene como resultado de un balance de fuerzas; donde las principales fuerzas implicadas son gravitatorias y de rozamiento (Hinds, 1999). El uso de este parámetro permite comparar partículas con densidades muy diferentes, aunque el diámetro aerodinámico puede diferir notablemente del real, aún incluso en el caso de partículas casi esféricas, si la densidad es muy diferente a $1 \mathrm{~g} / \mathrm{cm}^{3}$. 
Aunque el parámetro «diámetro de partícula», es genérico para todos los ámbitos, la denominación de las partículas incluidas en determinados rangos granulométricos varía en función del ámbito de estudio. A continuación, se identifica la nomenclatura seguida en tres de los ámbitos más conocidos: calidad del aire, emisiones industriales y salud laboral.

\section{- Calidad del aire (inmisión o aire ambiente)}

En el caso de estudios de calidad de aire se ha desarrollado toda una normativa que tiene por objeto limitar los niveles de contaminantes en el aire ambiente con el fin de evitar o reducir los efectos nocivos del PM sobre la salud humana y el medio ambiente en su conjunto. Las fracciones granulométricas consideradas son PST, PM10 y PM2.5. Asimismo, también son objeto de estudio intervalos aplicables a las fracciones anteriormente nombradas.

El término PST se refiere a partículas en suspensión totales, mientras que los términos PM10 y PM2.5 corresponden a partículas con un diámetro aerodinámico igual o inferior a 10 y $2.5 \mu \mathrm{m}$ respectivamente. Concretamente, la Norma UNE-EN 12341:2015, define PMX como la materia particulada en suspensión en el aire que es suficientemente pequeña para pasar a través de un cabezal de tamaño selectivo con una eficiencia de corte del $50 \%$ para un diámetro aerodinámico de $\mathrm{x} \mu \mathrm{m}$.

\section{- Emisiones industriales}

En el estudio de emisiones industriales de PM, las fracciones de mayor interés ambiental por su impacto sobre los niveles de calidad de aire son: PST, PM10 y PM2.5. La relación entre las diferentes fracciones granulométricas va a depender del tipo de proceso que dé origen a las emisiones, así como del tipo de contaminantes y otras características que definan la emisión generada.

En el caso concreto de las emisiones asociadas a la gestión de materiales sólidos de naturaleza pulverulenta al aire libre también suele controlarse las partículas sedimentables (PSD).

\section{- Salud laboral}

En el estudio de ambientes de trabajo, en higiene o salud laboral, se utiliza una nomenclatura diferente (UNE-EN 481:1995), con respecto a la utilizada en contaminación atmosférica (aire ambiente y emisión), aun así, se puede crear un paralelismo en cuanto a dicha nomenclatura para los diferentes tamaños de partículas sólidas y la normativa habitual en contaminación atmosférica, tal y como se detalla a continuación:

- Fracción inhalable: corresponde a aquellas partículas que resultan peligrosas al depositarse en cualquier parte del tracto respiratorio. En términos de contaminación atmosférica se puede asemejar a un PM100, es decir, a PST.

- Fracción torácica: corresponde a aquellas partículas que resultan peligrosas al depositarse en cualquier parte de las vías pulmonares y la región de intercambio de gases. En términos de contaminación atmosférica se puede asemejar a un PM10.

- Fracción respirable: corresponde a aquellas partículas que resultan peligrosas al depositarse en la región de intercambio de gases. En términos de contaminación atmosférica se puede asemejar a un PM4. 
Además, actualmente se están realizando numerosos estudios con el objetivo de evaluar la exposición laboral a nanopartículas (partículas con un tamaño inferior a $100 \mathrm{~nm}$ en salud laboral). Los daños derivados de esa exposición dependen de varios factores, entre ellos de su composición química y morfología, ya que en función de su tamaño pueden penetrar por diferentes vías (respiratoria o dérmica).

Por otro lado, cuando se hace referencia al tamaño de las partículas respecto a los efectos que producen sobre la salud humana, es importante matizar la diferencia del concepto concentración de partículas en las siguientes situaciones:

- Concentración de partículas en el aire ambiente, que es el aire que respira la población en general, incluida la población más sensible (niños, ancianos y personas con afecciones respiratorias).

- Concentración de partículas en el aire ambiente de trabajo (higiene industrial), que es el aire que respira un trabajador sano, durante periodos de exposición relativamente reducidos (alrededor de 40 horas semanales), éste es un parámetro que tiene una gran relevancia.

En la Tabla 1.1, a modo de resumen se detalla la nomenclatura y tamaño de partícula considerados en la normativa de calidad de aire, emisiones industriales y salud laboral.

Tabla 1. 1. Clasificación de las partículas en función de su granulometría.

\begin{tabular}{|c|c|c|c|}
\hline \multicolumn{2}{|r|}{ Calidad del aire/Emisiones industriales } & \multicolumn{2}{|r|}{ Salud laboral } \\
\hline Fracción & Definición & Fracción & Definición \\
\hline PSD & $\begin{array}{l}\text { Partículas existentes en el aire que son } \\
\text { depositadas por gravedad o arrastradas por la } \\
\text { lluvia. Fuente: Orden } 10 \text { de agosto de } 1976 \text {. }\end{array}$ & & n.a. \\
\hline PST & $\begin{array}{l}\text { Partículas que no precipitan fácilmente por la } \\
\text { acción gravitatoria, encontrándose animadas por } \\
\text { un movimiento browniano. Fuente: Orden } 10 \text { de } \\
\text { agosto de } 1976 \text {. }\end{array}$ & Inhalable & $\begin{array}{l}\text { Partículas suspendidas en el aire que } \\
\text { son inhaladas a través de la boca y } \\
\text { de la nariz. Fuente: UNE-EN } \\
481: 1995 .\end{array}$ \\
\hline PM10 & $\begin{array}{l}\text { Masa de partículas que atraviesa un cabezal de } \\
\text { tamaño selectivo para un diámetro aerodinámico } \\
\text { de } 10 \mu \mathrm{m} \text {, con una eficiencia de corte del } 50 \% \text {. } \\
\text { Fuente: UNE-EN 12341:2015. }\end{array}$ & Torácica & $\begin{array}{l}\text { Partículas que pueden penetrar en la } \\
\text { región traqueobronquial y son } \\
\text { eliminadas por acción ciliar. Fuente: } \\
\text { UNE-EN 481:1995. }\end{array}$ \\
\hline PM4 & n.a. & Respirable & $\begin{array}{l}\text { Fracción de partículas inhaladas que } \\
\text { penetran en las vías respiratorias no } \\
\text { ciliadas. Fuente: UNE-EN 481:1995. }\end{array}$ \\
\hline PM2.5 & $\begin{array}{l}\text { Masa de partículas que atraviesa un cabezal de } \\
\text { tamaño selectivo para un diámetro aerodinámico } \\
\text { de } 2.5 \mu \mathrm{m} \text {, con una eficiencia de corte del } 50 \% \text {. } \\
\text { Fuente: UNE-EN 12341:2015. }\end{array}$ & & n.a. \\
\hline
\end{tabular}

n.a.: no aplica 


\subsubsection{Morfología del PM atmosférico}

La morfología de las partículas incluye la forma de la partícula y las características de su superficie, como la porosidad o la rugosidad. Estas propiedades tienen gran importancia en los efectos de las partículas sobre la salud o en su comportamiento en las reacciones atmosféricas (Umbría et al., 1999). En la Figura 1.2 se presenta una muestra de la clasificación de los principales tipos de partículas en función de su forma (Cahn et al., 1993).

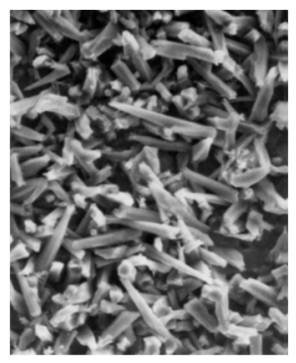

Aciculares

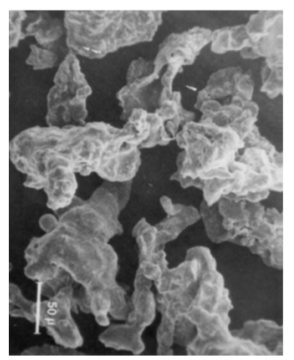

Irregulares

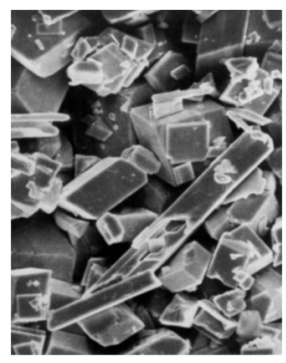

Angulares

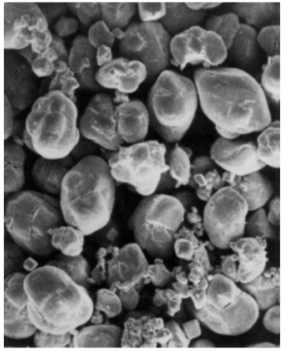

Nodulares

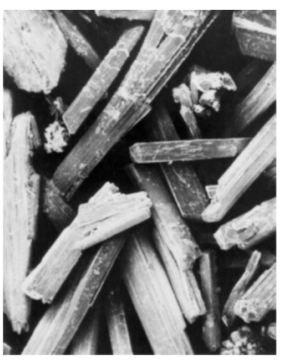

Fibrosas

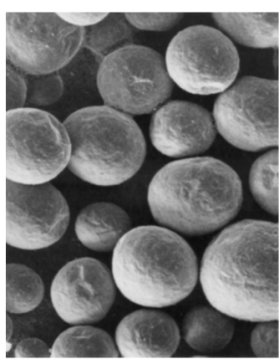

Esferoidales

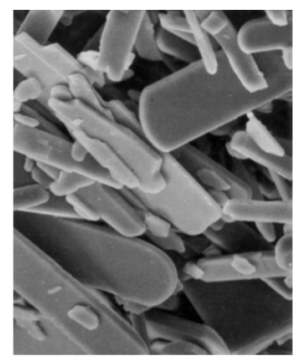

Laminares

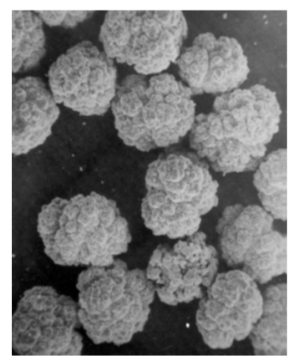

Granulares

Figura 1. 2. Clasificación de las partículas en función de su forma (Cahn, 1993).

La forma y la densidad determinan la relación entre la masa y el volumen. El área eficaz de reacción incluye la superficie específica de los eventuales poros, determinando la capacidad de las partículas para adsorber gases o cargas eléctricas. El estudio de la morfología de las partículas permite establecer las características de su superficie como rasgo diferenciador incluso entre partículas de tamaños similares emitidas a partir de un mismo foco emisor, además de servir para identificar posibles orígenes y mecanismos de formación: procesos térmicos (evaporación-condensación) y mecánicos, principalmente (Figura 1.3).
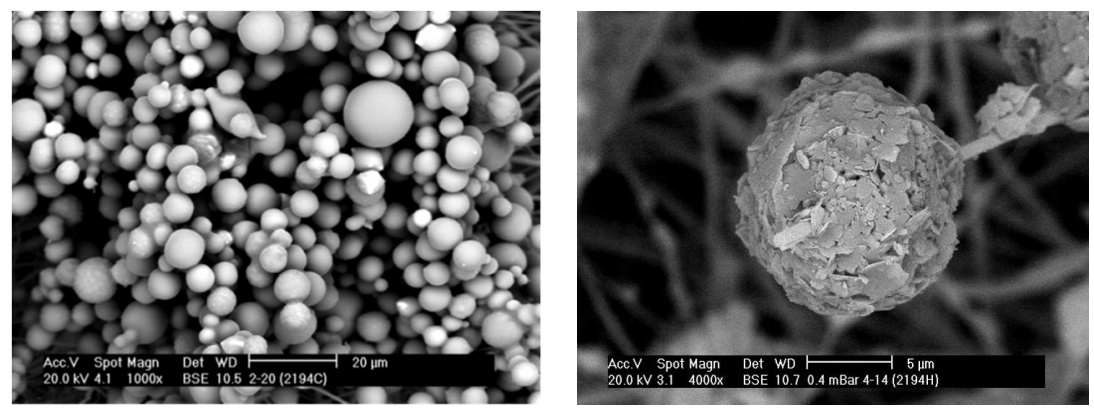

Figura 1. 3. Micrografía de MEB del PM formado por procesos térmicos (izquierda) y mecánicos (derecha) (Celades, 2013). 


\subsubsection{Composición química del PM atmosférico}

La composición química del PM atmosférico es una materia de estudio de enorme interés, así como la identificación de las especies químicas en las que se presentan los diferentes elementos en las partículas, de cara a conocer el impacto de las mismas sobre el medio y los seres vivos.

Dependiendo fundamentalmente de su origen, la composición química varía mucho de unas partículas a otras. En este sentido, determinadas zonas con influencia de emisiones industriales específicas pueden presentar niveles y características del PM diferentes, influenciadas por el tipo de industria y características climáticas entre otros (Querol et al., 2007b). En este caso, el perfil químico de la emisión va a depender del proceso productivo, es decir, de la naturaleza y del flujo de las materias primas y de los combustibles, así como de las condiciones de operación.

En función de su composición, una posible clasificación del PM puede ser: materia mineral, aerosol marino, compuestos de carbono, especies secundarias inorgánicas y metales.

A continuación, se detallan los principales tipos de partículas atmosféricas:

\section{- Materia mineral}

La materia mineral tiene principalmente un origen primario, dependiendo su emisión de varios factores, entre ellos: la velocidad del viento, las propiedades físicas del suelo (humedad, distribución del tamaño y cohesividad de las partículas depositadas) y las condiciones superficiales del terreno (rugosidad superficial y cobertura vegetal). Diferentes combinaciones de estos factores pueden causar que las partículas sean puestas en suspensión y transportadas por el viento (Usher et al., 2003).

Las partículas primarias de origen natural están compuestas principalmente de minerales de Al y Si (arcillas, cuarzos y feldespatos) y de carbonatos de $\mathrm{Ca}$ y $\mathrm{Mg}$, presentando una mayor proporción en el rango de 5-25 $\mu \mathrm{m}$ (Querol, 2001a).

A pesar de que la mayor parte de las emisiones de materia mineral a escala global es de origen natural, es necesario considerar la existencia de un número limitado de fuentes de PM mineral de origen antropogénico. Así, actividades como la agricultura, la construcción, la minería o la fabricación de productos cerámicos o cementos generan partículas minerales, ya sea a través de la propia actividad o durante los procesos de manipulación y transporte de materias primas. El tráfico también puede constituir una fuente de partículas minerales, a través de la erosión del firme de rodadura o, en el caso de viales no asfaltados, por la resuspensión del material previamente depositado (Querol et al., 2001a).

\section{- Aerosol marino}

Al igual que la materia mineral, las partículas de aerosol marino presentan en su mayoría un origen primario y natural (Buseck et al., 1999).

La composición química del aerosol marino deriva de su fuente de origen: el agua de los mares y océanos, así la fracción primaria del aerosol marino está principalmente compuesta por $\mathrm{NaCl}$, con menor contribución de $\mathrm{MgCl}_{2}, \mathrm{MgSO}_{4}$ y $\mathrm{Na}_{2} \mathrm{SO}_{4}$.

\section{- Compuestos de carbono}

Los compuestos carbonosos comprenden una amplia variedad de especies naturales y antropogénicas de composición y estructura diversa, cuya característica común es la presencia de 
C en su composición. Las principales fuentes que contribuyen a la emisión de estos compuestos son: tráfico rodado, generación de energía, procesos de combustión industriales y quema al aire libre de biomasa.

El carbono total presente en la atmósfera se puede expresar como carbono elemental, carbono orgánico, y carbono de carbonatos (principalmente $\mathrm{CaCO}_{3}$ y $\mathrm{MgCO}_{3}$, naturales y/o antrópicos), perteneciendo este último a la categoría de materia mineral (EPA, 1996).

El carbono elemental tiene su origen principalmente en emisiones primarias antrópicas, tales como las debidas a procesos de combustión incompleta de combustibles fósiles y biomasa, emitidos por el tráfico, la industria, el sector doméstico y las quemas de restos de poda agrícola (EEA, 2016).

Los compuestos de carbono orgánico pueden ser emitidos directamente a la atmósfera, por fuentes naturales y antrópicas, o formarse en ella (secundarios) a partir de compuestos orgánicos volátiles (COV) también de origen natural o antrópico (EPA, 1996).

\section{- Compuestos de azufre}

$\mathrm{El} \mathrm{SO}_{4}{ }^{-2}$ presente en la atmósfera es generalmente de origen secundario, ya que se generan mayoritariamente como resultado de la oxidación de precursores gaseosos (principalmente $\mathrm{SO}_{2}$ ) (Langner y Rodhe, 1992).

La producción antropogénica de gases precursores del $\mathrm{SO}_{4}^{-2}$ de origen secundario se localiza esencialmente en procesos de combustión de combustibles fósiles con alto contenido en $S$, mayoritariamente carbón y fuel-oil en centrales térmicas, complejos industriales y transporte marítimo (EEA, 2016).

\section{- Compuestos de nitrógeno}

Los principales gases emitidos por fuentes naturales y antropogénicas son: $\mathrm{NO}, \mathrm{NO}_{2}, \mathrm{~N}_{2} \mathrm{O}$ y $\mathrm{NH}_{3}$, cuya oxidación en la atmósfera tiene como resultado más frecuente la formación de $\mathrm{HNO}_{3}$ y $\mathrm{NH}_{4}{ }^{+}$ (Warneck, 1988; Mészáros, 1999).

Algunas fuentes antropogénicas de precursores gaseosos de $\mathrm{NO}_{3}{ }^{-}$son la producción eléctrica (combustión de gas, fuel-oil y carbón) y otros procesos de combustión a temperaturas elevadas, como son los motores de los vehículos y la quema de biomasa, capaces de oxidar el $\mathrm{N}_{2}$ atmosférico.

\section{- Metales}

Los metales tienen principalmente un origen antropogénico, sobre todo en entornos industriales y en zonas de elevado tráfico. A continuación, se presentan los metales traza identificados para los principales procesos industriales que se dan a nivel nacional y para el tráfico rodado (Querol et al., 2007b):

- Producción de acero: $\mathrm{Cr}, \mathrm{Mn}, \mathrm{Ni}, \mathrm{Zn}, \mathrm{Mo}, \mathrm{Cd}, \mathrm{Se}$ y Sn, y probablemente $\mathrm{Pb}$.

- Metalurgia del zinc: Cd y Zn.

- Metalurgia del cobre: $\mathrm{As}, \mathrm{Bi}, \mathrm{Ga}$ y $\mathrm{Cu}$.

- Fabricación de fritas y pigmentos cerámicos y fabricación de baldosas cerámicas: Zn, As, $\mathrm{Se}, \mathrm{Zr}$, Cs, Tl y $\mathrm{Pb}$.

- Plantas petroquímicas: Ni y V. Estos elementos también se consideran trazadores de la combustión de fuel oil.

- Tráfico: Zn, Cu, Sn y Sb. 
Las concentraciones y la granulometría de los metales en el PM dependen en gran medida de las fuentes de emisión que los generan, por ejemplo, en la bibliografía consultada (Allen et al., 2001; Querol et al., 2008; Viana et al., 2015) se han obtenido distribuciones de tamaño diferentes para un mismo elemento.

En la Tabla 1.2 se resumen las características del PM en función de su composición:

Tabla 1. 2. Características del PM atmosférico según su composición (Minguillón, 2007; Querol et al., 2008).

\begin{tabular}{|c|c|c|c|c|}
\hline Composición & Compuestos mayoritarios & Granulometría & Tipo partículas & $\begin{array}{c}\text { Gases } \\
\text { precursores }\end{array}$ \\
\hline \multirow{2}{*}{$\begin{array}{l}\text { Materia } \\
\text { mineral }\end{array}$} & $\begin{array}{l}\text { Mayoritariamente: calcita, cuarzo, } \\
\text { arcillas }\end{array}$ & \multirow{2}{*}{$\begin{array}{c}\text { Gruesa: } 5-25 \mu \mathrm{m} \\
\text { Modas: } 1.5,6.7,14.2 \mu \mathrm{m}\end{array}$} & \multirow{2}{*}{ Primarias } & \multirow{2}{*}{ n.a. } \\
\hline & $\begin{array}{l}\text { En menor medida: feldespatos, } \\
\text { dolomita, talco }\end{array}$ & & & \\
\hline \multirow{2}{*}{$\begin{array}{l}\text { Aerosol } \\
\text { marino }\end{array}$} & Mayoritariamente: $\mathrm{NaCl}$ & \multirow{2}{*}{$\begin{array}{l}\text { Moda principal: } 1-5 \mu \mathrm{m} \\
\text { Moda inferior:5-10 } \mu \mathrm{m}\end{array}$} & \multirow{2}{*}{ Primarias } & \multirow{2}{*}{ n.a. } \\
\hline & En menor medida: $\mathrm{MgCl}_{2}, \mathrm{MgSO}_{4}$ & & & \\
\hline \multirow{3}{*}{$\begin{array}{l}\text { Compuestos } \\
\text { de C }\end{array}$} & Carbono elemental & \multirow{2}{*}{$\begin{array}{l}\text { Moda: } 1 \mu \mathrm{m}(85 \% \text { en } \\
\text { número es }<0.1 \mu \mathrm{m})\end{array}$} & $\begin{array}{l}\text { Mayoritariamente } \\
\text { primarias }\end{array}$ & n.a. \\
\hline & Carbono orgánico & & $\begin{array}{l}\text { Primarias y } \\
\text { mayoritariamente } \\
\text { secundarias }\end{array}$ & $\begin{array}{c}\text { COV } \\
\text { (isopropeno, } \\
\text { monoterpenos) }\end{array}$ \\
\hline & $\begin{array}{c}\text { Carbono total } \\
\text { (elemental+orgánico+carbonatos) }\end{array}$ & $\begin{array}{c}\text { Bimodal: }<2.5 \mu \mathrm{m} \\
\text { (partículas orgánicas y } \\
\text { antrópicas) y }>10 \mu \mathrm{m} \\
\text { (carbonatos) }\end{array}$ & n.a. & n.a. \\
\hline \multirow{2}{*}{$\begin{array}{l}\text { Compuestos } \\
\text { de S }\end{array}$} & $\begin{array}{l}\text { Mayoritariamente: } \mathrm{NH}_{4} \mathrm{HSO}_{4} \text {, } \\
\qquad\left(\mathrm{NH}_{4}\right)_{2} \mathrm{SO}_{4}\end{array}$ & $<1 \mu \mathrm{m}$ & \multirow{2}{*}{$\begin{array}{l}\text { Mayoritariamente } \\
\text { secundarias }\end{array}$} & \multirow[t]{2}{*}{$\mathrm{SO}_{2}$} \\
\hline & En menor medida: $\mathrm{CaSO}_{4}, \mathrm{Na}_{2} \mathrm{SO}_{4}$ & $>1 \mu \mathrm{m},<10 \mu \mathrm{m}$ & & \\
\hline \multirow{2}{*}{$\begin{array}{l}\text { Compuestos } \\
\text { de N }\end{array}$} & $\mathrm{NH}_{4} \mathrm{NO}_{3}$ (inestable a $\mathrm{T}>25^{\circ} \mathrm{C}$ ) & $<1 \mu \mathrm{m}$ & \multirow{2}{*}{$\begin{array}{l}\text { Mayoritariamente } \\
\text { secundarias }\end{array}$} & \multirow{2}{*}{$\begin{array}{l}\mathrm{NO}, \mathrm{NO}_{2}, \mathrm{~N}_{2} \mathrm{O} \\
\mathrm{NH}_{3}, \mathrm{~N}_{2}\end{array}$} \\
\hline & $\mathrm{NaNO}_{3}, \mathrm{Ca}\left(\mathrm{NO}_{3}\right)_{2}$ & $>1 \mu \mathrm{m},<10 \mu \mathrm{m}$ & & \\
\hline \multirow{4}{*}{ Metales ${ }^{1}$} & Cs & $<30 \% \%^{2}<2.5 \mu \mathrm{m}$ & \multirow{4}{*}{$\begin{array}{l}\text { Mayoritariamente } \\
\text { primarias }\end{array}$} & \multirow{4}{*}{ n.a. } \\
\hline & $\mathrm{Mn}, \mathrm{Ga}, \mathrm{Mo}, \mathrm{Sb}$ & $40-50 \%{ }^{2}<2.5 \mu \mathrm{m}$ & & \\
\hline & $\begin{array}{c}\mathrm{Bi}, \mathrm{Cu}, \mathrm{Zn}, \mathrm{Cr}, \mathrm{As}, \mathrm{Zr}, \mathrm{V}, \mathrm{Se}, \mathrm{Ni}, \mathrm{Pb} \\
\text { TI, Sn, }\end{array}$ & $50-70 \%{ }^{2}<2.5 \mu \mathrm{m}$ & & \\
\hline & $\mathrm{Cd}$ & $>80 \%{ }^{2}<2.5 \mu \mathrm{m}$ & & \\
\hline
\end{tabular}

n.a.: no aplica

${ }^{1}$ Se han considerado los metales identificados como traza para los principales procesos industriales a nivel nacional y para el tráfico.

${ }^{2}$ Porcentaje en base a la fracción PM10. 
El conocimiento en detalle de la composición química del PM en estudios de calidad del aire ha permitido identificar las posibles fuentes de contribución. En este sentido, cabe destacar el proyecto AIRUSE LIFE+ en el que se ha evaluado y mejorado el conocimiento de las contribuciones de fuentes de emisión de PM al deterioro de la calidad del aire en ciudades del sur de Europa, permitiendo establecer propuestas de acciones concretas para mejorar la situación actual (LIFE11/ENV/ES/584; www.airuse.eu).

\subsubsection{Efectos del PM atmosférico}

El PM es, tal y como se ha descrito anteriormente, un conjunto heterogéneo de partículas emitidas por muy diversas fuentes, que incluye componentes de distinta naturaleza. Consecuentemente, los efectos del PM sobre el entorno son también muy variados.

\section{- Efectos del PM sobre la salud}

La relación existente entre elevados niveles de contaminación atmosférica y efectos adversos en la salud es conocida desde antiguo y cobró importancia a partir de la primera mitad del siglo XX, cuando en los países industrializados se produjo un incremento en la mortalidad (reducción de la esperanza de vida debido a la muerte prematura) y morbilidad (aparición de una enfermedad y los años vividos con la misma) que evidenció que los altos niveles de contaminación atmosférica se asociaban causalmente con un incremento en las muertes tempranas (Querol et al., 2012). No obstante, las primeras medidas de niveles de contaminación atmosférica no se iniciaron hasta 1930. Paralelamente, se iniciaron las políticas de control ambiental y, como consecuencia de ello, durante las décadas de los 70 y 80 se registró un notable descenso en los niveles de contaminación atmosférica.

En el año 1987, la Organización Mundial de la Salud (OMS) editó la primera edición de sus guías de calidad del aire para Europa (WHO, 1987), cuyo objetivo es aportar información para el establecimiento de políticas que conduzcan a la reducción del impacto en salud de la contaminación atmosférica.

Posteriormente, la OMS ha llevado a cabo la actualización de dichas guías, y lo está actualmente, con el fin de adaptarlas a los estudios científicos más recientes sobre la materia (contaminación atmosférica y su afección sobre la salud humana) (WHO, 2005). Aunque los valores propuestos por la OMS no tienen poder legal, son utilizados por muchos países para desarrollar los estándares nacionales de calidad del aire.

Por otro lado, la UE establece la normativa respecto a la calidad del aire que se debe cumplir en los países miembros. En ella se fijan los valores límite (VL) para los contaminantes más importantes (Directiva 2008/50/CE). EI VL es un valor fijado, que se basa en conocimientos científicos, con el fin de evitar, prevenir o reducir los efectos nocivos para la salud humana y/o para el medio ambiente en su conjunto.

En la Tabla 1.3 se presentan los valores guía de calidad del aire establecidos por la OMS y los VL para la salud humana en la UE, observándose que los valores propuestos por la OMS son más estrictos que los legislados. Los valores recomendados por la OMS deben considerarse como un objetivo aceptable y alcanzable para minimizar los efectos del PM sobre la salud, ya que no se ha identificado ningún umbral para PM por debajo del cual no se observen afecciones sobre la salud (EEA, 2016). 
En este sentido, recientemente el Centro Internacional de Investigaciones sobre el Cáncer ha clasificado como cancerígenos la contaminación atmosférica en general y específicamente a las partículas, como componente individual de la misma (IARC, 2013).

En la Tabla 1.4 se presenta el porcentaje de población en la UE expuesta a concentraciones de PM10 y PM2.5 superiores a las concentraciones establecidas en la normativa de la UE y por la OMS.

Tabla 1. 3. Valores de calidad de aire para PM.

\begin{tabular}{|c|c|c|c|c|}
\hline \multirow{2}{*}{ Fracción } & $\begin{array}{c}\text { Periodo de } \\
\text { referencia }\end{array}$ & $\operatorname{VL~UE}^{\mathrm{a}}\left(\boldsymbol{\mu g} / \mathbf{m}^{3}\right)$ & Fecha cumplimiento & Valor guía OMS $\mathbf{b}\left(\boldsymbol{\mu g} / \mathbf{m}^{3}\right)$ \\
\hline \multirow{2}{*}{ PM10 } & 1 año & 40 & 1 enero 2005 & 20 \\
\cline { 2 - 5 } & 1 día & 50 & 1 enero 2005 & 50 \\
\hline \multirow{2}{*}{ PM2.5 } & 1 año & 25 & 1 enero 2015 & 10 \\
\cline { 2 - 5 } & 1 año & 20 & 1 enero 2020 & 10 \\
\cline { 2 - 5 } & 1 día & n.a & n.a & 25 \\
\hline
\end{tabular}

${ }^{a}$ Normativa UE: Directivas 2008/50/CE.

${ }^{b}$ Valor guía de calidad de aire de la OMS (WHO, 2005).

n.a.: no aplica

Tabla 1. 4. Porcentaje de población expuesta a superaciones de PM (2012-2014) (EEA, 2016).

\begin{tabular}{|c|c|c|c|c|}
\hline Fracción & $\begin{array}{c}\text { VL UEa } \\
\left(\mu \mathbf{g} / \mathbf{m}^{3}\right)\end{array}$ & $\begin{array}{c}\text { Porcentaje de población } \\
\text { expuesta a superaciones } \\
(\%)\end{array}$ & $\begin{array}{c}\text { Valor guía OMS } \\
\left(\mu \mathbf{g} / \mathbf{m}^{3}\right)\end{array}$ & $\begin{array}{c}\text { Porcentaje de población } \\
\text { expuesta a superaciones } \\
(\%)\end{array}$ \\
\hline PM10 & 50 (diario) & $16-21$ & 20 (anual) & $50-63$ \\
\hline PM2.5 & 25 (anual) & $8-12$ & 10 (anual) & $85-91$ \\
\hline
\end{tabular}

${ }^{a}$ Normativa UE: Directivas 2008/50/CE.

bValor guía de calidad de aire de la OMS (WHO, 2005).

En la UE se ha estimado una pérdida de esperanza de vida debido a las PM2.5 en el aire alrededor de 8 meses, lo que equivale a 3.6 millones de años de vida perdidos anualmente en EU-28. Si se llevara a cabo la plena aplicación de las políticas existentes, la reducción sería de aproximadamente 5.5 meses (equivalentes a 2.5 millones de años de vida perdidos o 272000 muertes prematuras en la UE-28) (EEA, 2015). Concretamente, en 2013 las concentraciones de PM2.5 en aire ambiente fueron responsables de 436000 muertes prematuras en la UE-28, debido a exposiciones a largo plazo (EEA, 2016).

El programa «Aire puro» para Europa (EU, 2013) destaca que la calidad del aire en Europa ha mejorado notablemente en las últimas décadas, pero también que la contaminación atmosférica se mantiene como el principal factor ambiental asociado a las enfermedades evitables y a la mortalidad prematura en la UE, y sigue teniendo efectos negativos en gran parte del medio natural europeo. Así, según la Organización para la Cooperación y el Desarrollo Económicos (OCDE), la contaminación del aire en las ciudades se convertirá, de aquí a 2050, en la principal causa ambiental de mortalidad en todo el mundo, por delante de las aguas contaminadas y la falta de infraestructuras sanitarias (OCDE, 2012). 
Con el fin de minimizar las consecuencias de una deficiente calidad del aire, se considera necesario gestionar de forma adecuada la misma para garantizar el cumplimiento de los VL. Sin un control adecuado, el crecimiento socio-económico de las ciudades puede venir acompañado de un aumento de las emisiones de contaminantes atmosféricos. Estas emisiones pueden originar fuertes consecuencias para la salud pública, ya que la contaminación atmosférica afecta diariamente a toda la población, especialmente en las grandes ciudades, donde las concentraciones tienden a ser más altas que en las zonas rurales (con excepción del ozono) o en la población que presenta mayor vulnerabilidad a los problemas de salud (EEA, 2016).

Los efectos adversos sobre la salud que puede originar la presencia del PM dependen fundamentalmente de los siguientes factores: granulometría, composición y tiempo de exposición a un ambiente con altos niveles.

Para llevar a cabo la interpretación de los efectos que produce la contaminación atmosférica en la salud se pueden realizar dos clases de estudios: los toxicológicos y los epidemiológicos. Los estudios toxicológicos se basan en exponer a humanos o animales a la sustancia contaminante cuyos efectos se desean evaluar. En estos estudios, la concentración, duración y condiciones de la exposición son controladas por el investigador. Los estudios epidemiológicos se basan en la observación de los sucesos que se desarrollan en las poblaciones humanas bajo condiciones naturales.

Los resultados de los estudios toxicológicos y epidemiológicos señalan a las partículas como un indicador del riesgo sanitario que supone la contaminación atmosférica, concretamente la fracción PM10, para efectos a corto plazo (de pocas horas a días), y la fracción PM2.5 o partículas finas como indicadores de la exposición a largo plazo (de meses a años) (Querol et al., 2012).

La fracción torácica (PM10) pueden penetrar en la región bronquial y es eliminada por la acción ciliar. Las partículas de diámetro entre 0.1 y $2.5 \mu \mathrm{m}$ pueden alcanzar la cavidad alveolar, llegando a los bronquios y no son eliminadas, quedando retinadas de forma crónica (Leopold y Gough, 1957). Finalmente, las partículas de diámetro inferior a $0.1 \mu \mathrm{m}$ son demasiado pequeñas para sedimentar durante la respiración y llegan a translocar el pulmón alcanzando el sistema circulatorio y los órganos a los cuales éste accede, no obstante, se depositan en las paredes alveolares por difusión o bien se expulsan con la misma respiración (Churg y Brauer, 1997).

La mayoría de los estudios sobre los efectos de la contaminación en la salud tienden a centrarse en la mortalidad prematura, así como en los efectos respiratorios, cardiovasculares y cerebrovasculares atribuidos a la exposición de la contaminación atmosférica (WHO, 2008, 2013).

\section{- Otros efectos del PM}

Varios contaminantes tienen un impacto potencial sobre el clima y el calentamiento global. Según su composición, el PM pueden tener un efecto de calentamiento o de enfriamiento sobre el clima local y mundial. Por ejemplo, el carbono negro, uno de los componentes de las partículas finas, absorbe la radiación solar e infrarroja en la atmósfera y por consiguiente tiene un efecto de calentamiento. Otros componentes del PM, como el $\mathrm{NH}_{4}{ }^{+}, \mathrm{SO}_{4}{ }^{2-}$ y $\mathrm{NO}_{3}{ }^{-}$tienen un efecto contrario, suelen actuar como pequeños espejos que reflejan la energía solar y por consiguiente provocan un enfriamiento (EEA, 2013). Además, los cambios en los patrones climáticos debidos al cambio climático pueden cambiar el transporte, la dispersión, la deposición y la formación de contaminantes atmosféricos en la atmósfera (EEA, 2016). 
Los ecosistemas también sufren los efectos directos o indirectos de la exposición al PM atmosférico, tanto por deposición seca como húmeda. Estos efectos adversos se producen bajo la acción de las partículas atmosféricas, pero también cuando éstas actúan como soporte para otros contaminantes atmosféricos.

Las partículas de mayor diámetro (moda gruesa) tales como el polvo mineral, al depositarse sobre las hojas de las plantas pueden reducir la capacidad de intercambio gaseoso, así como afectar a la fotosíntesis, lo cual limita el crecimiento (WBG, 1998).

Cuando el PM se deposita sobre la superficie terrestre, las concentraciones de metales presentes en el PM pueden afectar a las características edáficas e inhibir funciones como la toma de nutrientes por parte de las plantas. Asimismo, la deposición del PM atmosférico puede suponer la acidificación y eutrofización de suelos y aguas superficiales, lo cual a su vez puede repercutir sobre la composición de las aguas subterráneas (EEA, 2016).

Al margen de estos efectos, en los entornos urbanos el PM puede contribuir a la alteración de los materiales de construcción y recubrimientos, debido al depósito de las partículas en la superficie de los materiales y su interacción con ellos, originando problemas de corrosión, biodegradación y suciedad. La transformación de estos materiales puede estar relacionada tanto con las partículas atmosféricas como con los principales gases asociados $\left(\mathrm{SO}_{2}\right.$ y $\left.\mathrm{NO}_{x}\right)$ (Alastuey, 1994).

Los efectos de la contaminación atmosférica sobre la salud, los cultivos, los ecosistemas, el clima y los edificios también implican considerables costes económicos.

Entre los costes económicos se incluyen la reducción de la productividad laboral, el gasto adicional en salud y pérdidas de rendimiento en cultivos y bosques. La OCDE prevé que estos costes alcanzarán el $2 \%$ del producto interior bruto europeo en 2060, provocando una reducción de la acumulación de capital y una desaceleración del crecimiento económico (EEA, 2016). 


\subsection{Emisiones difusas de PM en entornos industriales}

Las emisiones generadas durante el almacenamiento, manipulación y transporte de graneles sólidos de naturaleza pulverulenta se emiten a la atmósfera desde un área o volumen disperso, a diferencia de las emisiones canalizadas, que se emiten a través de una corriente de flujo confinada. En cuanto a la nomenclatura utilizada para referirse a estas emisiones, se ha observado que existe una cierta confusión, denominándolas indistintamente en la bibliografía como emisiones difusas y fugitivas.

A nivel europeo, los Documentos de Referencia sobre las Mejores Tecnologías Disponibles (BREF) nombran a las emisiones asociadas al almacenamiento, manipulación y transporte de sólidos emisiones difusas (IPTS, 2003). Si bien, en estos documentos las emisiones fugitivas se consideran un subgrupo de las emisiones difusas y, se definen como aquellas que se generan como resultado de la pérdida gradual de estanqueidad de una pieza de un equipo diseñada para contener un fluido (gaseoso o líquido).

Sin embargo, la normativa americana a las emisiones asociadas al almacenamiento, manipulación y transporte las denomina emisiones fugitivas y las define de una manera mucho más amplia, abarcando todas aquellas emisiones que no podrían pasar razonablemente a través de una chimenea, ventilación u otra abertura funcionalmente equivalente (US EPA, 1995). Esta definición por exclusión refleja la variedad y complejidad de este tipo de emisiones. Esta misma nomenclatura también se sigue en el documento AP-42 de la US EPA (US EPA, 1995), ampliamente utilizado para la realización de inventarios.

Lo anteriormente expuesto evidencia que no existe un criterio común a la hora de definir las emisiones difusas y fugitivas de PM. A este respecto, en el presente trabajo a las emisiones generadas durante el almacenamiento, manipulación y transporte de materiales de naturaleza pulverulenta se las ha denominado emisiones difusas, por coherencia con los BREF. No obstante, en los artículos se les ha denominado fugitive emissions, debido a la tendencia existente a utilizar este término en los artículos científicos más recientes (Marta et al., 2013; Amato et al., 2016; Hosseini y Stockie, 2016; Pérez et al., 2016).

A continuación, se presentan las características de las emisiones difusas de PM y su posible contribución a los niveles de calidad del aire, así como los diferentes métodos para la cuantificación de este tipo de emisiones. Asimismo, se han identificado las principales actividades industriales en las que se realizan operaciones potencialmente generadoras de emisiones difusas de PM, y se han recopilado las principales medidas correctoras para disminuir su impacto ambiental.

\subsubsection{Características y contribución de las emisiones difusas de PM}

En cuanto a las características que presentan las emisiones difusas de PM, cabe destacar que se emiten a alturas relativamente bajas, y por tanto su dispersión se ve afectada en gran medida por las variaciones en la velocidad del viento y la turbulencia que se generan en las capas más bajas de la atmósfera.

A escala local, la dispersión (transporte y difusión) de las emisiones difusas de partículas generadas por la manipulación, transporte y almacenamiento de materiales sólidos pulverulentos depende fundamentalmente de parámetros meteorológicos: velocidad y dirección del viento, estabilidad atmosférica, lluvia, entre otros (Watson, 2000a). La lluvia ejerce un efecto de «limpieza» sobre el 
PM en suspensión en el aire, así como sobre el depositado en el suelo, evitando su resuspensión. El viento puede ser el origen de muchas de las emisiones y también su mecanismo de transporte, pudiendo arrastrar las partículas en suspensión hasta kilómetros del foco, dependiendo del tamaño de las partículas y de la velocidad del viento. Cuanto más finas sean las partículas, más fácilmente podrán ser resuspendidas por la acción del viento y podrán ser transportadas a mayores distancias. El rozamiento del aire con el terreno provoca una reducción de la velocidad del viento en las capas próximas al suelo. Cerca del suelo la velocidad del viento es menor y la variación con la altura depende de la rugosidad del terreno (vegetación, edificios, etc.). En superficies con muy poca rugosidad (terrenos llanos sin arbolado, grandes superficies lisas de agua o de nieve, etc.) el gradiente vertical de velocidad de viento es suave, mientras que, por el contrario, en terrenos con gran rugosidad (edificaciones altas de las ciudades, bosques, etc.) el gradiente de velocidad es más acusado (Gobierno Vasco, 2012).

En consecuencia, las emisiones difusas de PM presentan una complejidad inherente como consecuencia tanto de su fenomenología de emisión como de otros factores, identificados durante la ejecución de campañas experimentales en entornos industriales:

- Son transportadas desde el inicio por la fluctuación del viento, y no por un caudal constante como ocurre en el caso de las emisiones canalizadas.

- La tasa de emisión se ve afectada por las condiciones meteorológicas (velocidad y dirección del viento, estabilidad atmosférica, etc.) y por la topografía del terreno (rugosidad superficial, cobertura vegetal, presencia de edificios, entre otros). Las condiciones meteorológicas influyen tanto en la generación de partículas, como en la posterior dispersión de las mismas en el aire.

- La mayor parte de las emisiones difusas generadas en actividades industriales son de naturaleza discontinua y de corta duración, pudiendo variar incluso la frecuencia e intensidad de la emisión dentro de un mismo día de trabajo.

- Las fuentes de emisión pueden ser móviles, variando su posición con el tiempo, e incluso en determinados casos, la fuente se mueve arbitrariamente a través de un área o vial.

- Muchas operaciones de manipulación y transporte se realizan en procesos no automatizados, lo que introduce la variabilidad del factor humano a la hora de ejecutar las mismas.

- Estas fuentes de emisión genéricas (almacenamiento, manipulación y transporte) suelen abarcar diferentes operaciones específicas, como, por ejemplo, la recepción de los materiales en un área destinada a tal efecto, su apilamiento para formar los montones, el transporte mediante máquina pala o similar, las operaciones de pretratamiento (trituración, molienda, entre otros.), la transferencia de materiales, la descarga final del material para su expedición, entre otros. Consecuentemente, muchas de estas operaciones individuales se realizan habitualmente de forma simultánea, lo que implica el solapamiento de focos de emisión.

Asimismo, debe considerarse que las emisiones difusas de PM dependen de las propiedades del material manipulado, tipo de pretratamiento realizado, medidas correctoras implementadas, entre otros. En la Tabla 1.5 se identifican y comentan las principales características del material que pueden presentar un efecto significativo sobre su poder de emisión, es decir, sobre la tendencia a generar emisiones de PM cuando son sometidos a una manipulación. 
Esta complejidad inherente dificulta la cuantificación y control de las emisiones difusas de PM, lo que conlleva que mientras para inventariar las emisiones canalizadas de PM se dispone de medidas experimentales en los propios focos, en el caso de las emisiones difusas se recurra a factores de emisión (FE), en muchas ocasiones genéricos, que pueden conducir a no representar la situación real considerada, dificultando la identificación de las operaciones más problemáticas y/o de las necesidades de actuación de mejora medioambiental.

Esta realidad se refleja en el tratamiento legislativo que han recibido tradicionalmente este tipo de emisiones, a las que se les ha prestado una atención limitada. Como resultado, las metodologías de control establecidas actualmente presentan una serie de limitaciones, las cuales se detallan en el apartado referente a normativa (apartado 1.3).

Tabla 1. 5. Influencia de las propiedades del material sobre el poder de emisión de polvo (TNO, 2009).

\begin{tabular}{|c|l|}
\hline Parámetro & \multicolumn{1}{|c|}{ Influencia } \\
\hline $\begin{array}{c}\text { Fracción de } \\
\text { finos }\end{array}$ & $\begin{array}{l}\text { Diversos estudios han mostrado que existe una relación entre el contenido en finos presente en el } \\
\text { material y el poder de emisión de polvo del mismo. No obstante, varios experimentos han } \\
\text { mostrado que al extraer partículas finas de un material el poder de emisión de polvo no disminuye } \\
\text { proporcionalmente y que materiales con una pequeña proporción de finos pueden ser casi tan } \\
\text { pulverulentos como materiales compuestos en su totalidad por finos. }\end{array}$ \\
\hline $\begin{array}{c}\text { Distribución } \\
\text { granulométrica }\end{array}$ & $\begin{array}{l}\text { Estudios experimentales han mostrado que los materiales con una amplia distribución de tamaño } \\
\text { presentan un mayor poder de emisión de polvo que materiales con una distribución estrecha. }\end{array}$ \\
\hline $\begin{array}{c}\text { Forma de las } \\
\text { partículas }\end{array}$ & Las partículas irregulares tienden a generar más polvo que las partículas esféricas. \\
\hline $\begin{array}{c}\text { Densidad del } \\
\text { lecho }\end{array}$ & $\begin{array}{l}\text { Los materiales con una menor densidad del lecho deberían tener un mayor poder de emisión de } \\
\text { polvo. No obstante, los estudios realizados no han demostrado que exista una relación tan clara. }\end{array}$ \\
\hline Humedad & $\begin{array}{l}\text { En general al aumentar la humedad de los materiales disminuye su poder de emisión de polvo. } \\
\text { No obstante, la relación entre el poder de emisión de polvo y la humedad es compleja y depende } \\
\text { de la naturaleza del material. }\end{array}$ \\
\hline Fluidez & $\begin{array}{l}\text { Algunos autores han relacionado el poder de emisión de polvo de los materiales con la cohesión, } \\
\text { observándose que al aumentar la cohesión se produce un descenso en el poder de emisión. }\end{array}$ \\
\hline
\end{tabular}

No obstante, en determinados entornos geográficos con presencia de actividades industriales en las que se manipulan materiales pulverulentos, la contribución relativa de las emisiones difusas de PM puede llegar a ser significativa (Watson, 2000a). Especialmente, en zonas de clima mediterráneo con pocas lluvias y elevada irradiación solar, donde habitualmente el almacenamiento y homogenización de materias primas se realiza al aire libre.

De hecho, dependiendo del proceso productivo, las emisiones difusas de PM pueden llegar a tener una importancia similar a las emisiones por fuentes canalizadas. Por ejemplo, en el proceso cerámico se ha cuantificado que la emisión de PM10 por focos difusos, puede llegar a contribuir hasta en un 60\% en el cómputo global (emisiones canalizadas y difusas) (Monfort et al., 2004).

En este sentido, cabe destacar que en el Plan de Mejora de la Calidad del Aire de la zona cerámica de Castellón (Generalitat Valenciana, 2008), se identificó una contribución de las emisiones canalizadas y difusas de PM10 del mismo orden (Tabla 1.6), al considerar en estas últimas las 
emisiones a nivel sectorial asociadas a las pérdidas de material durante su transporte por carretera en camiones tipo bañera.

Tabla 1. 6. Emisiones de PM10 en el clúster cerámico de Castellón para 2005 (Generalitat Valenciana, 2008).

\begin{tabular}{|c|c|c|c|}
\hline \multirow{2}{*}{ Unidades } & \multicolumn{3}{|c|}{ Emisiones de PM10 } \\
\cline { 2 - 4 } & Canalizadas & Pérdidas por transporte $^{\mathrm{a}}$ & Difusas $^{\text {b }}$ \\
\hline t/año & 3610 & 1215 & 2000 \\
\hline$\%$ & 53 & 17 & 29 \\
\hline
\end{tabular}

a Estimación a nivel sectorial de las pérdidas de material durante su transporte por carretera en camiones bañera.

b Incluye las emisiones asociadas al almacenamiento, manipulación y transporte interno.

\subsubsection{Métodos de cuantificación para las emisiones difusas de PM}

A continuación, se resumen las principales metodologías aplicadas para la determinación de FE para fuentes difusas a partir de medidas experimentales (EPA, 1993):

- El método de emisión cuasi-canalizada consiste en capturar en su totalidad el penacho de emisión mediante un cerramiento o cubierta, y posteriormente aplicar a la corriente confinada normas de muestreo desarrolladas para emisiones canalizadas. La aplicación práctica de esta metodología es muy limitada, debido a que resulta considerablemente complejo la canalización de una emisión difusa, sobre todo en el caso de fuentes asociadas a manipulación de materiales sólidos, tales como cargas y descargas.

- El método basado en determinar el flujo de materia a través de una apertura (conocido como Roof Monitor), el cual requiere conocer la concentración de PM y el flujo del aire a través de las principales aberturas de la instalación, tales como respiraderos, ventanas, puertas, etc. Posteriormente, se determina, a partir de dichas medidas, el flujo másico de partículas existente. Este método se aplica principalmente a instalaciones cerradas.

- El método basado en la obtención de perfiles isocinéticos consiste en determinar simultáneamente concentraciones de PM y velocidad del viento en diferentes puntos, intentando cubrir al máximo el área de la sección transversal del penacho. Posteriormente, a través de la integración de los perfiles de la pluma se determina el flujo másico de PM. Este método se encuentra ampliamente implementado en el cálculo de FE recogidos en el documento AP-42 de la US EPA (US EPA, 1995). A pesar de que a priori esta metodología puede aplicarse a cualquier tipo de fuente, presenta una serie de limitaciones:

- En el caso de cuantificar las emisiones originadas en un área extensa, la superposición de penachos asociados a diferentes fuentes, puede impedir la determinación de FE específicos por fuente.

- La consideración general de que el área está emitiendo de forma uniforme no permite conocer la variación espacial de la actividad. 
- El método basado en cálculos de dispersión (conocido como Reverse Dispersion Modelling, en adelante RDM), consiste en medir concentraciones de PM a sotavento (y a barlovento) de la fuente emisora, determinando dichas concentraciones bajo condiciones meteorológicas conocidas, y aplicando posteriormente modelos de dispersión atmosférica para calcular el FE. Las concentraciones netas (sotavento menos barlovento), junto con las variables meteorológicas determinadas (al menos velocidad y dirección del viento), son los principales datos de entrada al modelo de dispersión de contaminantes, normalmente de tipo gaussiano, para el cálculo de FE.

Este último método, junto con el desarrollo de un modelo de dispersión de contaminantes ajustado a las necesidades de las emisiones difusas de PM, es el que se propone en el presente trabajo para la obtención de FE específicos para los diferentes materiales y operaciones que componen una actividad.

\subsubsection{Actividades industriales potencialmente generadoras de emisiones difusas de PM}

Las principales actividades industriales que presentan una problemática ambiental asociada a las emisiones difusas de PM, según la bibliografía consultada (Gobierno Vasco, 2012; Querol et al., 2012) se pueden identificar principalmente en los siguientes entornos: industrias dedicadas a la fabricación de productos minerales no metálicos (cerámicas, cementeras, plantas de hormigón, fabricantes de cal, etc.), sector minero, siderúrgico, refino, termoeléctrico, construcción, agrícola y actividades portuarias.

A continuación, se analiza a nivel nacional la coyuntura de los sectores seleccionados y se describe el proceso de producción, centrándose en las etapas en las que se realizan operaciones potencialmente generadoras de emisiones difusas de PM. Para cada una de estas etapas se han identificado las operaciones específicas responsables de la emisión. El tipo de fuente emisora se ha clasificado en: manipulación, transporte y erosión, con el fin de proponer posteriormente FE que permitan cuantificar las emisiones difusas de PM en los procesos industriales seleccionados. Esta descripción se realiza con mayor grado de detalle para los procesos industriales objeto de estudio del presente trabajo: cerámicas, cementeras, plantas de hormigón prefabricado, canteras de áridos y puertos.

En la Figura 1.4 se detalla la metodología de cálculo propuesta para la identificación y cuantificación de las emisiones difusas de PM a nivel de etapa de proceso y/o global del proceso o la actividad.

No obstante, en cuanto a la aplicación de FE específicos por operación y/o material manipulado para la cuantificación de las emisiones difusas de PM, cabe destacar que actualmente la información disponible es escasa, reflejándose dicha situación en las principales guías utilizadas para la elaboración de inventarios, las cuales proponen FE genéricos para manipulación y transporte. Por tanto, se considera de interés disponer de un mayor grado de detalle, en términos de FE específicos para las distintas operaciones que componen una actividad, no solo para realizar una estimación más exacta de las emisiones, sino también para poder identificar qué operaciones son las más problemáticas y establecer medidas correctoras apropiadas. 


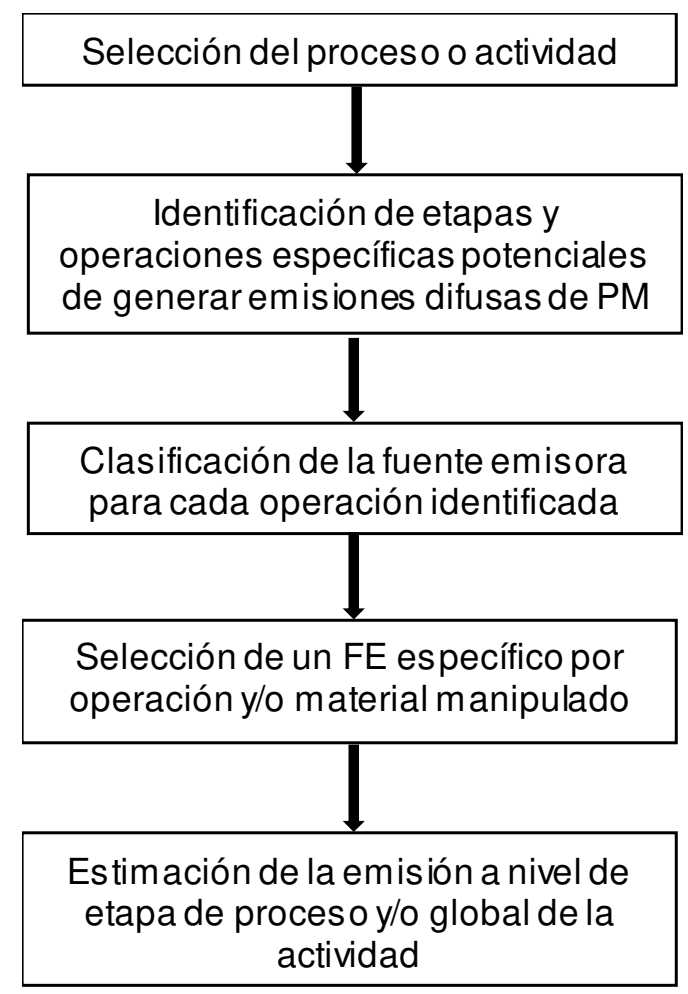

Figura 1. 4. Metodología de cálculo para la estimación de las emisiones difusas de PM.

\subsubsection{Cerámicas}

La fabricación de baldosas cerámicas, tejas y ladrillos presentan una mayor problemática ambiental asociada a las emisiones difusas de PM respecto al resto de procesos cerámicos. Esta situación, a nivel nacional, es debida principalmente a que la forma habitual de almacenar y gestionar las materias primas es al aire libre.

Las empresas fabricantes de cerámica estructural (ladrillos y tejas) se distribuyen a lo largo y ancho de todo el país, concentrándose en las provincias de Toledo, Jaén, Alicante, Valencia y Barcelona; donde se ubica casi el $50 \%$ de la producción nacional (HISPALYT, 2015).

Sin embargo, el sector español de baldosas cerámicas, con una producción en 2016 de 492 millones de $\mathrm{m}^{2}$, presenta un elevado grado de concentración industrial, formando lo que se denomina un «clúster industrial». En un área de unos $500 \mathrm{~km}^{2}$ de la provincia de Castellón (municipios de L'Alcora, Nules, Onda, Vilafamés y Vila-real) se sitúa aproximadamente el $80 \%$ de las empresas existentes, que producen cerca del 95\% de la producción española (ASCER, 2017).

\section{- Descripción del proceso de producción}

El proceso cerámico se inicia con la selección de las materias primas que deben formar parte de la composición de partida. En las industrias cerámicas tradicionales, las materias primas se suelen utilizar por lo general, tal y como se extraen de la mina o cantera o después de someterlas a un mínimo tratamiento. 
Las principales materias primas utilizadas son de naturaleza pulverulenta (arcillas de coloración roja y blanca en cocido, feldespatos, cuarzos, entre otros.), por ello durante su gestión se puede originar una suspensión de las fracciones más finas en el aire circundante.

El proceso de preparación de la composición del soporte se inicia con una molturación que puede ser vía seca o húmeda, procedimiento habitual en cerámica estructural (tejas y ladrillos) y en la fabricación de baldosas cerámicas, respectivamente. Posteriormente, se pasa al proceso de conformado (extrusionado o prensado), secado, esmaltado y cocción.

\section{- Operaciones generadoras de emisiones difusas de PM}

Dentro del sector de fabricación de baldosas cerámicas, las empresas fabricantes de gránulo atomizado son las que presentan mayores emisiones difusas de PM, debido a que necesitan grandes acopios de materias primas por el elevado volumen de producción (suministran gránulo atomizado a un elevado número de empresas) y, por el tipo de materias primas utilizadas, habitualmente sin homogeneizar.

En el caso de las empresas fabricantes de baldosas, cuando el ciclo de producción es completo y la molienda se realiza vía húmeda, generalmente la producción de gránulo atomizado es para consumo propio, reduciéndose considerablemente el volumen de acopios de materias primas, y por tanto su gestión. Esta misma situación se da en empresas fabricantes de baldosas cerámicas y de tejas y ladrillos en las que la molienda se realiza vía seca.

Las emisiones difusas de PM en el proceso cerámico se generan principalmente durante la recepción, almacenamiento, manipulación y transporte (mediante camiones, máquina pala, cintas transportadoras, entre otros) de materias primas y en la expedición a granel de productos semielaborados (gránulo atomizado) de naturaleza pulverulenta. La Figura 1.5 muestra alguna de las operaciones potencialmente generadoras de emisiones difusas de PM en el sector cerámico.

Cabe destacar, que en las operaciones de pretratamiento (trituración y molienda) de las materias primas, cuando estas no se encuentran confinadas, también generan emisiones difusas de PM.

También debe prestarse atención a las emisiones difusas asociadas a la gestión de los residuos sólidos pulverulentos (material recogido en los filtros de mangas, piezas crudas, entre otros).
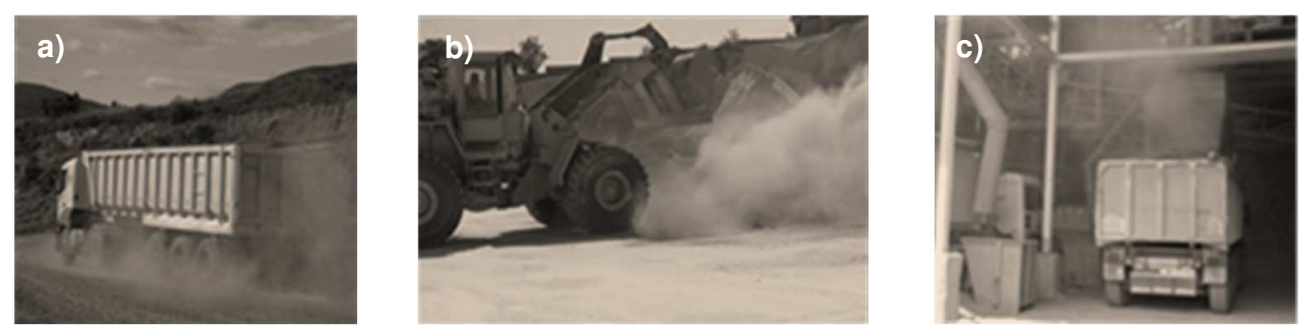

Figura 1.5. Operaciones generadoras de emisiones difusas de PM: a) Circulación por vías no asfaltadas, b) Descarga de máquina pala y c) Carga de producto a granel.

En el caso concreto del transporte, se generan emisiones por diferentes mecanismos: reboses o perdida de material, resuspensión, desgaste de frenos, neumáticos y firme de rodadura, combustión en motores diésel, entre otros. 
Dado que el transporte suele realizarse en camiones tipo bañera, las emisiones asociadas a la perdida de material por reboses o cierres deficientes son mucho más elevadas que las emisiones generadas por el motor o desgaste de frenos, neumáticos y firmes de rodadura. Además del impacto medioambiental provocado por esta emisión de PM al ambiente, se produce el depósito de materiales en las carreteras que puede ser resuspendido posteriormente e incluso provocar problemas de seguridad vial. Por tanto, se considera este foco de emisión como uno de los de mayor impacto ambiental.

En las Tablas 1.7 y 1.8 se detallan las operaciones identificadas como más significativas en cuanto a la generación de emisiones difusas de PM en el proceso de fabricación de baldosas cerámicas, tejas y ladrillos.

Tabla 1.7. Identificación de operaciones generadoras de emisiones difusas de PM en el sector cerámico: procesos con molienda vía húmeda.

\begin{tabular}{|c|c|c|c|c|}
\hline \multicolumn{2}{|r|}{ Etapa } & \multicolumn{2}{|r|}{ Operación } & \multirow{2}{*}{$\begin{array}{c}\begin{array}{c}\text { Clasificación fuente } \\
\text { emisora }\end{array} \\
\text { Transporte }\end{array}$} \\
\hline \multirow{3}{*}{1} & \multirow{3}{*}{$\begin{array}{l}\text { Recepción materias } \\
\text { primas }\end{array}$} & 1.1 & Circulación camión/máquina pala & \\
\hline & & 1.2 & Descarga camión & Manipulación \\
\hline & & 1.3 & Apilamiento con máquina pala & Manipulación \\
\hline \multirow{2}{*}{2} & \multirow{2}{*}{ Gestión materias primas } & 2.1 & Alimentación tolva con máquina pala & Manipulación \\
\hline & & 2.2 & Circulación máquina pala & Transporte \\
\hline 3 & Trituración & 3.1 & Trituración & Trituración \\
\hline \multirow{2}{*}{4} & \multirow{2}{*}{ Carga producto a granel } & 4.1 & Circulación camión & Transporte \\
\hline & & 4.2 & Carga camión & Manipulación \\
\hline \multirow{2}{*}{5} & \multirow{2}{*}{$\begin{array}{l}\text { Gestión finos (rechazo } \\
\text { filtros de mangas) }\end{array}$} & 5.1 & Carga/descarga máquina pala & Manipulación \\
\hline & & 5.2 & Circulación máquina pala & Transporte \\
\hline 6 & Almacenamiento & 6.1 & $\begin{array}{l}\text { Erosión por viento del material almacenado } \\
\text { a cielo abierto }\end{array}$ & Erosión \\
\hline
\end{tabular}


Tabla 1.8. Identificación de operaciones generadoras de emisiones difusas de PM en el sector cerámico: procesos con molienda vía seca.

\begin{tabular}{|c|c|c|c|c|c|}
\hline \multicolumn{3}{|r|}{ Etapa } & \multicolumn{2}{|r|}{ Operación } & $\begin{array}{c}\text { Clasificación fuente } \\
\text { emisora }\end{array}$ \\
\hline \multirow{3}{*}{1} & \multirow{3}{*}{\multicolumn{2}{|c|}{ Recepción materias primas }} & 1.1 & Circulación camión/máquina pala & Transporte \\
\hline & & & 1.2 & Descarga camión & Manipulación \\
\hline & & & 1.3 & Apilamiento con máquina pala & Manipulación \\
\hline \multirow{7}{*}{2} & \multirow{7}{*}{ 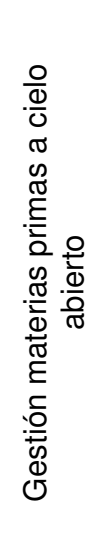 } & \multirow{2}{*}{$\begin{array}{l}2.1 \text { Formulación } \\
\text { composición }\end{array}$} & 2.1.1 & Carga/descarga máquina pala & Manipulación \\
\hline & & & 2.1 .2 & Circulación máquina pala & Transporte \\
\hline & & $\begin{array}{l}2.2 \text { Molienda del material } \\
\text { extendido en la era }\end{array}$ & 2.2.1 & $\begin{array}{l}\text { Circulación máquina pala con } \\
\text { dispositivo de molienda }\end{array}$ & Transporte \\
\hline & & 2.3 Acopio material seco y & 2.3 .1 & Apilamiento máquina pala & Manipulación \\
\hline & & & 2.3.2 & Circulación máquina pala & Transporte \\
\hline & & 2.4 Almacenamiento & 2.4 .1 & $\begin{array}{l}\text { Alimentación granero/tolva con } \\
\text { máquina pala }\end{array}$ & Manipulación \\
\hline & & & 2.4 .2 & Circulación máquina pala & Transporte \\
\hline \multirow{2}{*}{3} & \multirow{2}{*}{\multicolumn{2}{|c|}{$\begin{array}{l}\text { Gestión finos (rechazo filtros de } \\
\text { mangas) }\end{array}$}} & 3.1 & Carga/descarga máquina pala & Manipulación \\
\hline & & & 3.2 & Circulación máquina pala & Transporte \\
\hline 4 & \multicolumn{2}{|c|}{ Almacenamiento } & 4.1 & $\begin{array}{l}\text { Erosión por viento del material } \\
\text { almacenado a cielo abierto }\end{array}$ & Erosión \\
\hline
\end{tabular}

\subsubsection{Cementeras}

Actualmente, el sector de la fabricación de cemento, con producción propia de clínker, está constituido por unas 30 fábricas pertenecientes a 11 empresas. Las diferentes fábricas se distribuyen a lo largo de toda la península, alcanzándose una producción de 17 y 14 millones de toneladas de clínker y cemento respectivamente en 2015, lo que supone un consumo aproximado de 26 millones de toneladas de materias primas y 2 millones de toneladas de combustibles (fósil y biomasa). El máximo histórico de producción se obtuvo en 2007 con 56 millones de toneladas en global (OFICEMEN, 2016).

\section{- Descripción del proceso de producción}

Habitualmente las cementeras incluyen en su proceso la explotación de materias primas en canteras, ubicadas cercanas a la fábrica, para la extracción de arcillas y caliza.

Una vez extraído y clasificado el material, se procede a su trituración hasta obtener una granulometría adecuada para el producto de molienda y se traslada a la fábrica mediante cintas trasportadoras o camiones para su almacenamiento en el parque de prehomogenización.

Posteriormente, estos materiales se muelen para reducir su tamaño, obteniéndose una harina 0 crudo que se almacena en silos para incrementar la uniformidad de la mezcla. Esta se alimenta a un horno rotativo para su calcinación y obtención del clínker. 
Finalmente, el clínker se mezcla con el regulador de fraguado (yeso) y con las posibles adiciones y se introduce en los molinos para su molienda. Una vez alcanzada la finura deseada, el producto que obtenemos es el cemento.

A parte de las propias operaciones de tratamiento y transformación de las materias primas y del producto, y dado que entre los principales combustibles se encuentran el coque de petróleo o carbón, las empresas suelen contar con instalaciones para el almacenamiento, la micronización y el secado de estos combustibles sólidos.

\section{- Operaciones generadoras de emisiones difusas de PM}

La generación de emisiones difusas de PM se registra principalmente en la extracción de materias primas y en los parques de prehomogenización de materias primas y de almacenamiento de combustibles energéticos.

Las principales operaciones susceptibles de generar emisiones difusas de PM (Figura 1.6) en la industria cementera son operaciones de manipulación (realizadas con camiones, máquina pala, entre otros), transporte mediante cintas transportadoras, circulación interna de vehículos, entre otros. Las operaciones propias de la extracción de materias primas se tratan en el apartado 1.2.3.4.

En el caso de las cementeras, la carga de producto suele realizarse por medio de sistemas neumáticos.
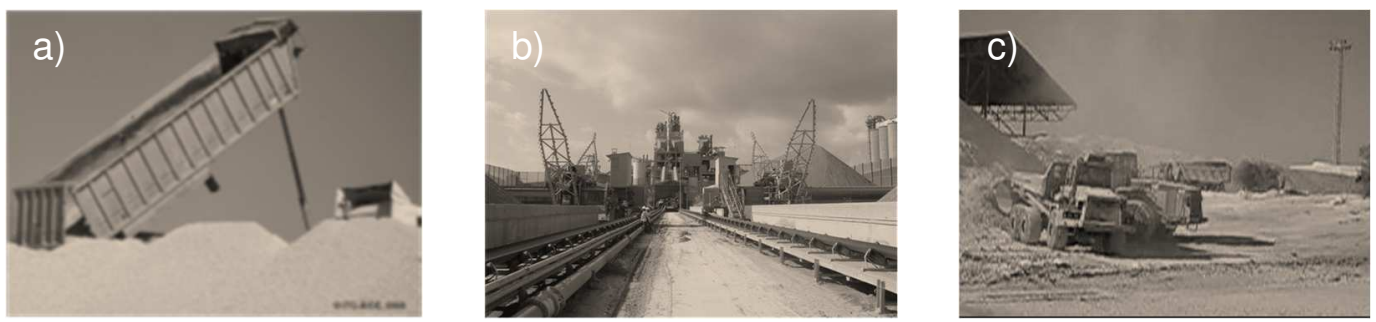

Figura 1.6. Operaciones generadoras de emisiones difusas de PM: a) Descarga de camión, b) Transporte materias primas mediante cintas y c) Descarga máquina pala.

Finalmente, en la Tabla 1.9 se detallan las operaciones identificadas como más significativas en cuanto a la generación de emisiones difusas de PM en el proceso de fabricación de cemento y clínker. 
Tabla 1.9. Identificación de operaciones generadoras de emisiones difusas de PM en el sector cementero.

\begin{tabular}{|c|c|c|c|c|}
\hline & Etapa & & Operación & $\begin{array}{c}\text { Clasificación fuente } \\
\text { emisora }\end{array}$ \\
\hline \multirow{4}{*}{1} & \multirow{4}{*}{$\begin{array}{l}\text { Recepción materias } \\
\text { primas/coque }\end{array}$} & 1.1 & Circulación camión/máquina pala & Transporte \\
\hline & & 1.2 & Descarga camión & Manipulación \\
\hline & & 1.3 & Apilamiento máquina pala/máquina rascadora & Manipulación \\
\hline & & 1.4 & Transporte cintas transportadoras & Manipulación \\
\hline \multirow{2}{*}{2} & \multirow{2}{*}{$\begin{array}{l}\text { Gestión materias } \\
\text { primas/coque }\end{array}$} & 2.1 & Carga/descarga en tolva con máquina pala & Manipulación \\
\hline & & 2.2 & Circulación máquina pala & Transporte \\
\hline \multirow{2}{*}{3} & \multirow{2}{*}{$\begin{array}{l}\text { Carga de producto } \\
\text { (clínker y cemento) }\end{array}$} & 3.1 & Circulación camión & Transporte \\
\hline & & 3.2 & Carga camión & Manipulación \\
\hline \multirow{2}{*}{4} & \multirow{2}{*}{$\begin{array}{l}\text { Gestión finos (rechazo } \\
\text { precipitador electrostático } \\
\text { /filtros de mangas) }\end{array}$} & 4.1 & Carga/descarga máquina pala & Manipulación \\
\hline & & 4.2 & Circulación máquina pala & Transporte \\
\hline 5 & Almacenamiento & 5.1 & $\begin{array}{l}\text { Erosión por viento del material almacenado a } \\
\text { cielo abierto }\end{array}$ & Erosión \\
\hline
\end{tabular}

\subsubsection{Plantas de hormigón prefabricado}

La producción nacional estimada en 2015 de hormigón prefabricado fue superior a los 16 millones de $\mathrm{m}^{3}$, distribuida a través de 1012 empresas localizadas en todo el territorio nacional, que cuentan con un total de 1949 plantas (ANEFHOP, 2016).

\section{- Descripción del proceso de producción}

Los principales materiales requeridos para la fabricación del hormigón incluyen los áridos (habitualmente en forma de arena y grava), cemento y cenizas volantes. Las arenas y gravas suelen almacenarse en los parques de almacenamiento a cielo abierto ubicados en las plantas.

Las plantas de hormigón son instalaciones completamente automatizadas, con sistemas integrados de control de peso y producciones, como son los sistemas de dosificación de aditivos, sistemas neumáticos de carga de cemento, entre otros.

Las actividades de recepción, almacenamiento, dosificación y mezclado de materias primas, es común en los procesos productivos de hormigón premezclado, hormigón prefabricado o mortero seco.

\section{- Operaciones generadoras de emisiones difusas de PM}

En las plantas de hormigón se producen emisiones difusas de PM principalmente en el almacenamiento y en las operaciones de manipulación de los áridos utilizados como materia prima, ya que el resto de materias primas se descargan por sistemas neumáticos. Además, debe considerarse el transporte interno que genera emisiones debido a la resuspensión del material depositado en las vías. 
En la Figura 1.7, se muestran algunos detalles de las operaciones realizadas en los parques de almacenamiento.
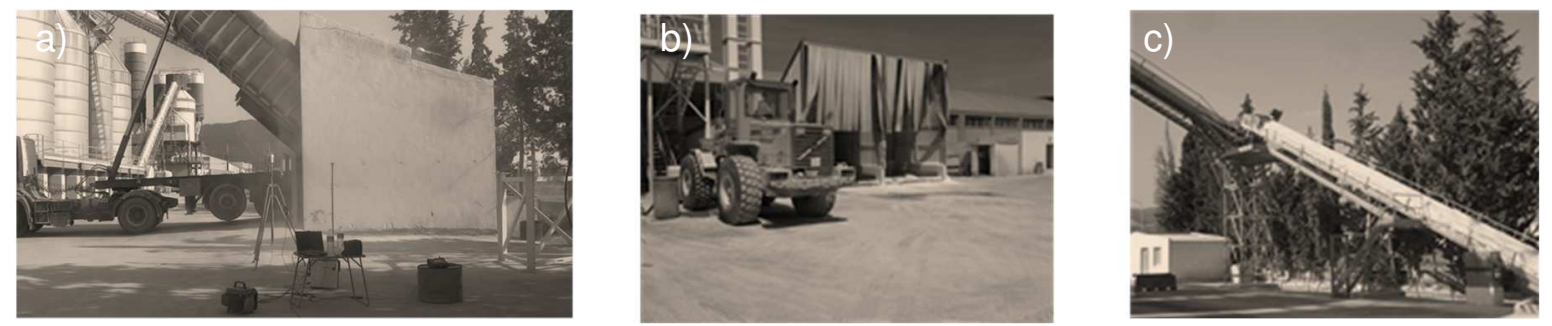

Figura 1.7. Operaciones generadoras de emisiones difusas de PM: a) Descarga de camión en tolva, b) Alimentación tolva con máquina pala y c) Transporte materias primas mediante cintas.

Finalmente, en la Tabla 1.10 se detallan las operaciones identificadas como significativas en cuanto a la generación de emisiones difusas de PM en el proceso de fabricación de hormigón prefabricado.

Tabla 1.10. Identificación de operaciones generadoras de emisiones difusas de PM en la fabricación de hormigón prefabricado.

\begin{tabular}{|c|l|c|l|c|}
\hline \multicolumn{2}{|c|}{ Etapa } & \multicolumn{2}{c|}{ Operación } & Clasificación fuente emisora \\
\hline \multirow{2}{*}{1} & $\begin{array}{l}\text { Recepción de materias } \\
\text { primas (arenas y } \\
\text { gravas) }\end{array}$ & 1.1 & Descarga de camión & Manipulación \\
\cline { 2 - 5 } & 1.2 & Apilamiento máquina pala & Manipulación \\
\cline { 2 - 5 } 2 & $\begin{array}{l}\text { Gestión de materias } \\
\text { primas (arenas y } \\
\text { gravas) }\end{array}$ & 2.1 & Alimentación tolva con máquina pala & Manipulación \\
\cline { 2 - 5 } & Almacenamiento & 3.1 & $\begin{array}{l}\text { Erosión por viento del material } \\
\text { almacenado a cielo abierto }\end{array}$ \\
\hline
\end{tabular}

\subsubsection{Sector minero: canteras de áridos}

Según la Estadística Minera de España 2014 (Ministerio de Industria, Energía y Turismo, 2014), el sector de los áridos cuenta con 1746 explotaciones censadas, que representan el 61\% del total de las explotaciones españolas. La producción de áridos (para la construcción y otros usos industriales) superó, en 2014, los 112 millones de toneladas. En toneladas producidas, la producción de áridos supone el $65 \%$ del total de la industria extractiva.

\section{- Descripción del proceso de producción}

Las canteras de áridos se dedican a la extracción de arenas y gravas, o piedra (caliza normalmente). Las canteras se explotan mediante voladuras controladas.

Una vez extraídos, los materiales se transportan al centro de procesamiento para someterlos a una primera clasificación. Posteriormente, tiene lugar un proceso sucesivo de trituración (molinos) y clasificación (cribas) hasta obtener el tamaño deseado. En ocasiones, debido a la presencia de impurezas, es necesario recurrir a un proceso de lavado, que se realiza siempre en un circuito de agua cerrado. 


\section{- Operaciones generadoras de emisiones difusas de PM}

La mayor parte de las emisiones de PM generadas en explotaciones mineras son de origen difuso. Estas emisiones se deben fundamentalmente a las actividades de extracción, tratamiento y transporte de las materias primas y la generación de las mismas dependerá de diversos factores, entre ellos de las condiciones meteorológicas y de las características del material extraído y procesado. En la Figura 1.8, se muestran algunos detalles de las operaciones realizadas en las canteras de áridos.
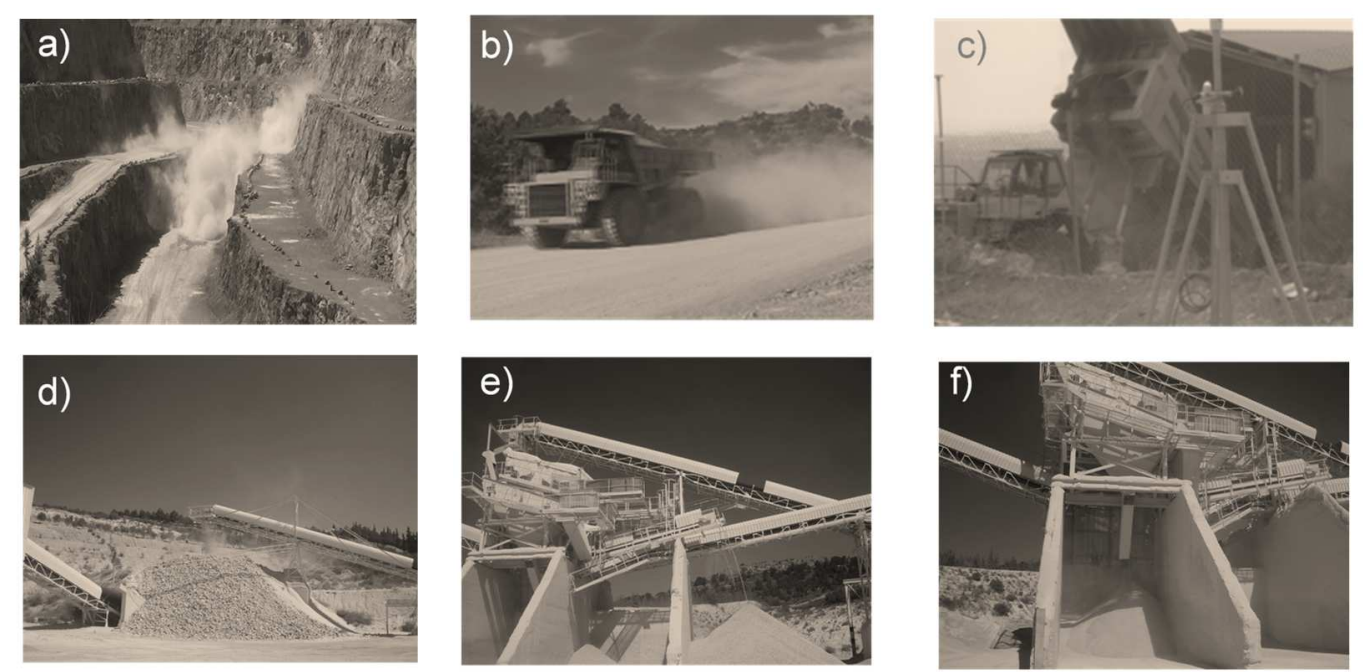

Figura 1.8. Operaciones generadoras de emisiones difusas de PM: a) Voladura, b) Circulación en vías no asfaltadas, c) Descarga al triturador, d) Descarga de materias primas, e) Clasificación de los materiales y f) Almacenamiento en celdas.

Las explotaciones de áridos suelen localizarse próximas a los centros de consumo, lo que presupone, que se encuentren próximas a áreas con alta densidad de población. Dado que en más del $95 \%$ de los casos el transporte de áridos se realiza en camión, el tráfico de estos vehículos pesados puede también suponer un problema adicional para las localidades más cercanas (ANEFA, 2013).

En la Tabla 1.11 se detallan las operaciones identificadas como más significativas en cuanto a la generación de emisiones difusas de PM en las diferentes operaciones realizadas en las canteras de áridos. 
Tabla 1.11. Identificación de operaciones generadoras de emisiones difusas de PM en la producción de áridos.

\begin{tabular}{|c|c|c|c|c|}
\hline & Etapa & & Operación & $\begin{array}{c}\text { Clasificación fuente } \\
\text { emisora }\end{array}$ \\
\hline \multirow{3}{*}{1} & \multirow{3}{*}{ Extracción } & 1.1 & Voladura & Manipulación \\
\hline & & 1.2 & Carga camión con máquina pala & Manipulación \\
\hline & & 1.3 & Circulación camiones volquete y máquina pala & Transporte \\
\hline \multirow{2}{*}{2} & \multirow{2}{*}{$\begin{array}{l}\text { Trituración } \\
\text { (machaqueo) }\end{array}$} & 2.1 & Descarga de material a tolva & Manipulación \\
\hline & & 2.2 & Trituración & Manipulación \\
\hline \multirow{5}{*}{3} & \multirow{5}{*}{ Molienda y clasificación } & 3.1 & Transporte material cintas transportadoras & Manipulación \\
\hline & & 3.2 & Trituración secundaria y terciaria & Manipulación \\
\hline & & 3.3 & Clasificación mediante cintas vibrantes & Manipulación \\
\hline & & 3.4 & Descarga de material & Manipulación \\
\hline & & 3.5 & Circulación vehículos & Transporte \\
\hline \multirow{3}{*}{4} & \multirow{3}{*}{$\begin{array}{l}\text { Almacenamiento a cielo } \\
\text { abierto }\end{array}$} & 4.1 & Carga/descarga mediante máquina pala & Manipulación \\
\hline & & 4.2 & Circulación máquina pala & Transporte \\
\hline & & 4.3 & Erosión por viento & Erosión \\
\hline \multirow{3}{*}{5} & \multirow{3}{*}{$\begin{array}{l}\text { Carga de producto a } \\
\text { granel }\end{array}$} & 5.1 & $\begin{array}{l}\text { Carga camión bañera directa desde tolva/silos } \\
\text { para su expedición }\end{array}$ & Manipulación \\
\hline & & 5.2 & $\begin{array}{l}\text { Carga camión bañera mediante máquina pala } \\
\text { desde acopios al aire libre }\end{array}$ & Manipulación \\
\hline & & 5.3 & Circulación camión y máquina-pala & Transporte \\
\hline
\end{tabular}

\subsubsection{Puertos: muelles de graneles sólidos}

En España existen 28 Autoridades Portuarias que gestionan los 46 puertos comerciales españoles más importantes, existiendo 24 Autoridades Portuarias con terminales específicas para graneles sólidos (Puertos del Estado, 2012). Durante el año 2012, el sistema portuario contaba con 59 terminales destinadas al movimiento de graneles sólidos, lo cual supone un $28 \%$ del total de terminales operativas. A la actividad de dichas terminales hay que sumarle las operaciones realizadas en terminales polivalentes, normalmente desarrolladas con medios de carga/descarga no especializados. (Puertos del Estado, 2015).

Estas instalaciones movieron en el año 2012 un total de 89 millones de toneladas de mercancía a granel, lo cual representa un $20 \%$ del paso de mercancía por los puertos. Por tanto, el tráfico de graneles sólidos representa una actividad importante por el nivel de actividad desarrollado en los puertos. (Puertos del Estado, 2015).

Además, existe una gran diversidad de materiales manipulados a granel, siendo los más comunes: carbón (mineral y coque), productos alimentarios (granos, cereales, harinas), minerales (arenas, arcillas, feldespatos, roca fosfórica, sulfato de cobre), productos inorgánicos (cemento, clínker), 
productos químicos (fertilizantes), productos residuales (biomasa, chatarra), cuyas propiedades físicas influyen en la emisión de PM a la atmósfera.

Estudios previos sobre el impacto ambiental en puertos han identificado la resuspensión del material depositado en el suelo, por medio del viento y/o del tráfico interno, como una de las fuentes que contribuye en gran medida a los niveles de PM10, junto con las emisiones del tráfico marítimo y del tráfico rodado (Alastuey et al., 2007).

En este sentido, debe considerarse que los puertos habitualmente se encuentran ubicados cerca de núcleos urbanos, por lo que su impacto sobre la calidad del aire en las zonas urbanas próximas puede ser significativo. Durante el año 2012 se registraron quejas ligadas a emisiones procedentes de la actividad del puerto en 11 Autoridades Portuarias. Estas se encuentran motivadas, en su mayor parte, por emisiones de partículas generadas por el almacenamiento de graneles sólidos a la intemperie y por la manipulación de dicha mercancía por métodos convencionales, lo que denota la relevancia de este tipo de emisiones (Puertos del Estado, 2012).

\section{- Operaciones generadoras de emisiones difusas de PM}

Debido al elevado volumen de mercancías sólidas que se transportan y cargan/descargan en los puertos en forma de granel, la gestión de graneles sólidos es una de las principales fuentes de generación de emisiones difusas de PM. Concretamente, las principales tareas ligadas a la operativa portuaria de gestión de graneles sólidos son: carga/descarga de buques, transporte horizontal y almacenamiento.

La carga/descarga de buques consiste en el intercambio de la mercancía entre el buque y los sistemas terrestres de acarreo de la mercancía. Esta fase requiere de equipos específicos, tales como grúa móvil-cuchara, cinta móvil, sistema neumático y grúa pórtico. El sistema de descarga con grúa pórtico consta de una cuchara que se mueve a lo largo del brazo del pórtico, la cual vierte en una tolva incorporada en la propia grúa, que a su vez descarga sobre una cinta transportadora.

El transporte horizontal se define como el proceso de acarreo de mercancía dentro del puerto. Puede darse entre muelles y almacenamientos o entre distintos puntos de almacenamiento en el puerto. A su vez, dicho movimiento puede efectuarse de modo discontinuo mediante camiones, o con un flujo continuo mediante trasportadores.

El almacenamiento supone el proceso de almacenamiento y espera de la mercancía en puerto y puede realizarse en parques de graneles, almacén horizontal (almacén cubierto conformado por una nave que puede contar con diferentes sistemas para depositar y extraer la mercancía), silos verticales, domos, entre otros.

Cuando las operaciones se realizan en una instalación especial, la carga/descarga se suele realizar mediante grúas móviles o sistemas de carga y descarga continuos de tipo neumático o mecánico, mientras que el trasporte horizontal se realiza, habitualmente, mediante cintas u otros sistemas de acarreo continuo.

La Figura 1.9 muestra algunas de las operaciones realizadas en los muelles de sólidos a granel en los puertos. 

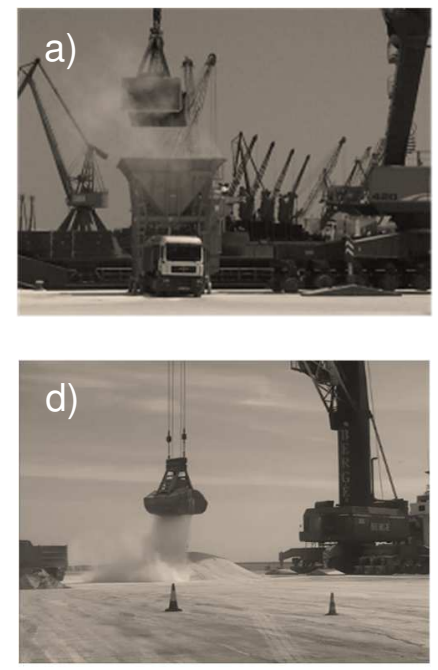
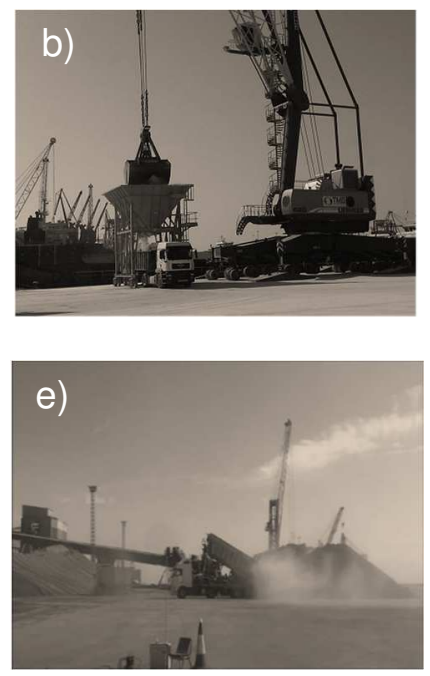
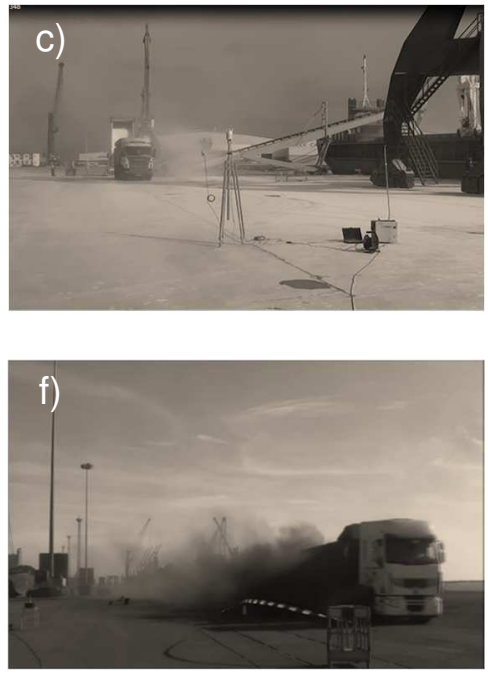

Figura 1.9. Operaciones generadoras de emisiones difusas de PM: a) Descarga a tolva con cuchara, b) Carga de camión con tolva, c) Descarga de camión y transferencia con cinta, d) Descarga en muelle con cuchara, e) Descarga de camión en muelle y f) Circulación vías asfaltadas.

En la Tabla 1.12 se detallan las operaciones identificadas como más significativas, en cuanto a la generación de emisiones difusas de PM, en las diferentes actividades realizadas en la gestión de graneles sólidos en puertos.

Tabla 1.12. Identificación de operaciones generadoras de emisiones difusas de PM en muelles de graneles sólidos.

\begin{tabular}{|c|c|c|c|c|}
\hline & Etapa & & Operación & $\begin{array}{l}\text { Clasificación fuente } \\
\text { emisora }\end{array}$ \\
\hline \multirow{5}{*}{1} & \multirow{5}{*}{ Descarga/carga buques } & 1.1 & $\begin{array}{l}\text { Carga/descarga con grúa móvil/cuchara: } \\
\text { recorrido cuchara, descarga sobre tolva o } \\
\text { descarga sobre acopio }\end{array}$ & Manipulación \\
\hline & & 1.2 & $\begin{array}{l}\text { Carga con cinta transportadora móvil (carga de } \\
\text { la tolva de alimentación mediante camión o } \\
\text { máquina pala, cinta transportadora, vertido en } \\
\text { bodega mediante tubo de descarga) }\end{array}$ & Manipulación \\
\hline & & 1.3 & $\begin{array}{l}\text { Descarga con grúa pórtico (recorrido cuchara, } \\
\text { descarga sobre tolva, transferencia a cinta) }\end{array}$ & Manipulación \\
\hline & & 1.4 & Carga camión con tolva o con máquinas pala & Manipulación \\
\hline & & 1.5 & Circulación de camiones y máquinas pala & Manipulación \\
\hline 2 & Transporte horizontal & 2.1 & Circulación de camiones y máquinas pala & Transporte \\
\hline \multirow{4}{*}{3} & \multirow{4}{*}{$\begin{array}{l}\text { Almacenamiento a cielo } \\
\text { abierto }\end{array}$} & 3.1 & Carga de camión y remonte con máquina pala & Manipulación \\
\hline & & 3.2 & Descarga camión & Manipulación \\
\hline & & 3.3 & Circulación de camiones y máquina pala & Transporte \\
\hline & & 3.4 & Erosión por viento & Erosión \\
\hline
\end{tabular}




\subsubsection{Otros procesos de interés}

A continuación, se identifican otros procesos en los que se realizan operaciones susceptibles de generar emisiones difusas de PM. Dado que estos procesos no son objeto de estudio del presente trabajo se describen brevemente.

\section{- Sector siderúrgico}

Las emisiones difusas de PM en el proceso de fabricación de acero se generan principalmente en el almacenamiento y transporte de materias primas y combustibles, así como durante la producción de coque. Generalmente el coque se almacena en tolvas para su uso inmediato; sin embargo, para un almacenamiento a largo plazo, se almacena al aire libre. Las materias primas que se pueden encontrar en la zona de almacenamiento pueden incluir minerales de hierro, chatarras, cal, caliza y carbón. Todos estos materiales son de naturaleza pulverulenta, incluso la chatarra, ya que, aunque suele comprarse limpia, siempre lleva asociada impurezas, como la cascarilla (polvo muy fino en la superficie de la chatarra), que durante su manipulación puede originar emisiones difusas de PM, al igual que el resto de materias primas (IPTS, 2013a).

\section{- Sector refino}

Las instalaciones de refino de petróleo son grandes complejos industriales en los que se desarrollan múltiples operaciones, siendo la operación que puede tener una mayor relevancia desde el punto de vista de las emisiones atmosféricas de PM, la fabricación y/o gestión de coque de petróleo. Las emisiones difusas de PM se generan principalmente en el almacenamiento, trituración y manipulación del coque (IPTS, 2015).

\section{- Sector termoeléctrico}

El uso de combustibles sólidos tales como carbón, coque de petróleo y biomasa pueden generar emisiones difusas de PM durante su almacenamiento, manipulación y transporte. En el caso concreto de la biomasa, previo al proceso de densificación (peletización) es necesario un acondicionamiento previo (descortezar, trocear, astillar, triturar, entre otros) de la materia prima empleada (madera virgen y subproductos de la industria de la madera), pudiendo generarse también emisiones difusas de PM (IPTS, 2016). Habitualmente, estas operaciones se realizan en centros logísticos y de comercialización de biomasa.

\section{- Fabricantes de cal}

En la fabricación de cal, las emisiones difusas de PM se producen principalmente durante las operaciones de acopio y preparación de materias primas (caliza, dolomía, caliza dolomítica, entre otros), clasificación y molienda, (en ocasiones se realiza en recintos y conducciones cerradas) y durante el mantenimiento, envasado y almacenamiento (IPTS, 2013b).

\section{- Industrias de minerales no férreos}

En las industrias de minerales no férreos el proceso llevado a cabo depende del producto a obtener (cobre, cinc, entre otros). No obstante, existen una serie de operaciones comunes, susceptibles de generar emisiones difusas de PM, que se realizan en este tipo de instalaciones: la recepción, clasificación y almacenamiento de materias primas (Gobierno Vasco, 2012). 


\section{- Sector construcción}

Las actividades de construcción y demolición son una fuente importante de contaminación del aire por PM en zonas urbanas, siendo el $100 \%$ de las emisiones generadas de origen difuso.

Concretamente, las actividades más comunes que emiten PM incluyen la preparación de la obra (demolición y excavación, acopios de tierra, carga y descarga de material, paso de vehículos, apilamiento de material, entre otros), movimientos de tierra (preparación de terrenos, compactación de suelos, entre otros), pavimentado de carreteras y la construcción de edificios y estructuras. Además, en la zona afectada, suele existir un elevado flujo de vehículos pesados, que transportan materiales o residuos de la obra, y de maquinaria pesada que también contribuyen a la emisión de PM por resuspensión del material depositado en el suelo (Querol et al., 2012).

\section{- Vertederos y tratamiento de residuos}

En vertederos y plantas de tratamiento de residuos se generan emisiones difusas de PM en el almacenamiento de residuos y en las operaciones de manipulación de los mismos tales como mezclado, separación, clasificación, transporte o reducción de tamaño de residuos no metálicos o de residuos metálicos pulverulentos (Gobierno Vasco, 2012).

\section{- Sector agrícola}

Las emisiones de PM procedentes del sector agrícola pueden llegar a ser significativas, afectando a la calidad del aire en entornos urbanos y rurales. Las principales actividades emisoras de PM en el sector agrícola son: quema de biomasa (rastrojos, residuos de poda, entre otros), labranza, recolecta, resuspensión por tráfico (tanto en las propias parcelas como en vías circundantes, generalmente no asfaltadas) y determinada producción industrial (operaciones de molienda y mezclado en secaderos de alfalfa, maíz, entre otros) (Querol et al., 2012).

\subsubsection{Medidas correctoras para las emisiones difusas de PM}

\subsubsection{Medidas correctoras para el almacenamiento, transferencia y manipulación de sólidos}

El documento "Reference Document on Best Available Techniques on Emissions from Storage" (IPTS, 2006) recoge las mejores técnicas disponibles (MTD) aplicables para disminuir las emisiones difusas de PM asociadas al almacenamiento, transferencia y manipulación de sólidos. Además de este documento, de carácter horizontal, existen documentos propios de determinados sectores industriales que recopilan medidas correctoras específicas para cada sector. No obstante, estos documentos específicos consideran básicamente las medidas correctoras contempladas en el documento horizontal. La Tabla 1.13 recoge las principales MTD propuestas en los diferentes BREF. Se puede observar fácilmente que las medidas propuestas abarcan un amplio rango de eficacias. 
Tabla 1.13. MTD para el almacenamiento, transferencia y manipulación (IPTS, 2006).

\begin{tabular}{|c|c|}
\hline \multicolumn{2}{|c|}{ Medidas correctoras para el almacenamiento, transferencia y manipulación } \\
\hline \multirow{8}{*}{ Almacenamiento al aire libre } & $\begin{array}{l}\text { Cerrar los acopios de materias primas (naves, silos, tolvas, } \\
\text { graneros, etc) y las zonas donde se realicen operaciones donde se } \\
\text { genere polvo y dotarlas de aspiraciones }\end{array}$ \\
\hline & Construir muros de contención \\
\hline & Instalar vallas de protección contra el viento \\
\hline & Cubrir los acopios \\
\hline & $\begin{array}{l}\text { Realizar un único acopio para disminuir la superficie expuesta al } \\
\text { viento }\end{array}$ \\
\hline & $\begin{array}{l}\text { Ubicar el eje longitudinal del acopio paralelo a la velocidad del } \\
\text { viento }\end{array}$ \\
\hline & Humectar la superficie de los acopios aplicando agua y/o aditivos \\
\hline & Realizar inspecciones visuales de forma regular \\
\hline \multirow{7}{*}{ Transferencia y manipulación } & $\begin{array}{l}\text { Reducir los escapes y derrames, realizando un buen } \\
\text { mantenimiento de las instalaciones }\end{array}$ \\
\hline & Manipular los materiales cuando la velocidad del viento es baja \\
\hline & $\begin{array}{l}\text { Reducir la altura y velocidad de descarga de sólidos a granel o } \\
\text { utilizar medios de descarga automáticos }\end{array}$ \\
\hline & Humectar el material \\
\hline & Reducir la distancia de transporte \\
\hline & $\begin{array}{l}\text { Aplicar métodos de transporte continuos, como por ejemplo cintas } \\
\text { transportadoras cubiertas, sistemas neumáticos,... }\end{array}$ \\
\hline & $\begin{array}{l}\text { Uso de cucharas con diseños óptimos y que aseguren un buen } \\
\text { cierre }\end{array}$ \\
\hline
\end{tabular}

Las Figuras 1.10-1.13 muestran fotografías de medidas correctoras concretas implementadas en plantas industriales.
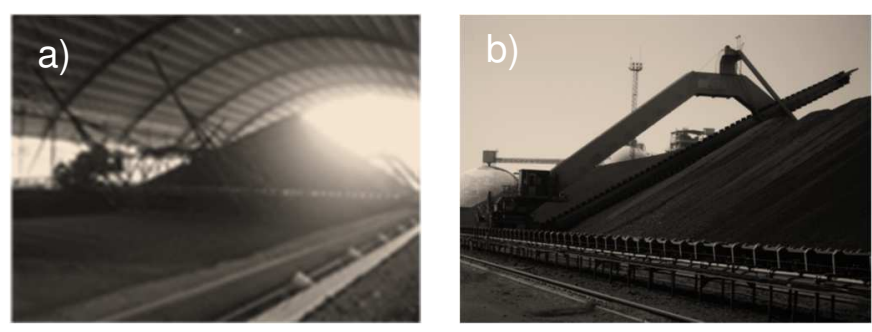

Figura 1.10. Medidas correctoras implementadas para el almacenamiento de coque: a) Almacenamiento tipo hangar y cintas transportadoras, b) Formación de acopios con apiladores. 

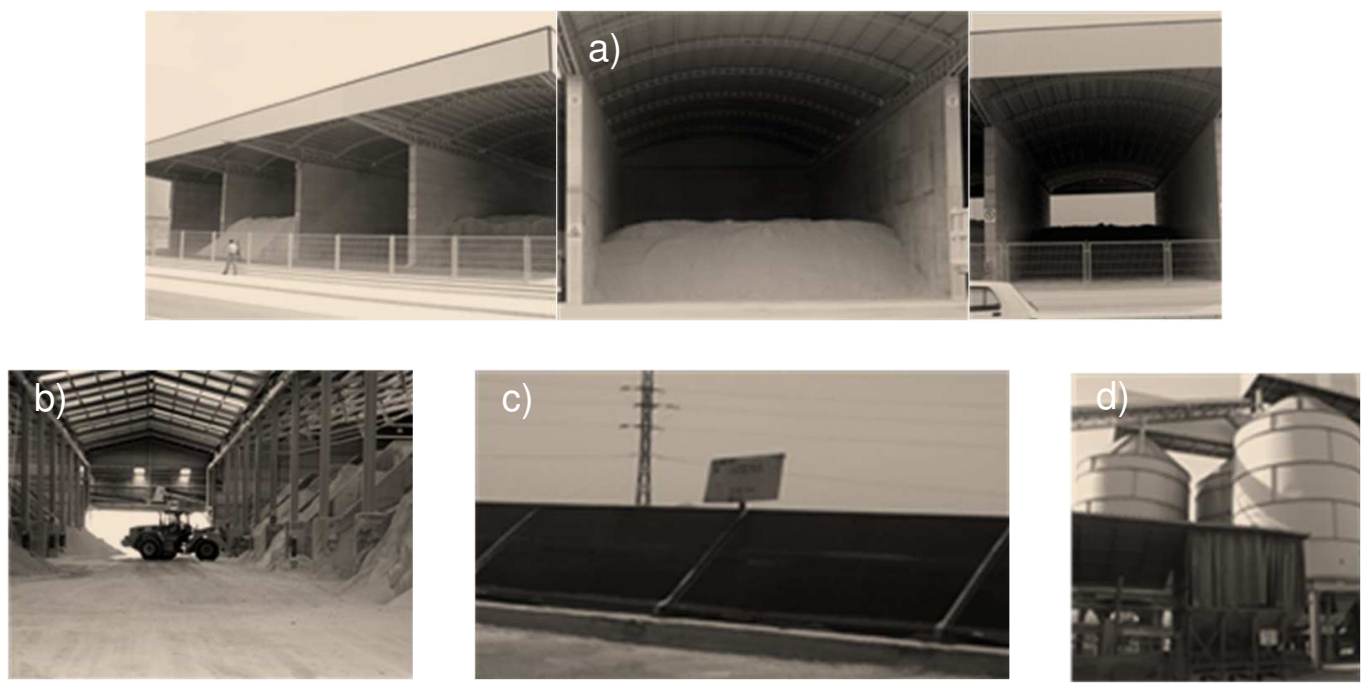

Figura 1.11. Medidas correctoras implementadas para el almacenamiento de materias primas a) Naves semicerradas: 2 y 3 paredes laterales, b) Naves cerradas, c) Tolvas y d) Silos.
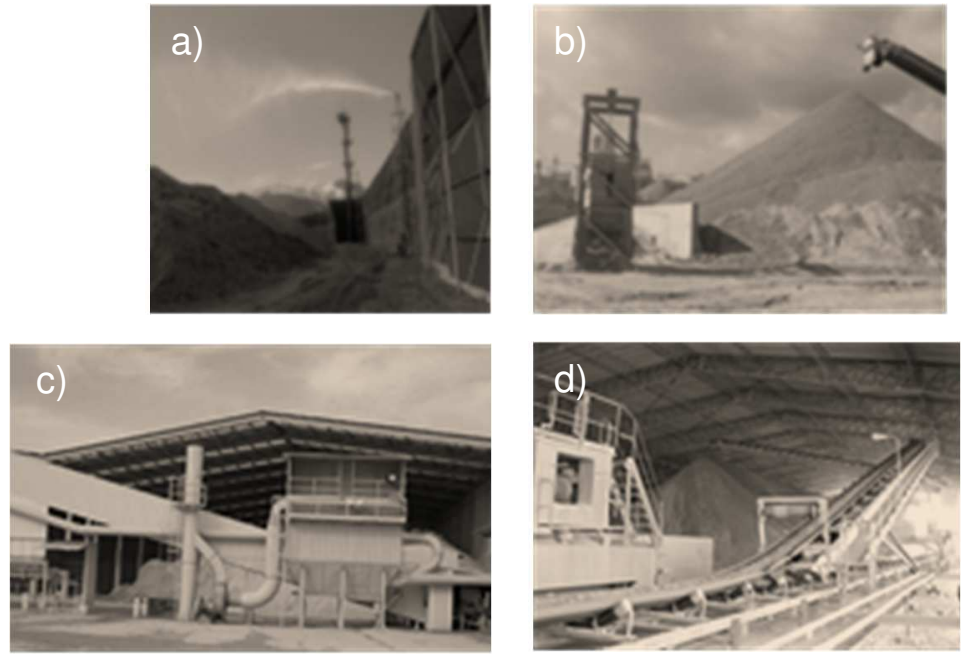

Figura 1.12. Medidas correctoras implementadas para la manipulación de materias primas: a) Humectación del material y pantallas perimetrales, b) Descarga de materias primas con manga de descarga,

c) Cerramiento de sistemas de transporte de materias primas, d) Sistema de carga y descarga de materias primas automatizado.

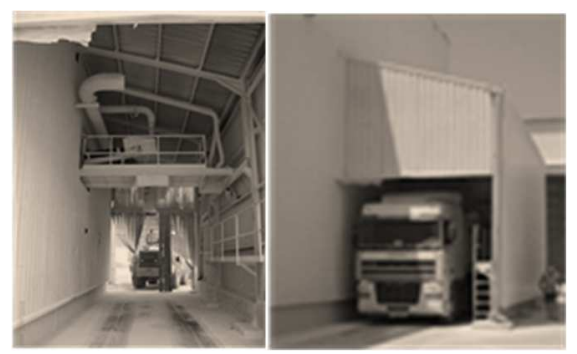

Figura 1.13. Medidas correctoras implementadas para la carga de producto a granel: cerramiento del punto de carga dotado de aspiración y filtro de mangas. 
En cuanto a las actividades portuarias, conviene destacar que Puertos del Estado ha elaborado una "Guía de Buenas Prácticas en almacenamiento y manipulación de Gráneles Sólidos en Instalaciones Portuarias" (Puertos del Estado, 2015), la cual establece recomendaciones de operación y de equipamiento para la elaboración de los convenios de buenas prácticas ambientales que la Autoridad Portuaria pueda firmar con las empresas portuarias. Además, la guía pretende, definir condiciones generales de operación que puedan ser formalizadas mediante ordenanzas portuarias que alcancen al conjunto de los usuarios del puerto.

En este sentido, la eficiencia ambiental de la operativa portuaria y el tipo de medidas que pueda ser necesario aplicar para mejorar el desempeño ambiental están condicionadas por el tipo de equipos e instalaciones utilizados en las fases de carga/descarga, la logística del transporte y el tipo de almacenamiento.

No obstante, la correcta manipulación de equipos resulta esencial a la hora de controlar los aspectos ambientales de la operación con graneles. El nivel adecuado de carga de cucharas, la altura de apertura de cucharas, el nivel de carga de cintas, el toldado de camiones, o la señalización de acopios procedentes de camiones que retornan al punto de carga por sobrepeso, son ejemplos de aspectos operativos que contribuyen al control de los aspectos ambientales ligados a la manipulación de graneles sólidos (Puertos del Estado, 2015).

\subsubsection{Medidas correctoras para el transporte de sólidos}

Las materias primas pulverulentas suelen ser transportadas entre las empresas, de minas a empresas, de puertos a empresas, por medio de camiones, siendo los camiones tipo bañera los más habituales, porque presentan muy pocas limitaciones técnicas en cuanto a la tipología de materiales a transportar.

Este tipo de camiones presenta el problema de las emisiones de PM por reboses o cierres deficientes, que dependen de las prácticas de carga y descarga de los sólidos (grado de llenado pare evitar reboses superiores, cobertura total de la carga con toldos, buen estado de la puerta trasera de la bañera que garantice un cierre adecuado, entre otros.) (Monfort et al., 2014).

Con el objetivo de minimizar el impacto de las emisiones difusas de PM asociadas al transporte, en la Tabla 1.14 se recogen las recomendaciones aplicables tanto al vehículo como a las empresas usuarias de este medio de transporte. Algunas de estas medidas se presentan en los BREF sectoriales.

La Figura 1.14 muestra fotografías de medidas correctoras específicas implementadas para el transporte.

No obstante, el transporte de materiales pulverulentos a granel puede realizarse, además de con los camiones tipo bañera, con otros tipos de camiones o sistemas que garantizan un mejor confinamiento, aunque todos ellos presentan limitaciones en su aplicación. En la Tabla 1.15 se presentan las ventajas y desventajas de tres de estos sistemas de transporte alternativos. 
Tabla 1.14. Medidas correctoras para el transporte (Monfort et al., 2014).

\begin{tabular}{|c|l|}
\hline \multicolumn{2}{|c|}{ Medidas correctoras para el transporte mediante camiones bañera } \\
\hline \multirow{2}{*}{ Aplicables al vehículo } & Cubrir la bañera con un toldo (con o sin carga) \\
\cline { 2 - 2 } & Asegurar un buen sellado de la puerta trasera \\
\cline { 2 - 2 } & Moderar la velocidad principalmente en vías no asfaltadas \\
\hline \multirow{2}{*}{$\begin{array}{c}\text { Aplicables a las empresas (proveedores } \\
\text { materias primas, minas, receptores) }\end{array}$} & Sistemas de llenado que eviten sobrecargas \\
\cline { 2 - 2 } & Zonas de circulación pavimentadas y limpias \\
\cline { 2 - 2 } & Circuitos internos bien definidos y velocidad adecuada \\
\cline { 2 - 2 } & Disponer de sistemas de limpieza de ruedas y bajos de vehículos \\
\hline
\end{tabular}
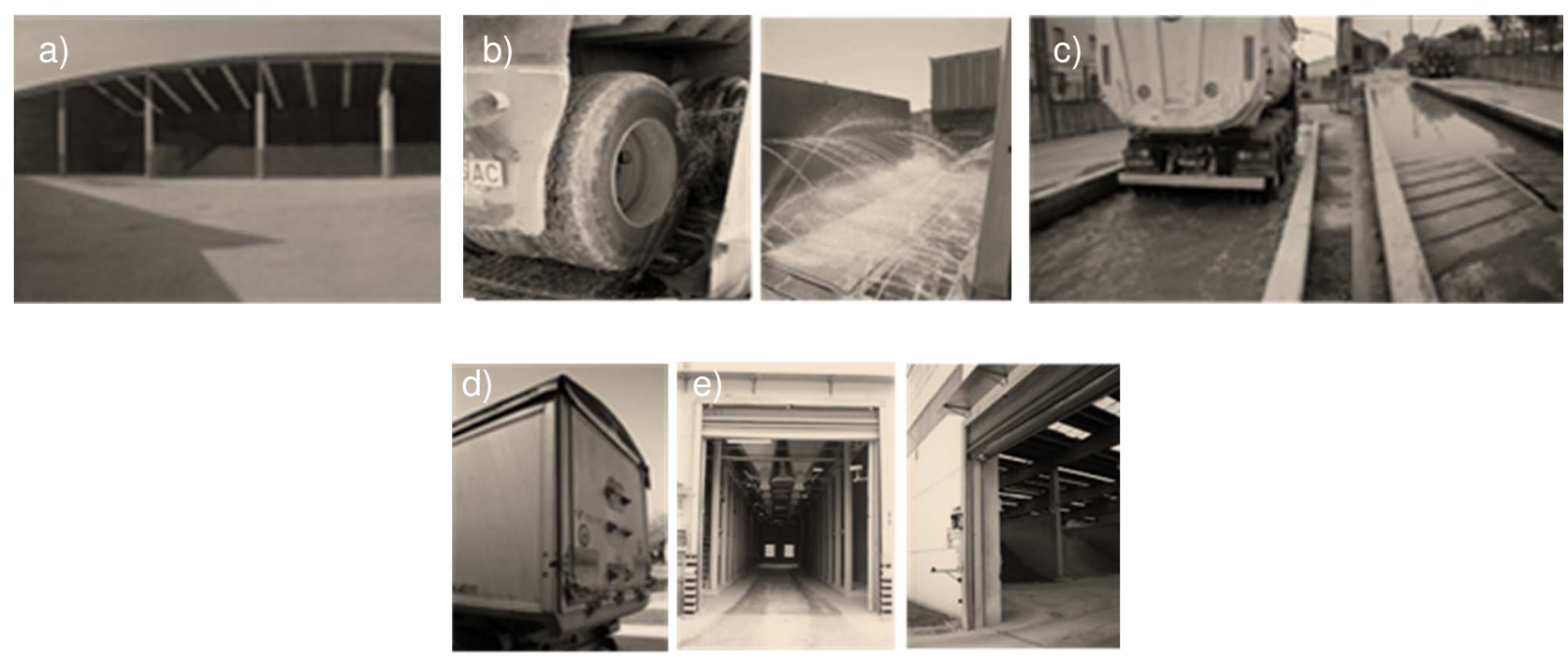

Figura 1.14. Medidas correctoras implementadas para el transporte: a) Asfaltado y limpieza de viales, b y c) Sistema de limpieza de ruedas y bajos de camión: agua a presión y tipo piscina, d) Sellado de la puerta trasera del camión y e) Estanqueidad de puertas en naves.

Tabla 1.15. Sistemas de transporte de sólidos a granel de alta eficacia (Monfort et al., 2014).

\begin{tabular}{|c|c|c|c|}
\hline Sistema de transporte & Ventajas & Desventajas & Aplicación general \\
\hline Camiones cisterna & Muy eficiente & Necesita infraestructura para carga/descarga & $\begin{array}{c}\text { Materiales de alto valor } \\
\text { o elevada toxicidad }\end{array}$ \\
\hline Silos transportables & $\begin{array}{c}\text { Muy eficiente } \\
\text { ambientalmente } \\
\text { Gran flexibilidad }\end{array}$ & $\begin{array}{c}\text { Materiales con buena fluidez } \\
\text { Necesita una infraestructura de silos y } \\
\text { camiones especiales. }\end{array}$ & Materiales de alto valor \\
Sacos o big-bags & Muy eficiente & Cantidades moderadas & Gestión de los envases \\
\hline
\end{tabular}




\subsubsection{Eficacia de las medidas correctoras}

Los diferentes BREF que proponen MTD para fuentes difusas carecen de información sobre las eficacias asociadas a las mismas, dificultando esta situación la selección de medidas correctoras apropiadas. No obstante, en determinadas guías (Generalitat de Catalunya, 2004; Australian Government, 2012) utilizadas para la elaboración de inventarios de PM para actividades mineras se recogen las eficacias para algunas de las medidas correctoras propuestas en los BREF (Tabla 1.16).

Tabla 1.16. Rendimientos de mejora asociados a medidas correctoras (Generalitat de Catalunya, 2004; Australian Government, 2012).

\begin{tabular}{|c|c|c|}
\hline Tipo de fuente de emisión & Medida correctora & Rendimiento (\%) \\
\hline \multirow{5}{*}{ Transporte zona no asfaltada } & Riego (<2 litros $\left./ \mathrm{m}^{2} / \mathrm{h}\right)$ & 50 \\
\hline & Riego (>2 litros/m²/h) & 75 \\
\hline & Pavimentar & 90 \\
\hline & Pavimentar+barrer & 97 \\
\hline & Pavimentar+barrer+riego con agua & 99 \\
\hline \multirow{3}{*}{ Transporte zona asfaltada } & Barrer & 70 \\
\hline & Riego con agua & 80 \\
\hline & Barrer+riego con agua & 94 \\
\hline \multirow{7}{*}{ Manipulación } & Riego por aspersión con agua de los montones & 50 \\
\hline & $\begin{array}{l}\text { Riego por aspersión con agua + aditivos } \\
\text { químicos de los montones }\end{array}$ & 90 \\
\hline & Apilador con altura variable & 25 \\
\hline & Tubos telescópicos con aspersión de agua & 75 \\
\hline & Cabina de cerramiento & 70 \\
\hline & $\begin{array}{l}\text { Cabina de cerramiento parcial+Instalación filtros } \\
\text { de mangas }\end{array}$ & 83 \\
\hline & $\begin{array}{l}\text { Cabina de cerramiento total+Instalación filtros } \\
\text { mangas }\end{array}$ & 99 \\
\hline \multirow{2}{*}{ Erosión } & Vallas perimetrales & 30 \\
\hline & Riego con agua por aspersión de los montones & 50 \\
\hline
\end{tabular}




\subsection{Instrumentos normativos aplicables a las emisiones difusas de PM}

La legislación en materia de protección del ambiente atmosférico se ha desarrollado principalmente para la consecución de los siguientes objetivos:

- Proteger a la población, los ecosistemas y bienes de cualquier naturaleza manteniendo una calidad del aire adecuada.

- Eliminar o reducir las emisiones de contaminantes atmosféricos, desde las diferentes fuentes, mediante la identificación e implementación de las medidas de reducción más efectivas.

\subsubsection{Legislación ambiental en materia de calidad del aire para PM}

La legislación en materia de calidad de aire viene definida principalmente en las Directivas 2004/107/CE y 2008/50/CE, relativas a la calidad del aire ambiente y a una atmósfera más limpia en Europa, donde se definen los estándares de las concentraciones ambientales de determinados contaminantes atmosféricos. Estas directivas unifican los criterios de calidad del aire utilizados con anterioridad y los actualiza tomando en consideración la investigación científica más reciente y la experiencia de los estados miembros.

La Directiva 2015/1480 modifica varios anexos de las directivas anteriores, en los que se establecen las normas relativas a los métodos de referencia, la validación de datos y la ubicación de los puntos de muestreo para la evaluación de la calidad del aire ambiente.

Los parámetros regulados a nivel europeo son: $\mathrm{PM} 10, \mathrm{PM} 2.5, \mathrm{O}_{3}, \mathrm{NO}_{2}, \mathrm{NO}, \mathrm{SO}_{2}, \mathrm{CO}, \mathrm{Pb}, \mathrm{As}, \mathrm{Cd}$, $\mathrm{Hg}, \mathrm{Ni}, \mathrm{BaP}$ y $\mathrm{C}_{6} \mathrm{H}_{6}$. Todos estos contaminantes deben monitorizarse a través de una red de calidad del aire equilibrada que albergue estaciones de medida en zonas industriales, urbanas (tráfico) y rurales.

Con el objetivo de transponer al derecho español la Directiva 2008/50/CE, desarrollar la Ley 34/2007 en los aspectos relativos a calidad del aire, y simplificar la normativa nacional, se aprobó el Real Decreto 102/2011, relativo a la mejora de la calidad del aire, el cual ha sido recientemente modificado por el Real Decreto 39/2017 para incorporar las novedades de la Directiva 2015/1480.

La Ley 34/2007 aborda aspectos relativos a la protección del ambiente atmosférico entre los que destacan la evaluación y gestión de la calidad del aire, la prevención y control de emisiones, los instrumentos de fomento de protección de la atmósfera y su planificación y los mecanismos de control, inspección y seguimiento de las emisiones, así como el régimen sancionador. En relación al control, inspección y seguimiento de las emisiones a la atmósfera, la ley atribuye a cada Comunidad Autónoma (CA) la responsabilidad de la adopción de las medidas de inspección necesarias.

Uno de los parámetros clásicos en el control de la calidad del aire es la medida de la concentración de PM en la atmósfera, debido a los efectos adversos del PM sobre la salud, el clima y los ecosistemas. Numerosos estudios (Gómez et al., 1999; Alastuey et al., 2000; Hernández et al., 2001; Querol et al., 2002, 2004, 2007a; Vicente et al., 2002; Viana, 2003; Moreno et al., 2007; AbdulWahab et al. 2006; Martín et al., 2007; Minguillón et al., 2007b, 2013; Sánchez de la Campa et al., 2010, 2011; Abril et al., 2014, 2016) ponen de manifiesto que las partículas en suspensión son uno de los parámetros más críticos en zonas donde se concentran industrias que manipulan materiales de naturaleza pulverulenta, así como en zonas portuarias donde se manipulan sólidos a granel. En 
la Tabla 1.17, se presenta un resumen histórico de los parámetros y valores límites (VL) fijados por las diferentes normativas para PM.

Tabla 1.17. Valores límites establecidos por la normativa de calidad del aire.

\begin{tabular}{|c|c|c|c|c|}
\hline Normativa europea & - & Directiva 1999/30/CE & \multicolumn{2}{|c|}{ Directiva 2008/50/CE } \\
\hline Normativa estatal & R.D. $1321 / 1992$ & R.D. $1073 / 2002$ & \multicolumn{2}{|c|}{ R.D. 102/2011 } \\
\hline Período & 1992-2001 & $2001-2010$ & \multicolumn{2}{|c|}{$2005-2015$} \\
\hline Parámetro & PST & PM10 & PM10 & PM2.5 \\
\hline VL anual $\left(\mu \mathrm{g} / \mathrm{m}^{3}\right)$ & 150 & 40 & 40 & 25 \\
\hline VL diario $\left(\mu \mathrm{g} / \mathrm{m}^{3}\right)$ & 300 & 50 & 50 & - \\
\hline № superaciones VL diario & 18 & 35 & 35 & - \\
\hline
\end{tabular}

Según muestra la Tabla 1.17, la normativa actual es considerablemente más restrictiva que la vigente en España en 1993 cuando entró en vigor el Real Decreto 1321/1992. En primer lugar, el cambio del parámetro de medida supuso un mayor grado de control de las emisiones de tipo antropogénico, ya que las PST tienen una importante fracción de origen natural que es menos significativa en PM10. Concretamente, estudios de calidad del aire realizados en zonas con un aporte significativo de partículas desde fuentes industriales (cementeras, plantas de hormigón, cerámicas, canteras de áridos, etc.), confirman que el mayor impacto se produce en el rango de 2.5-10 $\mu \mathrm{m}$, considerándose la fracción PM10 la más apropiada para el control de la calidad del aire en estas zonas (Querol et al., 2001a).

A pesar de esta situación, ciertas regiones europeas están sometidas a la influencia de fenómenos naturales que pueden dificultar o impedir el cumplimiento de los VL diario y anual establecidos por la Directiva 2008/50/CE. Las superaciones del VL diario de PM10 debidas a la presencia de uno de los fenómenos naturales contemplados en la directiva deben ser descontadas del cómputo final. En España, el fenómeno natural que incide con mayor frecuencia sobre los niveles de PM atmosférico es la intrusión de masas de aire de origen africano, cargadas con partículas procedentes del desierto del Sahara y/o del Sahel. Otro fenómeno natural con influencia en los niveles de PM en España es la resuspensión de partículas minerales a escala local en zonas semi-áridas y el aerosol marino en zonas costeras.

En el caso de no cumplir los objetivos de calidad de aire para los contaminantes regulados, las administraciones tienen que adoptar planes de mejora de la calidad del aire para reducir los niveles y cumplir así los límites establecidos.

\subsubsection{Legislación ambiental en materia de emisiones industriales}

En cuanto al control de emisiones, la legislación europea incluye la Directiva 2001/81/CE sobre Techos Nacionales de Emisión (TNE), que establece límites de emisión a los estados miembros sobre cuatro contaminantes atmosféricos: $\mathrm{NO}, \mathrm{SO}_{2}, \mathrm{COVNM}$ y $\mathrm{NH}_{3}$. El objetivo de esta directiva es reducir la contaminación atmosférica y sus afectos adversos sobre la salud pública y el medio ambiente, así como cumplir el protocolo de Gotemburgo, sobre la contaminación atmosférica 
transfronteriza a gran distancia para luchar contra la acidificación, la eutrofización y el $\mathrm{O}_{3}$ troposférico.

Sin embargo, se considera necesario revisar y actualizar dicha directiva para hacer frente a los importantísimos riesgos sanitarios e impactos ambientales que aún sigue planteando la contaminación atmosférica en la UE. Por este motivo, se está trabajando actualmente en una nueva propuesta de Directiva (2013/0443 (COD)).

El objetivo de la nueva propuesta es garantizar la aplicación hasta 2020 de los TNE establecidos en la Directiva 2001/81/CE para después de 2010 respecto a los contaminantes que contempla, y fijar nuevos compromisos nacionales de reducción de emisiones, aplicables a partir de 2020 y de 2030 a las emisiones de $\mathrm{NO}$, $\mathrm{SO}_{2}, \mathrm{COVNM}, \mathrm{NH}_{3}$, partículas finas (PM2.5) y $\mathrm{CH}_{4}$, así como niveles de emisión intermedios para el año 2025 aplicables a esos mismos contaminantes.

Por otro lado, también existe legislación dirigida a reducir las emisiones de contaminantes atmosféricos procedentes de fuentes específicas, siendo probablemente las emisiones industriales una de las fuentes de emisión más importante.

Precisamente por este motivo, las emisiones procedentes de instalaciones industriales han sido objeto de legislación europea desde hace algún tiempo y en la actualidad se basan, principalmente, en los siguientes instrumentos: Directiva 2010/75/EU sobre emisiones industriales, y el Reglamento 166/2006, que establece la obligación, para los estados miembros, de informar a la Comisión Europea de las principales emisiones contaminantes a la atmósfera, al agua y al suelo. Concretamente, el Registro Europeo de Emisiones y Transferencias de Contaminantes Integrado (E-PRTR), constituye un importante seguimiento de las emisiones industriales, facilitando datos medioambientales clave procedentes de más de 30000 instalaciones industriales de la UE que cubren 65 actividades económicas. El registro está disponible al público en Internet (http://prtr.ec.europa.eu).

El PRTR- España, también disponible en Internet (http://www.prtr-es.es), permite consultar información a nivel de complejo industrial o agregada por sectores de actividad, sustancias contaminantes y ámbito geográfico. La autoridad ambiental competente para recopilar toda la información de PRTR-España y validar o evaluar la calidad de los datos es designada por cada CA.

\subsubsection{Directiva de emisiones industriales}

La Directiva 2010/75/EU sobre emisiones industriales (DEI), incluye los requisitos de permiso y control de las instalaciones industriales y supone el marco normativo más importante en materia de emisiones industriales.

La DEI es de aplicación a las actividades industriales con un importante potencial de contaminación, como se define en el anexo I de la misma (las industrias de energía, producción y transformación de metales, la industria minera, la industria química, gestión de residuos, la cría de animales, entre otros). Asimismo, contiene disposiciones especiales para las siguientes instalaciones: instalaciones de combustión ( $\geq 50 \mathrm{MW}$ ); de incineración o coincineración de residuos; ciertas instalaciones y actividades que utilizan disolventes orgánicos e instalaciones que producen dióxido de titanio. En cuanto al caso de las instalaciones de combustión medianas ( $1-<50 \mathrm{MW})$, recientemente se ha aprobado la Directiva 2015/2193, la cual establece límites para las emisiones de $\mathrm{SO}_{2}, \mathrm{NO}$ y partículas. 
De acuerdo con la Directiva 2010/75/EU, cualquier instalación industrial donde se lleven a cabo las actividades enumeradas en el anexo I de la misma debe cumplir con ciertas obligaciones básicas:

- Implementar medidas preventivas contra la contaminación.

- Aplicar las MTD.

- No causar ningún tipo de contaminación significativo.

- Reducir los residuos, reciclarlos o eliminarlos de la manera que generen menor contaminación.

- Maximizar la eficiencia energética.

- Prevenir posibles accidentes y limitar su impacto.

- Rehabilitar los lugares cuando las actividades llegan a su fin.

La DEl concreta más el concepto de MTD, así como el papel de los documentos BREF, ya que determina la práctica obligatoriedad de las «conclusiones sobre MTD» para promover una aplicación más coherente de la Directiva IPPC.

A nivel estatal, el proceso de transposición de la Directiva 2010/75/UE ha consistido en la publicación de la Ley 5/2013, de 11 de junio, sobre emisiones industriales que modifica la Ley 16/2002, de 1 de julio, de prevención y control integrados de la contaminación, y del Real Decreto 815/2013, de 18 de octubre, por el que se aprueba el Reglamento de emisiones industriales que desarrolla la citada Ley 16/2002. Recientemente, el Real Decreto Legislativo 1/2016 integra en un texto único las sucesivas modificaciones introducidas en la Ley 16/2002, Ley 34/2007 y Ley 5/2013.

\section{- Requisitos de los permisos: Autorización Ambiental Integrada}

Los permisos que las instalaciones deben solicitar para desarrollar su actividad deben tener un enfoque integrado, es decir, considerar todo el desempeño ambiental de la planta, cubriendo las emisiones a la atmósfera, el agua y el suelo, la generación de residuos, el uso de materias primas, la eficiencia energética, el ruido, la prevención de accidentes y la restauración del lugar una vez producido el cierre.

Las disposiciones de la DEI indican que la Autorización Ambiental Integrada (AAI) deberá prever las medidas necesarias para garantizar el cumplimiento de las obligaciones básicas del operador y las normas de calidad ambiental. Estas medidas deberán incluir, entre otra información relevante: los valores límite de emisión (VLE) de sustancias contaminantes; las reglas para garantizar la protección del suelo, agua y aire; requisitos relativos a la metodología de medición de las emisiones, la frecuencia y el procedimiento de evaluación; las medidas relativas a las circunstancias excepcionales (fugas, fallos de funcionamiento, paradas momentáneas o definitivas, entre otros); disposiciones relativas a la minimización de la contaminación de larga distancia o la contaminación transfronteriza y las condiciones para evaluar el cumplimiento de los VLE.

Según la DEI, las condiciones de las AAI deben basarse en el contenido de las conclusiones sobre las MTD correspondientes a su sector de actividad. Estas conclusiones contienen los niveles de emisión asociados a las MTD (NEA - MTD). Según la legislación europea no es un VLE, aunque es un valor de referencia utilizado para establecer los VLE prescritos en la legislación, y que en algunos casos sus valores pueden coincidir. 
Los documentos que recogen estas MTD en el ámbito europeo son los denominados Documentos de Referencia (BREF) sobre las MTD. Actualmente, hay 31 aprobados por la Comisión Europea, 8 de ellos ya han sido revisados según los criterios de la DEI y tienen elaborado el Documento de Conclusiones MTD, aprobado a través de Decisiones.

En general los BREF sectoriales, como por ejemplo el de cemento y cerámica, identifican el PM asociado a fuentes difusas como un contaminante significativo (IPTS, 2007 y 2013b), por tanto, se han definido en los mismos las MTD para emisiones difusas de PM. Además, se ha elaborado un BREF horizontal para emisiones asociadas al almacenamiento, cuyas MTD se han identificado en el apartado 1.2.4.1.

A nivel nacional, el Ministerio de Agricultura y Pesca, Alimentación y Medio Ambiente (MAPAMA) tiene el compromiso y la obligación de facilitar la información disponible sobre MTD para la concesión de las AAI, tanto a las autoridades ambientales como a la industria. Los Documentos de Conclusiones MTD, Documentos BREF y las Guías de MTD en España por sectores pueden consultarse en http://www.prtr-es.es/documentos/documentos-mejores-tecnicas-disponibles. La autoridad ambiental competente para otorgar la AAI es designada por cada CA.

\section{- Requisitos de control}

La DEl también contiene requisitos obligatorios sobre las inspecciones medioambientales. Los estados miembros deben establecer sistemas de inspección medioambiental o planes sobre todas las instalaciones afectadas. Estos planes son revisados y actualizados periódicamente.

\subsubsection{Catálogo de actividades potencialmente contaminadoras de la atmósfera}

Por otro lado, se ha publicado el Real Decreto 100/2011 que tiene por objeto la actualización del catálogo de actividades potencialmente contaminadoras de la atmósfera (CAPCA-2010), así como establecer unos mínimos criterios comunes en relación con las medidas para el control de las emisiones que puedan adoptar las CCAA para las actividades incluidas en dicho catálogo. El CAPCA-2010 incluye todas las actividades potencialmente contaminadoras de la atmósfera (APCA) de origen antropogénico, que se consideran en el inventario nacional de emisiones, tratando de esta manera de garantizar la universalidad de la aplicación de la ley.

El nuevo CAPCA-2010 clasifica las actividades susceptibles de generar emisiones difusas de PM. Concretamente, se establecen como APCA el almacenamiento y operaciones de manipulación, mezclado, separación, clasificación, transporte o reducción de tamaño de materiales sólidos pulverulentos en diferentes procesos industriales, minería, agricultura, vertederos, puertos, centros logísticos, entre otros.

Las diferentes APCA identificadas se asignan a grupos ( $A, B, C)$, lo que supone una gradación del régimen de intervención administrativa ( $A$ y $B$ implican autorización y $C$ implica notificación). La clasificación se realiza en función del impacto ambiental, de la cantidad de materias primas manipulada, entre otros.

En relación a las asignaciones a grupos, se incorpora también la posibilidad de considerar ciertas actividades en un grupo más restrictivo en los casos en que, en determinadas zonas y conforme a los criterios fijados en los planes de calidad del aire, sea necesario para la consecución de los objetivos planteados en los mismos. Esta posibilidad de cambio de grupo se prevé también, a criterio de la autoridad competente, para aquellos casos en que la proximidad a núcleos urbanos o espacios 
naturales protegidos, o la emisión de determinadas sustancias peligrosas, suponga un mayor riesgo de generar daños o molestias.

El Real Decreto 100/2011 establece que los titulares de las instalaciones en las que se desarrollen actividades incluidas en el catálogo, minimizarán tanto las emisiones canalizadas como las difusas de contaminantes a la atmósfera aplicando, en la medida de lo posible, las MTD. Asimismo, el órgano competente podrá establecer las especificaciones técnicas y requisitos relativos a los procedimientos de control de las emisiones difusas.

\subsubsection{Metodologías de control de las emisiones difusas de PM recogidas en la normativa actual}

El Real Decreto 100/2011 identifica numerosas actividades con operaciones potencialmente generadoras de emisiones difusas de PM. No obstante, este mismo decreto establece que la metodología de control para este tipo de emisiones debe ser definida por cada CA. Esta situación, ha conllevado que las metodologías existentes difieran en cada CA, detectándose la necesidad de armonizar a nivel nacional los requisitos medioambientales y técnicos exigidos a las instalaciones.

Asimismo, la gran diversidad de actividades (desde refinerías hasta cultivos, silvicultura) catalogadas en el CAPCA-2010 que son susceptibles de generar emisiones difusas de PM, junto con el hecho de que los BREF no establecen VLE asociados a las MTD para las mismas, dificulta el establecimiento de requisitos medioambientales genéricos.

Consecuentemente, a pesar del reconocimiento de las emisiones difusas de PM en la legislación y del impacto significativo que pueden llegar a representar sobre la calidad del aire, no se ha establecido una metodología estandarizada para el control de las mismas.

Actualmente, según la información obtenida tras la consulta de varias AAI de diferentes CCAA, las emisiones difusas de PM en entornos industriales se están controlando mediante la adopción de una o varias de las siguientes metodologías de control:

- Implementación de una serie de medidas correctoras.

- Establecimiento de VLE en el perímetro de la instalación.

- Cuantificación de las emisiones difusas de PM.

Algunas de las CCAA que han establecido VLE para las emisiones difusas de PM en entornos industriales han sido: Comunidad Valenciana, Andalucía, País Vasco, Comunidad de Madrid, Cataluña, Región de Murcia, Cantabria y Castilla-La Mancha, exigiendo en algunos casos también la implementación de una serie de medidas correctoras para la disminución del impacto asociado a estas emisiones. En el caso concreto de Cataluña, se establece además la cuantificación de las emisiones difusas de PM para actividades extractivas. Estas metodologías se han adoptado a través de diferentes instrumentos: decreto, resolución, orden, instrucción técnica, etc.

No obstante, el modo en que se aplican estas metodologías actualmente presenta una serie de limitaciones, las cuales se comentan de forma concreta en los siguientes apartados.

Con el fin de plantear una posible solución al control de las emisiones difusas de PM, se propone una metodología de control basada en dos fases: fase de proyecto y de operación. La fase de proyecto consistiría en presentar un diseño de planta, el cual debería incorporar las MTD necesarias 
para que las emisiones difusas de PM sean inferiores a un FE, establecido en función de las peculiaridades de cada instalación, y el cumplimiento del cual permitiera la obtención y/o renovación de la AAI. En cuanto a la fase de operación, esta consistiría en un control experimental, de modo que se establecieran los mecanismos necesarios que permitan comprobar la correcta aplicación de las MTD seleccionadas en la fase de proyecto. La metodología propuesta se presenta con mayor detalle en el apartado de conclusiones del presente trabajo.

A continuación, se detallan y analizan las metodologías de control de emisiones difusas de PM aplicadas en la actualidad.

\subsubsection{Implementación de una serie de medidas correctoras}

Las principales medidas correctoras exigidas en las AAI para el control de las emisiones difusas de PM se recogen en el BREF horizontal para el almacenamiento (apartado 1.2.4.1) (IPTS, 2006). Además, los BREF propios de los sectores industriales que incluyen en el proceso productivo la manipulación y transporte de sólidos pulverulentos incorporan un apartado que recopila MTD específicas. Concretamente, 15 de los 31 tipos de actividades industriales incluidas en la DEI tienen establecidas estas medidas, las cuales coinciden básicamente con las MTD enumeradas en el BREF de almacenamiento. Estas MTD abarcan desde la humectación de las materias primas acopiadas al aire libre hasta la construcción de naves cerradas para el almacenamiento de las mismas.

Además, las diferentes MTD propuestas comparten el problema común de la ausencia de un VLE asociado a las mismas, por lo que resulta complejo seleccionar las MTD apropiadas para asegurar una eficacia determinada. Esta situación provoca que, las autoridades ambientales recurran a criterios propios para el establecimiento de estrategias de mitigación en las instalaciones.

\subsubsection{Establecimiento de valores límite en el perímetro de la instalación}

Los VLE establecidos para el control de las emisiones difusas de PM, en las AAI y la legislación sobre emisiones difusas, provienen de la legislación específica en materia de calidad del aire. En esta se definen como un VL, es decir, como un nivel que no debe superarse, con el fin de evitar, prevenir o reducir los efectos nocivos para la salud humana y para el medio ambiente en su conjunto. Concretamente, los VLE propuestos se han obtenido del Decreto 833/1975, Real Decreto 1321/1992 y Real Decreto 1073/2002, los cuales establecen como parámetros de control las fracciones PSD, PST y PM10, respectivamente.

La ausencia de una metodología reconocida, así como de VLE propios para emisiones difusas de $\mathrm{PM}$, ha desencadenado la presencia de diferencias significativas entre las metodologías propuestas en las distintas CCAA. En la Tabla 1.18 se recogen los diferentes parámetros de control y VLE adoptados por algunas de las CCAA con legislación propia para el control de las emisiones difusas de PM, debiéndose cumplir los VLE establecidos en el perímetro de la instalación.

En general, el ámbito de aplicación de los VLE son las instalaciones incluidas en el CAPCA, para las cuales se ha establecido la necesidad de realizar controles de emisiones difusas de partículas o la necesidad de elaborar un Plan de Vigilancia Atmosférica. 
Tabla 1.18. VLE de PM y PSD para focos difusos en entornos industriales.

\begin{tabular}{|c|c|c|c|c|c|}
\hline \multirow[b]{2}{*}{ CCAA } & \multirow{2}{*}{$\begin{array}{l}\text { Instrumento } \\
\text { normativo }\end{array}$} & \multirow{2}{*}{$\begin{array}{l}\text { Distancia } \\
\text { núcleo urbano }\end{array}$} & \multirow{2}{*}{$\begin{array}{l}\text { Parámetro } \\
\text { control }\end{array}$} & \multicolumn{2}{|c|}{ VLE } \\
\hline & & & & $\begin{array}{l}\text { Valor medio } \\
\text { valores diarios }\end{array}$ & $\begin{array}{l}\text { Máximo valores } \\
\text { diarios }\end{array}$ \\
\hline \multirow[t]{2}{*}{ Andalucía } & \multirow[t]{2}{*}{ Decreto } & \multirow{7}{*}{ No se especifica } & PSD & $\begin{array}{c}300 \\
\mathrm{mg} /\left(\mathrm{m}^{2} \mathrm{dí} a\right)\end{array}$ & \multirow{7}{*}{ No se especifica } \\
\hline & & & PST & $150 \mu \mathrm{g} / \mathrm{m}^{3}$ & \\
\hline Cantabria & Decreto & & PSD & $\begin{array}{c}300 \\
\mathrm{mg} /\left(\mathrm{m}^{2} \mathrm{dí} a\right)\end{array}$ & \\
\hline $\begin{array}{l}\text { Castilla La } \\
\text { Mancha }\end{array}$ & Orden & & PST & $150 \mu \mathrm{g} / \mathrm{m}^{3}$ & \\
\hline Cataluña & $\begin{array}{l}\text { Instrucción } \\
\text { técnica }\end{array}$ & & PSD & $\begin{array}{c}300 \\
\mathrm{mg} /\left(\mathrm{m}^{2} \mathrm{dí} a\right)\end{array}$ & \\
\hline \multirow{2}{*}{$\begin{array}{l}\text { Comunidad de } \\
\text { Madrid }\end{array}$} & \multirow{2}{*}{ Resolución } & & PSD & $\begin{array}{c}300 \\
\mathrm{mg} /\left(\mathrm{m}^{2} \mathrm{dí} a\right)\end{array}$ & \\
\hline & & & PST & $150 \mu \mathrm{g} / \mathrm{m}^{3}$ & \\
\hline \multirow{3}{*}{$\begin{array}{l}\text { Comunidad } \\
\text { Valenciana }\end{array}$} & \multirow{3}{*}{$\begin{array}{c}\text { Decreto }{ }^{1} \\
\text { Plan Mejora } \\
\text { Calidad Aire }\end{array}$} & $\leq 500 \mathrm{~m}$ & PM10 & $40 \mu \mathrm{g} / \mathrm{m}^{3}$ & $50 \mu \mathrm{g} / \mathrm{m}^{3}$ \\
\hline & & \multirow{2}{*}{$>500 m$} & PST & $150 \mu \mathrm{g} / \mathrm{m}^{3}$ & $300 \mu \mathrm{g} / \mathrm{m}^{3}$ \\
\hline & & & PSD & $\begin{array}{c}300 \\
\mathrm{mg} /\left(\mathrm{m}^{2} \mathrm{dí} a\right)\end{array}$ & No se especifica \\
\hline País Vasco & $\begin{array}{l}\text { Orden } \\
\text { Decreto }\end{array}$ & \multicolumn{4}{|c|}{$\begin{array}{l}\text { Definidos en el Plan de Vigilancia Atmosférica } \\
\text { Contaminantes a medir: PSD, PM10, PM2.5. }\end{array}$} \\
\hline $\begin{array}{l}\text { Región de } \\
\text { Murcia }\end{array}$ & Resolución & No se especifica & PSD & $\begin{array}{c}300 \\
\mathrm{mg} /\left(\mathrm{m}^{2} \mathrm{dí} a\right)\end{array}$ & No se especifica \\
\hline
\end{tabular}

${ }^{1}$ Decreto actualmente derogado.

En la Tabla 1.19 se resumen los criterios establecidos por diferentes CCAA para la metodología de muestreo de PM emitido desde focos difusos. Estos muestreos deben realizarse en días de funcionamiento normal de la instalación. 
Tabla 1.19. Metodologías de muestreo y medición de PM y PSD para el control de fuentes difusas de PM.

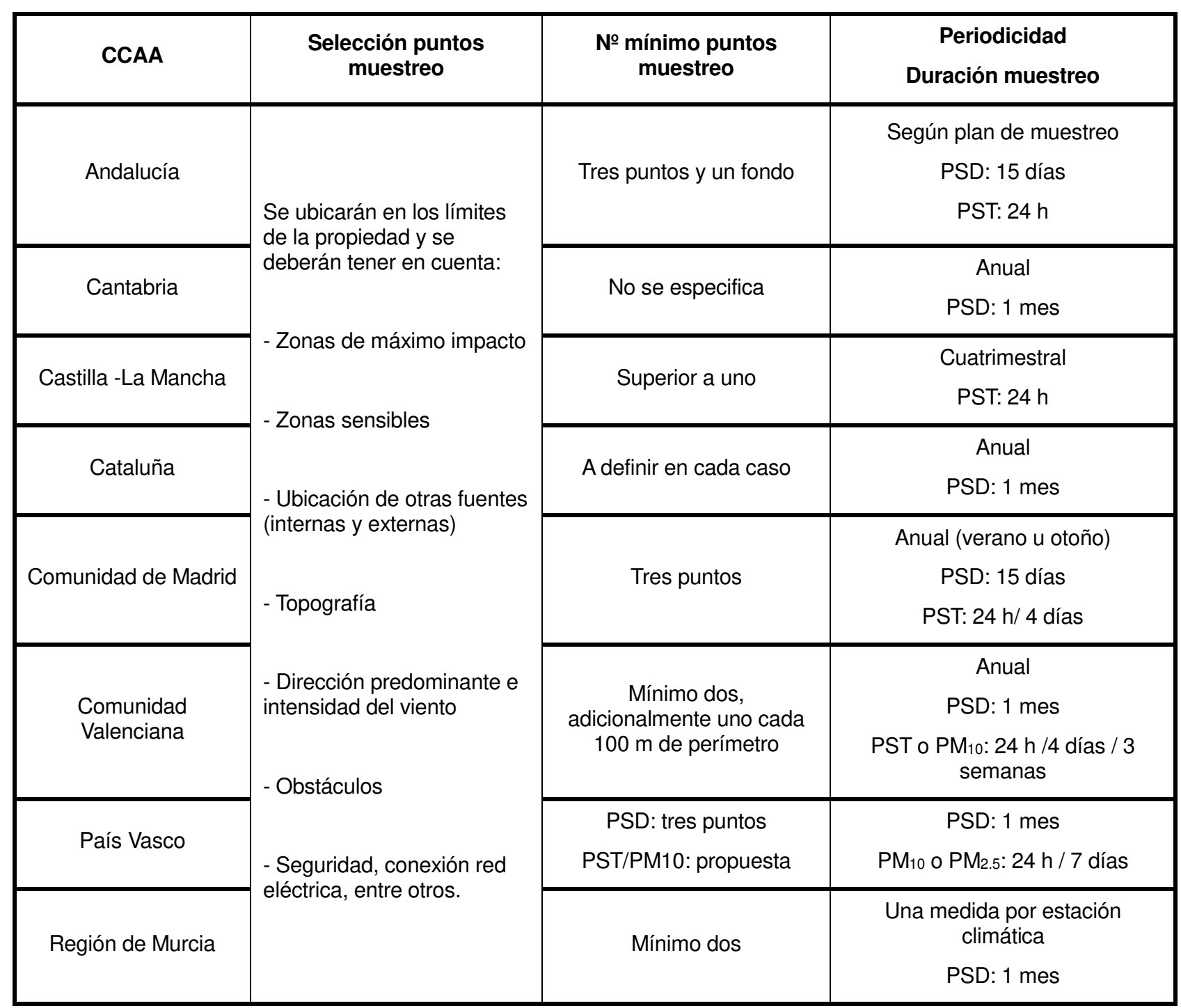

El análisis de la información recopilada en las Tablas 1.18 y 1.19 sugiere los siguientes comentarios:

- El desarrollo de una misma actividad se ve sometida a diferentes criterios de control dependiendo de la CA en la que se ubique la instalación, siendo la principal discrepancia el parámetro de control:

- A partir de la experiencia adquirida en la ejecución de campañas experimentales en instalaciones industriales, se ha observado que el PSD no resulta ser un parámetro apropiado para el control global de las emisiones difusas de PM, ya que la concentración obtenida se encuentra muy influenciada por las operaciones realizadas cerca del punto de medida.

- En general, la determinación de la concentración de PM10 supone una mayor restricción en el VLE exigido $\left(40 \mu \mathrm{gPM} 10 / \mathrm{m}^{3}\right)$. En el caso concreto del sector cerámico, si se aplica el ratio PM10/PST del 40\%, obtenido por Querol (2001a), al VLE de PST se obtiene una concentración de $60 \mu \mathrm{gPM} 10 / \mathrm{m}^{3}$. 
- Por otra parte, algunos de los principales inconvenientes que presentan este tipo de medidas son:

- La ejecución de las medidas presenta la dificultad de la ubicación de los equipos, ya que se precisan localizaciones con suministro eléctrico, seguras y despejadas, lo que en la práctica supone una limitación importante.

- Asimismo, la representatividad de los puntos de muestreo seleccionados puede verse influenciada por la elevada dispersión de las concentraciones registradas en distintos puntos, como consecuencia de la elevada variabilidad de fuentes de emisión existentes en una instalación y de la frecuencia de emisión de las mismas. Por este motivo, se considera necesario evaluar si la metodología aplicada en la ejecución de las campañas experimentales ofrece una respuesta repetitiva ante escenarios industriales similares.

- La dificultad de poder asignar las concentraciones de PM registradas en el perímetro de una instalación a la misma, sobre todo cuando esta se encuentra ubicada en un polígono industrial en el que convergen diversas empresas que manipulan el mismo tipo de materiales o se encuentra cercana a una zona de tránsito externa a la misma.

- La aplicación de VL establecidos para calidad de aire en entornos industriales no presenta un objetivo realista, considerándose recomendable la definición de VLE para ambientes industriales, en los que se considere el uso dominante del suelo y/o la distancia a núcleo urbano. Un ejemplo, en la línea de esta propuesta, podría ser la legislación en materia de contaminación acústica.

- No obstante, la definición de VLE en ambientes industriales se considera una tarea compleja, ya que el VLE debe ser lo suficientemente realista para poder permitir desarrollar las actividades propias del proceso productivo aplicando las MTD, y a su vez restrictivo para asegurar la protección sobre la salud humana y el medio ambiente en su conjunto. Esta complejidad viene agravada por la ausencia de NEA-MTD para emisiones difusas en los BREF.

- Finalmente, una de las desventajas que presenta este sistema de control es que no permite cuantificar las emisiones difusas en flujo másico, para lo que se requiere un tratamiento de datos y un plan de muestreo más sofisticado.

A pesar de las dificultades comentadas en la ejecución de las medidas planteadas para el control de las emisiones difusas de PM, se observa que esta metodología es una de las más aplicadas por las diferentes CCAA, probablemente debido a que es la forma habitual de controlar las emisiones canalizadas y a que presenta la ventaja de una mayor sencillez para el legislador.

\subsubsection{Cuantificación de las emisiones difusas de PM}

En el caso de las emisiones difusas de PM se suele recurrir a FE para su cuantificación, a diferencia de las emisiones canalizadas para las que se dispone de medidas experimentales de los propios focos. Esta situación, como ya se ha comentado anteriormente, se debe probablemente a la complejidad que conlleva abordar la cuantificación de fuentes difusas.

Los FE estiman la tasa de emisión de PM en base a una magnitud unitaria que cuantifica la intensidad de la operación, asumiendo que las emisiones son directamente proporcionales a dicha cantidad. En la práctica, los FE para la manipulación de graneles sólidos se refieren a la masa de 
material procesado, mientras que los FE para transporte se expresan por unidad de distancia recorrida.

Las guías más ampliamente reconocidas para la selección de FE son el documento AP-42 de la US Enviromental Protection Agency (US-EPA) (US-EPA, 1995) y a nivel europeo la guía EMEP/EEA (EMEP/EEA, 2016). Además, existen una serie de manuales técnicos elaborados por el gobierno australiano en los que se recogen FE para diferentes actividades (Australian Government, 2012).

A nivel nacional existe la norma UNE-EN 15445:2008: «Emisiones fugitivas y difusas de interés común a sectores industriales. Cualificación de fuentes de partículas fugitivas por Modelización de Dispersión Reversa», la cual se define como una herramienta que permite a cada planta industrial identificar las principales fuentes emisoras de PM.

\section{- Documento AP-42 de la US-EPA}

El documento «AP-42: Compilation of Air Pollutant Emission Factors» de la US EPA (US EPA, 1995) introduce un apartado exclusivo para fuentes difusas (sección 13.2). Los FE propuestos para la cuantificación de las emisiones difusas de PM se agrupan en función del tipo de fuente de emisión: manipulación y almacenamiento, transporte por vías asfaltadas, transporte por vías no asfaltadas y erosión por viento. En estos casos, todos los FE se expresan en forma de ecuaciones empíricas predictivas, las cuales dependen de determinados parámetros experimentales.

A nivel nacional, la Generalitat de Cataluña, dentro de la instrucción técnica IT-AT-08, establece una metodología para el control de las emisiones a la atmósfera en las actividades extractivas. Esta se basa principalmente en estimar las emisiones difusas de PST y PM10 aplicando los FE propuestos en el documento AP-42 de la US EPA.

En la Tabla 1.20 se muestra la ecuación formulada para estimar las emisiones asociadas a operaciones de manipulación de materiales de naturaleza pulverulenta (US EPA, 2006a). Esta ecuación ha recibido la máxima calificación en relación a la calidad y robustez que presenta, siempre y cuando se aplique dentro del intervalo indicado para las siguientes variables: contenido en finos (sL: 0.44-19\%), humedad del material (M: 0.25-4.8\%) y velocidad del viento ( $\mathrm{v}:$ : 0.6-6.7 m/s).

Tabla 1.20. FE para la manipulación de materiales pulverulentos (US EPA, 2006a).

\begin{tabular}{|c|l|}
\hline Ecuación & \multicolumn{1}{|c|}{ Parámetro } \\
\hline $\mathrm{FE}=\mathrm{k} \cdot 0.0016 \cdot \frac{\left(\frac{\mathrm{V}}{2.2}\right)^{1.3}}{\left(\frac{\mathrm{M}}{2}\right)^{1.4}}$ & $\begin{array}{l}\text { FE: factor de emisión }(\mathrm{kg} / \text { ton }) \\
\mathrm{k}: \text { factor adimensional dependiente del tamaño de } \\
\text { partícula: } \mathrm{k}_{\mathrm{PST}}=0.74 ; \mathrm{kPM} 10=0.35 ; \mathrm{k}_{\mathrm{PM} 2.5=0.053} \\
\text { v: velocidad media del viento }(\mathrm{m} / \mathrm{s}) \\
\mathrm{M} \text { : humedad del material }(\%)\end{array}$ \\
\hline
\end{tabular}

La existencia de la presente ecuación permite estimar las emisiones difusas asociadas a operaciones de manipulación para diferentes materiales, no disponiéndose en la mayoría de los casos de información más específica. No obstante, se considera que la ecuación propuesta plantea las siguientes cuestiones:

- Esta ecuación se propone para representar un conjunto muy amplio de operaciones de caída y materiales. Sin embargo, a pesar del alcance de la misma, esta se ha obtenido a partir de 
los resultados obtenidos en la ejecución de un número limitado de ensayos experimentales, siendo las operaciones evaluadas descarga de carbón en centrales térmicas, descarga de pellets de azufre y carga a camión de cenizas volantes (Muleski et al., 1987).

Por tanto, su extrapolación a otros escenarios tecnológicos (operaciones y material manipulado) pueden conllevar una cuantificación no apropiada de las emisiones difusas de PM, ya que como se ha comentado, esta depende tanto del tipo de operación a la que se someten los materiales como de las características del material manipulado.

- En cuanto a las características del material manipulado que pueden influir en la emisión, la ecuación propuesta considera únicamente la humedad. No obstante, se ha observado en campo que la emisión producida durante la manipulación de determinados materiales con una humedad similar puede llegar a ser significativamente diferente. Sin embargo, aplicando la ecuación propuesta se obtendrían emisiones similares para los dos materiales.

- La ecuación propuesta presenta el inconveniente de su aplicación en casos extremos en los que el material manipulado presenta humedades próximas a cero.

- Finalmente, se ha aplicado el método de cuantificación basado en la obtención de perfiles isocinéticos para la obtención de la ecuación planteada. Esta misma metodología ha sido utilizada para obtener la ecuación propuesta para transporte, siendo evaluada por Venkatram (2000) y cuyas objeciones se comentan posteriormente.

En cuanto a las emisiones por resuspensión en viales asfaltados y no asfaltados, en la Tabla 1.21 se recogen las diferentes ecuaciones propuestas (US EPA, 2006b y 2011). El fenómeno de resuspensión puede activarse por dos causas: el viento y la turbulencia generada por el tráfico. Algunas de las variables que pueden contribuir a la emisión por resuspensión son: el peso del vehículo, el número de ruedas, la velocidad de circulación, la humedad del suelo, el contenido en finos depositados en el vial, entre otros.

En relación con la estimación de las emisiones asociadas a la resuspensión del polvo depositado en las carreteras (road dust), esta se considera como una de las mayores contribuciones de PM en zonas urbanas (Amato et al., 2009 y 2014). Por ese motivo, la ecuación propuesta en el documento AP-42 para transporte en viales pavimentados es ampliamente conocida, siendo desarrollada originariamente por Cowherd y Englehart en 1974, quienes observaron una clara dependencia del FE con el contenido en finos depositado en la superficie. Posteriormente, se han incluido nuevos ensayos (US EPA, 1993 y 2011), obteniéndose nuevas ecuaciones empíricas dependientes de la carga de finos $(<75 \mu \mathrm{m})$ depositado en la superficie y del peso del camión. La ecuación propuesta en 2011 conserva la calificación de máxima calidad para PM10 (siendo inferior para PM2.5), si se aplica dentro del intervalo de valores definidos para las variables consideradas: carga finos en la superficie ( $\mathrm{sL}: 0.03-400 \mathrm{~g} / \mathrm{m}^{2}$ ), peso medio de los vehículos (W: 2-42 t) y velocidad media de circulación (v: 1-88 km/h) (US EPA, 2011).

En el caso de viales no pavimentados, la primera ecuación propuesta en el documento AP-42 data del año 1975, mejorándose en 1978 a partir de los resultados obtenidos durante la ejecución de un mayor número de estudios en plantas siderúrgicas. En esta ecuación, la emisión dependía del contenido en finos (s), del W, de la v, y del número de ruedas (w). Posteriormente, en la versión de 2006, se propusieron dos ecuaciones en función del tipo de vial. La ecuación propuesta para zonas industriales no pavimentadas presenta una robustez media, si se aplica dentro del intervalo de 
valores definidos para las variables consideradas: s (1.8-25.2\%), W (2-290 t), v (8-69 km/h), w (417) y humedad del suelo (0.03-13\%) (US EPA, 2006b).

Tabla 1.21. Ecuaciones para transporte por viales asfaltados y no asfaltados (US EPA, 2006b y 2011).

\begin{tabular}{|c|c|c|}
\hline Operación & Ecuación & Parámetro \\
\hline $\begin{array}{c}\text { Transporte zona } \\
\text { asfaltada }\end{array}$ & $\mathrm{FE}=\mathrm{k} \cdot \mathrm{sL}^{0.91} \cdot \mathrm{W}^{1.02}$ & $\begin{array}{l}\text { FE: factor de emisión ( } \mathrm{g} / \mathrm{km} / \text { vehículo) } \\
\mathrm{k} \text { : factor dependiente del tamaño de partícula } \\
(\mathrm{g} / \mathrm{km}): \mathrm{kPST}: 3.23 ; \mathrm{kPM} 10: 0.62 ; \mathrm{k}_{\text {PM2.5: } 0.15} \\
\mathrm{sL}: \text { Carga de finos }(\mathrm{d}<75 \mu \mathrm{m}) \text { en la superficie }\left(\mathrm{g} / \mathrm{m}^{2}\right) \\
\text { W: Peso medio de los vehículos }(\mathrm{t})\end{array}$ \\
\hline $\begin{array}{l}\text { Transporte zona no } \\
\text { asfaltada industrial }\end{array}$ & $\mathrm{FE}=\mathrm{k} \cdot\left(\frac{\mathrm{s}}{12}\right)^{\mathrm{a}} \cdot\left(\frac{\mathrm{W}}{3}\right)^{\mathrm{b}}$ & $\begin{array}{l}\text { FE: factor de emisión }(\mathrm{kg} / \mathrm{km} / \text { vehículo) } \\
\mathrm{k} \text { : Factor dependiente del tamaño de partícula } \\
(\mathrm{kg} / \mathrm{km}) \text { : kPST:1.381; kPM10: } 0.423 \\
\text { s: Contenido en finos }(\mathrm{d} \leq 75 \mu \mathrm{m})(\%) \\
\text { W: Peso medio de los vehículos }(\mathrm{t}) \\
\text { Constantes: PST ( } \mathrm{a}=0.7, \mathrm{~b}=0.45) \text { y PM10 ( } \mathrm{a}=0.9 \text {, } \\
\mathrm{b}=0.45)\end{array}$ \\
\hline $\begin{array}{l}\text { Transporte zona no } \\
\text { asfaltada acceso } \\
\text { público (vehículos } \\
\text { ligeros) }\end{array}$ & $\mathrm{FE}=\frac{\mathrm{k} \cdot\left(\frac{\mathrm{s}}{12}\right)^{\mathrm{a}} \cdot\left(\frac{\mathrm{S}}{30}\right)^{\mathrm{d}}}{\left(\frac{\mathrm{M}}{0.5}\right)^{\mathrm{c}}}$ & $\begin{array}{l}\text { FE: factor de emisión (kg/km/vehículo) } \\
\mathrm{k} \text { : Factor dependiente del tamaño de partícula } \\
(\mathrm{kg} / \mathrm{km}): \mathrm{kPST}: 1.381 ; \mathrm{kPM} 10: 0.423 \\
\mathrm{~s} \text { : Contenido en finos }(\mathrm{d} \leq 75 \mu \mathrm{m})(\%) \\
\text { S: velocidad media del vehículo }(\mathrm{m} / \mathrm{s}) \\
\text { M: Humedad del material depositado en la } \\
\text { superficie (\%) } \\
\text { Constantes: PST }(\mathrm{a}=1, \mathrm{c}=0.2, \mathrm{~d}=0.5) \text { y PM10 }(\mathrm{a}=1 \text {, } \\
\mathrm{C}=0.3, \mathrm{~d}=0.3)\end{array}$ \\
\hline
\end{tabular}

La ecuación propuesta para zonas asfaltadas ha sido ampliamente estudiada, como consecuencia de su extensiva aplicación en estudios de contribución en calidad del aire. A continuación, se resumen algunas de las consideraciones encontradas en la bibliografía consultada:

- Se ha argumentado que la carga de finos en la superficie no es una variable explicativa apropiada, debido a que su determinación comporta cierta ambigüedad (Venkatram, 2000).

- La metodología aplicada para obtener las ecuaciones propuestas por la AP-42 (Cowherd et al., 1979), se basan en determinar la tasa de emisión mediante el método de balance de flujos de materia a partir de valores promedios, en los que no se consideran las fluctuaciones turbulentas de la velocidad (Venkatram, 2000).

- La ecuación propuesta considera que la emisión únicamente depende del contenido en finos y del peso del vehículo, aunque se ha observado que la velocidad de circulación parece jugar un papel importante. Sin embargo, se ha demostrado que la velocidad media de circulación es inversamente proporcional al contenido en finos en la superficie (Nicholson, 2001) y, por tanto, no es viable hacer un ajuste con la misma variable. Ante esta situación, la EPA ha considerado oportuno mantener el parámetro de contenido en finos para introducir una variable de estacionalidad, ya que, en determinados países, a finales de invierno y comienzo 
de la primavera, el material depositado en las carreteras es más alto como consecuencia de un mayor control de la nieve/hielo (US EPA, 1993).

- Otros estudios, han obtenido relaciones distintas a las propuestas por la AP-42 entre el FE y el contenido en finos, obteniéndose FE diferentes para un mismo contenido en finos, un mismo FE para distintas carreteras, etc. (Amato, 2010).

- Por otro lado, los modelos de calidad del aire sugieren un gran sesgo positivo de manera sistemática en las estimaciones de las emisiones resultantes aplicando la ecuación propuesta (Watson y Chow, 2000b).

- Finalmente, algunos de los autores citados concluyen que es necesaria una mayor investigación para evaluar la influencia de determinados factores como el estado y la humedad de los viales, la lluvia, el patrón de conducción, entre otros. Además, también se especifica que los modelos validados a partir de campañas experimentales, deberían ser aplicados con extremada precaución en otras condiciones medioambientales y de densidad de tráfico (Nicholson, 2001).

\section{- Manuales Técnicos del gobierno de Australia}

El gobierno de Australia ha elaborado una serie de manuales técnicos para diferentes actividades, con el fin de facilitar a las empresas la información necesaria para inventariar sus emisiones. Los FE propuestos en estos documentos, prácticamente coinciden con los recogidos en el documento AP-42, aunque para determinados casos en los que se ha observado que estos no presentan buenos resultados se proponen alternativas.

Al respecto, el documento «Emission Estimation Technique Manual for Mining. Version 3.1» (Australian Government, 2012), indica que la ecuación propuesta por el documento AP-42 (US EPA, 2006a) para operaciones de manipulación subestima, en un factor entre 5 y 10, las emisiones de PST y PM10 asociadas a operaciones de carga y descarga de camión para carbón y minerales metálicos.

Ante esta situación, se proponen una serie de FE (Tabla 1.22) obtenidos de diferentes estudios realizados para minería del carbón, tanto para la obtención de FE de PST, como para la obtención del ratio PM10/PST.

Tabla 1.22. FE propuestos en el documento «Emission Estimation Technique Manual for Mining»

(Australian Government, 2012).

\begin{tabular}{|c|c|c|c|c|}
\hline \multirow{2}{*}{ Operación } & \multicolumn{3}{|c|}{ FE } \\
\cline { 2 - 5 } & PST & PM10 & Material & Unidades \\
\hline Carga frontal con máquina pala & 0.029 & 0.014 & Carbón & $\mathrm{kg} / \mathrm{ton}$ \\
\hline Descarga de camiones & 0.01 & 0.0042 & Carbón & $\mathrm{kg} / \mathrm{ton}$ \\
\hline $\begin{array}{c}\text { Circulación por zonas no } \\
\text { asfaltadas }\end{array}$ & 4.23 & 1.25 & n.a. & \\
\hline
\end{tabular}

n.a.: no aplica

Asimismo, el manual específico para la fabricación de cemento, «Emission Estimation Technique Manual for Cement Manufacturing. Version 2.1» (Australian Government, 2008), plasma la misma observación y propone el uso de la ecuación que se recoge en la Tabla 1.23 para el cálculo de la 
emisión de PM10 para operaciones de manipulación. Esta ecuación considera un valor de K (parámetro asociado al tamaño de partícula) de 0.75, similar al propuesto por la AP-42 para PST.

Para los vehículos con un peso superior a 5 toneladas que circulan por viales sin asfaltar, se propone la ecuación que se presenta en la Tabla 1.23 para la estimación de las emisiones de PM10 por resuspensión. En este caso, la ecuación únicamente depende del número de ruedas y del contenido en finos en la superficie.

Tabla 1.23. FE propuestos en el documento «Emission Estimation Technique Manual for Cement Manufacturing» (Australian Government, 2008).

\begin{tabular}{|c|c|c|}
\hline Operación & Ecuación & Parámetro \\
\hline Manipulación cemento & $\mathrm{FE}=0.75 \cdot 0.001184 \cdot \frac{\left(\frac{\mathrm{v}}{2.2}\right)^{1.3}}{\left(\frac{\mathrm{M}}{2}\right)^{1.4}}$ & $\begin{array}{l}\text { FE: factor de emisión de PM10 }(\mathrm{kg} / \mathrm{t}) \\
\text { v: velocidad del viento }(\mathrm{m} / \mathrm{s}) \\
\text { M: contenido humedad }(\%) \\
\text { Si M=0 FE }\end{array}$ \\
\hline $\begin{array}{c}\text { Transporte zona no } \\
\text { asfaltada }\end{array}$ & $\mathrm{FE}=0.0019 \cdot \mathrm{w}^{3.4} \cdot \mathrm{s}^{0.2}$ & $\begin{array}{l}\text { FE: factor de emisión de PM10 } \\
(\mathrm{kg} / \mathrm{km} / \mathrm{veh} \text { ćculo) } \\
\mathrm{w}: \mathrm{n}^{\circ} \text { de ruedas } \\
\mathrm{s}: \text { contenido en finos de la superficie } \\
\left(\mathrm{g} / \mathrm{m}^{2}\right)\end{array}$ \\
\hline
\end{tabular}

\section{- Guía EMEP/EEA}

A nivel europeo, la Agencia Europea de Medio Ambiente (EEA) ha publicado una guía técnica para elaborar los inventarios de emisiones nacionales. La versión más actual es la guía publicada en 2016, «EMEP/EEA air pollutant emission inventory guidebook 2016» (EMEP/EEA, 2016), siendo el trabajo original el antiguo EMEP/CORINAIR cuyo primer anexo se publicó en 1994. La versión de 2013 introdujo como novedad la consideración de las emisiones difusas de PM.

La guía EMEP-EEA facilita información sobre cómo realizar un inventario de emisiones atmosféricas, proporcionando tres métodos. Estos se clasifican en función del grado de detalle que consideran como nivel 1, 2 y 3 . Los diferentes niveles incluyen, si existe información técnica disponible, FE para PST, PM10 y PM2.5. Los FE del nivel 1 representan condiciones «típicas» o «promedio» del proceso. Los datos de actividad se obtienen de información estadística disponible (estadísticas de energía, estadísticas de producción, densidad de tráfico, tamaños de población, entre otros).

El nivel 2 utiliza los mismos datos o similares de actividad que el nivel 1, pero aplica FE específicos por país, utilizando información concreta en cuanto a condiciones del proceso, calidades de los combustibles, tecnologías de reducción, entre otros. En muchos casos este método también se puede aplicar a un nivel de detalle más alto, donde las estadísticas de actividad se dividieran en sub-actividades con unas características del proceso más o menos homogéneas.

Finalmente, el nivel 3 da un paso más, pudiendo llegar a considerar datos a nivel de instalación y/o modelos más sofisticados. En este caso, pueden utilizarse los datos de PRTR o de comercio de emisiones para instalaciones industriales. 
En cuanto a los FE propuestos en la guía EMEP/EEA (EMEP/EEA, 2016) para emisiones difusas de $\mathrm{PM}$, en el capítulo referente a procesos industriales y uso de materiales (capítulo 2), se establecen FE de PST, PM10 y PM2.5 asociados al almacenamiento y manipulación de productos minerales (apartado 2.A.5.c) para un nivel 2 (Tabla 1.24). El propio documento indica que no existe información disponible sobre FE específicos asociados a una actividad industrial especifica (nivel 3).

Tabla 1.24. FE propuestos en la guía EMEP/EEA para emisiones difusas de PM (EMEP/EEA, 2016).

\begin{tabular}{|c|c|c|c|c|c|}
\hline \multirow{2}{*}{ Operación } & \multirow{2}{*}{ MTD } & \multicolumn{3}{|c|}{ FE } \\
\cline { 3 - 6 } & & PST & PM10 & PM2.5 & Unidades \\
\hline Almacenamiento & Sin MTD & 16.4 & 8.2 & 0.82 & t/ha/año \\
\hline Almacenamiento & Con MTD & 1.64 & 0.82 & 0.082 & t/ha/año \\
\hline Manipulación & Sin MTD & 12 & 6 & 0.6 & $\mathrm{~g} / \mathrm{t}$ \\
\hline
\end{tabular}

A continuación, se resumen una serie de observaciones sobre los FE propuestos en la guía EMEP/EEA (EMEP/EEA, 2016):

- En el caso concreto del almacenamiento se ha considerado una eficacia de las MTD implementadas constante del $10 \%$ para las diferentes fracciones granulométricas, sin especificarse las MTD implementadas. No obstante, se considera relevante identificar bajo que MTD se ha obtenido el FE, dado que la eficacia de las MTD propuestas en los BREF abarca desde un 30\% (barreras vegetales) hasta un 99\% (cerramiento total) (Australian Government, 2012), pudiendo llegar a afectar considerablemente al FE obtenido.

- Se propone un FE genérico para la estimación de las emisiones asociadas a operaciones de manipulación de productos minerales. Sin embargo, la emisión depende tanto de las características del material manipulado como del tipo de manipulación al que es sometido (López-Lilao et al., 2017).

- De forma general se ha aplicado un ratio PM10/PST del 50\% y PM10/PM2.5 del 10\% para determinar los $\mathrm{FE}_{\mathrm{PM} 10}$ y $\mathrm{FE}_{\mathrm{PM} 2.5}$ respectivamente. Estos ratios son muy similares a los aplicados en el documento AP-42, 47 y 15\%. En entornos industriales (canteras de extracción de arcillas, parques de almacenamiento y homogenización de materias primas cerámicas) se ha obtenido experimentalmente un ratio PM10/PST del 40\% (Querol et al, 2001a).

De las evidencias anteriores se concluye que se dispone de información escasa sobre FE específicos por operación $y / 0$ material $y$, de la eficacia cuantitativa de las MTD para una cuantificación realista y precisa de las emisiones difusas de PM.

Una mejora en la calidad y representatividad de estas bases de datos, teniendo en cuenta los casos específicos de actividades potencialmente emisoras de PM, implicaría directamente una mejora sustancial de la calidad de las cuantificaciones efectuadas para el control de las emisiones difusas de PM y de todas sus consecuencias (establecimiento de requisitos de control, medidas de mitigación, reducción de límites de emisiones, planes de mejora de la calidad del aire). 


\subsubsection{Recomendaciones del Plan Aire para las emisiones difusas de PM}

El Plan Nacional de Calidad del Aire y Protección de la Atmósfera 2013-2016 (Plan Aire) (MAGRAMA, 2013), establece una serie de objetivos específicos encaminados a mejorar la información técnica disponible sobre emisiones difusas de PM y consensuar métodos de cálculo para la cuantificación de las mismas. Las diferentes medidas propuestas ponen de manifiesto la problemática ambiental asociada a las emisiones difusas de PM a nivel nacional. Los principales objetivos son:

- Mejorar la información de emisiones a la atmósfera: regular las metodologías de cálculo para inventarios (PRTR) y la información de las instalaciones sometidas a control por parte de las CCAA.

- Mejorar el control de las emisiones a la atmósfera: unificar criterios para el control de las emisiones (frecuencia y método de control, cumplimiento de requisitos técnicos, entre otros).

- Fomentar la I+D+i para prevenir y reducir la contaminación atmosférica: recopilar FE de PM10 y PM2.5 en focos difusos.

Además, el Plan Aire establece las siguientes medidas sectoriales:

- Seguimiento de las actuaciones en áreas industrializadas con problemas de calidad del aire: planes de calidad del aire locales y revisión de las AAI concedidas a actividades industriales ubicadas en zonas problemáticas.

- Actualización y desarrollo de VLE aplicables a instalaciones industriales que no estén bajo el ámbito de aplicación de la Ley 16/2002.

- Reducción de las emisiones de PM en el sector industrial, incidiendo sobre los focos de emisión difusa. Establecimiento de requisitos técnicos para su reducción, priorizando las instalaciones próximas a núcleos urbanos. 


\subsection{Fenomenología de la dispersión atmosférica}

\subsubsection{Estructura de la capa límite atmosférica}

La atmósfera constituye un sistema dinámico complejo, en el que los contaminantes emitidos a la atmósfera se ven afectados por el campo de movimientos de la misma. Por un lado, el viento predominante transporta los contaminantes en su dirección y sentido (advección). Por otro lado, la atmósfera produce una difusión efectiva conocida como difusión turbulenta, la cual produce movimientos relativos al movimiento medio del viento que dispersan los contaminantes. Como resultado de ambos fenómenos, advección y difusión, se produce la dispersión de los contaminantes (Stull, 1988).

El origen de la turbulencia en la atmósfera puede ser tanto térmico, debido al calentamiento de la superficie de la tierra, como mecánico, consecuencia de la cizalla del viento debida a la rugosidad del terreno. La turbulencia afecta tanto a la dispersión de los contaminantes en la atmósfera como al perfil de velocidades.

En general, los procesos turbulentos tendrán mayor o menor importancia en función de determinados factores, relacionados con la estructura de la atmósfera; en particular, de la capa límite atmosférica (CLA), también denominada en otros trabajos como capa de mezcla o capa límite planetaria.

La CLA admite múltiples definiciones según las características de la misma que se quieran resaltar en su descripción. Así, Stull (1988) la define como «la parte de la atmósfera que se encuentra influenciada de manera directa por la presencia de la superficie terrestre». Nieuwstadt y Duynkerke (1996) lo expresan como «aquella región de la atmósfera en la que los valores de las magnitudes atmosféricas (humedad, velocidad, temperatura) varían desde sus valores en la atmósfera libre a aquellos que tienen en la superficie terrestre». Garratt (1992), en cambio, la define a partir de las características que el flujo atmosférico presenta en su interior: «altamente rotacional, tridimensional, disipativo (para que la turbulencia no desaparezca debe existir un aporte continuo de energía), trayectorias detalladas de las partículas no predecibles con exactitud, velocidad de transporte y mezcla varios ordenes de magnitud superior respecto a la difusión molecular».

En conclusión, la CLA representa el estrato de la atmósfera sujeto a la influencia de la superficie terrestre y puede considerarse como una región con intensa turbulencia, en la que se favorece el fenómeno de difusión y transporte de energía y materia.

A continuación, se presenta la estructura vertical de la CLA, detallándose las diferentes capas que la componen, y su efecto sobre el comportamiento y la evolución de las magnitudes atmosféricas. En orden ascendente la CLA está constituida por (Castro et al., 1991):

- Capa interfacial: a la región en contacto físico con el suelo se le suele llamar subcapa interfacial o de transferencia $(0-1 \mathrm{~cm})$. En esta capa el efecto de la turbulencia es lo bastante pequeño como para que el flujo no se vea esencialmente afectado por ella, sino por la estructura de los elementos rugosos del terreno. En consecuencia, el transporte de cantidad de movimiento, calor y vapor de agua dependen casi por completo de la viscosidad y de las difusividades moleculares de calor y humedad. Cuando la superficie es lisa a esta capa se le da el nombre de subcapa viscosa, mientras que con suelo rugoso el de subcapa rugosa. 
- Capa superficial: en la CLA, las variaciones más significativas en la velocidad del viento y en las turbulencias térmica y mecánica se producen en la capa en contacto con la superficie, denominada capa superficial atmosférica (en inglés atmospheric surface layer). La capa superficial se suele definir como el estrato de la baja atmósfera en el que el esfuerzo cortante es constante. Esta capa se extiende desde una altura denominada rugosidad efectiva $\left(z_{0}\right)$, que varía dependiendo de la superficie, hasta una altura comprendida aproximadamente entre los 10 y 100m, variando en función del tipo de estratificación atmosférica, estructura del terreno y velocidad del viento.

- Capa de mezcla: la capa de mezcla es un estrato en el cual la temperatura potencial (ver apartado 1.4.2) y humedad no varían con la altura. Se denomina capa de mezcla debido a que la intensa turbulencia que se da en esta capa tiende a homogenizar las concentraciones de los contaminantes presentes en su seno. De esta forma, las emisiones que tienen lugar en las capas bajas quedan principalmente retenidas en esta capa, cuya extensión vertical abarca de los $100 \mathrm{~m}$ a $1 \mathrm{~km}$. Es por ello, por lo que puede decirse que existe una estrecha relación entre los índices de contaminación atmosférica y el espesor de este estrato del aire.

- Capa de transición: a lo largo de la capa de transición el viento medio va cambiando con la altura, de manera que finalmente en su borde superior se aproxima al viento geóstrofico, al tiempo que la magnitud de los flujos turbulentos disminuye drásticamente con la distancia al suelo. En esta capa el viento es prácticamente independiente de la naturaleza de la superficie aproximándose a la llamada atmósfera libre.

En cuanto a la distribución de las magnitudes atmosféricas, la superficie terrestre influencia a la atmósfera de varias formas (Arya, 2001). En primer lugar, la condición de adherencia causa que el viento describa un pronunciado perfil de velocidades y que exista una considerable disipación de energía por fricción. En segundo lugar, el mayor o menor calentamiento de la superficie terrestre con respecto al aire circundante origina corrientes de convección. Si existen corrientes de flotación ascendentes se dice que la atmósfera esta inestablemente estratificada, siendo la turbulencia de carácter térmico y mecánico. En caso contrario, cuando se produce la inhibición del movimiento vertical, esta situación se califica de estable, mostrando generalmente turbulencia de carácter mecánico exclusivamente, lo que suele suceder por las noches. Si no se da ninguna de estas situaciones, entonces las condiciones son neutras. Por tanto, la estabilidad atmosférica se ve influenciada en gran medida por el gradiente de temperatura vertical y el grado de turbulencia que genera el viento.

En este sentido, los flujos de calor entre la superficie terrestre y las capas bajas de la atmósfera tienen una gran importancia en la parametrización de la CLA. La variación diurna del espesor de dicha capa depende, en gran medida, de la radiación que recibe la superficie terrestre y de cómo esta energía se transmite en el entorno de la superficie terrestre.

De forma simplificada, el mecanismo de reparto de energía en la superficie del suelo es el siguiente: la radiación solar calienta la superficie terrestre y, a medida que aumenta la energía del suelo, parte del exceso de calor es trasmitido hacia la atmósfera en forma de calor sensible. A su vez, parte del calor también es conducido hacia las capas profundas del suelo (Figura 1.15). 


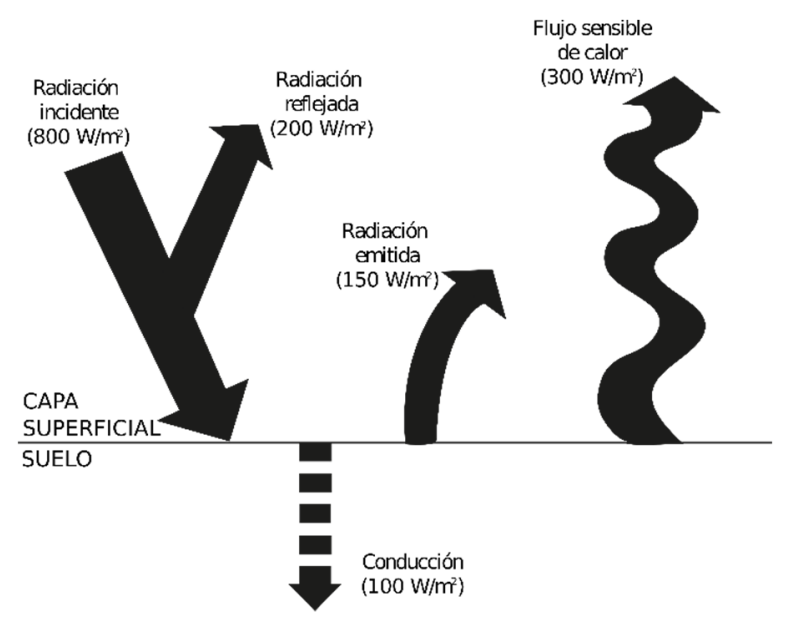

Figura 1.15. Balance de energía en la superficie del suelo.

\subsubsection{Teoría de semejanza de Monin Obukhov}

De forma general puede considerarse que la teoría de Monin-Obukhov (M-O) (1954) describe adecuadamente los procesos más significativos que tienen lugar en la CLA, región con intensa turbulencia donde suceden los eventos relacionados con la dispersión de contaminantes.

La teoría M-O permite calcular los perfiles verticales de velocidad y temperatura. Además, los parámetros que intervienen en estas ecuaciones tienen significado físico y permiten parametrizar de forma sencilla las condiciones de estratificación atmosférica.

De acuerdo con la teoría de M-O, la capa superficial se define como el estrato de la atmósfera en el que el flujo de cantidad de movimiento y de calor no varían sustancialmente con la altura. A continuación, se definen las ecuaciones para la determinación del perfil vertical de velocidades y de temperatura. En cada ecuación se describen las variables nuevas que introduce.

\section{- Perfil vertical de velocidades}

El flujo de cantidad de movimiento en la superficie del suelo puede escribirse:

$$
\tau \approx-\rho K_{m}\left(\frac{\partial u}{\partial z}\right)
$$

siendo:

$\tau:$ densidad de flujo de cantidad de movimiento $\left(\mathrm{kg} / \mathrm{m} \mathrm{s}^{2}\right)$

$\rho$ : densidad del aire $\left(\mathrm{kg} / \mathrm{m}^{3}\right)$

$\mathrm{K}_{\mathrm{m}}$ : difusividad turbulenta de cantidad de movimiento $\left(\mathrm{m}^{2} / \mathrm{s}\right)$

u: componente vertical del viento $(\mathrm{m} / \mathrm{s})$

Monin y Obukhov (1954) recurrieron a la teoría de la longitud de mezcla de Prandtl para obtener una expresión para el coeficiente de difusión de cantidad de movimiento:

$$
K_{m}=\kappa^{2} z^{2}\left(\frac{\partial u}{\partial z}\right)
$$


en la que $\kappa$ es la constante universal de von Kármán $(\approx 0.4)$.

La velocidad de fricción ( $u_{*}$ ) es una escala de velocidad definida como la raíz cuadrada entre el esfuerzo tangencial en la superficie y la densidad del aire:

$$
u_{*}=\sqrt{\frac{\tau}{\rho}}
$$

En esta ecuación se observa que valores elevados de la velocidad de fricción implican una mayor turbulencia de origen mecánico.

Sustituyendo (2) en (1) y considerando la expresión (3), se llega a la ecuación diferencial:

$$
\kappa z \frac{\mathrm{d} u}{\mathrm{~d} z}=u_{*}
$$

Esta ecuación puede integrarse, asumiendo que existe una rugosidad efectiva superficial $z_{0}$ para la que $u=0$ :

$$
u(z)=\frac{u_{*}}{\kappa} \ln \frac{z}{z_{0}}
$$

Esta ecuación es válida para condiciones neutras, es decir, para situaciones en las que el flujo neto convectivo de calor (flujo de calor sensible) es cero. Cuando no se da esta condición, bien sea una situación estable (existe un flujo de calor hacia la superficie terrestre) o inestable (movimientos convectivos ascendentes), debe corregirse la difusividad de cantidad de movimiento $\left(K_{m}\right)$ de la siguiente manera:

$$
K_{m}=\frac{\kappa u_{*} z}{\phi_{m}}
$$

donde $\phi_{\mathrm{m}}$ es una función de corrección por estabilidad. El perfil resultante de velocidades, tras incluir dicha corrección resulta ser:

$$
u(z)=\frac{u_{*}}{\kappa}\left(\ln \frac{z}{z_{0}}-\psi\left(\frac{z}{L}\right)+\psi\left(\frac{z_{0}}{L}\right)\right)
$$

Dónde $\psi$ representa una función universal que depende solo de $z / L$, siendo $L$ una escala de la estabilidad atmosférica, denominada longitud de Obukhov:

$$
L=\frac{T_{0} u_{*}^{3}}{\kappa g H}
$$

siendo:

$\mathrm{T}_{0}$ : Temperatura de referencia $(\mathrm{K})$

$\mathrm{g}$ : aceleración de la gravedad $\left(\mathrm{m} / \mathrm{s}^{2}\right)$

$\mathrm{H}$ : densidad de flujo de calor sensible $\left(\mathrm{W} / \mathrm{m}^{2}\right)$ 
Si $L<0$ la estratificación será inestable, si $L>0$ será estable y, finalmente, si $L=\infty$ las condiciones serán neutras. $L$ representa el espesor de la capa límite hasta donde predominan los efectos de fricción o cizalla, se tiene que para $z \ll|L|$, los efectos de cizalla se consideran predominantes, mientras que para $z \gg|L|$, la turbulencia generada por los procesos térmicos predomina frente al efecto de cizalla (Arya, 2001).

\section{- Perfil vertical de temperatura}

El flujo de calor en la superficie del suelo puede escribirse:

$$
q \approx-\rho c_{p} K_{h}\left(\frac{\partial \theta}{\partial z}\right)
$$

siendo:

$\mathrm{C}_{\mathrm{p}}$ : calor específico a presión constante $(\mathrm{W} / \mathrm{kgK})$

$\mathrm{K}_{\mathrm{h}}$ : difusividad turbulenta de calor $\left(\mathrm{m}^{2} / \mathrm{s}\right)$

$\theta$ : temperatura potencial $(\mathrm{K})$

La temperatura potencial $\theta$ se define como la temperatura que una parcela de aire seco a una presión $\mathrm{P}$ y temperatura $\mathrm{T}$ tendría, si fuera comprimida o expandida adiabáticamente hasta una presión de referencia $\mathrm{P}_{0}$ (normalmente 1000 mbar):

$$
\theta=T\left(\frac{P_{0}}{P}\right)^{R / C_{p}}
$$

siendo $\mathrm{R}$ la constante de los gases ideales.

En cuanto a la difusividad turbulenta de calor, ésta puede expresarse de manera similar a la $\mathrm{K}_{\mathrm{m}}$ :

$$
K_{h}=\frac{\kappa u_{* z}}{\phi_{h}}
$$

donde como en la ecuación (6), $\phi_{\mathrm{h}}$ es una corrección por estabilidad.

Procediendo de manera análoga al caso de la transferencia de cantidad de movimiento, se llega a la ecuación que describe el perfil de temperaturas en la CLA, en la que, como en el caso del perfil de velocidades de viento, surge una función de corrección por estabilidad atmosférica $\Psi_{\mathrm{h}}$.

$$
\theta(z)=\theta_{0}+\frac{\theta_{*}}{\kappa}\left(\ln \frac{z}{z_{0}}-\psi_{h}\left(\frac{z}{L}\right)+\psi_{h}\left(\frac{z_{0}}{L}\right)\right)
$$

donde $\theta$ se define como:

$$
\theta_{*}=\frac{q}{\rho c_{p} u_{*}}
$$




\subsubsection{Cálculo de la dispersión de contaminantes}

\subsubsection{Ecuación fundamental de la dispersión}

En contaminación atmosférica, la ecuación fundamental que rige su evolución espacial y temporal es la conocida como ecuación de advección-difusión que representa la conservación de la masa de contaminante, aplicada bajo los condicionantes de un fluido en régimen turbulento como es la atmósfera. Esto supone que las variables relativas a la concentración de un contaminante y el vector velocidad del viento, observadas en un volumen determinado y en un intervalo de tiempo concreto, presentan una componente aleatoria no despreciable, superpuesta a una componente media.

Prácticamente todos los modelos de dispersión atmosférica de contaminantes se basan, al menos implícitamente, en la ecuación de conservación de la masa (Versteeg y Malalasekera, 1995):

$$
\frac{\partial c}{\partial t}+\frac{\partial u c}{\partial x}+\frac{\partial v c}{\partial y}+\frac{\partial w c}{\partial z}=Q
$$

en la que:

$c=c(x, y, z, t)$ es la concentración del contaminante considerado,

$x, y, z, t$ son las coordenadas cartesianas espacio-temporales,

$u, v$ y $w$ son las componentes de la dirección del viento en el sistema cartesiano considerado, y $Q=Q(x, y, z, t)$ es la tasa de emisión del contaminante, que puede tener una distribución arbitraria en el tiempo y en el espacio.

La única aproximación que se ha adoptado en la ecuación (14) es despreciar la difusión molecular. Esta aproximación es válida en tanto en cuanto la dispersión de contaminantes atmosféricos se produce por procesos turbulentos. La turbulencia se manifiesta en forma de oscilaciones de las propiedades en torno a un valor promedio. Esta noción puede expresarse de manera simplificada por medio de la descomposición de Reynolds (Versteeg y Malalasekera, 1995):

$$
\begin{aligned}
c & =\bar{c}+c^{\prime} \\
u & =\bar{u}+u^{\prime} \\
v & =\bar{v}+v^{\prime} \\
w & =\bar{w}+w^{\prime}
\end{aligned}
$$

En esta descomposición se asume que los valores instantáneos de las propiedades, por ejemplo, de la magnitud $a$, vienen dados por la suma de dos componentes: una componente promedio $\bar{a}$, de lenta evolución, y una componente turbulenta $a^{\prime}$, en rápida variación, tal que $\overline{a^{\prime}}=0$.

Sustituyendo las ecuaciones (15) en la ecuación (14), se llega a:

$$
\frac{\partial \bar{c}}{\partial t}+\bar{u} \frac{\partial \bar{c}}{\partial x}+\bar{v} \frac{\partial \bar{c}}{\partial y}+\bar{w} \frac{\partial \bar{c}}{\partial z}+\frac{\partial \overline{u^{\prime} c^{\prime}}}{\partial x}+\frac{\partial \overline{v^{\prime} c^{\prime}}}{\partial y}+\frac{\partial \overline{w^{\prime} c^{\prime}}}{\partial z}=Q
$$


Los términos $\overline{u^{\prime} c^{\prime}}, \overline{v^{\prime} c^{\prime}}$ y $\overline{w^{\prime} c^{\prime}}$ (denominados generalmente como tensiones de Reynolds), constituyen la contribución turbulenta a la difusión, y representan el transporte neto de masa debido a las fluctuaciones del campo de velocidades y concentraciones.

Debido a la complejidad que encierran los procesos turbulentos, se suele recurrir a aproximaciones para su determinación. La aproximación habitualmente empleada en los estudios de dispersión atmosférica es la de Boussinesq (Versteeg y Malalasekera, 1995):

$$
\begin{aligned}
& \overline{u^{\prime} c^{\prime}} \approx-K_{x} \frac{\partial \bar{c}}{\partial x} \\
& \overline{v^{\prime} c^{\prime}} \approx-K_{y} \frac{\partial \bar{c}}{\partial y} \\
& \overline{w^{\prime} c^{\prime}} \approx-K_{z} \frac{\partial \bar{c}}{\partial z}
\end{aligned}
$$

$K_{x}, K_{y}$ y $K_{z}$ son difusividades turbulentas en cada una de las direcciones (el subíndice indica la dirección).

Sustituyendo (17) en (16) y prescindiendo en adelante de la barra para indicar los valores promedio se llega finalmente a la expresión (Pasquill y Smith, 1983):

$$
\frac{\partial c}{\partial t}+u \frac{\partial c}{\partial x}+v \frac{\partial c}{\partial y}+w \frac{\partial c}{\partial z}=\frac{\partial}{\partial x} K_{x} \frac{\partial c}{\partial x}+\frac{\partial}{\partial y} K_{y} \frac{\partial c}{\partial y}+\frac{\partial}{\partial z} K_{z} \frac{\partial c}{\partial z}+Q
$$

Esta ecuación constituye el punto de partida de la mayoría de modelos de dispersión atmosférica, los cuales se deducen mediante una serie de suposiciones y aproximaciones adicionales, sin las cuales la resolución de la ecuación (18) exige utilizar técnicas numéricas.

Queda pendiente definir las condiciones de contorno necesarias para resolver la ecuación (18). Las condiciones de contorno para un contaminante que se emite en un entorno en el que el suelo (ubicado en $z=0$ ) es esencialmente plano pueden escribirse (Llewelyn, 1982):

$$
\begin{gathered}
c(\infty, y, z, t)=0 \\
c(-\infty, y, z, t)=0 \\
c(x, \infty, z, t)=0 \\
c(x,-\infty, z, t)=0 \\
c(x, y, \infty, t)=0 \\
w c(x, y, 0, t)+K_{z} \frac{\partial c}{\partial z}(x, y, 0, t)=w_{d} c(x, y, 0, t)
\end{gathered}
$$

donde $w_{\mathrm{d}}$ es la velocidad de deposición del contaminante. Estas condiciones de contorno sencillamente implican que a una distancia infinita de la fuente la concentración es cero, mientras que en el suelo existe una cierta deposición. 


\subsubsection{Modelos de cálculo de la dispersión de contaminantes atmosféricos}

Los modelos de dispersión permiten describir matemáticamente los procesos implicados en la dispersión de contaminantes que suceden en la atmósfera, proporcionando la relación entre las emisiones y las concentraciones registradas en un receptor o en un área determinada. Existe una amplia gama de modelos o algoritmos matemáticos capaces de reproducir situaciones de dispersión de contaminantes; la elección de uno u otro depende de varios factores, entre los que tienen especial importancia (Barratt, 2013):

- Características de las fuentes emisoras (continuas o intermitentes, estacionarias o no estacionarias, canalizadas o difusas, etc.).

- Naturaleza del contaminante (gases, partículas, tamaño de partícula, etc.).

- Situación topográfica y tamaño del área considerada.

- Período de tiempo que se desea simular.

- Tamaño del dominio de interés.

En la clasificación de modelos de dispersión de contaminantes realizada en el presente trabajo, únicamente se han considerado los modelos que parten, al menos implícitamente, de la ecuación (14) por ser los más habituales.

Los modelos matemáticos de dispersión de contaminantes en la atmósfera pueden clasificarse en función de diferentes aspectos (Torres et al., 1991):

- Los modelos forman dos clases importantes: analíticos y numéricos. En los modelos analíticos, el campo de concentraciones viene dado por fórmulas matemáticas sencillas, las cuales se han obtenido por integración de alguna versión simplificada de la ecuación (18). Estos modelos se apoyan en parámetros definidos y obtenidos de manera empírica, tales como los coeficientes de dispersión de los contaminantes. Los más utilizados actualmente, tanto por su facilidad de aplicación como por el tiempo requerido para su solución, son los de tipo gaussiano. Los modelos numéricos consisten en la integración, por métodos numéricos, de la ecuación (18). En consecuencia, no requieren adoptar tantas simplificaciones, pero se necesita mucha mayor potencia de cálculo.

- A su vez, los modelos pueden ser estacionarios o transitorios, dependiendo si el tiempo está explícito en su formulación.

- El marco de referencia de los modelos, excepto para algunos modelos empíricos, es un sistema de coordenadas $x, y, z$. El marco es euleriano si el sistema de referencia es fijo, $y$ lagrangiano si el sistema de referencia se fija en una nube de contaminantes que se mueven en la dirección del viento predominante. 


\subsubsection{Soluciones analíticas: modelos gaussianos y no gaussianos}

\section{- Modelos gaussianos}

Existen modelos gaussianos tanto para fuentes instantáneas como para fuentes estacionarias. Los modelos MELPUFF y CALPUFF pertenecen a esta categoría.

El modelo gaussiano para fuentes instantáneas se obtiene a partir de la ecuación de la dispersión (18), adoptando las siguientes hipótesis (Turner, 1970):

- Fuente puntual e instantánea.

- Perfil de velocidades uniforme y estacionario, lo que significa que $u=c t e$ y $v=w=w_{d}=0$.

- Difusividades turbulentas constantes en el tiempo y el espacio.

La solución analítica de la ecuación diferencial de la dispersión para fuentes instantáneas es:

$$
c(x, y, z, t)=\frac{Q}{(2 \pi)^{3 / 2} \sigma_{y}^{2} \sigma_{z}} \exp \left(-\frac{(x-u t)^{2}+y^{2}}{2 \sigma_{y}^{2}}\right)\left(\exp \left(-\frac{(z-h)^{2}}{2 \sigma_{z}^{2}}\right)+\exp \left(-\frac{(z+h)^{2}}{2 \sigma_{z}^{2}}\right)\right)
$$

Entre los modelos concebidos bajo estas hipótesis se identifica el modelo MELPUFF, el cual simula el transporte atmosférico de contaminantes como una serie de nubes con una distribución gaussiana de concentración.

En el caso de modelos gaussianos para fuentes estacionarias, se parte también de la ecuación (18) y se toman además las siguientes hipótesis (Turner, 1970):

- Estado estacionario; esto es, $\frac{\partial c}{\partial t}=0$.

- Se desprecia la difusión en la dirección del viento; lo que implica, $\frac{\partial}{\partial x} K_{x} \frac{\partial c}{\partial x} \approx 0$.

- Las difusividades turbulentas restantes sólo dependen de la distancia a la fuente en la dirección del viento; es decir $K_{y}=K_{y}(x)$ y $K_{z}=K_{z}(x)$.

En el caso de fuentes estacionarias, la ecuación de la dispersión también puede integrarse analíticamente, obteniendo como resultado:

$$
c(x, y, z)=\frac{Q}{2 \pi u \sigma_{y} \sigma_{z}} \exp \left(-\frac{y^{2}}{2 \sigma_{y}^{2}}\right)\left(\exp \left(-\frac{(z-h)^{2}}{2 \sigma_{z}^{2}}\right)+\exp \left(-\frac{(z+h)^{2}}{2 \sigma_{z}^{2}}\right)\right)
$$

La principal ventaja de las fórmulas gaussianas es su extrema sencillez. Es probablemente por este motivo que la mayoría de los programas de ordenador para la simulación de la dispersión atmosférica estén basados en estas fórmulas. Además, las fórmulas gaussianas dependen de muy pocos parámetros: básicamente de los parámetros de dispersión $\sigma_{y}$ y $\sigma_{z}$. 
En general, los modelos gaussianos estacionarios tienen importantes limitaciones, que deben tenerse en cuenta (Ministry for the Environment, 2004):

- Asumen que los contaminantes son transportados en línea recta, de forma instantánea como un haz de luz- hasta el receptor, cuando en realidad este transporte puede llevar varias horas.

- Fallan bajo condiciones de baja velocidad del viento o condiciones de calma, prediciendo concentraciones más altas, como consecuencia de haber despreciado $\frac{\partial}{\partial x} K_{x} \frac{\partial c}{\partial x}$.

- Consideran que la atmósfera es uniforme en todo el dominio, y que las condiciones de transporte y dispersión existentes permanecen invariables hasta que el contaminante alcanza al receptor. Como se ha comentado anteriormente, en la atmósfera real no se dan estas condiciones uniformes (apartado 1.4.1).

Por tanto, una debilidad manifiesta de los modelos gaussianos es que ignoran, desde su planteamiento, la estructura de la CLA. No obstante, es posible evitar algunas de las limitaciones de los modelos gaussianos utilizando modelos avanzados que suelen realizar complejas parametrizaciones. Los modelos gaussianos modernos, cuyos máximos exponentes son CALPUFF (Scire et al., 2000) y AERMOD (Cimorelli et al., 2005), intentan incorporar los avances en la parametrización de la CLA en el marco gaussiano.

\section{- Modelos no gaussianos}

Existen un buen número de modelos que incorporan ciertas características que no se tienen en cuenta en la deducción de las fórmulas gaussianas. Salvo algunas excepciones, no han tenido una gran repercusión práctica. En esta sección se enumeran aquellos que se han considerado relevantes.

En primer lugar, con el objeto de demostrar la complejidad añadida de las soluciones resultantes, se presenta la solución de la ecuación de dispersión propuesta en el modelo de Ermak (1977), el cual con respecto al modelo gaussiano incorpora la deposición del contaminante:

$$
\begin{aligned}
c(x, y, z)= & \frac{Q}{2 \pi u \sigma_{y} \sigma_{z}} \exp \left(-\frac{y^{2}}{2 \sigma_{y}}\right) \exp \left(-\frac{w(z-h)}{2 K_{z}}-\frac{w \sigma_{z}^{2}}{8 K_{z}^{2}}\right)\left(\exp \left(-\frac{(z-h)^{2}}{2 \sigma_{z}^{2}}\right)+\right. \\
& \left.+\exp \left(-\frac{(z-h)^{2}}{2 \sigma_{z}^{2}}\right)-\sqrt{2 \pi} \exp \left(\frac{W(z+h)}{K_{z}}-\frac{W^{2} \sigma_{z}^{2}}{2 K_{z}}\right) \operatorname{erfc}\left(\frac{W \sigma_{z}}{\sqrt{2} K_{z}}+\frac{z+h}{\sqrt{2} \sigma_{z}}\right)\right)
\end{aligned}
$$

La expresión obtenida pone de manifiesto la complejidad adicional de los modelos no gaussianos respecto a las expresiones obtenidas bajo las premisas de los modelos gaussianos.

Los modelos indicados hasta este punto parten del supuesto de un perfil de velocidades uniforme, lo que, como se ha visto, no se ajusta a la realidad cuando las emisiones se generan en la capa superficial de la atmósfera. 
Por el contario, Smith (1957) y Pasquill (1974) definieron tanto $u$ como $K_{y}$ y $K_{z}$ como funciones potenciales de $z$. Posteriormente, van Ulden (1978) demostró que, si se ajustan las funciones potenciales de manera que éstas reproduzcan adecuadamente los perfiles derivados de la teoría de $\mathrm{M}-\mathrm{O}$, este esquema resulta una aproximación excelente de la realidad.

Finalmente, entre los modelos no gaussianos, debe destacarse los trabajos de Lin y Hildemann (1996 y 1997). En estos artículos se combina la existencia de perfiles verticales para $u$ y $K_{z}$, junto con la presencia de deposición y una capa elevada de inversión (para la que $\frac{\partial c}{\partial z}=0$ ). Las expresiones resultantes son muy complicadas.

\section{- Soluciones numéricas}

En el apartado precedente ha quedado claro que, a medida que se incorporan características relevantes en el proceso de dispersión atmosférica se consigue un mejor acuerdo con la realidad, pero con el precio de involucrar expresiones que, aunque sean de forma cerrada, son en general poco manejables y susceptibles de conducir a errores de programación.

Una alternativa a los modelos analíticos consiste en recurrir a los métodos numéricos, los cuales permiten mantener la formulación original, esencialmente simple, sin recurrir a aproximaciones. La principal desventaja de estos métodos es que requieren varios órdenes de magnitud más de tiempo de cálculo y de memoria necesaria.

Los métodos numéricos se han venido utilizando para resolver la ecuación (18), pero de una manera dispersa y generalmente limitada a simulaciones de 2D. Entre los trabajos realizados en este sentido pueden citarse Runca y Sardei (1975), Belot et al. (1976) y Nieuwstadt y van Ulden (1978).

Más recientemente, Qian y Venkatram (2011) pusieron de manifiesto el enorme potencial de las soluciones numéricas de la ecuación del transporte. Se comprobó que combinando ésta con la teoría de $\mathrm{M}-\mathrm{O}$ se obtienen mejores estimaciones de las observaciones realizadas durante la ejecución de una serie de experimentos en campo, Pairie Grass Experiment (Barad, 1958), que las obtenidas con el modelo AERMOD, habiéndose ajustado los parámetros de este último con los datos del Pairie Grass Experiment.

\subsubsection{Métodos para la estimación de los parámetros de dispersión}

En el presente apartado, se muestran los principales métodos para la determinación de los parámetros de dispersión. Estos se han clasificado como métodos empíricos, métodos basados en el teorema de Taylor y métodos que incorporan la teoría de M-O.

\section{- Métodos empíricos}

En general, en los métodos empíricos, los parámetros de dispersión han sido obtenidos como una función del tipo de estratificación atmosférica y de la distancia, siendo los métodos empíricos más conocidos los desarrollados por Pasquill (1961), Gifford (1961) y Turner (1970).

Pasquill (1961) presentó un conjunto de curvas empíricas para $\sigma_{y}$ y $\sigma_{z}$, en función de $x$, para varias categorías de estabilidad atmosférica, asumiendo una distribución gaussiana de la concentración.

Las curvas se obtuvieron a partir de las observaciones de los experimentos ejecutados durante el Prairie Grass Experiment en Nebraska en 1956. En la mayoría de experimentos se consideraban emisiones continuas desde el suelo, sin efecto de flotabilidad, distancias desde las fuentes no 
superiores a $1 \mathrm{~km}$, terrenos llanos con baja vegetación, tiempos promedios de muestreo de 3 a 10 minutos y vientos estacionarios (Barad, 1958).

Con el fin de identificar el tipo de estratificación atmosférica, Pasquill (1961) clasificó las diferentes situaciones meteorológicas en seis categorías, en función de parámetros de observación macróscopica que permiten determinar el tipo de estratificación. Asimismo, propuso un sistema general para la estimación de estas categorías en función de la velocidad del viento, la insolación (durante el día) y la nubosidad (durante la noche). Las clases A, B y C corresponden a condiciones inestables en las que la difusión turbulenta es debida principalmente a la existencia de corrientes de flotación. El flujo de calor sensible bajo estas condiciones es ascendente. La clase A corresponde a la situación más inestable y está asociada a una velocidad de dispersión elevada; los valores de $\sigma_{y}$ y $\sigma_{z}$ para una distancia dada decrecen al pasar de las clases A a C. La clase D corresponde a condiciones neutras donde la difusión turbulenta está dominada por el efecto de cizalla del viento. Las clases E y $\mathrm{F}$ están asociadas a condiciones estables, siendo la clase $\mathrm{F}$ la que presenta una velocidad de dispersión menor.

Gifford (1961) y, especialmente, Turner (1970) modificaron y difundieron este esquema y, por este motivo, frecuentemente se las conoce como curvas de Pasquill-Gifford-Turner (PGT).

Las categorías de estabilidad atmosférica, según Turner (1970), vienen recogidas en la Tabla 1.25, estableciéndose una metodología sencilla para determinar la clase de estabilidad a partir de datos cualitativos, así como los coeficientes de dispersión a partir de las curvas de PGT, una vez determinada la clase de estabilidad aplicable.

Tabla 1.25. Clases de estabilidad atmosférica según Turner (1970).

\begin{tabular}{|c|c|c|c|c|c|}
\hline \multirow{3}{*}{$\mathrm{u}_{10^{(1)}}(\mathrm{m} / \mathrm{s})$} & \multicolumn{3}{|c|}{ Día } & \multicolumn{2}{|c|}{ Noche } \\
\hline & \multicolumn{3}{|c|}{ Radiación solar } & \multirow{2}{*}{ Nubosidad baja } & \multirow{2}{*}{ Nubosidad alta } \\
\hline & Fuerte & Moderada & Débil & & \\
\hline$<2$ & A & $A-B$ & B & & \\
\hline $2-3$ & $A-B$ & $B$ & C & $E$ & $\mathrm{~F}$ \\
\hline $3-5$ & B & $B-C$ & C & $\mathrm{D}$ & $E$ \\
\hline $5-6$ & C & $C-D$ & $\mathrm{D}$ & $\mathrm{D}$ & $\mathrm{D}$ \\
\hline$>6$ & C & $\mathrm{D}$ & $\mathrm{D}$ & $\mathrm{D}$ & $\mathrm{D}$ \\
\hline
\end{tabular}

(1): $\mathrm{U}_{10}$ : velocidad del viento a una altura de $10 \mathrm{~m}$.

Con el fin de poder aplicar las curvas de PGT a situaciones en las que no se cumplen las condiciones bajo las que estas han sido obtenidas, diferentes autores propusieron factores de corrección (Singer et al., 1966; McElroy y Pooler, 1971; Gifford, 1976). 


\section{- Métodos basados en el teorema de Taylor}

El teorema de Taylor establece que la capacidad de difusión de la atmósfera puede valorarse estadísticamente mediante la varianza de la posición de un conjunto de partículas al cabo de un cierto tiempo $t$, antes del cual esas partículas estaban localizadas en un origen común.

En este sentido, si se analizan estadísticamente las trayectorias del conjunto de partículas en el seno de un medio fluido con turbulencia homogénea (las fluctuaciones de velocidad no dependen de la posición), se puede obtener la desviación estándar de sus posiciones transcurrido un cierto tiempo y, por tanto, cuánto se han dispersado. Basándose en este principio, Taylor (1921) expresó estas ideas en términos matemáticos:

$$
\sigma_{y}^{2}=2 \sigma_{v}^{2} \int_{0}^{\tau} \int_{0}^{t} R_{\xi} \mathrm{d} \xi \mathrm{d} t
$$

siendo:

$\sigma_{y}$ : desviación estándar del camino recorrido por las partículas en el eje $y\left(\mathrm{~m}^{2} / \mathrm{s}^{2}\right)$

$\sigma_{v}:$ desviación estándar de $v\left(=\sqrt{\overline{v^{\prime 2}}}\right)(\mathrm{m} / \mathrm{s})$

$R_{\xi}:$ es el coeficiente de autocorrelación de $v^{\prime}\left(=\frac{\overline{v^{\prime}(t) v^{\prime}(t+\xi)}}{\sigma_{v}^{2}}\right)$

$\tau$ : tiempo de difusión (s)

Hanna et al. (1977) reescribieron el teorema de Taylor de una manera mucho más conveniente:

$$
\sigma_{y}=\sigma_{v} \tau f(\tau)
$$

donde $f(\tau)$ es una función adimensional, de la que se conocen sus valores límite:

- en las proximidades de la fuente (near-field limit):

$$
\lim _{\tau \rightarrow 0} f(\tau)=1
$$

- en la lejanía de la fuente (far-field limit):

$$
\lim _{\tau \rightarrow \infty} f(\tau) \propto \tau^{-1 / 2}
$$

El coeficiente de autocorrelación parte de un valor de 1 y alcanza el valor cero para tiempos de difusión largos. Por tanto, en las proximidades de la fuente se puede considerar que el crecimiento de la pluma es lineal con respecto al tiempo de difusión, mientras que para tiempos largos es proporcional a la raíz cuadrada de $\tau$. No obstante, el conocimiento exacto del comportamiento de la función de autocorrelación en un tiempo intermedio, durante un tiempo de difusión $\tau$, es difícil de determinar teóricamente. Los investigadores han intentado que las fórmulas empíricas para determinar $\sigma_{y}$ y $\sigma_{z}$ sean coherentes con los valores límite del teorema de Taylor. Por ejemplo, Briggs (1973) propuso unas fórmulas de interpolación que combinaban las curvas de PGT junto con otras 
curvas empíricas, intentando además que la forma de estas curvas fuera consistente con el teorema de Taylor (es decir, que $\lim _{x \rightarrow 0} \sigma_{y} \propto x$ y $\lim _{x \rightarrow \infty} \sigma_{y} \propto x^{1 / 2}$ ). Asimismo, distinguió entre entornos urbanos y rurales. En la Tabla 1.26 se presentan las expresiones para el cálculo de $\sigma_{\mathrm{y}}$ y $\sigma_{\mathrm{z}}$ en entornos rurales según Briggs.

Tabla 1.26 Curvas de Briggs para el cálculo de $\sigma_{y}$ y $\sigma_{z}$ en entornos rurales.

\begin{tabular}{|c|c|c|}
\hline Estabilidad & $\sigma_{y}(\mathbf{m})$ & $\sigma_{z}(\mathbf{m})$ \\
\hline $\mathrm{A}$ & $0.22 \times(1+0.0001 \mathrm{x})^{-1 / 2}$ & $0.20 \mathrm{x}$ \\
\hline $\mathrm{B}$ & $0.16 \mathrm{x}(1+0.0001 \mathrm{x})^{-1 / 2}$ & $0.12 \mathrm{x}$ \\
\hline $\mathrm{C}$ & $0.11 \times(1+0.0001 \mathrm{x})^{-1 / 2}$ & $0.08 \times(1+0.0002 \mathrm{x})^{-1 / 2}$ \\
\hline $\mathrm{D}$ & $0.08 \times(1+0.0001 \mathrm{x})^{-1 / 2}$ & $0.06 \times(1+0.0015 \mathrm{x})^{-1 / 2}$ \\
\hline $\mathrm{E}$ & $0.06 \mathrm{x}(1+0.0001 \mathrm{x})^{-1 / 2}$ & $0.22 \times(1+0.0003 \mathrm{x})^{-1}$ \\
\hline $\mathrm{F}$ & $0.04 \times(1+0.0001 \mathrm{x})^{-1 / 2}$ & $0.22 \times(1+0.0003 \mathrm{x})^{-1}$ \\
\hline
\end{tabular}

Otros autores, como Draxler (1976) e Irwin (1983) han obtenido expresiones empíricas para determinar $f(\tau)$ que pueden expresarse de forma generalizada como:

$$
f(\tau)=\frac{1}{1+\left(\tau / 2 \tau_{L}\right)^{1 / 2}}
$$

donde $\tau_{L}$ es la escala de tiempo Lagrangiana. Esta magnitud cuantifica la transición entre las dos situaciones límite indicadas anteriormente.

En esta línea, es remarcable el trabajo de Eckman (1994), quien argumentó que los valores obtenidos de $\tau_{\llcorner}$no tenían justificación teórica. En este sentido, observó que a las distancias a las que se realizaban las observaciones todavía no se debería haber producido la transición entre el near-field y el far-field limit, y atribuyó los valores aparentes de $\tau_{\llcorner}$al hecho de haber ignorado el perfil vertical de velocidades para calcular $\tau$. Suponiendo que en las situaciones prácticas siempre se cumple la condición de near-field limit, y teniendo en cuenta el perfil de viento dado por la teoría de M-O, Eckman pudo obtener teóricamente coeficientes de dispersión mejores que los que Pasquill Gifford (1961) o Irwin (1983) habían obtenido por ajuste de los datos experimentales.

\section{- Métodos que incorporan la teoría de Monin-Obukhov}

Hasta el momento, la mayoría de las ecuaciones presentadas para el cálculo de $\sigma_{\mathrm{y}}$ y $\sigma_{\mathrm{z}}$ dependen únicamente de manera explícita de la distancia a la fuente e implícitamente de una clasificación cualitativa de la estabilidad atmosférica.

No obstante, muchos modelos modernos de dispersión, incorporan de manera explícita ciertos parámetros relacionados con la estabilidad atmosférica en las fórmulas para calcular $\sigma_{\mathrm{y}}$ y $\sigma_{\mathrm{z}}$. Dichas formulaciones son función de variables micrometeorológicas, tales como la $u_{*}$ y la $L$. 
Por ejemplo, el modelo AERMOD (Cimorelli, 2005), diseñado para el tratamiento de emisiones continuas, incorpora los avances en la parametrización de la CLA dentro del marco gaussiano. En este sentido, el modelo considera que las condiciones meteorológicas son estacionarias durante el periodo de promedio (1h) y horizontalmente homogéneas. Sin embargo, tiene en cuenta las variaciones verticales de los parámetros meteorológicos en la CLA.

Si bien el grado de mejora alcanzado con estas fórmulas con respecto a las curvas de PGF es sustancial, se ha demostrado que los modelos que incorporan la teoría de M-O en su concepción proporcionan en muchos casos mejores resultados (Qian y Venkatram, 2011), además de resultar más sencillos en cuanto a formulación.

Por otro lado, AERMOD requiere de una gran cantidad de información meteorológica como datos de entrada al modelo, incluyendo además de la $u_{*}$ y la $L$, la velocidad convectiva ( $\left.w_{*}\right)$, gradiente vertical de temperatura potencial, altura de la capa límite convectiva, altura de la capa límite mecánica, rugosidad de la superficie, velocidad y dirección del viento, temperatura, desviación estándar de la dirección y velocidad del viento.

\subsubsection{Método de cálculo de tasas de emisión}

La ecuación en derivadas parciales (18) es lineal respecto de las concentraciones. Esto implica que, si $\chi_{1}(x, y, z, t)$ es una solución para una emisión $Q_{1}(x, y, z, t)$ y $\chi_{2}(x, y, z, t)$ lo es para $Q_{2}(x, y, z, t)$ , $\lambda_{1} \chi_{1}(x, y, z, t)+\lambda_{2} \chi_{2}(x, y, z, t)$ es una solución para la emisión $\lambda_{1} Q_{1}(x, y, z, t)+\lambda_{2} Q_{2}(x, y, z, t)$, donde $\lambda_{1}$ y $\lambda_{2}$ son escalares arbitrarios (Calder, 1977).

Esta propiedad se conoce como principio de superposición y es muy importante pues posibilita la determinación de tasas de emisión mediante el método basado en cálculos de dispersión (RDM) de una manera muy directa.

La utilidad de esta propiedad se comprende mejor con un ejemplo. Supóngase que se tiene un escenario en el que intervienen $p$ fuentes, con una determinada tasa de emisión desconocida, y se toman $m$ datos de concentración en $n$ posiciones distintas. La manera de proceder empezaría suponiendo una tasa de emisión unitaria para todas las fuentes, obteniendo como resultado una matriz de concentraciones calculadas para cada fuente aislada que podría componerse en la siguiente forma:

$$
\left[\begin{array}{cccc}
\chi_{111} & \chi_{112} & \cdots & \chi_{11 p} \\
\chi_{211} & \chi_{212} & \cdots & \chi_{21 p} \\
\vdots & \vdots & & \vdots \\
\chi_{m 11} & \chi_{m 12} & \cdots & \chi_{m 1 p} \\
\vdots & \vdots & & \vdots \\
\chi_{1 n 1} & \chi_{1 n 2} & \cdots & \chi_{1 n p} \\
\chi_{2 n 1} & \chi_{2 n 2} & \cdots & \chi_{2 n p} \\
\vdots & \vdots & & \vdots \\
\chi_{m n 1} & \chi_{m n 2} & \cdots & \chi_{m n p}
\end{array}\right]
$$

Según el principio de superposición, si se multiplica cada una de las columnas de esta matriz por una serie de coeficientes podría obtenerse el vector de concentraciones experimentales: 


$$
\left[\begin{array}{cccc}
\chi_{111} & \chi_{112} & \cdots & \chi_{11 p} \\
\chi_{211} & \chi_{212} & \cdots & \chi_{21 p} \\
\vdots & \vdots & & \vdots \\
\chi_{m 11} & \chi_{m 12} & \cdots & \chi_{m 1 p} \\
\vdots & \vdots & & \vdots \\
\chi_{1 n 1} & \chi_{1 n 2} & \cdots & \chi_{1 n p} \\
\chi_{2 n 1} & \chi_{2 n 2} & \cdots & \chi_{2 n p} \\
\vdots & \vdots & & \vdots \\
\chi_{m n 1} & \chi_{m n 2} & \cdots & \chi_{m n p}
\end{array}\right]\left[\begin{array}{c}
\lambda_{1} \\
\lambda_{2} \\
\vdots \\
\lambda_{p}
\end{array}\right]=\left[\begin{array}{c}
c_{11} \\
c_{21} \\
\vdots \\
c_{m 1} \\
\vdots \\
c_{1 n} \\
c_{2 n} \\
\vdots \\
c_{m n}
\end{array}\right]
$$

Puesto que se ha escogido una tasa de emisión unitaria, estos coeficientes son precisamente las tasas de emisión de cada fuente $\left[\begin{array}{llll}Q_{1} & Q_{2} & \cdots & Q_{p}\end{array}\right]^{T}$, por lo que se puede reescribir (29)29) en forma matricial:

$$
[\chi][\mathbf{Q}]=[\mathbf{c}]
$$

En principio, serían necesarias solamente $p$ medidas de concentración en un único punto para poder determinar $[\mathbf{Q}]$. No obstante, debido a errores, tanto experimentales como del modelo utilizado para calcular $[\chi]$, es conveniente realizar muchas medidas en varios puntos, de manera que el sistema (30) pase a estar sobredeterminado. En tal caso, el método más simple para obtener una estimación de $[\mathbf{Q}]$ es mediante el uso de mínimos cuadrados ordinarios. 

2 Estado del arte, motivaciones,
objetivos y alcance 



\subsection{Estado del arte}

Con el fin de plantear los objetivos y el alcance del presente estudio, se considera oportuno contextualizar el marco legislativo, socio-económico y científico-técnico en el cual se circunscribe. Si bien estos aspectos han sido comentados ampliamente en la introducción, a continuación, se resumen los temas más relevantes que identifican las principales carencias en cuanto al estudio de las emisiones difusas de PM y sugieren la necesidad del trabajo realizado.

\subsubsection{Marco legislativo}

La legislación en materia de protección del ambiente atmosférico se ha desarrollado para la consecución de los siguientes objetivos: i) proteger a la población, los ecosistemas y bienes de cualquier naturaleza manteniendo una calidad del aire adecuada y, ii) eliminar o reducir las emisiones de contaminantes atmosféricos, mediante la identificación e implementación de las medidas de reducción más efectivas y el establecimiento de valores límite y objetivos.

Sin embargo, a nivel europeo, la aplicación de las políticas actuales no ha sido suficiente para alcanzar los objetivos inicialmente planteados en calidad del aire para PM, especialmente si se considera el contenido de las directrices marcas por la OMS. Por ello, a pesar de los numerosos esfuerzos y mejoras significativas alcanzadas, los graves impactos generados por una deficiente calidad de aire todavía persisten en determinadas áreas urbanas e industriales de Europa (EEA, 2016).

Asimismo, a nivel nacional el Plan Aire (MAGRAMA, 2013) muestra la problemática existente en ciertas zonas de España para cumplir los límites de PM. Para las zonas industriales, identifica tres problemas principales: las emisiones primarias canalizadas, las emisiones difusas y las emisiones de precursores gaseosos que dan lugar a partículas secundarias. El mismo Plan, considera que las primeras son fácilmente controlables, y que en muchas situaciones ya lo están. Sin embargo, para el caso concreto de las emisiones difusas y de precursores gaseosos, se estima necesario una serie de intervenciones adicionales enfocadas a mejorar la calidad del aire en zonas industrializadas con problemas ambientales.

En este sentido, y tal y como refleja el Plan, puede considerarse que la aplicación de las directivas industriales sobre emisiones, para la prevención y control integrado de la contaminación atmosférica, se han centrado principalmente en el control de las emisiones canalizadas de PM. Esta situación puede deberse al mayor grado de información técnica sobre MTD disponible en los BREF para este tipo de emisiones, lo que facilita el establecimiento de criterios de control en las AAI.

Sin embargo, a diferencia de los focos canalizados, y a pesar de que determinados BREF identifican el PM asociado a fuentes difusas como un contaminante significativo, las MTD para este tipo de fuentes se definen de una manera mucho más cualitativa y abierta. Así, por ejemplo, se considera MTD desde la humectación de los materiales pulverulentos hasta el cerramiento parcial o total de las zonas de almacenamiento de dichos materiales. Además, las MTD propuestas carecen de VLE asociados a las mismas.

Esta situación se refleja en el establecimiento de los VLE para focos difusos en las AAI, los cuales tienen su origen en normativa específica para calidad de aire, dando lugar a la introducción de 
diferentes parámetros de control (PSD, PST y PM10) para las emisiones difusas de PM, debido a la ausencia de una metodología de control estandarizada.

Por todo ello, se considera que la realización de estudios técnicos sobre emisiones difusas de PM permitirá disponer de información relevante para tratar este tipo de emisiones con mayor rigor y detalle, de forma que pueda ser aplicada en el desarrollo de futura normativa.

\subsubsection{Marco socio-económico}

En los últimos años, la mayor concienciación ciudadana y sensibilidad en temas ambientales ha desencadenado la realización de estudios de calidad de aire y epidemiológicos, que ponen de manifiesto un destacado impacto de las emisiones de PM sobre la salud.

En este sentido, la legislación europea más reciente sobre calidad del aire, en coherencia con los informes elaborados por la OMS, señala que existe una relación directa entre la exposición al PM y la salud humana, haciendo especial hincapié en el efecto de las fracciones PM10 y PM2.5.

Concretamente, en la UE-28 se ha estimado una pérdida de esperanza de vida debido a las PM2.5 en el aire alrededor de 8 meses, lo que equivale a 3,6 millones de años de vida perdidos anualmente. Si se llevará a cabo la plena aplicación de las políticas existentes, la reducción sería de aproximadamente 5,5 meses (equivalentes a 2,5 millones de años de vida perdidos 0272000 muertes prematuras) (EEA, 2015).

Además, el programa "Aire puro" para Europa (EU, 2013) destaca que la calidad del aire en Europa ha mejorado notablemente en las últimas décadas, pero también que la contaminación atmosférica se mantiene como el principal factor ambiental asociado a las enfermedades evitables y a la mortalidad prematura en la UE, y sigue teniendo efectos negativos en gran parte del medio natural europeo. Así, según la OCDE, la contaminación del aire en las ciudades se convertirá, de aquí a 2050, en la principal causa ambiental de mortalidad en todo el mundo, por delante de las aguas contaminadas y la falta de infraestructuras sanitarias (OCDE, 2012).

Por tanto, las autoridades nacionales y locales necesitan elaborar planes de mejora de la calidad del aire, con el objetivo de establecer estrategias de mitigación óptimas para cumplir con la legislación sobre calidad del aire y protección de la atmósfera, así como con las directrices marcadas por la OMS. Estos planes son instrumentos públicos que permiten informar a la ciudadanía sobre la calidad del aire en zonas específicas que presentan una problemática ambiental.

En este sentido, en determinadas zonas industriales y portuarias de España se han desarrollado planes (zona cerámica de Castellón, zona cerámica de L'Alacantí, zona cerámica de Bailén, zona industrial de Carboneras, zona industrial de Huelva, zona industrial de la Bahía de Algeciras, entre otros), en los que se analiza la problemática asociada a la contaminación por PM y se proponen una serie de medidas preventivas y correctivas. En algunos de los citados planes, se indica que uno de los puntos a mejorar, es disponer de una buena caracterización de las emisiones industriales, para orientar mejor los esfuerzos de aplicación de estrategias de mitigación.

Al respecto, las principales deficiencias que presentan se relacionan principalmente con la consideración de las emisiones difusas de PM, en muchos casos no incluidas en los inventarios de emisiones. Esta situación se debe probablemente a una carencia de información tanto de los FE de fuentes difusas de PM como del rendimiento de medidas correctoras propuestas, enmascarando en 
esta situación el impacto de las emisiones difusas de PM y dificultando la identificación de necesidades de actuación de mejora medioambiental.

Por tanto, un mayor conocimiento sobre las emisiones difusas de PM se traducirá en un control eficaz de este tipo de emisiones por parte de las industrias, autoridades portuarias, administraciones públicas, así como en una mejora de la calidad del aire, la cual repercute directamente en una mejora de la salud de los ciudadanos.

Desde un punto de vista económico, la OCDE prevé que los efectos de la contaminación atmosférica alcanzarán un impacto económico aproximado del $2 \%$ del producto interior bruto europeo en 2060 , provocando una reducción de la acumulación de capital y una desaceleración del crecimiento económico (EEA, 2016).

\subsubsection{Marco científico-técnico}

A pesar del impacto que las emisiones difusas de PM pueden llegar a suponer sobre la calidad de aire, actualmente no existen herramientas apropiadas que permitan abordar su control y cuantificación de una manera precisa.

Esta situación, se debe probablemente a la dificultad que conlleva abordar la cuantificación de las emisiones difusas, tanto por las características que presentan (carácter discontinuo, se generan a alturas relativamente bajas, su tasa de emisión se ve afectada por las condiciones meteorológicas, etc.), como por la complejidad que refleja el tratamiento de determinadas fuentes de emisión en entornos industriales (fuentes móviles). Además, pueden realizarse simultáneamente diferentes operaciones generadoras de emisiones difusas de PM, lo que implica el solapamiento de focos de emisión.

Consecuentemente, las metodologías existentes para la determinación de FE específicos a partir de medidas experimentales, no presentan la flexibilidad necesaria para tratar este tipo de fuentes complejas en entornos industriales. Asimismo, las metodologías que requieren el uso de modelos de dispersión presentan ciertas limitaciones a la hora de considerar la estructura de la capa superficial, región en la que se producen las emisiones difusas de PM.

Esta situación conlleva que para inventariar las emisiones difusas de PM se recurra al uso de FE genéricos. Sin embargo, el uso extendido de estos FE para un conjunto amplio de operaciones de manipulación y de materiales puede conllevar desviaciones importantes en su cuantificación, ya que han sido obtenidos para un conjunto de materiales y operaciones específicas. Además, desde los trabajos iniciales realizados en la década de los setenta para la obtención de los FE recogidos en el documento AP-42 de la US EPA, comparativamente a otro tipo de emisiones, se han llevado a cabo un reducido número de estudios para proponer FE (Vrins et al., 1994; Muleski et al., 2005; Martin et al., 2007; Hosseini y Stockie, 2016). Dicha carencia de información, también se aprecia al analizar los FE propuestos en la guía EMEP/EEA.

Por otro lado, en cuanto a los estudios técnicos sobre eficacias de medidas correctoras, estos no siempre van acompañados de información útil para su correcta aplicación. Por ejemplo, a la implementación del riego y barrido de viales o de la humectación de acopios, generalmente se les asocia un rendimiento de mejora constante. Sin embargo, experimentalmente se ha comprobado que la eficacia asociada a estas medidas presenta una relación directa con el tiempo y, además depende en gran parte del modo de aplicación de las mismas, regularidad con la que se aplican, cantidad de agua utilizada en cada riego, condiciones meteorológicas, etc. 
Por tanto, se considera de gran interés disponer de un mayor grado de detalle, en términos de metodologías de cuantificación, modelos de dispersión, obtención de FE específicos por operación, obtención de rendimientos de mejora asociados a medidas correctoras, no solo para poder realizar una cuantificación más exacta de las emisiones, sino también para identificar qué operaciones son más problemáticas y establecer medidas correctoras apropiadas.

\subsection{Motivaciones del estudio}

Como consecuencia de los diferentes aspectos comentados en el apartado de estado del arte, se considera que el desarrollo de una metodología de cuantificación acorde a las particularidades de las emisiones difusas de PM, y que a su vez sea lo suficientemente flexible para el tratamiento de las fuentes de emisiones difusas propias de entornos industriales, facilitará obtener la consecución de las siguientes acciones:

- Determinar FE de PM específicos por operación y/o material.

- Determinar rendimientos de mejora asociados a las MTD propuestas en los BREF y guías sectoriales.

- Identificar las operaciones más problemáticas en una instalación y establecer medidas correctoras concretas.

- Seleccionar el diseño de las instalaciones que permita minimizar al máximo las emisiones difusas de PM.

- Disponer de información suficientemente específica para la realización de inventarios de emisiones difusas de PM de detalle.

- Cuantificar con mayor exactitud las emisiones difusas de PM, lo que permitirá conocer el impacto real de las mismas.

- Incorporar en los planes de mejora de la calidad del aire las emisiones difusas de PM y proponer estrategias de mitigación óptimas, que permitan alcanzar los estándares de calidad del aire.

- Definir mecanismos de control más apropiados para este tipo de emisiones.

Por tanto, se considera relevante desde un punto de vista legislativo, socio-económico y científicotécnico realizar estudios específicos sobre las emisiones difusas de PM en entornos industriales, con el fin de proponer mecanismos apropiados que permitan dar respuesta a un problema ambiental de gran importancia como es la cuantificación y control de las emisiones difusas de PM. 


\subsection{Objetivos y alcance}

El objetivo principal del presente estudio es desarrollar las herramientas necesarias para la identificación y cuantificación de las emisiones difusas de PM en entornos industriales, cuya aplicación permitirá obtener información de detalle para su prevención, minimización y control. Para alcanzar este objetivo se ha propuesto el desarrollo de las siguientes metodologías:

- Metodología para la elaboración de inventarios de detalle de emisiones difusas de PM, basada en la identificación exhaustiva de operaciones generadoras de este tipo de emisiones a nivel de etapa de proceso y/o de instalación.

- Metodología para la determinación de FE específicos por operación y/o material manipulado, la cual involucra:

- El desarrollo de un modelo específico de dispersión de contaminantes que presente la flexibilidad necesaria para tratar las fuentes de emisiones difusas de PM que se pretenden estudiar.

- La elaboración de un protocolo de ejecución de las campañas experimentales en entornos industriales, que permita introducir de la forma más realista posible la información de entrada requerida por el modelo propuesto.

La aplicación de las diferentes metodologías propuestas a las actividades y fuentes de emisión industriales incluidas dentro del alcance del estudio, permite obtener la siguiente información:

- Identificación de las operaciones generadoras de emisiones difusas de PM en el sector cerámico.

- Determinación de FE y eficacias globales asociadas a las principales tipologías de parques de almacenamiento de materias primas en el sector cerámico.

- Identificación de las MTD para el sector cerámico.

- Determinación de FE específicos para las operaciones y materiales seleccionados.

- Cuantificación de la eficacia del riego con agua y con aditivos en viales no pavimentados y de la variación temporal de su efecto.

El alcance del proyecto se ha definido en base a las diferentes variables de interés para la determinación de FE y disponibilidad de entornos industriales para la aplicación de las metodologías desarrolladas:

- Actividades: cerámicas, plantas de hormigón preparado, canteras de áridos, cementeras y muelles de gestión de graneles sólidos en puertos.

- Operaciones: carga y descarga, embarque y desembarque, circulación por vías asfaltadas y no asfaltadas.

- Materiales: arcilla, arena, clínker, chatarra y sulfato sódico.

- Maquinaria utilizada para la realización de las operaciones estudiadas: máquina pala, cuchara, cinta transportadora, camión tipo bañera y volquete. 


\subsection{Estructura de la tesis}

La memoria de la tesis se presenta con la siguiente estructura:

- El primer capítulo presenta una amplia introducción sobre aspectos generales y efectos del PM, y en especial sobre las características, contribución y métodos de cuantificación de las emisiones difusas de PM en entornos industriales. Asimismo, se realiza una identificación de las principales operaciones generadoras de emisiones difusas de PM para diferentes actividades industriales y se muestra una revisión de los instrumentos normativos aplicables a este tipo de emisiones. Finalmente, se describe la fenomenología de la dispersión para el caso de las emisiones difusas y, se clasifican y evalúan los principales modelos de cálculo de la dispersión atmosférica existentes.

- El segundo capítulo contextualiza el marco legislativo, socio-económico y científicotécnico en el cual se circunscribe el presente trabajo y recoge los objetivos de la investigación, el alcance y, finalmente, la estructura del presente documento.

- En el tercer capítulo se presenta un resumen muy sucinto de las metodologías utilizadas para la consecución de los objetivos propuestos, el detalle de los mismos está en los artículos.

- En el cuarto capítulo se presentan los resultados alcanzados. Dichos resultados se han dividido en dos grandes bloques, los cuales incluyen los cuatro artículos publicados y que describen el presente trabajo de investigación. En cada uno de los bloques se exponen resultados adicionales no incluidos en dichas publicaciones. Finalmente, se realiza una discusión de los resultados obtenidos.

- En el quinto capítulo se muestran las conclusiones generales obtenidas a partir de la realización del presente trabajo. Las conclusiones específicas de cada estudio se recogen en cada uno de los artículos publicados.

- El sexto capítulo muestra las futuras líneas de investigación recomendadas para completar los resultados obtenidos.

- En el capítulo séptimo se presentan las diferentes publicaciones a congresos relacionadas con el trabajo presentado.

- Se ha creído conveniente añadir dos capítulos adicionales con el fin de simplificar la lectura de la memoria de la tesis, dedicados a glosario de términos y acrónimos y anexos.

- En el décimo capítulo, debido a que cada artículo incluye su propia bibliografía, se recoge únicamente la bibliografía citada en los capítulos de introducción, estado del arte, metodología y en el apartado de información adicional y discusión de resultados. 
3 Metodología 



\subsection{Metodologías para la cuantificación de las emisiones difusas de PM}

En el presente trabajo se han aplicado diferentes metodologías para la cuantificación de las emisiones difusas de PM, en función del objetivo planteado: FE globales por tipo de instalación y FE específicos por operación y/o material manipulado.

\subsubsection{Determinación de FE globales en el sector cerámico}

La estimación de FE globales, para diferentes tipologías de parques de almacenamiento de materias primas en el sector cerámico, se ha realizado aplicando la metodología analítica descrita en los artículos nำ1 y nำ. Esta metodología se basa principalmente en realizar un inventario de detalle de las operaciones que generan emisiones difusas de PM y de las medidas correctoras implementadas por operación. Posteriormente, a cada operación identificada se le ha asignado un FE seleccionado de las guías técnicas utilizadas ampliamente para la realización de inventarios de PM (US EPA, 1995; Australian Government, 2012). Asimismo, también se han recopilado los rendimientos de mejora disponibles para las principales medidas correctoras implementadas en el sector cerámico. Los FE y las eficacias propuestas en estas guías se describen ampliamente en la introducción, en el apartado 1.3.3.3 y 1.2.4.3 respectivamente, y los seleccionados para el sector cerámico se presentan en los artículos ํㅜㄴ y ํㅡ.

Previamente a la aplicación de estos FE, se ha evaluado experimentalmente su idoneidad para las principales operaciones y materiales propios del sector cerámico mediante la ejecución de campañas experimentales. Con este fin se ha aplicado el método Roof Monitor, para instalaciones cerradas, y la metodología RDM, junto con el modelo de dispersión de contaminantes gaussiano MELPUFF, para instalaciones abiertas y semicerradas. Ambas metodologías se describen en el apartado 1.2.2 de la introducción, mientras que su aplicación al sector cerámico se detalla en el artículo $\mathrm{n}^{\circ}$ 2. Las tasas de emisión obtenidas experimentalmente se han comparado con las estimadas aplicando los FE seleccionados.

\subsubsection{Equipamiento requerido para la ejecución de las campañas experimentales}

A continuación, se describe el equipamiento requerido para la determinación de la concentración de PM y de las variables meteorológicas en la zona de estudio, información necesaria para la aplicación de las metodologías de cuantificación comentadas en el punto anterior.

\section{- Determinación de la concentración de PM}

Para la determinación de la concentración de PM, con una resolución temporal de 1 minuto, se han utilizado espectrómetros ópticos (GRIMM) que permiten obtener en tiempo real la medida simultánea de las concentraciones ambientales de PM con diferentes tamaños de partículas (PM10, PM2.5 y PM1).

El mecanismo de funcionamiento de este equipo se basa en hacer pasar un caudal conocido de una corriente de aire a través de un cabezal de entrada, para posteriormente medir mediante un detector la dispersión de un haz láser producida por las diferentes partículas (Light-Scattering). 


\section{- Determinación de las variables meteorológicas}

El registro de las variables meteorológicas se ha llevado a cabo mediante el uso de una torre meteorológica Vaisala WXT510, equipada con un anemómetro sónico 2D, el cual determina las componentes horizontales de la velocidad a una altura de $2.5 \mathrm{~m}$ y a una frecuencia de $1 \mathrm{~Hz}$. La precisión de la velocidad es $\pm 3 \%$ y de la dirección $\pm 3^{\circ}$. Además, también se han registrado con esta torre datos de temperatura con una precisión de $\pm 0.3^{\circ} \mathrm{C}$.

\section{- Registro de información de campo}

Las diferentes experiencias realizadas se han grabado en video con el objetivo de poder asignar picos de concentración a operaciones concretas.

\subsubsection{Determinación de parámetros para la aplicación de los FE del AP-42}

Para la aplicación de los FE propuestos en el documento AP-42, expresados en forma de ecuación, es necesario conocer diferentes parámetros: la humedad de los materiales y la velocidad media del viento para la estimación de las emisiones asociadas a operaciones de manipulación; y el contenido y carga de finos en la superficie para calcular las emisiones por resuspensión en viales no asfaltados y asfaltados. Estos se han determinado experimentalmente aplicando las siguientes técnicas:

- Para la determinación del contenido en humedad de las muestras se ha empleado el procedimiento descrito en la norma EN 15051:2006, basado en el secado de la muestra en estufa. La pérdida de masa registrada por el material en dicho proceso de secado se utiliza para calcular su contenido en humedad.

- La velocidad del viento se ha determinado instalando un anemómetro en la zona de estudio.

- Para la determinación del contenido de finos en la superficie se ha recogido el material depositado en aproximadamente $1 \mathrm{~m}^{2}$ de superficie en diferentes zonas de la instalación y posteriormente mediante un vibrotamiz se ha obtenido la fracción inferior a $75 \mu \mathrm{m}$.

\subsubsection{Determinación de FE específicos por operación y/o material}

La metodología propuesta para la determinación experimental de FE específicos se presenta como un resultado del presente trabajo en el artículo 꾸․ Esta metodología, descrita ampliamente en el citado artículo y en el correspondiente apartado de información adicional, se basa en aplicar la metodología RDM junto con un modelo de dispersión de contaminantes desarrollado en el marco del presente trabajo. Asimismo, se ha elaborado un protocolo de ejecución de las campañas experimentales para determinar de forma satisfactoria la información requerida por el modelo.

\subsubsection{Equipamiento requerido para la ejecución de las campañas experimentales}

A continuación, se describe el equipamiento utilizado para la realización de las diferentes campañas:

\section{- Determinación de la concentración de PM}

La concentración de PM, con una resolución temporal de 6 segundos, se ha registrado con contadores ópticos (GRIMM y DUSTRAK). EI DUSTRAK determina la concentración másica de PM10, PM2.5 y PM1 combinando medidas fotométricas de conjuntos de partículas con el recuento óptico de partículas individuales (Wang et al., 2009). El GRIMM se describe en el punto 3.1.1.1.

\section{- Determinación de las variables meteorológicas}

En las diferentes experiencias realizadas se han utilizado los siguientes anemómetros sónicos: 
- $\quad$ Un anemómetro sónico 2D, descrito en el apartado 3.1.1.1.

- Un anemómetro sónico 3D (Delta Ohm HD2003.1) que permite conocer las tres componentes de la velocidad y la temperatura ambiente a una altura de $3.25 \mathrm{~m}$ y a una frecuencia máxima de $50 \mathrm{~Hz}$. La precisión en la medida de la velocidad es $\pm 1 \%$ y en la dirección del viento $\pm 1^{\circ}, y$ para la temperatura $\pm 0.1^{\circ} \mathrm{C}$.

Las componentes horizontales de la velocidad del viento pueden determinarse tanto con el anemómetro 2D como el 3D. Adicionalmente, el anemómetro 3D permite registrar las fluctuaciones turbulentas de la componente vertical de la velocidad, las cuales combinadas con los datos de temperatura permiten determinar directamente el flujo de calor sensible $(\mathrm{H})$ (anexo 9.1) y por consiguiente el perfil vertical de la velocidad.

El uso de anemómetros 2D en algunas campañas ha supuesto tener que recurrir a otros métodos para conocer $\mathrm{H}$. Concretamente, en el presente trabajo se ha determinado $\mathrm{H}$ planteando un balance de energía en la superficie del suelo (anexo 9.1). Con este fin, se han medido los diferentes términos del balance empleando la siguiente instrumentación:

- Albedómetro: permite determinar la densidad de flujo de radiación solar incidente y reflejada.

- Flujómetro: permite determinar el flujo de calor a través del suelo.

- Termopar: permite determinar la temperatura de la superficie del suelo.

\section{- Parametrización de las fuentes de emisión}

A partir del uso de sistemas de posicionamiento global diferencial (DGPS), de los videos grabados durante la ejecución de las experiencias y de los registros de campo, se ha identificado con exactitud la posición y el instante en el que se produce la emisión por parte de las fuentes estudiadas. Asimismo, también se ha registrado de manera precisa la posición de los muestreadores en continuo.

Concretamente, se ha utilizado un DGPS Leica de precisión submétrica o centimétrica. El uso de estos dispositivos diferenciales permite mejorar el posicionamiento basado en el sistema de posicionamiento global (GPS), desde los 10 metros hasta una precisión inferior a 1 metro en el caso de los DGPS submétricos y cerca de $10 \mathrm{~cm}$ en el caso de los centimétricos.

\subsubsection{Tratamiento de datos para la obtención de FE}

La aplicación de la metodología propuesta consiste en medir experimentalmente las concentraciones de PM a sotavento de las fuentes de emisión a caracterizar y las variables meteorológicas requeridas para la determinación del perfil vertical de velocidad y de los coeficientes de dispersión vertical y horizontal. Subsiguientemente, las concentraciones de PM de cada fuente individual son simuladas en los puntos de muestreo aplicando el modelo de dispersión de contaminantes desarrollado, considerando un FE unitario. El modelo de dispersión de contaminantes propuesto consiste en resolver numéricamente la ecuación de transporte, la cual es una ecuación de derivadas parciales que se resuelve por el método de volúmenes finitos. Puesto que el FE es desconocido, el objetivo consiste en determinarlo. Para ello, se aplica el principio de superposición, el cual permite expresar las concentraciones en un punto dado como una combinación lineal de las calculadas individualmente para cada fuente. Los coeficientes lineales desconocidos representan los FE que se calculan mediante el método de mínimos cuadrados. En la Figura 3.1 se presenta la metodología seguida para el tratamiento de datos y obtención de FE. 


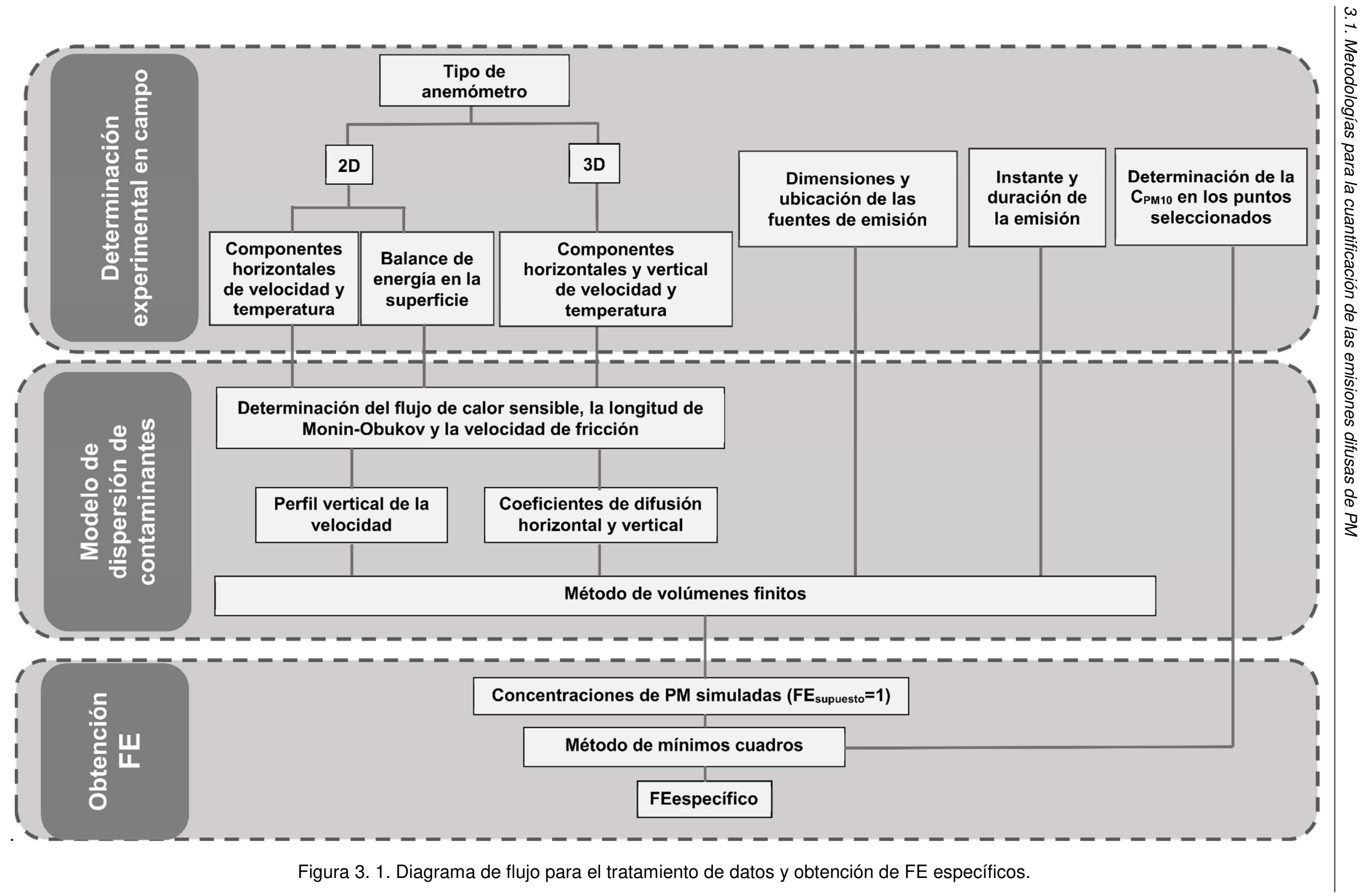




\subsection{Metodologías para la caracterización del PM y de los materiales manipulados}

A continuación, se describen las técnicas analíticas utilizadas para la caracterización química y morfológica del PM emitido y para la caracterización física de los materiales manipulados.

\subsubsection{Caracterización química y morfológica del PM}

De forma genérica, la metodología seguida en el estudio de caracterización química ha consistido en los siguientes procesos: obtención de muestras; acondicionamiento y tratamiento de las muestras; análisis químico y morfológico.

- Obtención de muestras de PM10

Se han utilizado captadores de alto volumen para recoger muestras del PM10 emitido durante las operaciones de manipulación y transporte. Concretamente, se han utilizado captadores MCV CAV$\mathrm{A} / \mathrm{M}$, con un caudal de aspiración de $30 \mathrm{~m}^{3} / \mathrm{h}$. El principio de funcionamiento de estos captadores se basa en aspirar un caudal de aire conocido, el cual se hace pasar a través de un cabezal de corte que sólo permite el paso de las partículas con un determinado tamaño, en este caso PM10. Las partículas que pasan a través del cabezal son retenidas en un filtro de fibra de cuarzo de $150 \mathrm{~mm}$ de diámetro. La masa retenida se determina gravimétricamente por diferencia de pesada del filtro posterior y anterior a la toma de muestras, asegurando en ambos casos unas mismas condiciones ambientales durante la pesada.

Los captadores se han ubicado a sotavento del foco emisor. Los filtros se han acondicionado siguiendo las especificaciones descritas en las normas de determinación de PM por gravimetría (UNE ISO 9096 y UNE EN 13284-1).

\section{- Caracterización química del PM}

Los análisis químicos se han realizado en el Instituto de Diagnóstico Ambiental y Estudios del Agua (IDAEA) del CSIC de Barcelona, siguiendo la metodología descrita en Querol et al. (2001b). En primer lugar, se ha realizado una digestión ácida $\left(\mathrm{HNO}_{3}, \mathrm{HF}\right.$ y $\left.\mathrm{HClO}_{4}\right)$ de los filtros. Posteriormente, las soluciones resultantes se han analizado mediante Espectrometría Atómica de Emisión con Fuente de Plasma Acoplada Inductivamente (ICP-AES), para el análisis de elementos mayoritarios y/o, mediante Espectrometría de Masas con Fuente de Plasma Acoplada Inductivamente (ICP-MS), para el análisis de elementos traza.

Debido a la naturaleza de los filtros (fibra de cuarzo) no ha sido posible analizar el $\mathrm{SiO}_{2}$ en las muestras estudiadas. La concentración de este óxido se ha determinado de forma indirecta aplicando la relación $\mathrm{SiO}_{2} / \mathrm{Al}_{2} \mathrm{O}_{3}$ obtenida para las arcillas predominantes en la zona de estudio: arcillas rojas (ratio medio 2.7) y blancas (ratio medio 2.8) (Barba et al., 2002).

\section{- Caracterización morfológica del PM}

Se ha realizado un análisis morfológico de las PM10 retenidas sobre los filtros, utilizando un equipo de microanálisis por Dispersión de Energía de Rayos $X$ con un detector de Si(Li), conectado al microscopio electrónico. 


\subsubsection{Caracterización física de los materiales manipulados}

Se han determinado aquellos parámetros más relevantes de los materiales relacionados con la capacidad de generar polvo:

- Humedad: para la determinación del contenido en humedad de las muestras, como ya se ha comentado anteriormente, se ha empleado el procedimiento descrito en la norma EN $15051: 2006$.

- Distribución granulométrica: la distribución granulométrica se ha determinado por difracción láser vía húmeda o vía seca, dependiendo del material. Para ello se ha utilizado el equipo Mastersizer 2000, el cual mide la variación angular en la intensidad de la luz cuando el haz del láser pasa a través de una muestra de partículas dispersadas. Posteriormente, esta información se analiza para calcular el tamaño de las partículas que crearon el patrón de dispersión. El tamaño de partícula se indica como un diámetro de esfera equivalente en volumen.

- Poder de emisión de polvo: la determinación del poder de emisión de polvo de las muestras se ha llevado a cabo con el método de caída continua, uno de los métodos de referencia definidos en la Norma EN 15051: 2014. El principio de operación del ensayo por caída continua consiste en dejar caer el material a ensayar desde una cierta altura sobre una corriente de aire ascendente. Cuanto mayor sea la cantidad de material que se incorpore a la corriente ascendente de gases, mayor será la capacidad de dicho material para liberar polvo en suspensión (López-Lilao et al., 2014). Ligeramente por encima de la posición de descarga del material se ubican un par de cabezales de muestreo de fracciones granulométricas con relevancia en la salud. Las fracciones estudiadas han sido la inhalable y la respirable (UNE EN 481:1995). 
4 Resultados y discusión 



\subsection{Introducción a los resultados}

En el presente apartado se muestra el trabajo de investigación desarrollado a través de cuatro artículos científicos junto con información adicional de interés, finalizando con una discusión de los principales resultados alcanzados. El trabajo realizado se ha dividido en dos grandes bloques:

- Determinación de FE y de eficacias de medidas correctoras globales, asociadas a los principales tipos de parques de almacenamiento y gestión de materias primas en la industria cerámica (artículos $\mathrm{n}$ ำ1 y $\mathrm{n}$ 으).

- Determinación de FE específicos asociados a una operación y/o material manipulado y de la eficacia de medidas correctoras concretas (artículos ํㅜㄱ y ํㅜㄴ).

\subsection{Determinación de factores de emisión y de eficacias de medidas correctoras en la industria cerámica}

Con el objeto de conocer el alcance de las emisiones difusas de PM10 y las necesidades de control en el proceso cerámico, en los artículos $\mathrm{n} \times 1$ y ํㅜㄹ se han cuantificado dichas emisiones y se han estimado los rendimientos de mejora alcanzados al implementar las medidas correctoras, propuestas en las AAl otorgadas a empresas del sector cerámico. El estudio se ha completado mediante la caracterización química y morfológica de las emisiones difusas de PM. Esta caracterización se presenta en el apartado de resultados adicionales. 
4.2.1 Estimación de emisiones difusas de PM10 y de eficacias de MTD en el sector cerámico

\title{
ARTÍCULO nำ1
}

\author{
Monfort, E., Celades, I., Sanfélix, V., \\ López J.L., Calpe, V.
}

\section{Estimación de emisiones difusas de PM10 y rendimiento de MTD en el sector cerámico}

Boletín de la Sociedad Española de Cerámica y Vidrio, 48 (1), 15-24, 2009

Publicado en: 2009

Número de citas (fuente: SCOPUS el 8 de mayo de 2017): 6

Factor de impacto de la revista (2009): 0.35 
4.2.2 Determinación de factores de emisión de PM10 y de eficacias de medidas correctoras globales por tipo de instalación en el sector cerámico

\section{ARTÍCULO nำ2}

Monfort, E., Sanfélix, V., Celades, I.,

Gomar, S., Martín, F., Aceña, B., Pascual, A.

\section{Diffuse PM10 emission factors associated with dust abatement technologies}

Atmospheric Environment, 45(39), 7286-7292, 2011

Publicado en: 2011

Número de citas (fuente: SCOPUS el 8 de mayo de 2017): 16

Factor de impacto de la revista (2011): 3.465

Factor de impacto de la revista en cinco años (2011): 3.742 


\subsubsection{Resultados adicionales: Caracterización química y morfológica de las emisiones difusas de PM10 en la industria cerámica}

El estudio de las emisiones difusas de PM10 en el sector cerámico, se ha completado determinando el perfil químico y morfológico de las mismas.

Con este fin, se han ejecutado campañas experimentales en tres instalaciones ubicadas en el clúster cerámico de la provincia de Castellón, cubriendo la fabricación de gránulo atomizado y baldosas cerámicas tanto de coloración roja como de coloración blanca en cocido.

Las principales materias primas gestionadas para la obtención de estos productos son: arcillas de coloración roja, arcillas de coloración blanca, caolines, carbonato cálcico, feldespatos y arenas feldespáticas, siendo las arcillas y los feldespatos las materias primas de mayor consumo.

Los captadores gravimétricos utilizados para la ejecución de los muestreos se han ubicado en áreas en las que la gestión de materias primas se realiza al aire libre. Consecuentemente, en los filtros se han captado tanto las partículas generadas durante las operaciones de manipulación y transporte, como las partículas presentes en el aire ambiente.

Como incertidumbre de la concentración, se ha considerado la dispersión entre las diferentes medidas ejecutadas en una misma instalación.

Las Tablas 4.1 y 4.2 muestran las concentraciones, de los compuestos mayoritarios y de los elementos traza, obtenidas para la fracción PM10 de las emisiones difusas asociadas a la manipulación y transporte de las materias primas cerámicas. Se presenta un perfil químico promedio por instalación, dado que, aunque se han seleccionado puntos de muestreo específicos en zonas propias de manipulación y de transporte, no se han observado perfiles significativamente diferentes por operación. Los perfiles individuales se recogen en el anexo 9.2. La clasificación en compuestos mayoritarios y elementos traza se basa en el criterio utilizado para caracterizar las emisiones canalizadas del proceso cerámico en trabajos previos (Celades, 2013).

Mediante la determinación de los compuestos mayoritarios analizados se obtienen porcentajes de recuperación entre el $50-80 \%$ y para los elementos traza $<10 \%$.

En el análisis de los resultados de los perfiles químicos, mostrados en las Tablas 4.1 y 4.2 , se ha valorado la influencia de las materias primas manipuladas. Con este fin, se ha comparado el perfil químico de las mismas con el rango de concentraciones obtenido en estudios previos (Celades, 2013) para las principales materias primas utilizadas en el sector cerámico.

Las Figuras 4.1 y 4.2 muestran las concentraciones promedio obtenidas, en cada una de las instalaciones estudiadas, para las emisiones difusas de PM10 (puntos) y el rango de concentraciones para las principales materias primas. Los rangos se presentan en forma de cajas, siendo los extremos los valores máximo y mínimo obtenidos. 
Tabla 4. 1. Compuestos mayoritarios de las emisiones difusas de PM10 en instalaciones de manipulación de materias primas cerámicas.

\begin{tabular}{|c|c|c|c|c|c|c|c|c|}
\hline \multirow{2}{*}{$\begin{array}{c}\text { Compuestos } \\
\text { mayoritarios (\%) }\end{array}$} & \multicolumn{2}{|c|}{ Instalación A ( $n=2)$} & \multicolumn{2}{|c|}{ Instalación B ( $n=8)$} & \multicolumn{2}{|c|}{ Instalación C ( $(\mathrm{n}=8)$} & \multicolumn{2}{|c|}{ Promedio $(n=18)$} \\
\hline & Media & Desviación & Media & Desviación & Media & Desviación & Media & Desviación \\
\hline $\mathrm{SiO}_{2}$ & 46 & 8 & 47 & 7 & 30 & 10 & 40 & 10 \\
\hline $\mathrm{Al}_{2} \mathrm{O}_{3}$ & 15 & 3 & 16 & 2 & 11 & 4 & 14 & 3 \\
\hline $\mathrm{Fe}_{2} \mathrm{O}_{3}$ & 4.8 & 0.5 & 2.1 & 0.7 & 2.8 & 0.8 & 2.9 & 0.9 \\
\hline $\mathrm{CaO}$ & 6 & 4 & 7 & 2 & 7 & 1 & 7 & 1 \\
\hline MgO & 1.4 & 0.1 & 0.9 & 0.3 & 1.6 & 0.4 & 1.3 & 0.4 \\
\hline $\mathrm{Na}_{2} \mathrm{O}$ & 0.5 & 0.2 & 1.3 & 0.3 & 1.9 & 0.9 & 1.3 & 0.8 \\
\hline $\mathrm{K}_{2} \mathrm{O}$ & 3.1 & 0.4 & 2.2 & 0.3 & 2.4 & 0.5 & 2.6 & 0.5 \\
\hline $\mathrm{TiO}_{2}$ & 0.7 & 0.2 & 0.7 & 0.1 & 0.5 & 0.2 & 0.6 & 0.1 \\
\hline $\mathrm{ZrO}_{2}$ & 0.05 & 0.01 & 0.17 & 0.09 & 0.08 & 0.04 & 0.10 & 0.06 \\
\hline $\mathrm{BaO}$ & 0.04 & 0.02 & 0.09 & 0.08 & 0.09 & 0.03 & 0.08 & 0.03 \\
\hline $\mathrm{Li}_{2} \mathrm{O}$ & 0.021 & 0.001 & 0.011 & 0.002 & 0.011 & 0.002 & 0.014 & 0.006 \\
\hline $\mathrm{PbO}$ & 0.03 & 0.01 & 0.10 & 0.07 & 0.11 & 0.07 & 0.08 & 0.04 \\
\hline ZnO & 0.1 & 0.1 & 0.2 & 0.2 & 0.2 & 0.2 & 0.2 & 0.1 \\
\hline $\mathrm{P}_{2} \mathrm{O}_{5}$ & 0.12 & 0.01 & 0.15 & 0.02 & 0.19 & 0.09 & 0.16 & 0.04 \\
\hline
\end{tabular}


Tabla 4. 2. Elementos traza de las emisiones difusas de PM10 de instalaciones de manipulación de materias primas cerámicas.

\begin{tabular}{|c|c|c|c|c|c|c|c|c|}
\hline \multirow{2}{*}{$\begin{array}{l}\text { Elementos traza } \\
(\mathbf{m g} / \mathbf{k g})\end{array}$} & \multicolumn{2}{|c|}{ Instalación A ( $n=2)$} & \multicolumn{2}{|c|}{ Instalación B ( $\mathrm{n}=8)$} & \multicolumn{2}{|c|}{ Instalación C $(n=8)$} & \multicolumn{2}{|c|}{ Promedio $(n=18)$} \\
\hline & Media & Desviación & Media & Desviación & Media & Desviación & Media & Desviación \\
\hline $\mathbf{s}$ & 1000 & 1000 & 9000 & 6000 & 40000 & 20000 & 20000 & 20000 \\
\hline v & 94 & 8 & 3 & 5 & 140 & 40 & 110 & 20 \\
\hline $\mathrm{Cr}$ & 129 & 9 & 110 & 20 & 200 & 100 & 150 & 50 \\
\hline $\mathbf{M n}$ & 355 & 3 & 170 & 60 & 320 & 50 & 200 & 100 \\
\hline $\mathbf{N i}$ & 40 & 3 & 30 & 30 & 110 & 70 & 50 & 50 \\
\hline $\mathrm{Cu}$ & 70 & 50 & 130 & 40 & 300 & 100 & 200 & 100 \\
\hline As & 22 & 3 & 30 & 10 & 36 & 9 & 31 & 5 \\
\hline Se & 12 & 3 & 40 & 20 & 80 & 40 & 50 & 20 \\
\hline $\mathbf{R b}$ & 150 & 30 & 100 & 10 & 100 & 20 & 90 & 10 \\
\hline $\mathrm{Sr}$ & 160 & 10 & 140 & 30 & 190 & 20 & 150 & 40 \\
\hline Cd & 1 & 1 & 6 & 5 & 5 & 3 & 6 & 1 \\
\hline Sn & 11 & 3 & 30 & 40 & 20 & 20 & 20 & 10 \\
\hline Sb & 14 & 4 & 40 & 10 & 30 & 20 & 35 & 7 \\
\hline Cs & 15 & 2 & 14 & 2 & 13 & 5 & 13 & 2 \\
\hline $\mathrm{Hf}$ & 10 & 1 & 30 & 20 & 10 & 10 & 20 & 10 \\
\hline $\mathrm{TI}$ & 4 & 1 & 16 & 8 & 70 & 70 & 40 & 40 \\
\hline U & 3 & 1 & 6 & 5 & 11 & 9 & 7 & 4 \\
\hline
\end{tabular}




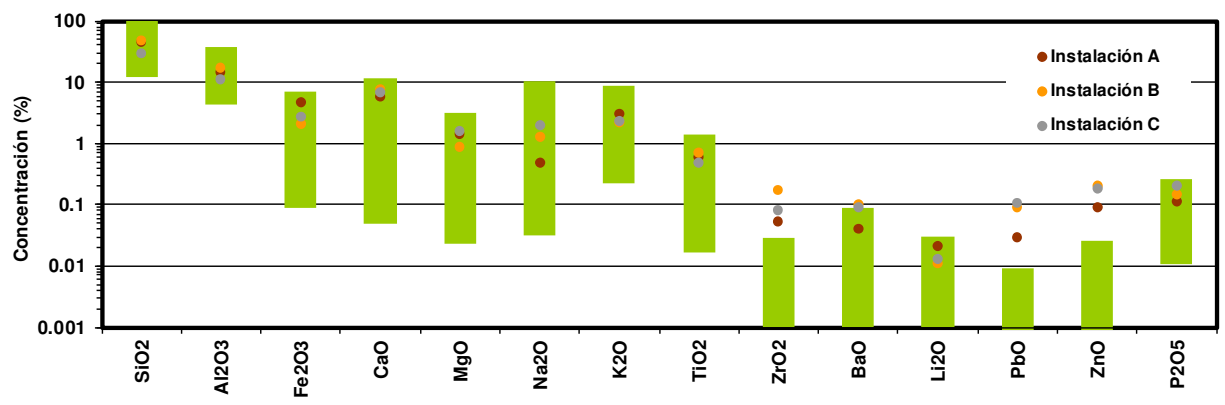

Figura 4. 1. Perfil químico por instalación de las emisiones difusas de PM10 en puntos y de las materias primas en cajas con intervalo mín-máx. Componentes mayoritarios.

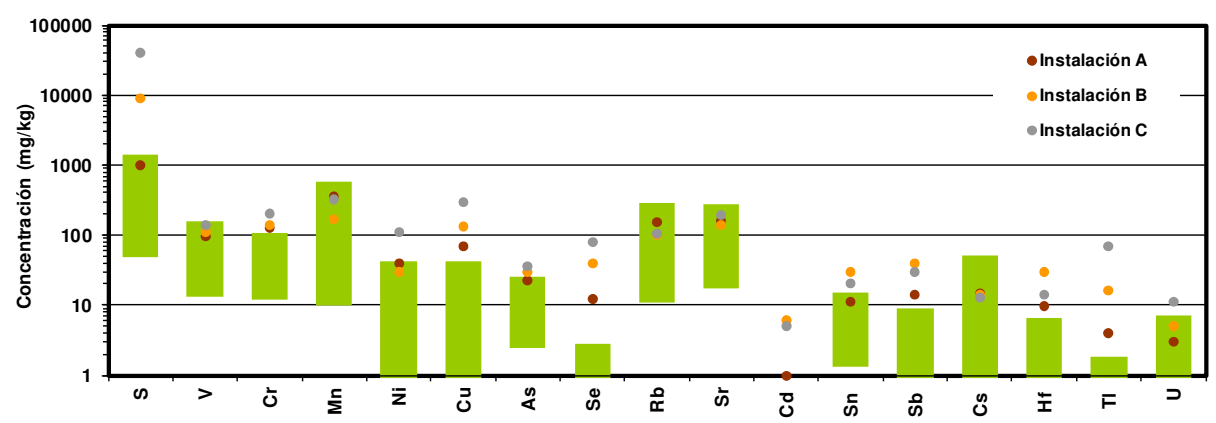

Figura 4. 2. Perfil químico por instalación de las emisiones de PM10 en puntos y de las composiciones en cajas con intervalo mín-máx. Elementos traza.

De la observación de las Figuras 4.1 y 4.2 se puede destacar que, como cabría esperar, el perfil químico de los componentes mayoritarios de las emisiones difusas de PM10 es similar al de las materias primas manipuladas. Los componentes mayoritarios se encuentran dentro de los intervalos de variación de las materias primas analizadas, con la excepción del $\mathrm{ZrO}_{2}, \mathrm{PbO}$ y $\mathrm{ZnO}$ para los que se observa un claro enriquecimiento en el PM10 captado para las tres instalaciones estudiadas.

Sin embargo, en los elementos traza, se observa que la mayor parte de los elementos analizados presentan concentraciones más elevadas en las emisiones difusas de PM10 que en las materias primas analizadas. Concretamente, los elementos que presentan un aumento en al menos dos instalaciones son: $\mathrm{S}, \mathrm{Cr}, \mathrm{Ni}, \mathrm{Cu}, \mathrm{As}, \mathrm{Se}, \mathrm{Cd}, \mathrm{Sn}, \mathrm{Sb}, \mathrm{Hf}$ y $\mathrm{Tl}$.

Entre estos elementos traza se identifican los trazadores para tráfico rodado asociados al desgaste de neumáticos y frenos: Zn, Cu, Sn y Sb (Schauer et al., 2006; Querol et al., 2007b; Amato et al., 2008). Consecuentemente, parte del enriquecimiento observado para estos elementos puede atribuirse a esta fuente, debido al paso frecuente de camiones y máquinas pala en el entorno inmediato de los equipos de medida.

Por otra parte, un aspecto importante a destacar, por su posible influencia sobre todo en componentes traza, es la gestión de los residuos de piezas crudas, cocidas, lodos de la depuración de aguas y residuos de los sistemas de depuración de gases, que normalmente se reutilizan como materias primas del soporte; por lo que, dependiendo del sistema de gestión de cada instalación, puede incorporar a las emisiones difusas elementos propios de las materias primas del esmalte y/o productos de decoración (tintas, entre otros). 
No obstante, a partir de la influencia de las materias primas manipuladas y de las emisiones del tráfico, no es posible explicar completamente el perfil químico obtenido para las emisiones difusas de PM10. Este hecho sugiere la presencia de otras fuentes externas que posiblemente puedan interferir en la composición química.

Entre estas fuentes pueden identificarse el fondo local y regional, así como la presencia de emisiones colindantes, debido a que la toma de muestra de las emisiones difusas se ha realizado al aire libre y, a que las instalaciones estudiadas se encuentran localizadas en polígonos industriales con abundantes plantas cerámicas.

En cuanto al fondo regional y local, estudios previos de calidad de aire en el clúster cerámico de Castellón (Minguillón et al., 2009; Querol et al., 2007a y 2007b) han identificado los siguientes elementos como trazadores:

- Fondo local: Zr, Zn, Pb, As, Se y TI.

○ Fondo regional: $\mathrm{SO}_{4}^{-2}, \mathrm{NH}_{4}^{+}, \mathrm{V}$ y Ni.

- Aerosol marino: $\mathrm{Na}$ y $\mathrm{Cl}^{-}$.

En el entorno estudiado se tienen concentraciones de fondo que podrían explicar, al menos parcialmente, la concentración de determinados elementos, como por ejemplo Pb, As, Cd, Se y Sn (Minguillón, 2007). Sin embargo, dichas concentraciones de fondo parecen insuficientes para justificar el enriquecimiento observado en $\mathrm{S}, \mathrm{Cr}, \mathrm{Cu}, \mathrm{Ni}, \mathrm{Zr}$ y Zn.

En cuanto a la presencia de focos de emisión colindantes, los trazadores identificados para las emisiones de las etapas de preparación de esmaltes y cocción en estudios previos (Celades, 2013) han sido:

- Compuestos mayoritarios: $\mathrm{PbO}$ y $\mathrm{ZnO}$.

- Elementos traza: S, TI, As, Cr, Cs, Rb, Cu, Cd, Sn y Hf.

El bajo grado de implementación de sistemas de depuración en los hornos cerámicos durante el periodo en el que se desarrollaron las campañas, inferior al 5\% en el clúster cerámico de Castellón (Minguillón et al., 2009), puede haber contribuido al aumento de la concentración observada para metales pesados en el PM captado, dado que, a pesar de ser poco importantes en masa, sí que lo son en cuanto a emisiones de metales pesados (Minguillón et al., 2013).

Con el fin de evaluar esta posible influencia, en las Figuras 4.3 y 4.4 se compara el intervalo de concentraciones (valores mínimo y máximo) obtenido para las emisiones difusas de PM10 en las diferentes campañas realizadas, con el intervalo de las emisiones canalizadas de PM10 del proceso cerámico obtenido por Celades (2013).

Las Figuras 4.3 y 4.4 muestran que el perfil químico de las emisiones difusas de PM10, para la mayor parte de los compuestos y elementos analizados, se encuentran dentro del intervalo de concentraciones obtenidas para las emisiones canalizadas.

En principio, el perfil químico de las emisiones difusas de PM10 debería ser similar al perfil químico de las emisiones de atomización y prensado. Respecto a estas etapas, se observa un evidente 
aumento en la concentración de $\mathrm{PbO}$ para las emisiones difusas, encontrándose el nivel de $\mathrm{ZnO}$ en el rango superior de las mismas. Esta observación coincide con los compuestos que presentan un claro enriquecimiento al comparar las emisiones difusas con las materias primas manipuladas (Figura 4.1 y 4.2 ).

Con respecto a los elementos traza, los elementos que presentan un aumento en la concentración al compararlos con las etapas de atomización y prensado son S, Se y TI. Asimismo, los niveles de $\mathrm{Mn}, \mathrm{Cu}, \mathrm{As}$ y Sb se encuentran próximos al valor superior del intervalo. No obstante, cabe destacar que probablemente el perfil químico que presentan estas etapas puede verse alterado por la incorporación de residuos procedentes de la etapa de esmaltado en el gránulo atomizado, de igual modo que se ha observado al comparar con la composición de las materias primas cerámicas.

La mayor parte de estos elementos identificados, presentan las concentraciones más altas en las emisiones de la etapa de cocción, en relación al resto de etapas del proceso cerámico.

Las diferentes observaciones alcanzadas ponen de manifiesto que los factores externos evaluados contribuyen a modificar el perfil químico de las muestras obtenidas, sobre todo en elementos traza. Por ello, el estudio de la composición química de las emisiones difusas de PM, asociadas a la manipulación y transporte de graneles sólidos al aire libre, exige un amplio conocimiento del fondo local y regional, así como de las fuentes de emisión colindantes para realizar una correcta interpretación de los resultados, ya que como se ha observado todos los componentes del PM no tienen un origen asociado a las propias emisiones difusas. 
- Atomización $\square$ Prensado Esmaltado Cocción Difusas

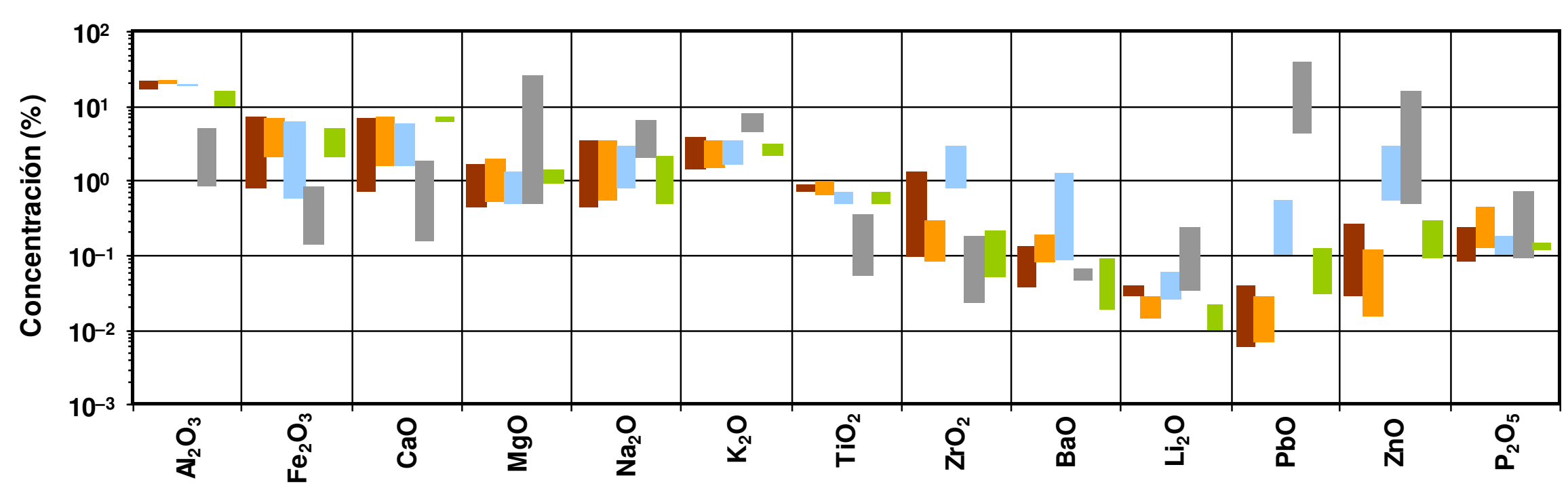

Figura 4. 3. Perfil químico (intervalo mín-máx) de las emisiones canalizadas (atomización, prensado, esmaltado y cocción) y difusas de PM10 asociadas al proceso cerámico. Componentes mayoritarios. 
Atomización $\square$ Prensado Esmaltado $\square$ Cocción $\square$ Difusas

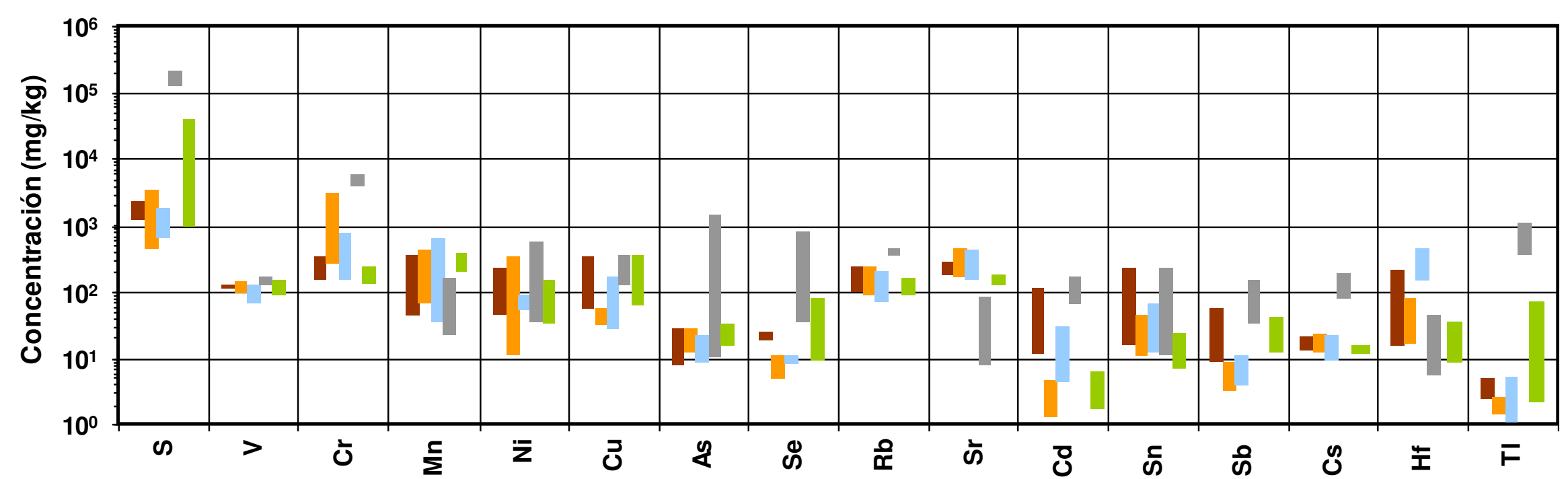

Figura 4. 4. Perfil químico (intervalo mín-máx) de las emisiones canalizadas (atomización, prensado, esmaltado y cocción) y difusas de PM10 asociadas al proceso cerámico. Elementos traza. 
En las Figuras de 4.5 a 4.12, se adjuntan las micrografías del MEB y de los análisis EDX realizados para el estudio de las muestras de PM10 obtenidas, identificándose la presencia de partículas que puedan explicar una posible contribución de las emisiones canalizadas y del fondo local y regional sobre las muestras del PM10 captado.
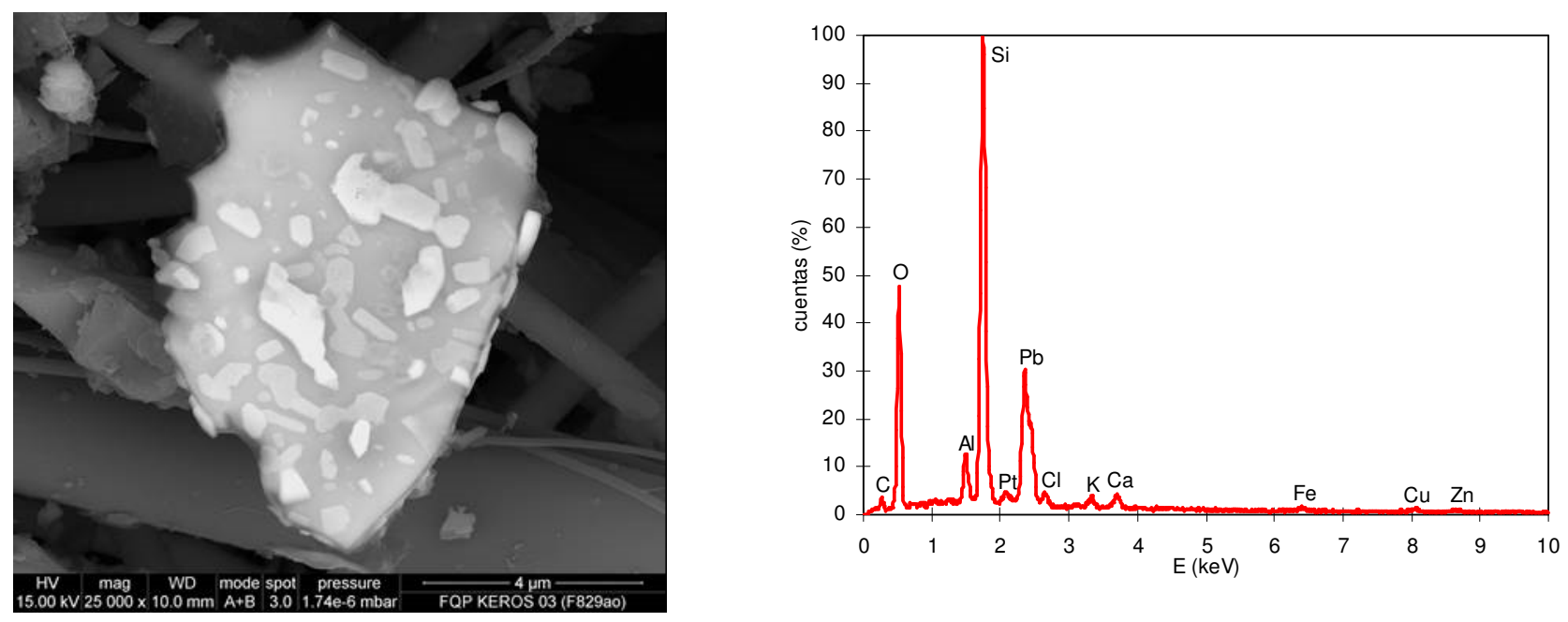

Figura 4. 5. Micrografía de MEB (izquierda) y análisis EDX (derecha) de una partícula rica en $\mathrm{Pb}$.
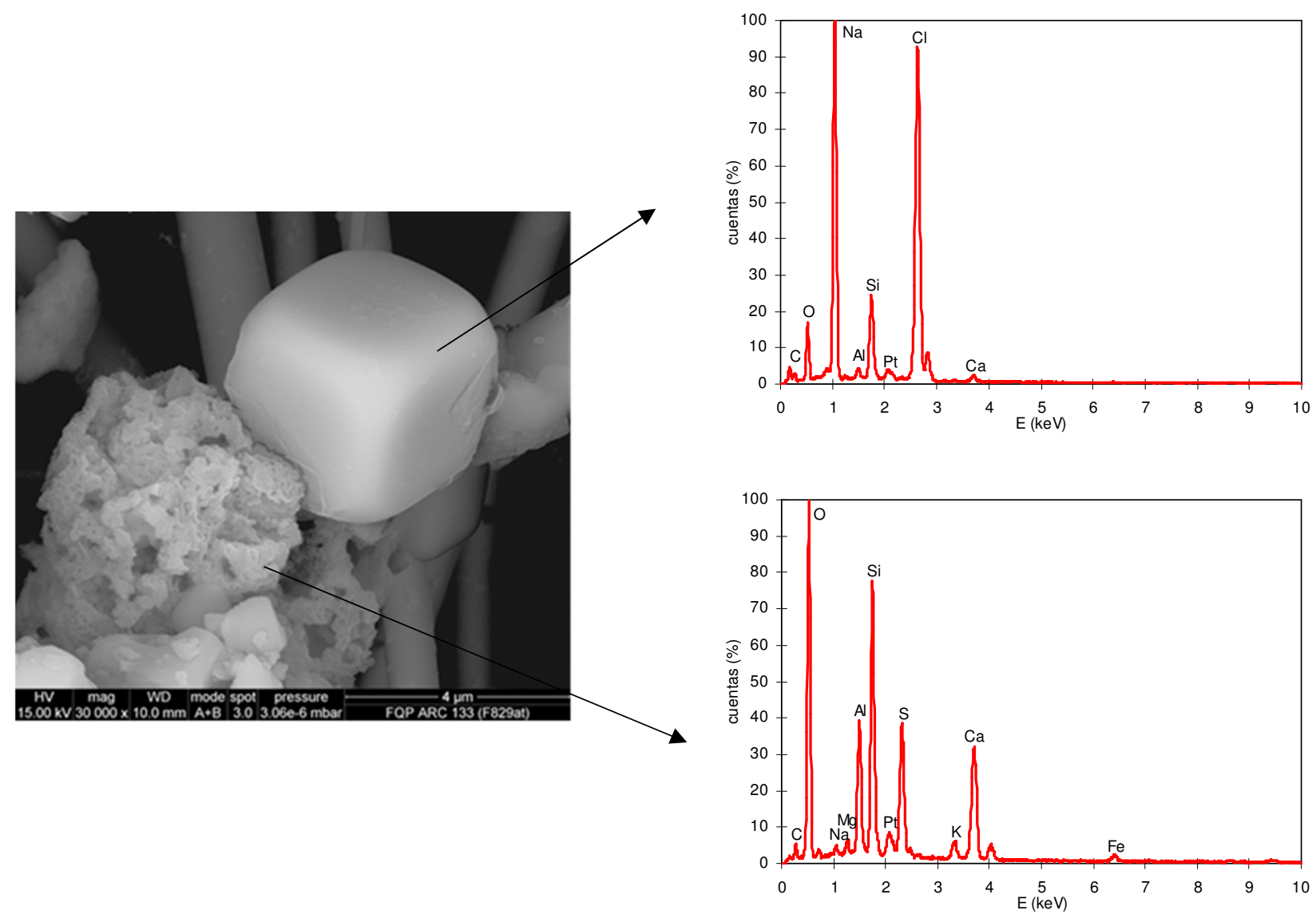

Figura 4. 6. Micrografía de MEB (izquierda) y análisis EDX (derecha) de cristalizaciones de $\mathrm{NaCl}$ (arriba) y de una partícula de $\mathrm{CaSO}_{4}$ (abajo). 

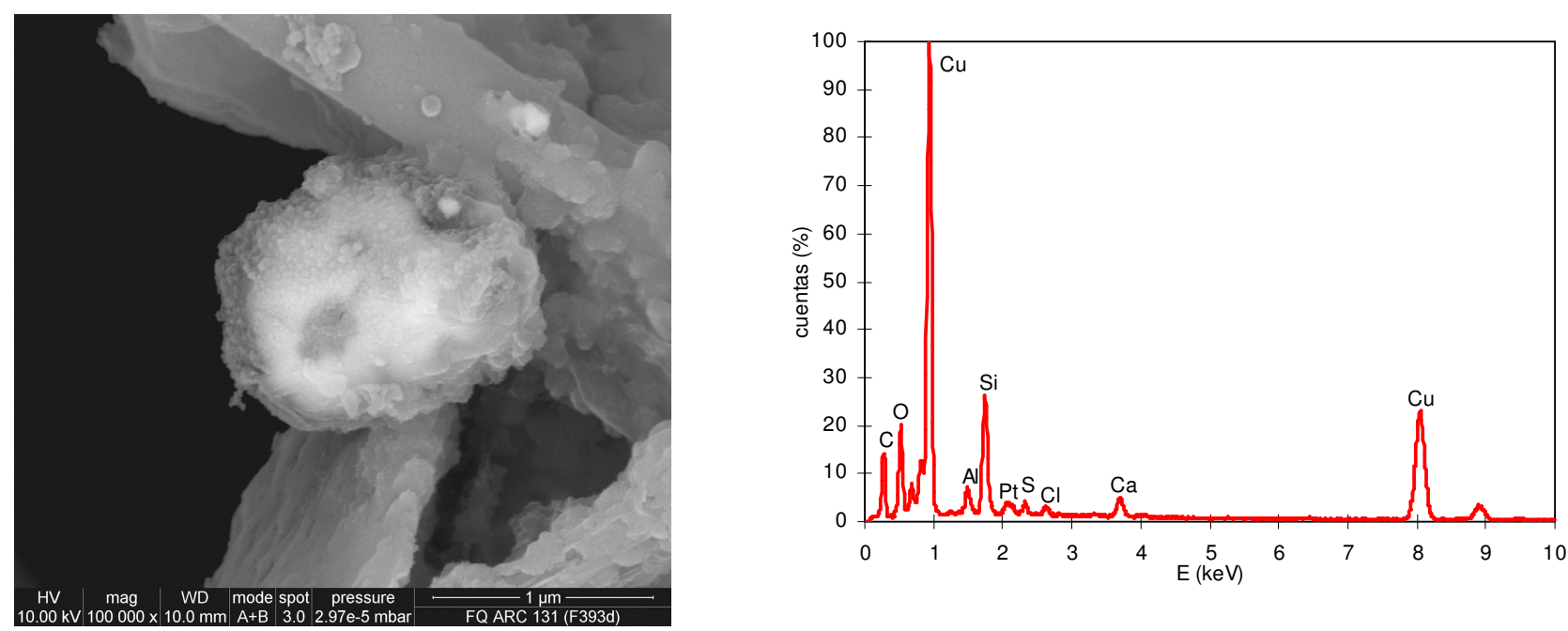

Figura 4. 7. Micrografía de MEB (izquierda) y análisis EDX (derecha) de una partícula rica en Cu.
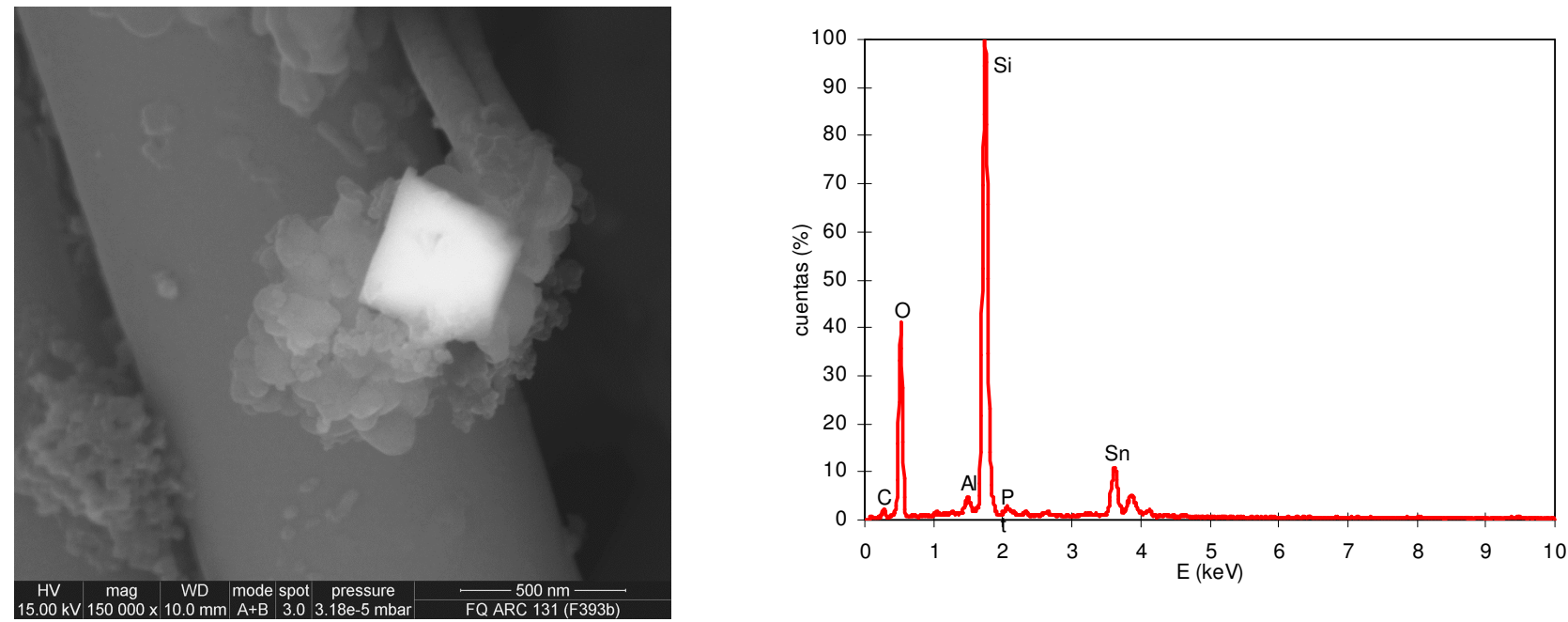

Figura 4. 8. Micrografía de MEB (izquierda) y análisis EDX (derecha) de una partícula rica en Sn.
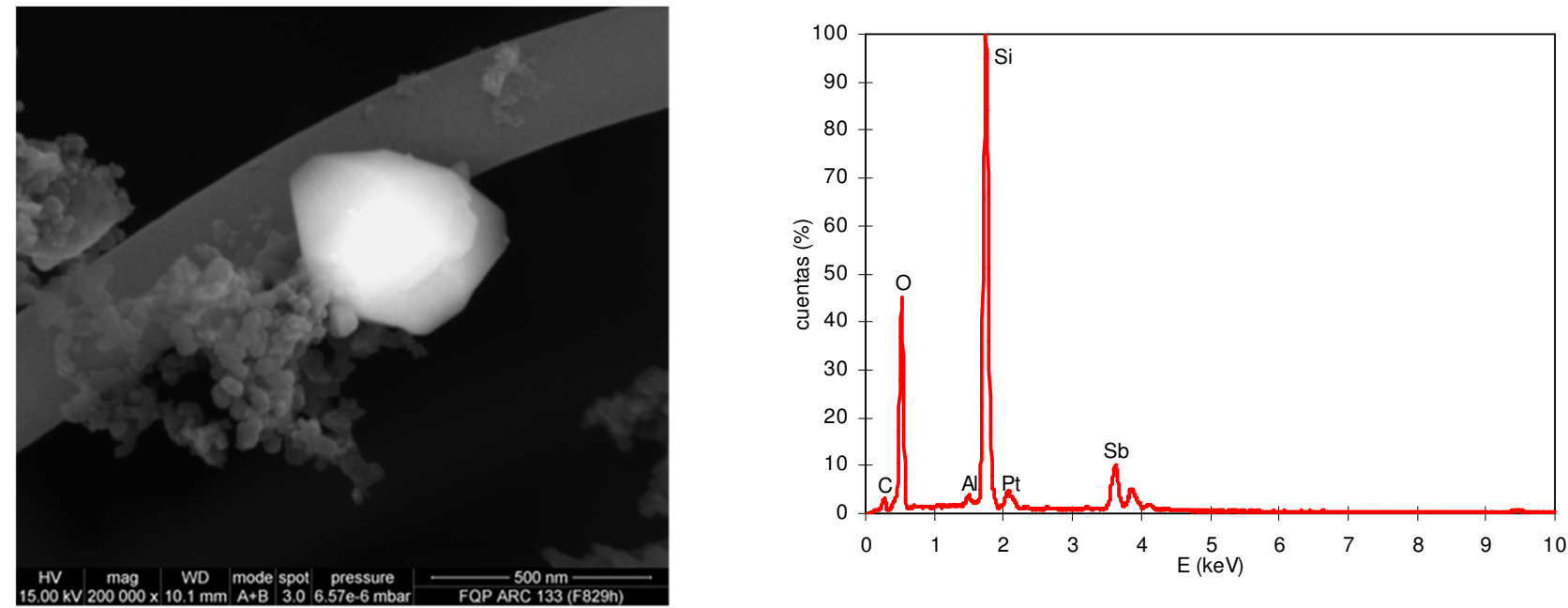

Figura 4. 9. Micrografía de MEB (izquierda) y análisis EDX (derecha) de una partícula rica en Sb. 

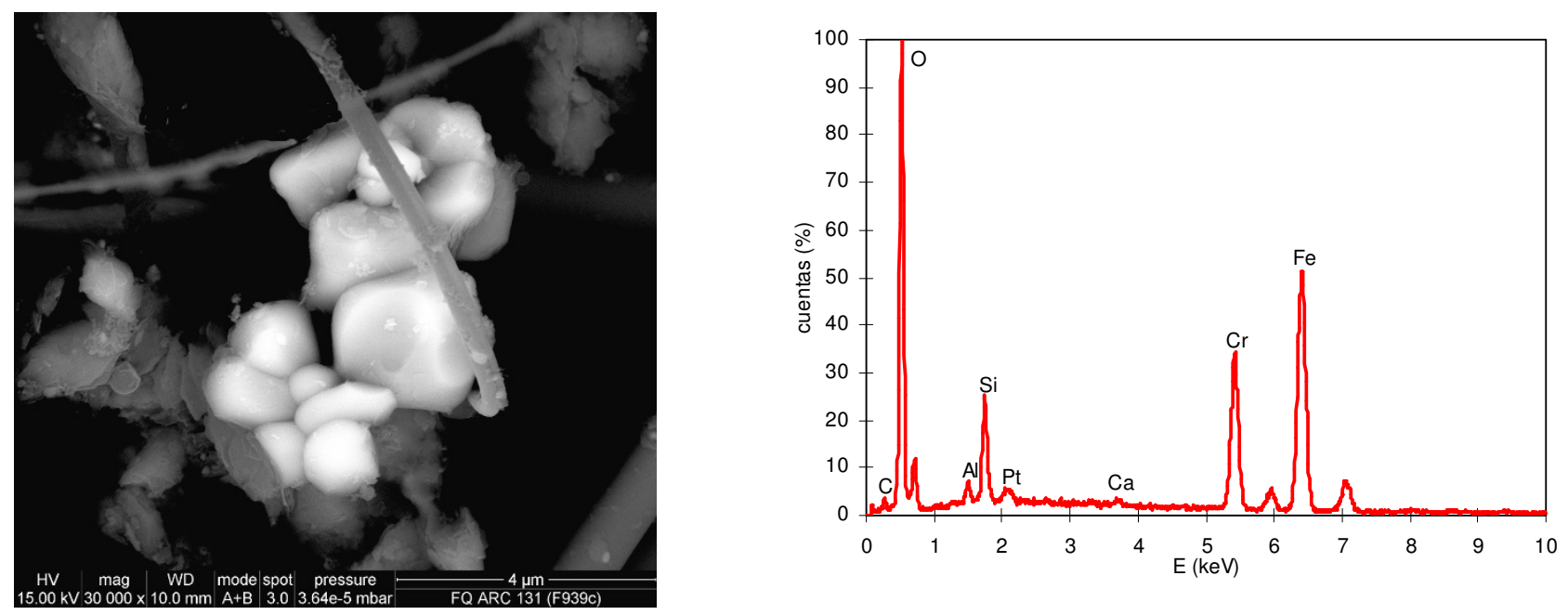

Figura 4. 10. Micrografía de MEB (izquierda) y análisis EDX (derecha) de partículas de Cr y Fe.
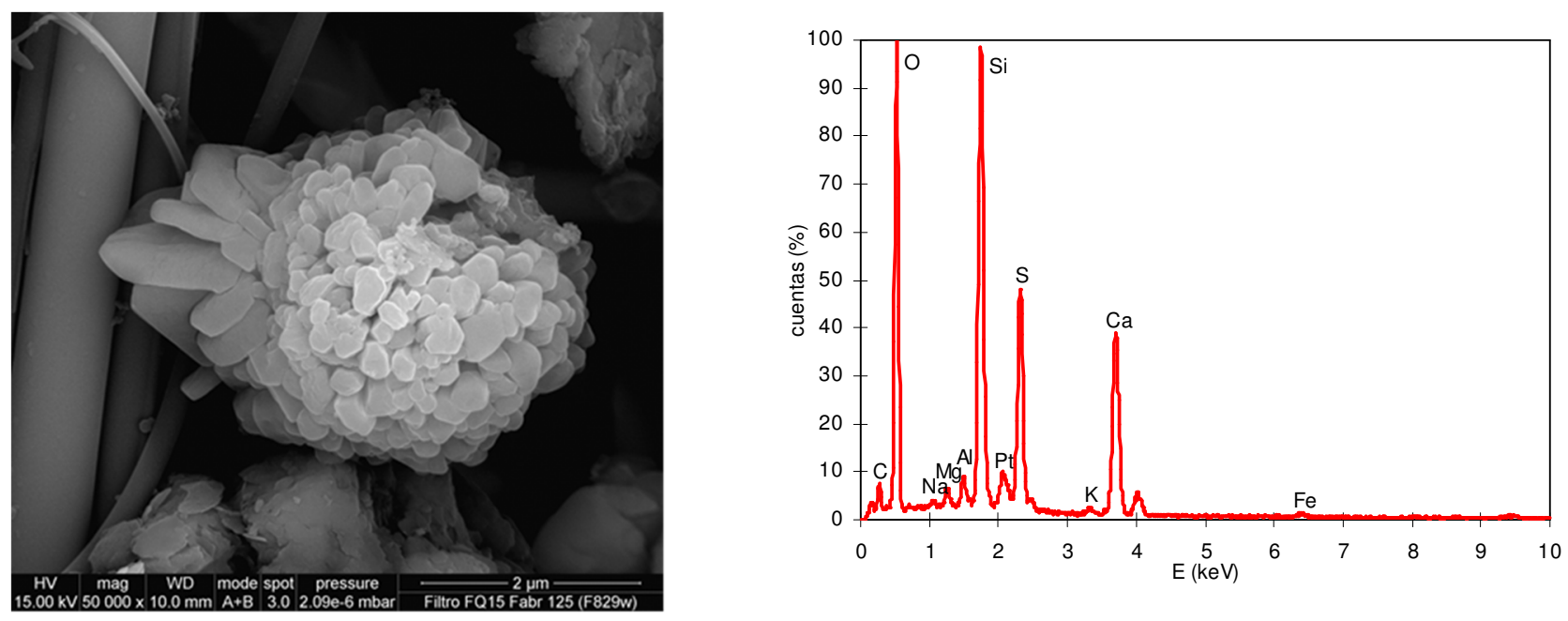

Figura 4. 11. Micrografía de MEB (izquierda) y análisis EDX (derecha) de partículas de $\mathrm{CaSO}_{4}$.
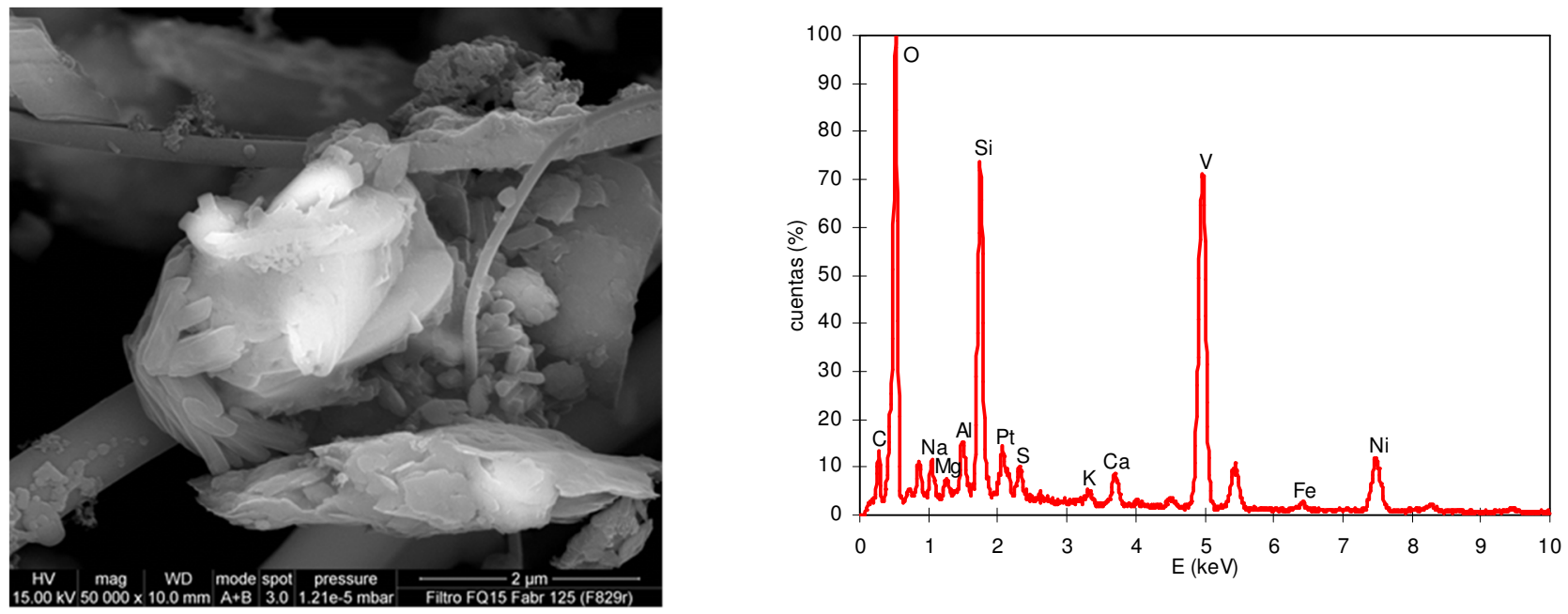

Figura 4. 12. Micrografía de MEB (izquierda) y análisis EDX (derecha) de artículas ricas en $\mathrm{V}$ y Ni. 
El estudio morfológico de la fracción PM10 muestreada indica la presencia de partículas con un aspecto y composición similar a las partículas emitidas por focos canalizados en las diferentes etapas del proceso cerámico. Concretamente, en los filtros estudiados se han identificado puntualmente partículas blancas y brillantes, con un tamaño inferior a $2.5 \mu \mathrm{m}$, ricas en $\mathrm{Pb}, \mathrm{Cr}, \mathrm{Fe}$, $\mathrm{Cu}, \mathrm{Sn}$ y Sb. Estas partículas blancas y brillantes se han detectado también en las emisiones canalizadas asociadas a las etapas de esmaltado y de cocción. Además, también se observan en la etapa de secado por atomización por la incorporación de lodos (procedentes de la etapa de esmaltado y decoración) (Celades, 2013).

Asimismo, se han observado partículas de $\mathrm{CaSO}_{4}$ asociadas probablemente a impurezas de yeso presentes en algunas materias primas (Barba et al., 2002).

La presencia de cristales de $\mathrm{NaCl}$ y partículas ricas en $\mathrm{V}$ y $\mathrm{Ni}$, puede indicar que existe un contribución significativa de fuentes externas de contaminantes, en este caso concreto, contaminantes transportados por la brisa marina. Esta tipo de contribución se ha observado en estudios publicados de calidad de aire en el cluster cerámico de Castellón (Minguillón et al., 2007a; Querol et al., 2007a y 2007b), en los que se detectan contenidos significativos de $\mathrm{NaCl}$ (de origen marino) y de $\mathrm{V}$ y Ni (de origen industrial por la refinería y central térmica ubicada en la costa y/o por el combustible de los barcos asociado al puerto). No obstante, se requiría un estudio más exhaustivo para extraer conclusiones definitivas.

Estos resultados obtenidos en la caracterización morfológica confirman la influencia del fondo local y regional y de las emisiones colindantes observada al analizar el perfil químico de las emisiones difusas de PM.

\subsection{Determinación de factores de emisión y de eficacias de medidas correctoras específicas}

En el presente apartado se propone una metodología experimental para la determinación de FE específicos y de la eficacia de MTD concretas (artículo n-3). El proceso de refinamiento de la metodología propuesta se explica en mayor detalle en el apartado de resultados adicionales.

En el artículo no4 se ha adaptado la metodología experimental propuesta para fuentes de mayor complejidad, incluso para fuentes móviles, en las que el punto de emisión puede producirse desde una posición arbitraria en el escenario considerado. Como resultados adicionales al artículo n4 se presentan las eficiencias del riego con agua y con aditivos químicos en viales no pavimentados. 
4.3.1 Metodología propuesta para la determinación de factores de emisión específicos de PM

\section{$\underline{\text { ARTÍCULO no3 }}$}

Sanfélix, V., Escrig, A., López-Lilao, A., Celades, I., Monfort, E.

\section{On the source inversion of fugitive surface layer releases. Part I. Model formulation and application to simple sources}

Atmospheric Environment, 109, 171-177, 2015

Publicado en: 2015

Número de citas (fuente: SCOPUS el 8 de mayo de 2017): 3

Factor de impacto de la revista (2015): 3.459

Factor de impacto de la revista en cinco años (2015): 3.841 


\subsubsection{Resultados adicionales al artículo no3: refinamiento de la metodología experimental propuesta}

Como método de partida para la obtención de FE específicos se ha seleccionado la metodología RDM. Esta metodología consiste básicamente en realizar mediciones de las concentraciones de PM en puntos estratégicos alrededor de la fuente. La tasa de emisión de la fuente estudiada se determina mediante un modelo de dispersión del contaminante aplicado de forma inversa a la habitual, es decir, a partir de la concentración se calcula la emisión, de manera que las concentraciones experimentales y calculadas sean lo más similares posibles.

A continuación, se detallan las mejoras que se han ido introduciendo en la metodología propuesta, con el fin de conseguir reproducir los más satisfactoriamente posible las concentraciones experimentales registradas en campo. Este refinamiento de la metodología ha permitido establecer un protocolo de ejecución de las campañas experimentales, el cual se detalla en el presente apartado. Asimismo, se presenta un caso práctico de aplicación de dicho protocolo.

\subsubsection{Ensayos preliminares para refinar la metodología experimental}

La capacidad predictiva del modelo de dispersión de contaminantes desarrollado se ha evaluado en entornos industriales, mediante la valoración del acuerdo entre las concentraciones de PM10 obtenidas experimentalmente y las calculadas.

Para ello, se han ejecutado cuatro campañas experimentales para la caracterización de una operación específica en una planta de fabricación de gránulo atomizado. Se ha considerado relevante caracterizar operaciones que permitan determinar el instante, duración y posición de la emisión con exactitud, de modo que se puedan asignar inequívocamente los picos significativos de concentración a la fuente seleccionada.

Con estas premisas, las operaciones seleccionadas han sido la carga/descarga mediante máquina pala de una arcilla blanca (Figura 4.13), ya que la emisión se producía de una manera razonablemente controlada con la cooperación de los operarios.

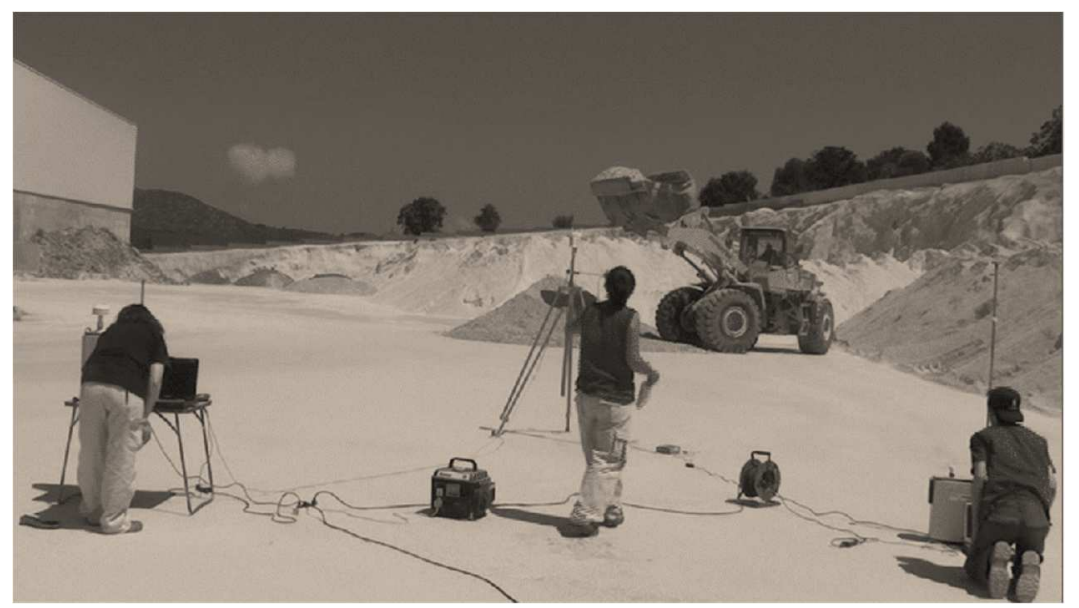

Figura 4. 13. Operación seleccionada para la evaluación del modelo de dispersión propuesto. 
A continuación, se detallan las mejoras que se han ido introduciendo en cada una de las campañas realizadas, con el fin de conseguir que estas se realicen acorde a las necesidades del modelo:

\section{Campaña 1}

Objetivo: Evaluar el efecto de la distancia y orientación de los equipos de muestreo de PM respecto a la fuente.

\section{Conclusiones alcanzadas:}

- Los equipos de muestreo de PM deben ubicarse en la dirección predominante del viento por razones obvias. Por otra parte, la distancia a la que deben posicionarse con respecto a la fuente debe ser suficiente para que el efecto de la dispersión minimice posibles no uniformidades en la emisión, pero no debe ser excesiva permitiendo siempre que los picos de concentración puedan asociarse a la fuente estudiada. En los escenarios estudiados esto ha supuesto ubicar los equipos a distancias entre 50 y 100 m del foco de emisión.

- La resolución temporal de las medidas de PM debe ser acorde a la duración de la operación estudiada. Para la mayoría de las fuentes estudiadas se precisa la máxima resolución que ofrecen los equipos de muestreo utilizados (6 s), debido a que la duración de la operación es limitada (del orden de segundos).

- El estudio en detalle de los datos de concentración de PM registrados y de los periodos de actividad, ponen de manifiesto que, a pesar de sincronizar todos los relojes, los captadores de muestreo de PM utilizados presentan un pequeño desfase. Se observó que los muestreadores registran un aumento de concentración de PM asociado a la fuente antes del inicio de la actividad. En campañas posteriores se ha corregido este desfase.

- Se requiere una precisión elevada en la determinación de la ubicación de los equipos de muestreo de PM y de la fuente.

\section{Campaña 2}

Objetivo: Evaluar la respuesta de diferentes GPS convencionales.

\section{Conclusiones alcanzadas:}

- Se observó que los diferentes GPS convencionales utilizados presentaban variaciones muy significativas en las coordenadas determinadas (hasta $10 \mathrm{~m}$ ). Además, estas diferían de las medidas realizadas con cinta métrica.

- El hecho de que las medidas de concentración sólo puedan llevarse a cabo en posiciones determinadas tiene importantes consecuencias en la metodología RDM aplicada para la obtención de los FE. Un error de unos pocos grados en el ángulo formado entre la dirección del viento y la línea que une la fuente con el muestreador puede dar lugar a errores considerables en la predicción de la posición del centro de la pluma, influyendo significativamente en las concentraciones calculadas. Por tanto, se considera fundamental conocer con precisión la posición de la fuente y de los equipos, así como orientar perfectamente los anemómetros.

- Consecuentemente, se decidió utilizar un GPS diferencial de elevada precisión para la ejecución de las posteriores campañas. 


\section{Campaña 3}

Objetivo: Ampliar la información meteorológica registrada durante las campañas y su introducción en el modelo de dispersión.

\section{Conclusiones alcanzadas:}

- La velocidad y dirección del viento son de vital importancia en el transporte advectivo del contaminante emitido. Asimismo, la intensidad de turbulencia determina la dispersión horizontal de la pluma. La dispersión vertical depende, además, de la intensidad de las corrientes de convección. En consecuencia, se considera imprescindible determinar estos efectos en las campañas experimentales.

- Con este fin, sería ideal emplear anemómetros sónicos 3D para registrar las componentes de la velocidad del viento a alta frecuencia a diferentes alturas sobre el nivel del suelo.

- Como únicamente se disponía de un anemómetro sónico 2D, se decidió aumentar la frecuencia de adquisición de datos de velocidad de viento a la máxima frecuencia permitida por el anemómetro utilizado $(1 \mathrm{~Hz})$, con el fin de conocer las fluctuaciones de la componente horizontal de la velocidad. Esta información se considera muy valiosa para incorporar al modelo la dispersión horizontal de las partículas.

- El uso de anemómetros sónicos 2D no permite determinar las fluctuaciones turbulentas de la componente vertical de la velocidad. Por este motivo, se ha establecido una metodología que permite estimar $u_{*}$ y $\mathrm{L}$ (parámetros de los perfiles de $\mathrm{M}-\mathrm{O}$ ), sin tener que recurrir a anemómetros sónicos 3D. Esta metodología está basada en estimar el flujo de calor sensible (convectivo) planteando un balance de energía en la superficie del suelo.

- El flujo de calor sensible viene determinado por el descuadre entre el flujo radiativo de onda corta incidente y reflejado, el flujo de onda larga de radiación y el flujo de calor conducido hacia el seno del suelo, los cuales pueden determinarse empleando un albedómetro, un termopar y un flujómetro, respectivamente.

- Para las campañas finales se adquirió un anemómetro sónico 3D, lo que simplificó el montaje experimental y el tratamiento de datos.

\section{Campaña 4}

Objetivo: Realizar una campaña experimental introduciendo todas las mejoras descritas anteriormente para evaluar la respuesta del modelo de dispersión de contaminantes desarrollado.

\section{Conclusiones alcanzadas:}

En la Figura 4.14, se presentan las concentraciones de PM10 obtenidas experimentalmente y las obtenidas mediante el modelo de dispersión propuesto, obteniéndose un ajuste que se considera muy satisfactorio tras las mejoras adoptadas. 


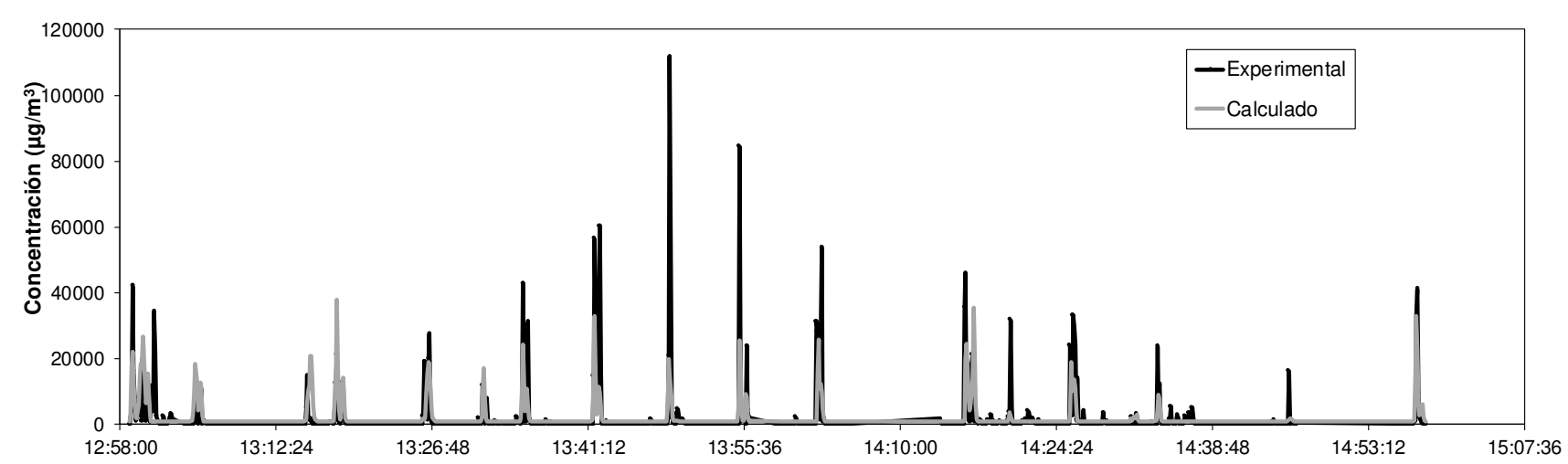

Figura 4. 14. Operación seleccionada para la evaluación del modelo de dispersión propuesto.

Por tanto, se concluye que las mejoras introducidas en la metodología experimental para la ejecución de las campañas son necesarias para simular de forma real las emisiones generadas.

\subsubsection{Protocolo de ejecución de las campañas experimentales}

A partir de la información adquirida en el refinamiento de la metodología experimental, se ha establecido el siguiente protocolo para la ejecución de las campañas experimentales:

- Determinación de las concentraciones de PM

- Las concentraciones de PM deben registrarse en continuo y con una resolución temporal del orden de segundos, con el fin de poder identificar todos los eventos que suceden durante el muestreo. Para ello se propone el uso de al menos dos muestreadores.

- Previamente a la ejecución de la campaña, se recomienda realizar una comparación entre los muestreadores de PM que vayan a utilizarse. Dicha comparación debe llevarse a cabo con la resolución temporal seleccionada y en ambientes que cubran el rango de niveles de PM habitual en la zona a estudiar.

- Los captadores deben colocarse a sotavento de la fuente emisora y en la dirección predominante del viento, de modo que sean capaces de captar la nube de polvo generada por las operaciones a caracterizar, y a una distancia tal que los picos de concentración registrados puedan asociarse inequívocamente a la fuente (habitualmente distancias entre 50-100 m).

- La ubicación de los muestreadores debe registrarse con elevada precisión (submétrica o centimétrica). Para ello se recomienda el uso de DGPS.

- Los relojes de los diferentes equipos deben sincronizarse a nivel de segundos previamente a cada ensayo.

\section{- Determinación de las variables meteorológicas}

- Las fluctuaciones de las componentes de la velocidad y la dirección del viento, así como la temperatura, deben registrarse a elevadas frecuencias mediante el uso de anemómetros sónicos (3D o 2D).

- En caso de utilizar un anemómetro sónico 2D es necesario estimar el flujo de calor sensible para reconstruir el perfil vertical de velocidades. 
- El flujo de calor sensible puede estimarse planteando un balance de energía sobre la superficie del suelo. Para ello, debe determinarse la radiación solar incidente y reflejada (para lo que se utiliza un albedómetro), la temperatura de la superficie para calcular la densidad de flujo radiativo de onda larga (mediante el uso de un termopar) y el flujo de calor a través del suelo (utilizando un flujómetro).

- El anemómetro debe ubicarse en una zona no apantallada y alejada de obstáculos, de modo que las variables meteorológicas registradas sean representativas del área de estudio.

\section{- Parametrización de las fuentes de emisión}

- En el protocolo de campañas experimentales se ha considerado imprescindible el control, en la medida en la que sea posible, de la fuente de emisión, de manera que se conozca con exactitud dónde y cuándo se produce la emisión, así como la duración de la misma. Para ello, debe realizarse un registro de las fuentes de emisión operativas durante la realización de la campaña y de su área de actuación (se recomienda realizar una grabación con cámaras) y, debe determinarse la identificación exacta de las fuentes mediante un DGPS.

- Se considera interesante disponer de la cooperación de las empresas a la hora de desarrollar las campañas experimentales, para que éstas se lleven a cabo de una manera razonablemente controlada.

- Se recomienda realizar una validación de los datos registrados mediante la visualización de los videos grabados.

\subsubsection{Importancia del protocolo experimental en la bondad de los ajustes}

Con el fin de mostrar la importancia de una apropiada ejecución de las campañas experimentales, se describe un caso de estudio en el que se muestra como mejora la bondad del ajuste entre las concentraciones experimentales y calculadas, a medida que se va refinando la parametrización de las fuentes emisoras.

Concretamente, se ha seleccionado una experiencia en la que se ha estudiado la operativa de recepción de clínker en un puerto. La forma habitual de operar, observada durante el periodo de muestreo, consistía en transportar mediante camiones el material hasta el muelle de gráneles sólidos, descargar el clínker en la zona habilitada y realizar un remonte con la máquina pala, mediante el cual se elevaba la altura de los acopios (Figura 4.15).

La campaña se ejecutó aplicando el protocolo descrito anteriormente. En cuanto a la parametrización de las fuentes de emisión, se registró la siguiente información:

- La extensión del muelle habilitada para la descarga de clínker era un rectángulo de $30 \mathrm{~m}$ de largo y $18 \mathrm{~m}$ de ancho, abarcando una superficie total de $650 \mathrm{~m}^{2}$. La altura que alcanzaban los acopios era aproximadamente $7 \mathrm{~m}$. En este caso, debido a que la zona habilitada para la descarga del material era bastante amplia, esta se dividió en tres zonas, identificándose durante el periodo de muestreo en que zona se realizaba cada una de las operaciones de descarga y remonte.

- La operativa del puerto durante la campaña experimental se registró tanto mediante anotaciones en campo como con la grabación de un video. 


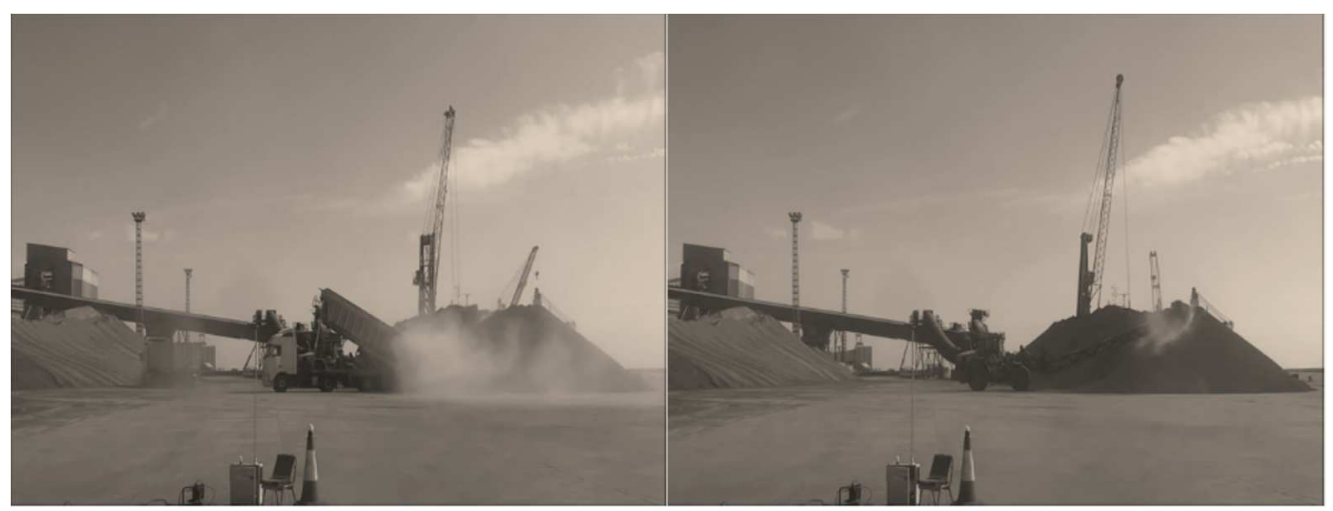

Figura 4. 15. Operaciones caracterizadas durante la campaña. Izquierda: descarga del camión; derecha: remonte con la máquina pala.

Una primera simulación de las concentraciones de PM10 se ha realizado considerando como fuente de emisión el área total de la extensión habilitada para la descarga y remonte de clínker. La Figura 4.16 muestran las concentraciones de PM10 experimentales junto con las calculadas tras el ajuste por mínimos cuadrados en los tres puntos de muestreo, observándose que no se obtiene un buen ajuste, lo que limita la obtención de FE robustos y representativos de la realidad.

Con el fin de mejorar la bondad de los resultados obtenidos, en los datos de entrada del programa de ordenador se detallaron, para cada una de las operaciones de descarga y remonte realizadas, las coordenadas de la zona específica en la que se realizaba cada operación. Esta información de detalle se verificó y mejoró con la visualización de los videos grabados, permitiendo también ajustar la duración de la emisión de cada operación.

La Figura 4.17 muestra las concentraciones experimentales y calculadas tras la realización de los ajustes detallados en los tres puntos de muestreo. Teniendo en cuenta la complejidad del escenario caracterizado, debido principalmente a la dificultad de establecer las coordenadas exactas del punto de emisión de cada operación, se considera que el acuerdo entre las concentraciones experimentales y calculadas es aceptable y mejora considerablemente respecto al ajuste anterior. En la Tabla 4.3 se presentan los FE específicos por operación obtenidos.

Tabla 4. 3. FE $E_{\mathrm{PM} 10}$ específicos para operaciones de manipulación de clínker.

\begin{tabular}{|c|c|c|}
\hline Material manipulado & Operación & $\begin{array}{c}\text { FEPM10 } \\
\mathbf{( g / t )}\end{array}$ \\
\hline \multirow{2}{*}{ Clínker } & Descarga de camión en muelle & 1.8 \\
\cline { 2 - 3 } & Remonte con máquina pala & 1.3 \\
\hline
\end{tabular}



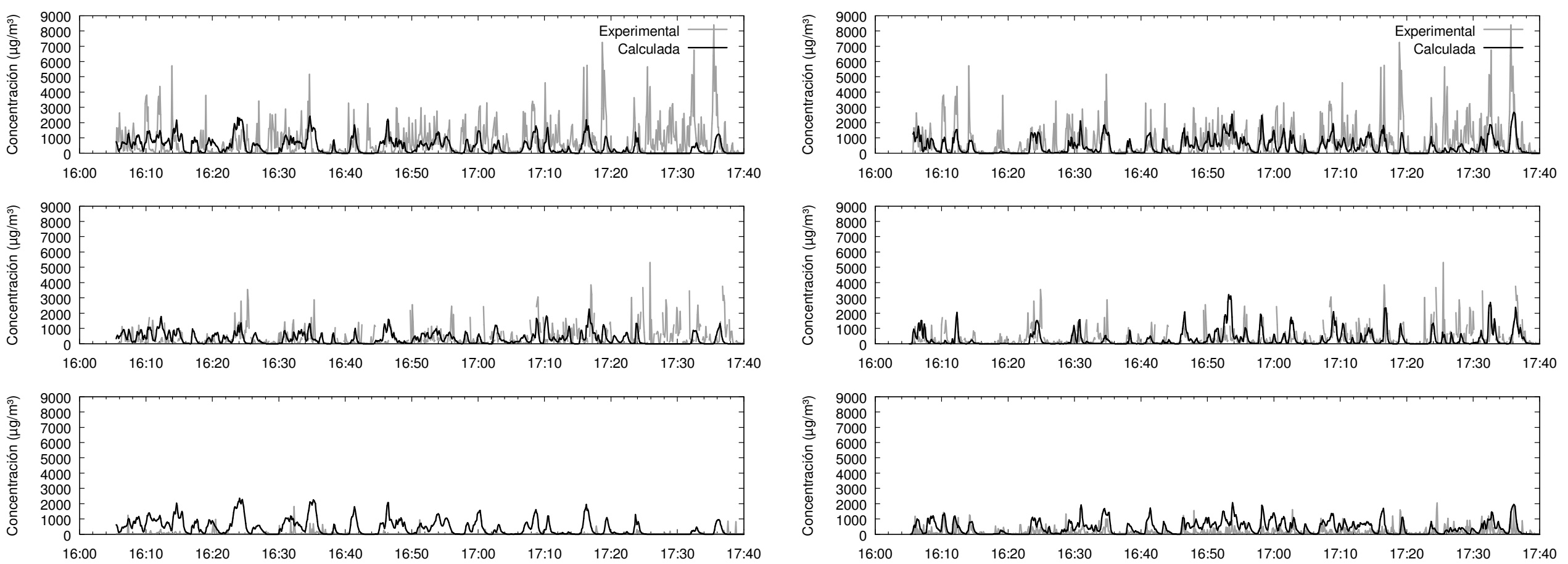

Figura 4. 16. Series temporales de concentraciones experimentales y calculadas considerando una única zona de descarga.

Figura 4. 17. Series temporales de concentraciones experimentales y calculadas considerando tres zonas de descarga. 
4.3.3 Determinación de factores de emisión específicos de PM10 para fuentes difusas de interés

\section{ARTíCULO nํ4}

Sanfélix, V., Escrig, A., López-Lilao, A., Celades, I., Monfort, E.

\section{On the source inversion of fugitive surface layer releases. Part II. Complex sources}

Atmospheric Environment, 158, 27-35, 2017

Publicado en: 2017

Número de citas (fuente: SCOPUS el 8 de mayo de 2017): 0

Factor de impacto de la revista (2015): 3.459

Factor de impacto de la revista en cinco años (2015): 3.841 


\subsubsection{Resultados adicionales al artículo no4: Determinación de la eficacia del riego con agua y aditivos en viales no pavimentados}

Las experiencias detalladas en el presente apartado tienen como objetivo determinar la eficiencia del riego con agua en viales no pavimentados, y su posible mejora mediante la utilización de aditivos. El aditivo estudiado ha sido el acetato de calcio y magnesio (CMA, por sus siglas en inglés), el cual se ha utilizado ampliamente en los países nórdicos para reducir las emisiones difusas de PM debido al tráfico rodado en la época de deshielo.

La información disponible sobre la aplicación de CMA en escenarios industriales permite conocer el porcentaje de reducción que presentan las concentraciones de PM tras la aplicación de este aditivo (Amato et al., 2016), pero este dato no permite cuantificar la reducción en las emisiones. En el caso del riego con agua, la información actual disponible en las principales guías utilizadas para la realización de inventarios de PM sobre la eficacia del mismo es limitada, ya que suele proporcionarse una eficacia en función de la cantidad de agua aplicada, sin detallarse el tiempo durante el que persiste el efecto (US-EPA, 2006; Australian Goverment, 2008 y 2012).

Por este motivo, se considera interesante determinar cuantitativamente la eficiencia de estas medidas, en lo que se refiere tanto al grado de prevención de emisiones tras su aplicación, como a la duración temporal del efecto, la cual depende de diferentes factores tales como: la cantidad aplicada; el periodo de tiempo entre aplicaciones; el peso, velocidad y número de vehículos que circulan sobre el vial; y las condiciones meteorológicas.

Las experiencias presentadas se han realizado en una cantera de áridos, siguiendo la planificación descrita en la experiencia 3 del artículo nำ4 para la ejecución de las mismas.

En la experiencia en la que se regó con agua se dosificaron aproximadamente $3.5 \mathrm{l} / \mathrm{m}^{2}$. Esta cantidad de agua se estableció de manera que se obtuviera una aplicación bastante homogénea sobre la superficie estudiada. Se trataba de aproximadamente el doble de la cantidad de agua aplicada rutinariamente por la empresa. No obstante, a pesar de haber aplicado una cantidad bastante importante de agua, su efecto prácticamente desapareció tras unas $3 \mathrm{~h}$.

Asimismo, se estudió la posibilidad de incrementar la eficiencia del riego mediante la utilización de CMA. La experiencia se realizó siguiendo las recomendaciones del suministrador para la aplicación del mismo. En primer lugar, se efectuó un riego con agua del tramo estudiado, empleando las cantidades de agua utilizadas rutinariamente por la empresa $\left(<2 \mathrm{l} / \mathrm{m}^{2}\right)$. De este modo, se pretendía limitar la capacidad de succión de la vía no asfaltada, para posteriormente pulverizar la cantidad deseada de CMA (aproximadamente $100 \mathrm{~g} / \mathrm{m}^{2}$ ) sobre la superficie húmeda.

En esta experiencia la vía se secó más rápidamente que en la experiencia anterior, lo que concuerda con el hecho de haber aplicado una menor cantidad de agua y con las observaciones descritas en Amato et al. (2016). La película de CMA, bajo condiciones típicas del clima mediterráneo, no parece tener un efecto acusado en prevenir las emisiones puesto que las concentraciones registradas en las proximidades de la vía se incrementaron rápidamente. 
Como se ha indicado, el propósito de las experiencias detalladas es determinar la eficiencia del riego, y su posible mejora mediante la utilización de CMA. A tal efecto, se realizó un primer experimento (experiencia 3 del artículo $\mathrm{n}^{\circ} 4$ ) para determinar la emisión en ausencia de la aplicación de medidas correctoras.

Con el objetivo de expresar tanto la eficacia inicial de la medida como su evolución temporal en términos cuantitativos, se ha supuesto la siguiente dependencia:

$$
\eta=\left\{\begin{array}{cc}
\eta_{0} & \text { si } t<t_{0} \\
\eta_{0} \mathrm{e}^{-\frac{t-t_{0}}{\tau}} & \text { si } t \geq t_{0}
\end{array}\right.
$$

En cuanto a los parámetros que se detallan en la ecuación 31, el valor $\eta_{0}$ es el rendimiento inicial, el cual se mantiene hasta un determinado tiempo $t_{0}$. El periodo hasta $t_{0}$ puede interpretarse como aquel en el que la superficie de la vía está completamente saturada de humedad. Transcurrido este periodo, la superficie de la vía se va secando progresivamente, por lo que las emisiones se ven incrementadas con la consiguiente reducción de eficacia. La manera más simple de describir este fenómeno es suponer que la cinética de secado es de primer orden, en la que $1 / \tau$ es la constante cinética.

En el ajuste, se ha exigido que los FE obtenidos en las diversas experiencias fueran coherentes, es decir, que el FE que correspondería a la vía totalmente seca fuera el mismo. Para ello, al aplicar la metodología RDM, las concentraciones experimentales obtenidas en las diversas experiencias se ajustaron colectivamente a las concentraciones calculadas con el modelo de dispersión.

Así pues, se ha realizado el cálculo de las concentraciones en los puntos de muestreo mediante el programa de cálculo de dispersión de contaminantes desarrollado. Los valores calculados se han ajustado a los experimentales mediante la técnica de los mínimos cuadrados, siendo los parámetros de ajuste $\eta_{0}, t_{0}$ y $\tau$.

En la Figura 4.18 se presenta el ajuste obtenido entre las concentraciones experimentales y calculadas para las dos experiencias ejecutadas, observándose una buena correlación entre ambas concentraciones. En la Tabla 4.4 se detallan los valores obtenidos para cada uno de los parámetros que determinan las eficacias alcanzadas. 

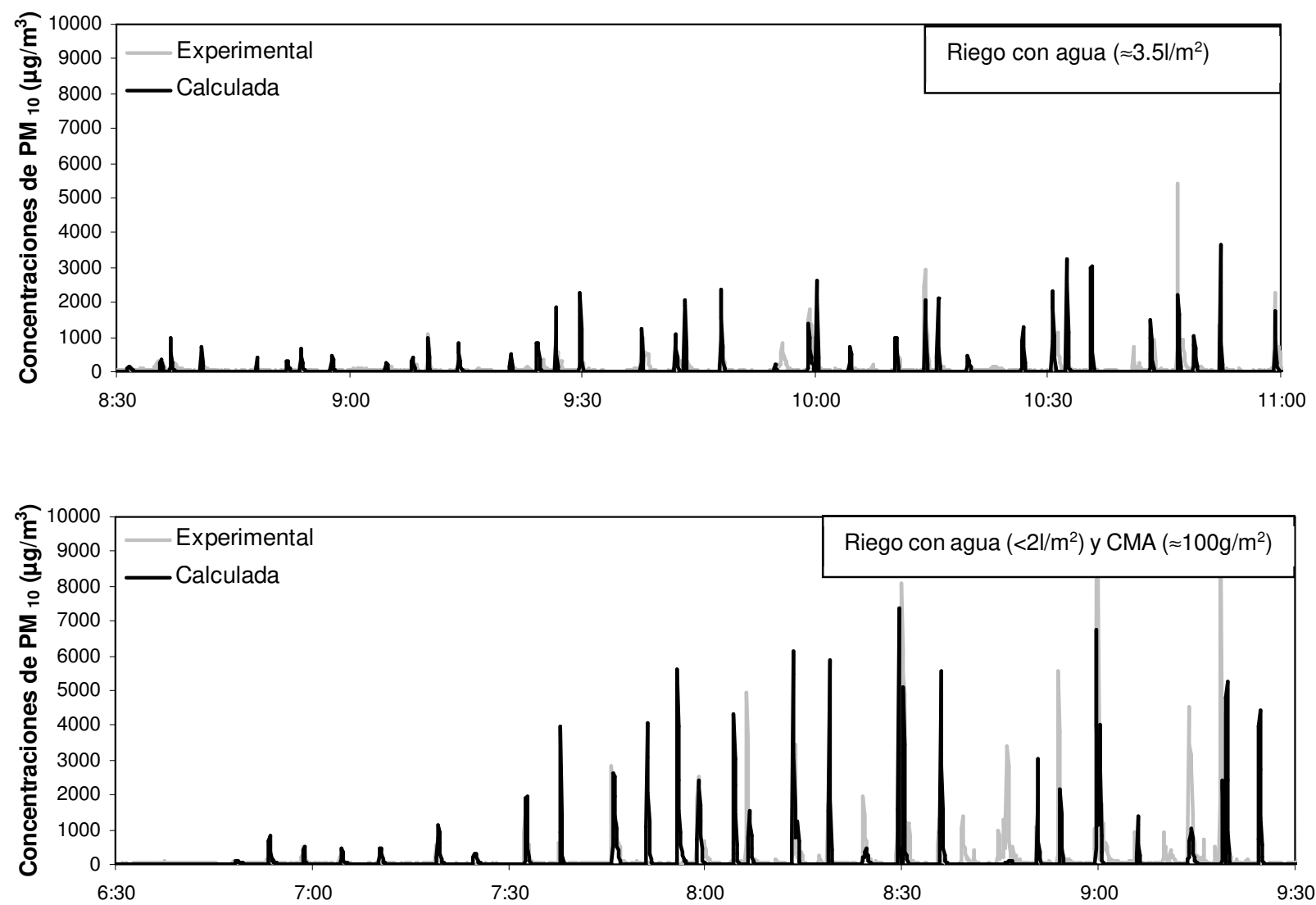

Figura 4. 18. Series temporales de concentraciones experimentales y calculadas en las experiencias realizadas.

Tabla 4. 4. Parámetros de la ecuación (31) obtenidos para las experiencias realizadas.

\begin{tabular}{|c|c|c|c|}
\hline Medida correctiva & $\boldsymbol{\eta}_{\mathbf{0}}(\%)$ & $\boldsymbol{t}_{\mathbf{0}}(\mathbf{h}: \mathbf{m m})$ & $\boldsymbol{T}(\mathbf{h}: \mathbf{m m})$ \\
\hline Riego con agua $\left(\approx 3.5 \mathrm{l} / \mathrm{m}^{2}\right)$ & 87 & $0: 36$ & $1: 33$ \\
\hline $\begin{array}{c}\text { Riego con agua }\left(<2 \mathrm{l} / \mathrm{m}^{2}\right)+ \\
\text { pulverización de CMA }\left(100 \mathrm{~g} / \mathrm{m}^{2}\right)\end{array}$ & 83 & $0: 36$ & $0: 50$ \\
\hline
\end{tabular}

Evidentemente, como ya se ha comentado, la duración de la medida está muy influenciada por factores meteorológicos, tales como la radiación solar incidente, la temperatura ambiente o la velocidad del viento, así como por la propia frecuencia de paso de camiones. No obstante, se considera muy importante haber establecido una correspondencia entre la cantidad de agua aplicada y la duración del efecto. En la Tabla 4.5, se presenta información relevante para el uso adecuado de las eficacias obtenidas. 
Tabla 4. 5. Información relevante para el uso de las eficacias obtenidas.

\begin{tabular}{|c|c|c|c|c|c|c|}
\hline \multirow[b]{2}{*}{ Experiencia } & \multicolumn{3}{|c|}{ Variables meteorológicas } & \multicolumn{3}{|c|}{ Información vehículos } \\
\hline & $\begin{array}{c}V_{\text {media viento }} \\
(\mathrm{m} / \mathrm{s})\end{array}$ & $\begin{array}{c}T^{\mathrm{a}} \\
\left({ }^{\circ} \mathrm{C}\right)\end{array}$ & $\begin{array}{c}\text { Densidad de } \\
\text { flujo de radiación } \\
\text { solar incidente } \\
\left(\mathrm{W} / \mathrm{m}^{2}\right)\end{array}$ & $\begin{array}{c}\text { Peso } \\
(t)\end{array}$ & $\begin{array}{l}V_{\text {media }} \\
(\mathrm{m} / \mathrm{s})\end{array}$ & $\begin{array}{c}\text { Frecuencia de } \\
\text { paso } \\
\left(\mathrm{min}^{-1}\right)\end{array}$ \\
\hline Riego con agua $\left(\approx 3.5 \mathrm{l} / \mathrm{m}^{2}\right)$ & 3.1 & 24 & 900 & \multirow[b]{2}{*}{80} & \multirow[b]{2}{*}{11} & \multirow[b]{2}{*}{3} \\
\hline $\begin{array}{l}\text { Riego con agua }\left(<2 \mathrm{l} / \mathrm{m}^{2}\right) \\
+ \text { CMA }\left(100 \mathrm{~g} / \mathrm{m}^{2}\right)\end{array}$ & 2.1 & 24 & 600 & & & \\
\hline
\end{tabular}

Finalmente, en la Figura 4.19 se muestra gráficamente la variación temporal de las eficacias obtenidas. Según estos resultados, el riego con $3.5 \mathrm{l} / \mathrm{m}^{2}$ de agua parece ser una medida más efectiva y duradera en las condiciones estudiadas que la aplicación de CMA, el cual se ha aplicado siguiendo el procedimiento de aplicación recomendado por el suministrador de este producto.

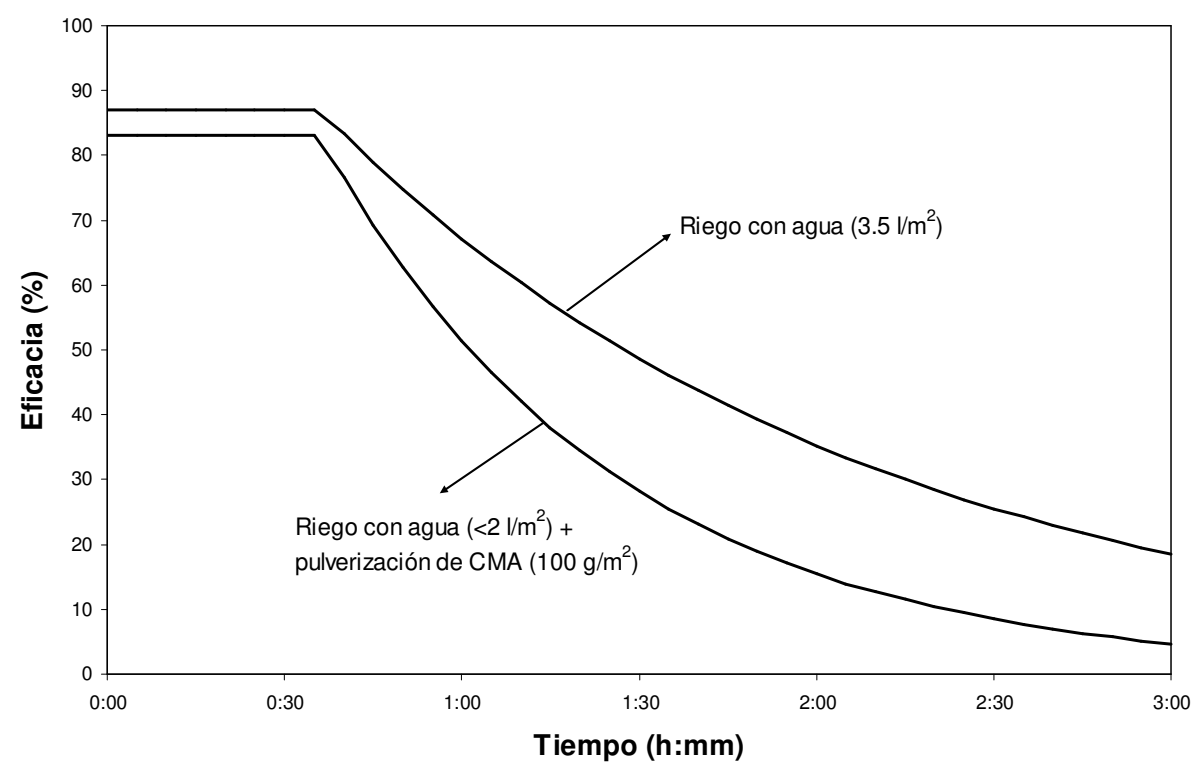

Figura 4. 19. Evolución temporal de las eficacias de las medidas correctoras estudiadas.

\subsection{Discusión de los resultados obtenidos}

\subsubsection{Discusión de los resultados obtenidos en los artículos no1 y n2}

La metodología analítica propuesta consiste en realizar un inventario de detalle de las fuentes de emisiones difusas de PM presentes en una instalación. Para la cuantificación de las emisiones difusas de PM10 totales de cada instalación se han aplicado FE existentes en la bibliografía, debido a la dificultad de disponer de medidas experimentales de los propios focos por la complejidad inherente que presentan las emisiones difusas y que han limitado la obtención de FE específicos para el sector cerámico. 
La aplicación de dicha metodología ha requerido la identificación exhaustiva de todas las operaciones generadoras de emisiones difusas de PM y de los diferentes materiales manipulados, así como de las medidas correctoras implementadas en las diferentes operaciones. Posteriormente, se ha considerado la frecuencia temporal de realización de cada operación y se les ha asignado un FE y una eficacia a las medidas correctoras implementadas.

No obstante, la escasez de información disponible, en cuanto a FE específicos por operación y/o material y a eficacias de medidas correctoras concretas, ha dificultado enormemente la aplicación de la metodología propuesta. Esta situación ha conllevado a tener que evaluar la idoneidad de la aplicación de los FE genéricos para las operaciones y materiales propios del sector cerámico. Con este objetivo se ha realizado una comparación entre las emisiones determinadas experimentalmente para un conjunto de operaciones y las determinadas aplicando FE existentes, permitiendo seleccionar aquellos FE que presentaban una mejor aproximación a la realidad.

La metodología propuesta ha permitido determinar FE globales y eficacias de las medidas correctoras implementadas en cada una de las instalaciones estudiadas, obteniéndose FE dentro de un mismo orden de magnitud cuando el escenario tecnológico (definido en función del proceso de fabricación y del grado de medidas correctoras implementadas) era similar.

El estudio en detalle de las operaciones generadoras de PM y de las medidas correctoras implementadas en trece plantas cerámicas ha facilitado agruparlas en función del escenario tecnológico que presentaban, obteniéndose un FE y una eficacia de las medidas correctoras por tipo de parque de almacenamiento de materias primas (Tabla 4.6). Esta información permite definir de forma concreta las MTD para las emisiones difusas del sector cerámico, ya que actualmente en el BREF de cerámica las MTD para fuentes difusas se definen de una manera mucho más cualitativa y abierta que en el caso de las emisiones canalizadas, considerándose como MTD desde la humectación de las materias primas acopiadas al aire libre hasta la construcción de naves cerradas y, no disponiéndose además de información sobre la eficacia asociada a la implementación de las mismas.

Además, se considera de enorme interés práctico la obtención de FE globales por tipo de instalación, ya que permite simplificar la cuantificación de las emisiones difusas para dar respuesta a determinados requisitos legislativos, como, por ejemplo, la cumplimentación del PRTR.

Esta metodología aplicada a la industria cerámica puede ser obviamente extrapolable a otras actividades industriales, siempre que se disponga de información concreta de los escenarios habituales de aplicación de medidas correctoras y de las operaciones generadoras de emisiones difusas de PM. En este sentido, en el apartado 1.2.3 de la introducción se presenta una recopilación de operaciones específicas para las diferentes actividades industriales estudiadas en el presente trabajo: cerámicas, cementeras, plantas de hormigón, canteras de áridos y muelles de graneles sólidos en puertos. 
Tabla 4. 6. FEpM10 y eficacia de las MTD para los principales tipos de parques de almacenamiento de materias primas en la industria cerámica.

\begin{tabular}{|c|c|c|c|c|c|}
\hline $\begin{array}{c}\text { Tipo de } \\
\text { instalación }\end{array}$ & & MTD & $\mathbf{n}$ & $\begin{array}{c}\text { Eficacia } \\
(\%)\end{array}$ & $\begin{array}{c}\text { FE } \\
(\mathbf{g} / \mathbf{t})\end{array}$ \\
\hline Cerrada & \multicolumn{2}{|c|}{$\begin{array}{l}\text { Transporte por zonas asfaltadas } \\
\text { Cerramiento total } \\
\text { Sistemas de aspiración + depuración de la emisión }\end{array}$} & 2 & $>95$ & $7-11$ \\
\hline Semicerrada & \multicolumn{2}{|c|}{$\begin{array}{l}\text { Transporte por zonas asfaltadas } \\
\text { Cerramiento parcial }\end{array}$} & 2 & $75-80$ & $71-84$ \\
\hline \multirow{2}{*}{ Abierta } & $\begin{array}{l}\text { Implementación } \\
\text { extensiva de MTD }\end{array}$ & $\begin{array}{l}\text { Vías asfaltadas (>75\%) } \\
\text { Riego de vías no asfaltadas } \\
\text { Nave cerrada + aspiración } \\
\text { en operaciones con } \\
\text { materiales pulverulentos } \\
\text { (triturador) }\end{array}$ & 3 & $25-50$ & $220-240$ \\
\hline & $\begin{array}{l}\text { Implementación } \\
\text { escasa de MTD }\end{array}$ & $\begin{array}{l}\text { Vías no asfaltadas (>75\%) } \\
\text { Vallas perimetrales } \\
\text { Escasas medidas } \\
\text { correctoras en operaciones } \\
\text { con materiales } \\
\text { pulverulentos }\end{array}$ & 6 & $<20$ & $270-350$ \\
\hline
\end{tabular}

Finalmente, se comentan las limitaciones detectadas en las metodologías aplicadas, de las que cabe destacar las siguientes:

- El protocolo de actuación seguido para la ejecución de las campañas experimentales en plantas cerámicas no permitió obtener FE asociados a operaciones concretas, debido principalmente a que la parametrización de las fuentes no presentaba la exactitud requerida para este objetivo. Consecuentemente, se obtuvieron tasas de emisión experimentales asociadas a un conjunto de operaciones realizadas en un periodo de tiempo determinado.

- La metodología RDM aplicada para cuantificar experimentalmente las emisiones difusas de PM requiere el uso de un modelo de dispersión de contaminantes. En este caso, se ha utilizado el modelo MELPUFF, el cual es un modelo lagrangiano basado en fuentes instantáneas gaussianas, que fue desarrollado para el estudio de las emisiones difusas de PM en operaciones portuarias (Martín et al., 2002 y 2007). Este tipo de modelos se utilizan ampliamente, tanto por la facilidad de aplicación que presentan como por el tiempo requerido para su solución. No obstante, una debilidad de los mismos es que no tienen en cuenta, desde su planteamiento, la estructura de la capa límite atmosférica, determinando los coeficientes de difusión por métodos empíricos. Sin embargo, la velocidad del viento varía con la altura, especialmente en la capa superficial, lo que propicia que, al menos la distribución vertical de concentraciones no pueda considerarse gaussiana. Por tanto, su aplicación a las emisiones difusas de PM no es del todo apropiada.

- La evaluación de la aplicación de los FE existentes para el sector cerámico se ha realizado por comparación entre las tasas de emisión determinadas experimentalmente y las calculadas 
para el mismo periodo y escenario, obteniéndose resultados coherentes. Sin embargo, la aplicación generalizada de estos FE a operaciones individuales o a otro conjunto de operaciones puede ocasionar errores en la cuantificación, puesto que incluso en el caso en que el valor global sea acorde al obtenido experimentalmente, puede ocurrir que se obtenga por compensación de FE específicos no representativos de operaciones concretas.

- El uso de FE globales no permite identificar las operaciones más problemáticas en un proceso, situación que dificulta la determinación de medidas correctoras específicas para cada operación. Esta información sería de gran interés para la optimización del diseño de las instalaciones, por lo que para un mayor control operacional e inventarios de detalle este tipo de FE puede no ser suficiente.

Para superar estas limitaciones, se ha considerado necesario ampliar el estudio, desarrollando una metodología experimental para la obtención de FE específicos y eficacias de MTD concretas que se adapte mejor a la casuística de las emisiones difusas de PM en escenarios industriales.

En relación a la caracterización química y morfológica de las emisiones difusas de PM asociadas al almacenamiento, manipulación y transporte de materias primas y granulo atomizado, cabría esperar a priori, que el perfil químico y morfológico de las mismas derive de la composición de las materias primas manipuladas y de las emisiones generadas por tráfico, como consecuencia del continuo movimiento de maquinaria en las instalaciones. Sin embargo, se ha observado que en entornos industriales el perfil químico y morfológico de las emisiones difusas de PM puede verse afectado por diferentes fuentes externas, tales como: el fondo local y regional y las fuentes de emisión colindantes, presentando perfiles que requieren conocer las posibles contribuciones de las fuentes externas para una correcta interpretación de los resultados.

\subsubsection{Discusión de los resultados obtenidos en los artículos no3 y no4}

La complejidad que presentan las fuentes de emisión estudiadas hace inviable el uso de la mayor parte de los métodos de cuantificación de emisiones difusas de PM enumerados en el apartado 1.2.2. de la introducción, siendo únicamente aplicable la metodología RDM. Consecuentemente, en el presente trabajo se propone esta metodología para obtener experimentalmente FE específicos por operación y/o material manipulado en entornos industriales.

Dado que la aplicación de la metodología RDM requiere el uso de un modelo de dispersión de contaminantes, se ha considerado relevante que este considere las principales características de las emisiones difusas de PM. Desafortunadamente, los modelos disponibles presentan una serie de limitaciones a la hora de simular fuentes difusas de PM, entre las que cabe destacar:

- Algunos modelos son estacionarios, como por ejemplo AERMOD, y por tanto no son aplicables a fuentes intermitentes y/o móviles.

- La mayoría de los modelos se basan en un marco gaussiano, lo que implica ignorar características relevantes de la capa superficial, como, por ejemplo, la variación de la velocidad con la altura.

- Determinados programas de ordenador que implementan los modelos de dispersión existentes requieren la entrada de más datos meteorológicos de los necesarios para el estudio de las emisiones difusas de PM, como por ejemplo, la altura de la capa de mezcla. 
- En los modelos existentes resulta complejo expresar determinadas características del comportamiento de las fuentes difusas en términos de sus datos de entrada, como por ejemplo, el cambio de posición de la fuente con el tiempo.

- La mayor parte de los modelos de dispersión han sido desarrollados para escalas mucho mayores de la requerida para el estudio de las emisiones difusas. Por ejemplo, CALPUFF ha sido diseñado para simular el transporte a larga distancia.

Como consecuencia de las limitaciones detectadas en los modelos de dispersión existentes para su aplicación a las fuentes de emisión que se pretenden estudiar, se ha desarrollado un modelo de dispersión de contaminantes ad hoc para las emisiones difusas de PM, de modo que permita alcanzar el objetivo planteado de obtener FE específicos y realistas. El modelo desarrollado es un modelo no estacionario, que consiste en resolver numéricamente la ecuación de transporte, la cual es una ecuación de derivadas parciales que se resuelve por el método de volúmenes finitos.

Al resolver la ecuación de transporte numéricamente, resulta sencillo incorporar el perfil vertical de velocidades de acuerdo con la teoría de M-O. Además, esta teoría también proporciona un valor teórico para la difusividad turbulenta de materia en la vertical, el cual coincide con la difusividad turbulenta de calor por la hipótesis de Schmidt (1925). Se ha demostrado que los modelos que incorporan la teoría de similitud de M-O en su concepción proporcionan en la mayoría de los casos mejores resultados (Qian y Venkatram, 2011), además de resultar más sencillos en cuanto a su formulación respecto a otros modelos existentes.

En el sentido horizontal, en el modelo se distingue entre dispersión relativa (origina el ensanchamiento de la pluma) y dispersión absoluta (propicia que la pluma describa meandros). En general, cuanto menor es la velocidad del viento, mayor peso tiene la dispersión absoluta sobre la relativa. La manera seleccionada para determinar la dispersión horizontal se basa en la interpretación de Eckman (1994) del teorema de Taylor (1921). Este establece que, para el tipo de emisiones estudiadas, las difusividades turbulentas horizontales son proporcionales al tiempo de viaje de las partículas.

Para fuentes estáticas, el tiempo de viaje puede calcularse mediante el uso de ecuaciones propuestas en estudios anteriores. En el caso de fuentes complejas, dado que el planteamiento seleccionado para abordar este tipo de fuentes ha sido tratar la emisión continua como si se tratara de una sucesión infinita de puffs, el tiempo de viaje de las partículas puede conocerse exactamente.

Este marco de cálculo ha permitido tratar la dispersión de PM emitido por fuentes móviles que siguen una trayectoria arbitraria, con una velocidad variable. Para estas fuentes, la concentración total se ha obtenido simplemente sumando las contribuciones de todos los puffs.

Atendiendo a estas consideraciones se ha desarrollo un modelo de dispersión de contaminantes muy flexible, el cual requiere el registro en campo de información limitada, condiciones atmosféricas y características de las emisiones, y que presenta las siguientes ventajas frente a otros modelos:

- Posibilidad de tratar fuentes de geometría arbitraria e intermitentes.

- Simulación de los meandros descritos por las plumas (dispersión absoluta).

- Coeficientes de dispersión basados únicamente en la teoría de M-O (dispersión vertical) y en el teorema de Taylor (dispersión horizontal). 
- Tratamiento de la deposición del PM incorporada en las ecuaciones fundamentales y no basada en aproximaciones.

En contrapartida, el programa desarrollado para su resolución requiere muchos órdenes de magnitud más de tiempo de cálculo.

Con el fin de introducir adecuadamente la información requerida por el modelo, se ha establecido un protocolo de ejecución de las campañas experimentales, en el que se considera imprescindible realizar una parametrización exhaustiva de las fuentes de emisión. En este sentido, es relevante caracterizar operaciones que permitan determinar el instante, duración y posición de la emisión con precisión para poder realizar posteriormente una correcta interpretación de los picos de concentración registrados. Esto requiere que los equipos de muestreo se ubiquen a distancias entre 50 y 100 m del foco de emisión, limitando de este modo también la contribución de otras fuentes no controladas.

La cuantificación de la bondad de los ajustes para fuentes relativamente simples se ha realizado comparando las concentraciones experimentales y las ajustadas con el modelo desarrollado. Para ello, se ha calculado la concentración media de cada pico a partir de la determinación del área del mismo, tanto para las series de concentraciones experimentales como las ajustadas.

Los resultados obtenidos muestran que el $72 \%$ de los valores se encuentran dentro de un factor 2 , criterio de aceptación ampliamente utilizado (Venkatram et al., 2008; Perry et al., 2005), y encontrándose el $90 \%$ dentro de un factor 3 . Estos resultados son similares a los obtenidos al evaluar los modelos más avanzados con valores de experimentos controlados (realizados con gases trazadores) (Venkatram et al., 2004), lo que indica que la metodología experimental propuesta funciona bastante bien para fuentes reales. Por tanto, se considera que permite reproducir apropiadamente las concentraciones experimentales de PM10 y, por tanto, la obtención de FE satisfactorios.

En el caso de fuentes complejas, debido principalmente a que los picos de concentración de PM10 no presentan un área bien definida, superponiéndose en ocasiones, la robustez de los FE obtenidos se ha evaluado aplicando el método bootstrap (Efron and Tibshirani, 1993). Con este fin se han modificado aleatoriamente tanto los intervalos de concentración de PM10 como el valor límite de concentración por debajo del cual no se consideran las concentraciones en la suma de los residuos cuadrados. Se han obtenido intervalos de confianza relativamente estrechos en las diferentes experiencias realizadas, lo que resalta la robustez de los FE obtenidos.

No obstante, en determinadas experiencias se ha observado un sesgo sistemático entre las concentraciones experimentales y las ajustadas, el cual persistía en las diferentes replicas obtenidas al aplicar el método bootstrap. Esta situación puede deberse al hecho de realizar el ajuste por el método de mínimos cuadrados, cuando están implicados picos de concentración extremadamente cortos (a nivel de segundos), ya que, en estos casos resulta prácticamente imposible cuadrar con exactitud el tiempo de inicio y la duración de los picos experimentales y calculados. En consecuencia, esto puede haber resultado en una ligera subestimación del FE en algunas experiencias.

En concreto se han determinado FE específicos para operaciones y materiales habituales en cerámicas, en plantas de fabricación de hormigón prefabricado, en canteras de áridos, en cementeras y en muelles de graneles sólidos en puertos. 
Por otro lado, se ha determinado la eficacia del riego con agua y del riego con agua y CMA en viales no pavimentados, observándose que la adición de CMA no mejora la eficacia del riego con agua, bajo las condiciones meteorológicas y de aplicación estudiadas. Evidentemente, como ya se ha comentado, la duración de la eficacia está muy influenciada por factores meteorológicos, tales como la radiación solar incidente, la temperatura ambiente o la velocidad del viento, así como por la propia frecuencia de paso de vehículos. En cualquier caso, aunque no sea de aplicación universal, se considera muy importante haber establecido una correspondencia entre la cantidad de agua y de CMA aplicada y la duración temporal del efecto, dado que esta información de gran interés práctico no se refleja en la bibliografía consultada.

En la Tabla 4.7 se recogen los FE específicos y las eficacias de mejora obtenidas en las diferentes experiencias realizadas. Los FE se han acompañado de información complementaria de interés para facilitar el uso de los mismos (Tabla 4.8 y 4.9). Asimismo, en caso de no disponer de un FE específico para una operación o material concreto, esta información mejorará la selección de un FE de características similares al requerido.

En este sentido, en el caso de FE asociados a una operación de manipulación se ha realizado una caracterización física del material manipulado, con el objetivo de mejorar la representatividad del FE. Para este fin, se han determinado los parámetros más relevantes de los materiales relacionados con la capacidad de generar polvo: humedad, distribución granulométrica y poder de emisión de polvo. Este último, se ha clasificado en muy bajo, bajo y moderado-bajo siguiendo las indicaciones de la norma EN 15051: 2014.

En el caso de FE obtenidos para la circulación de vehículos por vías asfaltadas y no asfaltadas se facilita información sobre el tipo de vehículo y el contenido de finos depositado sobre el vial.

Los FE específicos obtenidos en el presente trabajo evidencian diferencias significativas en la emisión de PM10 que se genera cuando un mismo material es sometido a diferentes operaciones. Sin embargo, estas diferencias no pueden apreciarse si se aplican los FE propuestos en las principales guías utilizadas para la realización de inventarios de PM a nivel europeo (EMEP/EEA) y americano (AP-42).

Del mismo modo, se ha comprobado que existe una elevada variabilidad entre los FE obtenidos para distintos materiales y operaciones (hasta un factor 100). Sin embargo, la guía EMEP/EEA propone un único FE para la manipulación de minerales. En consecuencia, el uso de FE genéricos puede conllevar errores de varios ordenes de magnitud en los inventarios de emisiones, resultando inapropiados para establecer prioridades en la adopción de medidas correctoras.

En cuanto a la ecuación predictiva propuesta en el documento AP-42 para operaciones de manipulación, se han obtenido discrepancias entre los FE estimados aplicando dicha ecuación y los obtenidos experimentalmente aplicando la metodología propuesta. A este respecto, se considera importante tener en cuenta que esta ecuación se utiliza para representar un conjunto muy amplio de operaciones de caída y materiales. Sin embargo, esta se ha obtenido a partir de los resultados obtenidos en la ejecución de un número limitado de ensayos experimentales para materiales y operaciones concretas. Por tanto, a pesar de que su uso permite estimar las emisiones para operaciones y materiales para los que no se dispone de información específica, se recomienda realizar una evaluación previa de su representatividad para otros escenarios (operaciones y materiales). Además, la aplicación de dicha ecuación no es factible para casos extremos en los que se manipulen materiales con humedades muy bajas. 
En el caso del FE experimental obtenido para la circulación de vehículos en viales no pavimentados, este presenta un valor tres veces inferior al estimado aplicando la ecuación propuesta en el documento AP-42. Sin embargo, para el caso de viales asfaltados se obtienen FE similares. Este comportamiento observado requiere de la realización de un mayor número de experiencias para poder ser interpretado.

Estas limitaciones sugieren la necesidad de una cuantificación más precisa de las emisiones difusas de PM10 para poder dar respuesta a inventarios de detalle. En este sentido, se considera que la obtención de FE específicos y eficacias de medidas correctoras, aplicando la metodología experimental propuesta, permitirá alcanzar el objetivo de iniciar una base de datos para una cuantificación más realista de las emisiones difusas.

De este modo, las empresas a nivel individual o bien a través de asociaciones empresariales podrán disponer de información relevante para la elaboración de guías para la cuantificación de las emisiones difusas de PM y propuesta de medidas correctoras.

Por otra parte, permitirá a las administraciones públicas disponer de información específica para cuantificar el impacto real de las emisiones difusas de PM asociadas a determinadas actividades, y de este modo poder identificar las operaciones más problemáticas y evaluar su contribución sobre la calidad del aire. Esta información posibilitará controlar y establecer estrategias de mitigación óptimas en los planes de mejora de la calidad del aire, de forma que se alcancen los estándares de calidad del aire legislados y se asegure una buena calidad del aire a los ciudadanos de las áreas afectadas. 
Tabla 4. 7. FE y eficacias obtenidas en las diferentes experiencias realizadas.

\begin{tabular}{|c|c|c|c|c|}
\hline Actividad & Operación & $\begin{array}{c}\text { Material } \\
\text { manipulado }\end{array}$ & Medidas correctoras & FE PM10 \\
\hline \multirow{2}{*}{ Cerámicas } & Carga de máquina pala & \multirow{2}{*}{ Arcilla } & \multirow{2}{*}{ Sin medidas correctoras } & $7.4 \mathrm{~g} / \mathrm{t}$ \\
\hline & Descarga de máquina pala & & & $23 \mathrm{~g} / \mathrm{t}$ \\
\hline $\begin{array}{l}\text { Plantas de } \\
\text { hormigón } \\
\text { prefabricado }\end{array}$ & Descarga de camión en tolva & Arena & Tolva semicubierta & $0.29 \mathrm{~g} / \mathrm{t}$ \\
\hline \multirow{3}{*}{ Cementeras } & Paso de máquina pala por vías asfaltadas & \multirow{3}{*}{ Caliza } & \multirow{2}{*}{ Sin medidas correctoras } & $130 \mathrm{~g} / \mathrm{km}$ \\
\hline & Carga de máquina pala & & & $0.1 \mathrm{~g} / \mathrm{t}$ \\
\hline & Descarga de camión en tolva & & Tolva semicubierta & $0.1 \mathrm{~g} / \mathrm{t}$ \\
\hline
\end{tabular}


Tabla 4. 7. FE y eficacias obtenidas en las diferentes experiencias realizadas (Cont.).

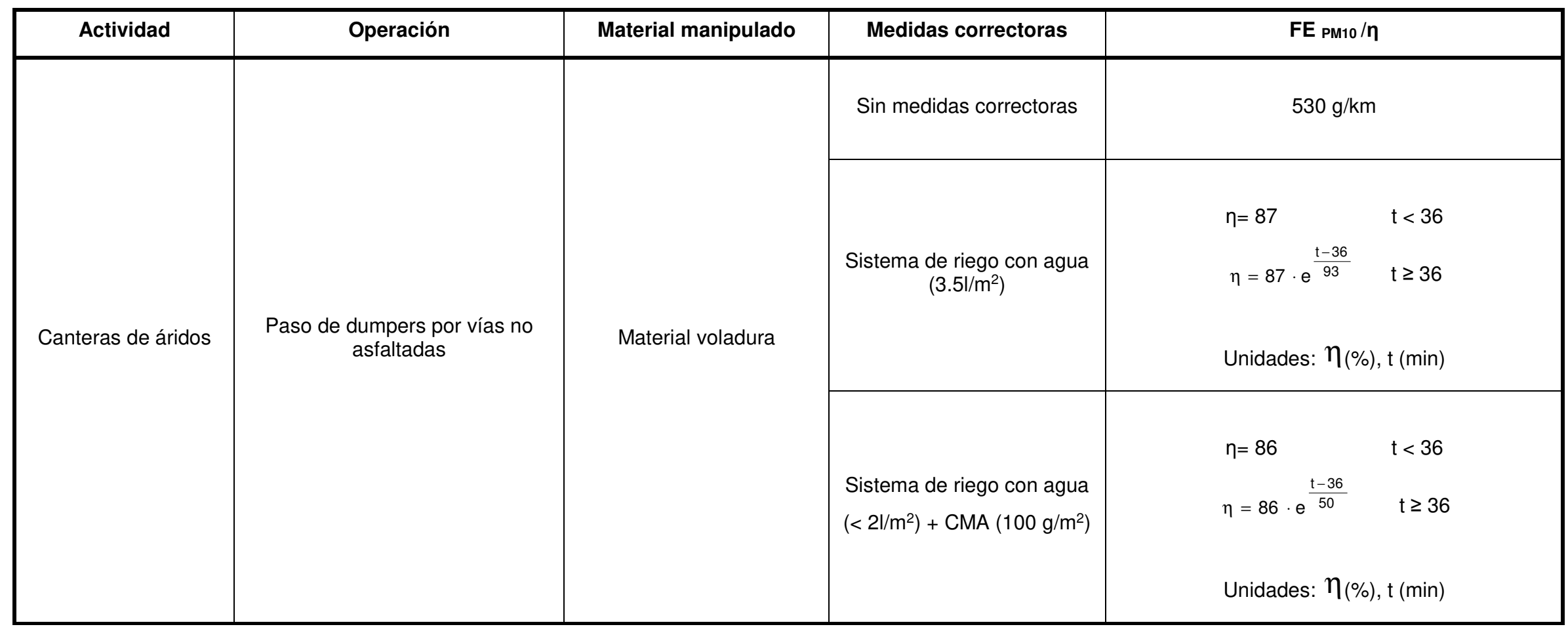


Tabla 4. 7. FE y eficacias obtenidas en las diferentes experiencias realizadas (Cont.).

\begin{tabular}{|c|c|c|c|c|}
\hline Actividad & Operación & Material manipulado & Medidas correctoras & FE PM10 \\
\hline \multirow{5}{*}{$\begin{array}{c}\text { Puertos (terminal de sólidos a } \\
\text { granel) }\end{array}$} & $\begin{array}{l}\text { Embarque con cinta } \\
\text { transportadora (descarga de } \\
\text { camión en tolva + cinta móvil) }\end{array}$ & Sulfato amónico & Sin medidas correctoras & $9.6 \mathrm{~g} / \mathrm{t}$ \\
\hline & $\begin{array}{l}\text { Descarga de camión en } \\
\text { muelle }\end{array}$ & \multirow{3}{*}{ Clínker } & \multirow{3}{*}{ Sin medidas correctoras } & $1.8 \mathrm{~g} / \mathrm{t}$ \\
\hline & Remonte con máquina pala & & & $1.3 \mathrm{~g} / \mathrm{t}$ \\
\hline & $\begin{array}{l}\text { Descarga de cuchara directa } \\
\text { en muelle }\end{array}$ & & & $19 \mathrm{~g} / \mathrm{t}$ \\
\hline & $\begin{array}{l}\text { Descarga de cuchara directa } \\
\text { en muelle }\end{array}$ & Chatarra triturada & Sin medidas correctoras & $7.3 \mathrm{~g} / \mathrm{t}$ \\
\hline
\end{tabular}


Tabla 4. 8. Información de interés para la aplicación correcta de los FE asociados a operaciones de manipulación.

\begin{tabular}{|c|c|c|c|c|c|c|}
\hline \multirow{3}{*}{ Material } & \multirow{3}{*}{$\begin{array}{c}\text { Humedad } \\
\text { (\%) }\end{array}$} & \multirow{2}{*}{\multicolumn{3}{|c|}{ DTP $(\mu \mathrm{m})$}} & \multicolumn{2}{|c|}{ Poder de emisión de polvo (mg/kg) } \\
\hline & & & & & \multirow{2}{*}{ Fracción inhalable } & \multirow{2}{*}{ Fracción respirable } \\
\hline & & $d_{10}$ & $d_{50}$ & $d_{90}$ & & \\
\hline Arcilla & 8 & 2.4 & 8.3 & 43.3 & $\begin{array}{l}1988 \\
\text { Bajo }\end{array}$ & $\begin{array}{c}8 \\
\text { Muy bajo }\end{array}$ \\
\hline Arena & $<0.5$ & 9.7 & 110.1 & 591.3 & $\begin{array}{l}2436 \\
\text { Bajo }\end{array}$ & $\begin{array}{c}14 \\
\text { Muy bajo }\end{array}$ \\
\hline $\begin{array}{l}\text { Sulfato } \\
\text { sódico }\end{array}$ & $<0.5$ & 151.9 & 300.6 & 522.7 & $\begin{array}{c}250 \\
\text { Muy bajo }\end{array}$ & $\begin{array}{c}10 \\
\text { Muy bajo }\end{array}$ \\
\hline Caliza & 2 & & 10000 & & n.d. & n.d. \\
\hline Clínker & 0.6 & 54.8 & 143.8 & 314.4 & $\begin{array}{c}3819 \\
\text { Moderado-bajo }\end{array}$ & $\begin{array}{c}16 \\
\text { Muy bajo }\end{array}$ \\
\hline $\begin{array}{l}\text { Chatarra } \\
\text { triturada }\end{array}$ & $\approx 0$ & & n.d. & & & \\
\hline
\end{tabular}


Tabla 4. 9. Información de interés para la aplicación correcta de los FE asociados a la circulación de vehículos.

\begin{tabular}{|c|c|c|c|}
\hline Tipo de vía & Vehículo & Peso medio del vehículo $(\mathrm{t})$ & Contenido en finos $(<75 \mu \mathrm{m})$ en la superficie \\
\hline Vías no asfaltadas & Dumpers & 80 & $11 \%$ \\
\hline Vías asfaltadas & Máquina pala & 33 & $8 \mathrm{~g} / \mathrm{m}^{2}$ \\
\hline
\end{tabular}




\section{Conclusiones}





\subsection{Conclusiones}

El trabajo de investigación desarrollado pretende profundizar en el conocimiento científico relativo a las emisiones difusas de PM que se generan durante el almacenamiento, manipulación y transporte de gráneles sólidos de naturaleza pulverulenta en entornos industriales.

Si bien es cierto que las conclusiones derivadas de cada uno de los artículos publicados se presentan en los mismos, en el presente apartado se sintetizan las conclusiones alcanzadas en cuanto a la identificación, cuantificación y control de las emisiones difusas de PM mediante el uso de FE y de eficacias de MTD.

\section{Sobre el uso y determinación de FE:}

- La metodología analítica establecida para la estimación de las emisiones difusas de PM en el sector cerámico, basada en la realización de un inventario de detalle, ha permitido determinar FE globales y eficacias de las medidas correctoras implementadas en cada una de las instalaciones estudiadas, obteniéndose FE dentro de un mismo orden de magnitud cuando el escenario tecnológico (definido en función del proceso de fabricación, materias primas manipuladas y del grado de medidas correctoras implementadas) es similar.

- El estudio en detalle de las operaciones generadoras de emisiones difusas de PM10 y de las medidas correctoras implementadas en trece plantas cerámicas (fabricantes de granulo atomizado, baldosas cerámicas, tejas y ladrillos), ha permitido definir tres tipos de escenarios tecnológicos (cerrado, semicerrado y abierto) en el sector cerámico, siendo el grado de cerramiento del área de almacenamiento y gestión de materias primas el principal parámetro utilizado para su clasificación. Para cada uno de estos escenarios tecnológicos se ha establecido un FE global y una eficacia de las medidas correctoras implementadas.

- Los resultados obtenidos presentan una gran utilidad práctica, permitiendo simplificar la realización de inventarios de emisiones difusas para los que no se requiere un elevado grado de detalle, como, por ejemplo, la cumplimentación del PRTR, así como la comparación de diferentes escenarios tecnológicos.

- No obstante, la información disponible actualmente para la obtención de FE globales no siempre permite llevar a cabo inventarios exhaustivos por instalación, como consecuencia de la carencia de FE específicos.

- En este sentido, se ha propuesto una metodología experimental para la obtención de FE específicos por operación y/o material manipulado basada en aplicar la metodología RDM, resultando necesario para ello el desarrollo de un modelo de dispersión de contaminantes ad hoc para las emisiones difusas de PM. La flexibilidad del modelo de dispersión de contaminantes desarrollado, así como la parametrización exhaustiva de las fuentes de emisión, ha permitido obtener de forma satisfactoria FE específicos tanto para fuentes simples como complejas.

- El modelo de dispersión desarrollado consigue reproducir satisfactoriamente las concentraciones de PM10 registradas en campo, a pesar de la complejidad que presentan las fuentes de emisiones difusas de PM para su modelización de forma realista, tanto por sus características inherentes como por su fenomenología de dispersión. El modelo propuesto 
permite tratar fuentes intermitentes, de geometría arbitraria y móviles, e incluso incorporar los meandros de la pluma.

- El protocolo de ejecución de las campañas experimentales establecido ha permitido introducir de la forma más realista posible las condiciones atmosféricas y las características de la emisión en el modelo de dispersión, requiriendo para ello el registro en campo de información limitada: variables meteorológicas y parametrización exhaustiva de las fuentes emisoras. En este sentido, se considera relevante caracterizar operaciones que permitan determinar el instante, duración y posición de la emisión con exactitud.

- De la comparación entre los FE obtenidos experimentalmente y los FE genéricos, recogidos en las principales guías utilizadas para la realización de inventarios, se concluye la necesidad de realizar una evaluación previa de los FE genéricos para su correcta aplicación a operaciones y/o materiales concretos. Esta reflexión se plantea como consecuencia del elevado rango de variabilidad (hasta un factor 100) observado en los diferentes FE obtenidos experimentalmente en el presente trabajo.

\section{Sobre la caracterización química y morfológica:}

- En relación a la caracterización química y morfológica de las emisiones difusas de PM, se ha identificado la contribución del fondo local y regional, así como de emisiones colindantes en el perfil químico obtenido. En consecuencia, se han obtenido perfiles químicos complejos que exigen un amplio conocimiento de las fuentes externas de emisión para realizar una correcta interpretación de los resultados.

- Con este fin, se propone identificar y cuantificar los elementos traza de las fuentes de interés $y$ de las fuentes colindantes que puedan potencialmente impactar sobre los puntos de muestreo, así como disponer de información sobre los trazadores del fondo local y regional.

\section{Sobre el uso y eficacia de medidas correctoras:}

- La cuantificación de las emisiones difusas de PM10 en el sector cerámico, asociadas al almacenamiento, manipulación y transporte de materiales pulverulentos, ha puesto de manifiesto la contribución significativa de este tipo de emisiones si no se aplican medidas correctoras de elevada eficacia, tales como el cerramiento parcial o total del área de almacenamiento. Esta información se considera de enorme interés para definir de forma concreta las MTD para el sector cerámico.

- En las instalaciones estudiadas se ha apreciado que la resuspensión de PM debido al transporte interno suele ser una fuente muy significativa de emisiones difusas de PM10, incluso cuando el transporte se realiza sobre viales asfaltados. Para minimizar estas emisiones se ha observado que es preferible realizar el transporte por zonas asfaltadas y mantener la superficie de los viales con una mínima carga de partículas finas, lo que exige establecer protocolos de limpieza apropiados (tipo de equipos, frecuencia, entre otros.).

- El estudio de la eficacia del riego con agua y agua con CMA demuestra que, bajo las condiciones de clima mediterráneo, el uso de CMA en viales industriales no asfaltados no produce mejoras significativas de la eficacia con respecto al uso de agua sin aditivos.

- En el trabajo desarrollado se ha establecido una correspondencia cuantitativa entre la cantidad de agua y de CMA aplicada y la duración temporal de su efecto en vías no asfaltadas. A pesar 
de que la duración de la eficacia se encuentra muy influenciada por factores meteorológicos, así como por la propia frecuencia de paso de vehículos, está información resulta de enorme interés para la definición de protocolos de aplicación para el riego.

\section{Sobre el control de las emisiones difusas de PM:}

- La obtención de FE específicos y de eficacias de medidas correctoras concretas ha permitido iniciar una base de datos con información de detalle para lograr obtener una cuantificación más real de las emisiones difusas de PM. Esta información se considera de gran utilidad para incorporar de forma cuantitativa el control de las emisiones difusas de PM.

- Al mismo tiempo, el hecho de haber determinado FE y eficacias de MTD por tipo de escenario tecnológico, abre la posibilidad de poder utilizar una metodología similar a la que se aplica al control de las emisiones canalizadas de PM, de forma que se pueda mejorar la sistematización del control de las emisiones difusas de PM.

A modo de conclusión general y basándose en la experiencia adquirida en el estudio realizado, a continuación, se propone un sistema de control de las emisiones difusas de PM diferenciado las dos fases principales de toda actividad: fase de proyecto (diseño de la instalación) y fase operativa (gestión de la actividad):

- En la fase de proyecto, complementariamente a la descripción cualitativa de las MTD a adoptar (por ejemplo: asfaltado de viales de circulación o cerramiento de acopios de materias primas) se propone realizar un inventario cuantitativo de las emisiones difusas de PM siguiendo la metodología analítica propuesta, considerando cada una de las operaciones unitarias del proceso, y teniendo presente la eficacia de las MTD propuestas para la obtención de la AAI. Esta información permitiría determinar el diseño de planta que conlleve unas menores emisiones, junto con unos valores de emisión absoluta y de emisión relativa, para que puedan ser evaluados por la administración competente. En este sentido, la emisión absoluta se considera interesante para el inventario de emisiones, mientras que la emisión relativa permitiría comprobar si el diseño de planta cumple un FE global (por ejemplo, en grm1o/t de producto), establecido previamente por la administración competente como un VLE para su cumplimiento por parte de las instalaciones. Estos FE pueden establecerse en función del tipo y tamaño de la actividad, distancia a núcleos urbanos, entre otros.

- En cuanto a la fase de operación, con carácter general, en todas las instalaciones se propone instalar sistemas de registro que permitan verificar la correcta aplicación de las MTD seleccionadas en la fase de proyecto e implementadas, como, por ejemplo: consumo de agua de riego o tiempo de utilización de barredoras, medidas necesarias para la minimización de las emisiones difusas por resuspensión. Además, se propone que todas las instalaciones presenten una declaración anual cuantitativa de emisiones difusas de PM, con el fin de registrar las mejoras que anualmente se van implementado en cada instalación, registrar cambios en la producción, modificaciones de materia primas, entre otros. Los sistemas comentados de registro e inventario presentan las ventajas de que permiten la verificación por un tercero y la inclusión de las emisiones difusas de PM en los inventarios de emisiones. Adicionalmente, sólo en algunos casos (sobre todo para cercanía a núcleos urbanos, espacios protegidos) se podrían complementar estos controles con medidas perimetrales de concentraciones ambientales de PM. Finalmente, únicamente se considera interesante una comprobación experimental del cumplimiento de los FE establecidos en casos extremos. 
La aceptación de esta propuesta conllevaría la realización de instrucciones técnicas en las que se facilitaran FE específicos y rendimientos de mejora, al menos para las MTD recogidas en los BREF, así como el establecimiento de VLE para emisiones difusas de PM en entornos industriales (definidos en forma de FE global) para su cumplimiento por parte de las instalaciones. Dicha instrucción técnica difícilmente podría elaborarse con la información actual disponible en estos temas. 
6 Futuras líneas de investigación 



\subsection{Futuras líneas de investigación}

Con el fin de completar el estudio realizado, se plantean a continuación una serie de recomendaciones para futuras líneas de investigación. Sin pretender realizar una relación exhaustiva, se destacan a continuación las más interesantes:

\section{Sobre el modelo de dispersión de contaminantes:}

- Determinadas configuraciones de plantas no permiten la ubicación de los equipos de muestreo sin la presencia de obstáculos, alterando sustancialmente el perfil de velocidades la presencia de los mismos. Como consecuencia de esta situación, se considera interesante incorporar el efecto de la presencia de obstáculos en el modelo de dispersión de contaminantes desarrollado, aumentando de este modo la versatilidad del mismo y permitiendo obtener FE satisfactorios para la mayor parte de disposiciones de plantas existentes. Además, está ampliación del modelo permitirá simular y evaluar la ubicación idónea de pantallas perimetrales para disminuir el impacto ambiental de las emisiones difusas de PM, así como determinar su eficacia.

- Adaptación y aplicación del modelo de dispersión de contaminantes atmosféricos a otras fuentes de emisiones difusas de PM de interés para determinar FE. Como, por ejemplo, a la quema de restos de poda al aire libre, fuente que parece contribuir significativamente sobre los niveles de calidad del aire. La aplicabilidad del modelo a esta fuente, requiere de su adaptación para que contemple las corrientes convectivas que resultan de las elevadas temperaturas que se dan durante la combustión. Actualmente, se están llevando a cabo proyectos en el ITC relacionados con esta línea. Además, también se considera interesante cuantificar la fracción de PM condensable que da lugar a PM secundario, debido a que esta fracción es significativa en las emisiones de PM generadas durante la combustión de biomasa.

\section{Sobre el estudio del efecto de variables sobre la emisión:}

- Determinar correlaciones empíricas entre las características del material manipulado (humedad, distribución granulométrica, fluidez, poder de emisión de polvo) y las tasas de emisión obtenidas para diferentes operaciones realizadas con materiales sólidos pulverulentos. En el momento de redactar esta memoria, en el ITC se están desarrollando trabajos centrados en esta línea de investigación.

- Determinar la influencia de la velocidad del viento sobre la emisión de un material determinado. Por ejemplo, en las actividades de embarque y desembarque realizadas en los muelles de graneles sólidos en puertos se considera de enorme interés disponer de este tipo de información, para evaluar a priori la posible contribución de estas operaciones sobre los niveles de calidad del aire del entorno, dado su habitual proximidad a núcleos urbanos. Esta información permitiría modificar los protocolos de operativas de embarque y/o desembarque, identificar la necesidad de aplicar barreras corta-viento móviles, e incluso en casos extremos paralizar la actividad.

- Ampliar el estudio realizado a otras fracciones granulométricas de interés, por ejemplo, la fracción PM2.5, con el fin de disponer de información de detalle sobre la contribución de las emisiones difusas de PM2.5 a los niveles de calidad del aire y de este modo, conocer su impacto ambiental y poder establecer las necesidades de control para esta fracción. 


\section{Sobre el estudio de medidas correctoras}

- Estudiar la eficacia de otros aglomerantes para minimizar las emisiones por resuspensión en viales industriales no pavimentados. Se considera interesante determinar la eficacia de este tipo de medida, dado que la resuspensión de PM debido al transporte interno se ha identificado como una de las fuentes más significativas de emisiones difusas de PM10. 
7 Publicaciones en congresos 



\subsection{Publicaciones en congresos}

Del estudio realizado se han presentado las siguientes comunicaciones y pósteres a congresos:

\begin{tabular}{|c|l|}
\hline Autores & $\begin{array}{l}\text { Monfort, E., Celades, I., Gomar, S., Gazulla, M.F., Sanfélix, V., Martín, F., de } \\
\text { Pascual, A., Aceña, B. }\end{array}$ \\
\hline Título & Control de las emisiones difusas de PM en la industria cerámica \\
\hline Tipo de participación & Ponencia oral \\
\hline Congreso & $\begin{array}{l}\text { IX Congreso Mundial de la Calidad del Azulejo y del Pavimento Cerámico, } \\
\text { QUALICER } 2006\end{array}$ \\
\hline Lugar de celebración & Cámara Oficial de Comercio, Industria y Navegación de Castellón \\
\hline Fecha & $12-15$ de febrero de 2006 \\
\hline
\end{tabular}

\begin{tabular}{|c|l|}
\hline Autores & Monfort, E., Celades, I., Gomar, S., Sanfélix, V. \\
\hline Título & Control y estimación de emisiones difusas de PM en operaciones al aire libre \\
\hline Tipo de participación & Ponencia oral \\
\hline Congreso & X Congreso de Ingeniería Ambiental, PROMA 2006 \\
\hline Lugar de celebración & Bilbao Exhibition Center - BEC \\
\hline Fecha & $2-6$ de octubre de 2006 \\
\hline
\end{tabular}

\begin{tabular}{|c|l|}
\hline Autores & Monfort, E., Celades, I., Gomar, S., Sanfélix, V., López, J.L., Calpe, V. \\
\hline Título & $\begin{array}{l}\text { Estimación de emisiones difusas de PM y rendimiento de MTD en el sector } \\
\text { cerámico }\end{array}$ \\
\hline Tipo de participación & Ponencia oral \\
\hline Congreso & XLVI Congreso Anual de la Sociedad Española de Cerámica y Vidrio \\
\hline Lugar de celebración & Vall D'Alba (Castellón) \\
\hline Fecha & $25-27$ de octubre de 2006 \\
\hline
\end{tabular}

\begin{tabular}{|c|l|}
\hline Autores & $\begin{array}{l}\text { Monfort, E., Celades, I., Sanfélix, V., Gomar, S., Martín, F., Aceña, B., de } \\
\text { Pascual, A. }\end{array}$ \\
\hline Título & Estimates of fugitive PM10 emissions from the ceramic tile industry \\
\hline Tipo de participación & Ponencia oral \\
\hline Congreso & $\begin{array}{l}10 \text { th International Conference and Exhibition of the European Ceramic Society } \\
- \text { ECERS }\end{array}$ \\
\hline Lugar de celebración & Berlín \\
\hline Fecha & $17-21$ de junio de 2007 \\
\hline
\end{tabular}




\begin{tabular}{|c|l|}
\hline Autores & $\begin{array}{l}\text { Monfort, E., Celades, I., Sanfélix, V., Gomar, S., Martín, F., Aceña, B., de } \\
\text { Pascual, A. }\end{array}$ \\
\hline Título & $\begin{array}{l}\text { Experimental fugitive PM10 emission factors from solid bulk handling } \\
\text { areas in the open air }\end{array}$ \\
\hline Tipo de participación & Póster (premiado como el mejor poster del congreso CEM 2007) \\
\hline Congreso & 8th International Conference on Emissions Monitoring, CEM \\
\hline Lugar de celebración & Zürich \\
\hline Fecha & $5-6$ de septiembre de 2007 \\
\hline
\end{tabular}

\begin{tabular}{|c|l|}
\hline Autores & $\begin{array}{l}\text { Sanfélix, V., Monfort, E., Celades, I., Gomar, S., Martín, F., Aceña, B., de } \\
\text { Pascual, A. }\end{array}$ \\
\hline Título & $\begin{array}{l}\text { Estimates of diffuse PM10 emissions from solid bulk handling areas in } \\
\text { ceramic plants with different technological scenarios }\end{array}$ \\
\hline Tipo de participación & Póster \\
\hline Congreso & International Aerosol Conference - IAC 2010 \\
\hline Lugar de celebración & Helsinki \\
\hline Fecha & 29 de agosto -3 de septiembre de 2010 \\
\hline
\end{tabular}

\begin{tabular}{|c|l|}
\hline Autores & Sanfélix, V., Escrig, A., López, A., Celades, I., Monfort, E. \\
\hline Título & $\begin{array}{l}\text { Estrategias en emisiones difusas de PM en entornos industriales: } \\
\text { inventario de factores de emisión y eficiencia de MTD para su control }\end{array}$ \\
\hline Tipo de participación & Ponencia oral \\
\hline Jornada & $\begin{array}{l}\text { Nuevas medidas para la mejora de la calidad del aire y protección de la } \\
\text { atmósfera }\end{array}$ \\
\hline Lugar de celebración & Universidad Internacional Menéndez Pelayo, Santander \\
\hline Fecha & $25-26$ de junio de 2013 \\
\hline
\end{tabular}


8 Glosario y acrónimos 



\subsection{Glosario de términos}

Para facilitar la lectura de la memoria se incluyen en este apartado algunos de los términos de ingeniería ambiental y tecnología cerámica que aparecen con frecuencia en el texto o que se considera que pueden ser de utilidad para el lector.

Autorización Ambiental Integrada (AAI): documento que agrupa los permisos medioambientales de una instalación industrial en uno solo. Es la resolución del órgano competente de la CA en la que se ubique la instalación industrial. El permiso incluirá todas las medidas necesarias para conseguir un alto nivel de protección del medio ambiente en su conjunto y para asegurar que la explotación de la instalación se efectúe de acuerdo con los principios generales aplicables a las obligaciones fundamentales del titular. El permiso también incluirá VLE para las sustancias contaminantes, o parámetros equivalentes o medidas técnicas, requisitos adecuados para la protección del suelo y las aguas subterráneas y requisitos para el control.

Baldosas cerámicas (pavimentos y revestimientos): Son placas de poco grosor, generalmente utilizadas para revestimiento de suelos y paredes, fabricadas a partir de composiciones de arcillas y otras materias primas inorgánicas, que se someten a molienda y/o amasado, se moldean y seguidamente son secadas y cocidas a temperatura suficiente para que adquieran establemente las propiedades requeridas.

BREF (BAT Reference Document): Documento elaborado para determinadas actividades, en el que se describen, en particular, las técnicas aplicadas, las emisiones actuales, los niveles de consumo, las consideraciones que se tienen en cuenta para determinar las MTD, así como las conclusiones sobre las MTD y las técnicas emergentes, tomando especialmente en consideración los criterios que se enumeran en el anexo III de la Directiva 2010/75/UE.

Capa superficial atmosférica: representa la capa atmosférica en contacto con la superficie terrestre, en la que se producen las variaciones más significativas en la velocidad del viento y en las turbulencias térmica y mecánica.

Diámetro aerodinámico, $d_{a e}$ : diámetro de una partícula ficticia esférica de densidad $1 \mathrm{~g} / \mathrm{cm}^{3}$ que tiene el mismo comportamiento aerodinámico (misma velocidad terminal en régimen estacionario en el aire) que la partícula real.

Dispersión de contaminantes: la atmósfera constituye un sistema dinámico complejo, en el que los contaminantes emitidos a la atmósfera se ven afectados por el campo de movimientos de la misma. Por un lado, el viento predominante transporta los contaminantes en su dirección y sentido (advección). Por otro lado, la atmósfera produce una difusión efectiva conocida como difusión turbulenta, la cual produce movimientos relativos al movimiento medio del viento que dispersan los contaminantes. Como resultado de ambos fenómenos, advección y difusión, se produce la dispersión de los contaminantes en la atmósfera.

Escenario tecnológico: en el presente trabajo la definición de escenario tecnológico engloba tanto el propio proceso de fabricación u operación específica como las MTD implantadas.

Emisión: la expulsión a la atmósfera de sustancias, vibraciones, calor o ruido procedentes de forma directa o indirecta de fuentes canalizadas o difusas de la instalación. 
Emisión canalizada: corriente vertida a la atmósfera a través de una conducción, bien sea fija o móvil.

Emisión difusa: emisión no canalizada vertida a la atmósfera desde una superficie o volumen.

Esmalte cerámico: material preparado a partir de fritas y pigmentos cerámicos y otras materias primas que se aplica sobre un soporte para dar lugar a un recubrimiento vidriado tras el proceso de cocción.

Factor de emisión (FE): los FE estiman la tasa de emisión de PM en base a una magnitud unitaria que cuantifica la intensidad de la operación, asumiendo que las emisiones son directamente proporcionales a dicha cantidad. En la práctica, los FE para operaciones de manipulación se refieren a la masa de material procesado, mientras que los de transporte se expresan por unidad de distancia recorrida.

Fuentes complejas: fuente de emisiones difusas cuya emisión puede producirse desde una posición arbitraria en el escenario considerado. Además, es frecuente que la emisión de este tipo de fuentes dependa del estado de movimiento de la fuente.

Gránulo atomizado: aglomerados esféricos huecos de partículas los cuales se obtienen mediante un proceso de secado continuo y automático (atomización) de las materias primas.

Inmisión o calidad de aire: nivel de contaminación en el ambiente gaseoso, en puntos suficientemente alejados de las fuentes, como para no poder discernir cuál de ellas es la causante de los niveles de contaminación alcanzados, a los que van a estar expuestos los receptores.

Inversión térmica: en general, la temperatura del aire disminuye con la altitud; las masas de aire más cercanas a la superficie terrestre al calentarse los gases se expanden y disminuyen su peso por unidad de volumen; al ser más ligeras ascienden hacia capas más altas; durante su ascensión se van enfriando progresivamente al tiempo que permiten una buena dispersión vertical de los gases y partículas. En condiciones de inversión térmica, las capas de aire en altitud son más calientes que las de los niveles cerca de la tierra, frenando la dispersión vertical de los contaminantes. Los contaminantes se encuentran entonces confinados bajo una 'capa de inversión' que actúa como un tapón térmico.

Material particulado atmosférico (PM): conjunto de partículas sólidas y/o líquidas, a excepción del agua pura, presentes en la atmósfera.

Modelos de dispersión de contaminantes: son protocolos matemáticos que proporcionan estimaciones de concentraciones de contaminantes en las coordenadas espaciales y temporales en función de una serie de parámetros meteorológicos, químicos, topográficos y de cantidad y velocidad de emisión.

Mejor Técnica Disponible (MTD): Se entiende por la técnica más eficaz para proteger al medio ambiente en su conjunto, donde la tecnología empleada, incluye el diseño, la construcción, el mantenimiento y la explotación, y debe ser viable técnica y económicamente (término utilizado en inglés como BAT: best available technique).

Nivel de Emisión Asociado a una MTD (NEA-MTD): Según la legislación europea no es directamente un VLE, aunque es un valor de referencia utilizado para establecer los VLE prescritos en la legislación, y que en algunos casos sus valores pueden coincidir. 
PMx: material particulado en suspensión que atraviesa un cabezal de tamaño selectivo para un diámetro aerodinámico de $x \mu \mathrm{m}$ con una eficiencia de corte del $50 \%$. Los parámetros más habituales son PM10 y PM2.5. Las siglas PM vienen del inglés particulate matter (material particulado o materia particulada).

PSD: Partículas sedimentables, las cuales son fácilmente depositadas por gravedad o arrastradas por la lluvia.

PST: partículas totales en suspensión, las cuales no precipitan fácilmente por la acción de la gravedad, encontrándose animadas por un movimiento browniano.

Puff: emisión instantánea o bocanada.

Roof Monitor: Metodología para la cuantificación de las emisiones difusas de PM, basada en determinar el flujo de materia a través de una apertura.

Tasa de emisión: cantidad de contaminante emitido por unidad de tiempo $(\mathrm{g} / \mathrm{h})$.

Valor Límite (VL): nivel fijado para calidad del aire, basándose en conocimientos científicos, con el fin de evitar, prevenir o reducir los efectos nocivos para la salud humana, el medio ambiente y demás bienes de cualquier naturaleza.

Valor límite de emisión (VLE): es el nivel de emisión prescrito por la administración y que no puede ser superado por un foco o instalación determinado.

\subsection{Acrónimos}

AAl: Autorización Ambiental Integrada.

APCA: Actividad potencialmente contaminadora de la atmósfera.

AP-42: Documento que compila FE de la US-EPA (Compilation of Air Emission Factors).

BREF: Documento europeo que propone MTD y VLE (Reference documents under the IPPC Directive and the IED).

CAPCA: Catálogo de actividades potencialmente contaminadoras de la atmósfera.

CA: Comunidad autónoma.

CLA: Capa límite atmosférica.

CMA: Acetato de calcio y magnesio.

DEI: Directiva de emisiones industriales.

EETM: Manuales técnicos que proponen FE para Australia.

EMEP/EEA: Guía europea que recopila FE (Air pollutant emission inventory guidebook).

PRTR: Registro estatal de emisiones y fuentes contaminantes.

FE: Factor de emisión.

$\mathrm{FE}_{\text {global: }}$ Factor de emisión por instalación. 
IPPC: Siglas de la Directiva 1996/61/CE.

M-O: Teoría de semejanza de Monin-Obukov.

MTD: Mejor Técnica Disponible.

NEA-MTD: Nivel de Emisión Asociado a una MTD.

OMS: Organización mundial de la salud.

PGT: Curvas de Pasquill-Gifford-Turner.

PM: Material particulado.

RDM: Metodología para la cuantificación de emisiones difusas de PM, basada en cálculos de dispersión.

TNE: Techos nacionales de emisión.

UE: Unión Europea.

VL: Valor límite.

VLE: Valor límite de emisión.

\subsection{Variables}

A continuación, se recogen las variables utilizadas con mayor frecuencia en el presente documento:

$\mathrm{H}$ : Densidad de flujo de calor sensible.

L: Longitud de Monin-Obukov.

$u_{*}$ : velocidad de fricción. 
9 Anexos 



\subsection{Anexo I. Determinación de la densidad de flujo de calor sensible para la reconstrucción del perfil vertical de la velocidad}

La reconstrucción del perfil vertical de velocidades puede obtenerse a partir de la determinación de la $u_{*}$ y de la $\mathrm{L}$, siendo necesario conocer $\mathrm{H}$ para estimar $\mathrm{L}$ (ecuación 8 ).

Con este fin se requiere disponer de las componentes de la velocidad. El uso de anemómetros 3D permite determinar directamente $\mathrm{H}$. Sin embargo, el uso de anemómetros 2D conlleva recurrir a otros métodos para conocer $\mathrm{H}$. Concretamente, en el presente trabajo se ha determinado $\mathrm{H}$ planteando un balance de energía en la superficie del suelo. A continuación, se detalla la manera de proceder en función del tipo de anemómetro utilizado.

\section{- Anemómetro 3D}

En este caso $\mathrm{H}$ y $u_{*}$ pueden calcularse fácilmente, aplicando las ecuaciones 32 y 33.

$$
H=\rho C_{p}\left\langle w^{\prime} T^{\prime}\right\rangle
$$

siendo:

$\mathrm{H}$ : densidad de flujo de calor sensible $\left(\mathrm{W} / \mathrm{m}^{2}\right)$

$\rho:$ densidad del aire $\left(\mathrm{kg} / \mathrm{m}^{3}\right)$

$\mathrm{C}_{\mathrm{p}}$ : calor específico del aire a presión constante $(\mathrm{W} / \mathrm{KgK})$

T': fluctuaciones de la temperatura $(\mathrm{K})$

w': fluctuaciones de la velocidad vertical $(\mathrm{m} / \mathrm{s})$

$$
u_{*}=\sqrt{\left\langle w^{\prime} u^{\prime}\right\rangle}
$$

siendo:
$u_{*}$ : velocidad de fricción $(\mathrm{m} / \mathrm{s})$
u': fluctuaciones de la velocidad horizontal $(\mathrm{m} / \mathrm{s})$
w': fluctuaciones de la velocidad vertical $(\mathrm{m} / \mathrm{s})$

\section{- Anemómetro 2D}

El método utilizado para determinar $\mathrm{H}$ consiste en plantear un balance de energía en la superficie del suelo (ver figura 1.15 de la introducción):

$$
Q^{*}=H+E+G
$$

siendo:

$\mathrm{Q}^{*}$ : densidad de flujo neto radiativo $\left(\mathrm{W} / \mathrm{m}^{2}\right)$

$\mathrm{H}$ : densidad de flujo de calor sensible $\left(\mathrm{W} / \mathrm{m}^{2}\right)$ 
E: densidad de flujo de calor latente $\left(\mathrm{W} / \mathrm{m}^{2}\right)$

G: densidad de flujo de calor conducido hacia el seno del suelo $\left(\mathrm{W} / \mathrm{m}^{2}\right)$

De acuerdo al método descrito en la bibliografía (Holtslag et al, 1981; Holtslag y van Ulden, 1983; van Ulden y Holtslag, 1985), $Q^{*}$ puede desglosarse en los siguientes términos:

$$
Q^{*}=q_{S i}-q_{S r}-q_{L}
$$

siendo:

$\mathrm{q}_{\mathrm{si}}$ : densidad de flujo radiativo de onda corta incidente $\left(\mathrm{W} / \mathrm{m}^{2}\right)$

$\mathrm{q}_{\mathrm{sr}}$ : densidad de flujo radiativo de onda corta reflejada $\left(\mathrm{W} / \mathrm{m}^{2}\right)$

qL: densidad de flujo radiativo de onda larga $\left(\mathrm{W} / \mathrm{m}^{2}\right)$

Dado que, para los casos estudiados puede considerarse despreciable el flujo de calor latente, debido a procesos de evaporación, el flujo de calor sensible puede calcularse aplicando la ecuación 36:

$$
H=q_{S i}-q_{S r}-q_{L}-G
$$

Los diferentes términos del balance se han determinado empleando la siguiente instrumentación:

- $\quad$ Albedómetro: permite determinar la densidad de flujo de radiación incidente y reflejada ( $q_{s i} y$ $\mathrm{q}_{\mathrm{sr}}$, respectivamente).

- Flujómetro: permite determinar el flujo de calor a través del suelo (G).

- Termopar: permite determinar la temperatura de la superficie, a partir de la cual puede calcularse qı aplicando la ecuación:

$$
q_{L}=\varepsilon \sigma\left(T_{s}^{4}-T_{s k y}^{4}\right)
$$

siendo:

$\varepsilon$ : emisividad efectiva (0.85)

$\sigma:$ constante de Stefan-Boltzmann $\left(5.67 \cdot 10^{-8} \mathrm{~W} / \mathrm{m}^{2} \mathrm{~K}^{4}\right)$

$\mathrm{T}_{\mathrm{s}}$ : temperatura de la superficie $(\mathrm{K})$

$\mathrm{T}_{\text {sky: }}$ temperatura efectiva de intercambio radiativo de la atmósfera $(\mathrm{K})$, la cual está correlacionada con la temperatura ambiente (disponible en https://energyplus.net/weather/sources\#SWEC). 


\subsection{Anexo II. Perfiles químicos individuales de las emisiones difusas de PM10}

Tabla 9.1. Compuestos mayoritarios de las emisiones difusas de PM10 asociadas a la manipulación y transporte de materias primas cerámicas.

\begin{tabular}{|c|c|c|c|c|c|c|c|c|c|c|}
\hline \multirow{2}{*}{$\begin{array}{c}\text { Compuestos } \\
\text { mayoritarios (\%) }\end{array}$} & \multicolumn{2}{|c|}{ Instalación A } & \multicolumn{8}{|c|}{ Instalación B } \\
\hline & M1 & M2 & M1 & M2 & M3 & M4 & M5 & M6 & M7 & M8 \\
\hline $\mathrm{SiO}_{2}$ & 40.9 & 51.6 & 47.7 & 44.8 & 51.9 & 41.3 & 50.6 & 55.2 & 34.7 & 53.2 \\
\hline $\mathrm{Al}_{2} \mathrm{O}_{3}$ & 13.6 & 17.2 & 15.9 & 14.9 & 17.3 & 13.7 & 16.9 & 18.4 & 11.6 & 17.7 \\
\hline $\mathrm{Fe}_{2} \mathrm{O}_{3}$ & 4.47 & 5.16 & 1.30 & 1.39 & 2.05 & 3.16 & 2.68 & 1.68 & 2.23 & 2.54 \\
\hline $\mathrm{CaO}$ & 9.25 & 3.59 & 6.13 & 6.91 & 6.39 & 9.63 & 6.01 & 9.18 & 2.56 & 5.57 \\
\hline MgO & 1.39 & 1.49 & 0.689 & 0.736 & 1.02 & 1.19 & 1.05 & 0.621 & 0.526 & 1.16 \\
\hline $\mathrm{Na}_{2} \mathrm{O}$ & 0.411 & 0.653 & 1.71 & 1.19 & 1.18 & 1.26 & 1.13 & 1.29 & 0.721 & 1.76 \\
\hline $\mathrm{K}_{2} \mathrm{O}$ & 2.81 & 3.37 & 1.70 & 1.82 & 2.29 & 2.46 & 2.61 & 2.01 & 2.44 & 2.31 \\
\hline $\mathrm{TiO}_{2}$ & 0.580 & 0.820 & 0.64 & 0.66 & 0.77 & 0.59 & 0.80 & 0.76 & 0.54 & 0.85 \\
\hline $\mathrm{ZrO}_{2}$ & 0.050 & 0.054 & 0.122 & 0.168 & 0.374 & 0.064 & 0.180 & 0.114 & 0.154 & 0.148 \\
\hline $\mathrm{BaO}$ & 0.030 & 0.058 & $<0.0001$ & $<0.0001$ & 0.039 & 0.018 & $<0.0001$ & 0.308 & 0.105 & 0.073 \\
\hline $\mathrm{Li}_{2} \mathrm{O}$ & 0.021 & 0.021 & 0.009 & 0.008 & 0.012 & 0.012 & 0.012 & 0.011 & 0.014 & 0.012 \\
\hline $\mathrm{PbO}$ & 0.033 & 0.027 & 0.037 & 0.065 & 0.058 & 0.117 & 0.182 & 0.073 & 0.219 & 0.031 \\
\hline ZnO & 0.096 & 0.080 & 0.079 & 0.099 & 0.179 & 0.183 & 0.122 & 0.285 & 0.547 & 0.104 \\
\hline $\mathrm{P}_{2} \mathrm{O}_{5}$ & 0.115 & 0.118 & 0.142 & 0.120 & 0.154 & 0.118 & 0.175 & 0.154 & 0.181 & 0.150 \\
\hline
\end{tabular}




\begin{tabular}{|c|c|c|c|c|c|c|c|c|c|c|}
\hline \multirow{2}{*}{$\begin{array}{c}\text { Elementos traza } \\
(\mathrm{mg} / \mathrm{kg})\end{array}$} & \multicolumn{2}{|c|}{ Instalación A } & \multicolumn{8}{|c|}{ Instalación B } \\
\hline & M1 & M2 & M1 & M2 & M3 & M4 & M5 & M6 & M7 & M8 \\
\hline$S$ & 1789 & 83 & 6345 & 5328 & 9652 & 8862 & 7675 & 6942 & 24720 & 6235 \\
\hline V & 88 & 99 & 92 & 71 & 106 & 121 & 101 & 115 & 135 & 119 \\
\hline $\mathrm{Cr}$ & 135 & 122 & 97 & 113 & 222 & 185 & 248 & 36 & $<1$ & 210 \\
\hline Mn & 353 & 357 & 133 & 103 & 161 & 243 & 238 & 97 & 195 & 166 \\
\hline $\mathbf{N i}$ & 42 & 38 & 10 & $<1$ & 28 & 18 & 22 & $<1$ & 92 & 34 \\
\hline $\mathrm{Cu}$ & 104 & 32 & 100 & 80 & 178 & 192 & 131 & 108 & 165 & 92 \\
\hline As & 24 & 20 & 26 & 24 & 33 & 46 & 25 & 24 & 59 & 20 \\
\hline $\mathrm{Se}$ & 14 & 10 & 41 & 40 & 38 & 59 & 40 & 24 & 72 & 17 \\
\hline $\mathbf{R b}$ & 131 & 173 & 75 & 83 & 111 & 113 & 113 & 90 & 88 & 100 \\
\hline $\mathrm{Sr}$ & 174 & 154 & 122 & 128 & 162 & 165 & 158 & 131 & 70 & 166 \\
\hline Cd & 1 & 1 & $<1$ & $<1$ & 5 & $<1$ & $<1$ & 4 & 14 & 2 \\
\hline Sn & 13 & 9 & 10 & 5 & 33 & 19 & 13 & 61 & 117 & 22 \\
\hline $\mathrm{Sb}$ & 17 & 11 & $<1$ & $<1$ & 39 & 41 & 58 & 26 & 36 & 37 \\
\hline Cs & 14 & 17 & $<1$ & $<1$ & 14 & 13 & 13 & 14 & 13 & 14 \\
\hline $\mathrm{Hf}$ & 10 & 10 & 16 & 23 & 67 & $<1$ & 27 & 15 & 7 & 32 \\
\hline $\mathrm{TI}$ & 5 & 3 & $<1$ & $<1$ & 11 & 21 & 14 & 14 & 29 & 8 \\
\hline $\mathbf{U}$ & 2 & 4 & 4 & 4 & 6 & 3 & 4 & 5 & $<1$ & 6 \\
\hline
\end{tabular}


Tabla 9.3. Compuestos mayoritarios de las emisiones difusas de PM10 asociadas a la manipulación y transporte de materias primas cerámicas.

\begin{tabular}{|c|c|c|c|c|c|c|c|c|}
\hline \multirow{2}{*}{$\begin{array}{l}\text { Compuestos } \\
\text { mayoritarios (\%) }\end{array}$} & \multicolumn{8}{|c|}{ Instalación C } \\
\hline & M1 & M2 & M3 & M4 & M5 & M6 & M7 & M8 \\
\hline $\mathrm{SiO}_{2}$ & 32.4 & 27.8 & 16.9 & 13.7 & 47.9 & 49.2 & 35.8 & 29.9 \\
\hline $\mathrm{Al}_{2} \mathrm{O}_{3}$ & 10.8 & 9.28 & 5.7 & 4.6 & 16.0 & 16.4 & 12.0 & 10.0 \\
\hline $\mathrm{Fe}_{2} \mathrm{O}_{3}$ & 3.40 & 3.31 & 2.08 & 1.54 & 2.59 & 2.20 & 3.93 & 3.39 \\
\hline $\mathrm{CaO}$ & 9.96 & 7.51 & 5.23 & 6.08 & 7.65 & 6.95 & 8.91 & 7.28 \\
\hline MgO & 1.86 & 1.73 & 1.73 & 1.09 & 1.10 & 1.13 & 2.10 & 2.09 \\
\hline $\mathrm{Na}_{2} \mathrm{O}$ & 0.155 & 0.285 & 4.43 & 2.03 & 0.939 & 1.077 & 0.858 & 3.30 \\
\hline $\mathrm{K}_{2} \mathrm{O}$ & 3.06 & 2.50 & 1.58 & 2.17 & 2.36 & 2.04 & 2.94 & 2.70 \\
\hline $\mathrm{TiO}_{2}$ & 0.418 & 0.416 & 0.321 & 0.273 & 0.732 & 0.792 & 0.446 & 0.399 \\
\hline $\mathrm{ZrO}_{2}$ & 0.112 & 0.084 & 0.074 & 0.041 & 0.121 & 0.130 & 0.029 & 0.032 \\
\hline $\mathrm{BaO}$ & $<0.0001$ & $<0.0001$ & 0.098 & 0.115 & 0.122 & 0.102 & 0.053 & 0.054 \\
\hline $\mathrm{Li}_{2} \mathrm{O}$ & 0.014 & 0.009 & 0.007 & 0.008 & 0.013 & 0.012 & 0.012 & 0.010 \\
\hline $\mathrm{PbO}$ & 0.102 & 0.080 & 0.093 & 0.151 & 0.069 & 0.254 & 0.053 & 0.048 \\
\hline $\mathrm{ZnO}$ & 0.010 & 0.037 & 0.737 & 0.364 & 0.294 & 0.233 & 0.083 & 0.092 \\
\hline $\mathrm{P}_{2} \mathrm{O}_{5}$ & 0.446 & 0.354 & 0.011 & $<0.0001$ & 0.005 & 0.072 & 0.141 & 0.116 \\
\hline
\end{tabular}


Tabla 9.4. Elementos traza de las emisiones difusas de PM10 asociadas a la manipulación y transporte de materias primas cerámicas.

\begin{tabular}{|c|c|c|c|c|c|c|c|c|}
\hline \multirow{2}{*}{$\begin{array}{l}\text { Elementos traza } \\
\qquad(\mathbf{m g} / \mathbf{k g})\end{array}$} & \multicolumn{8}{|c|}{ Instalación C } \\
\hline & M1 & M2 & M3 & M4 & M5 & M6 & M7 & M8 \\
\hline $\mathbf{S}$ & 46548 & 38512 & 74268 & 57877 & 11484 & 7589 & 41518 & 49837 \\
\hline V & 130 & 171 & 218 & 100 & 129 & 113 & 111 & 117 \\
\hline $\mathrm{Cr}$ & 143 & 22 & 246 & 385 & 325 & 281 & 21 & 51 \\
\hline Mn & 354 & 398 & 335 & 370 & 275 & 230 & 304 & 315 \\
\hline $\mathrm{Ni}$ & 118 & 98 & 183 & 241 & 132 & 79 & 25 & 41 \\
\hline $\mathrm{Cu}$ & 257 & 240 & 342 & 523 & 315 & 269 & 93 & 229 \\
\hline As & 29 & 41 & 35 & 53 & 40 & 40 & 26 & 25 \\
\hline Se & 76 & 83 & 57 & 142 & 34 & 40 & 66 & 108 \\
\hline $\mathbf{R b}$ & 118 & 97 & 51 & 82 & 107 & 108 & 119 & 113 \\
\hline $\mathrm{Sr}$ & 204 & 155 & 165 & 193 & 215 & 192 & 206 & 176 \\
\hline Cd & $<1$ & $<1$ & 6 & 9 & 5 & 3 & 3 & 2 \\
\hline Sn & 9 & $<1$ & 24 & 46 & 51 & 33 & 17 & 17 \\
\hline Sb & $<1$ & $<1$ & 27 & 22 & 51 & 51 & 8 & 15 \\
\hline Cs & $<1$ & $<1$ & 5 & 12 & 13 & 14 & 16 & 18 \\
\hline $\mathrm{Hf}$ & 2 & $<1$ & 23 & 9 & 28 & 30 & 5 & 4 \\
\hline $\mathrm{TI}$ & 39 & 37 & 31 & 170 & 13 & 23 & 94 & 185 \\
\hline U & $<1$ & $<1$ & 15 & 24 & 15 & 9 & 2 & 1 \\
\hline
\end{tabular}


10 Bibliografía 

La bibliografía específica de los artículos publicados se ha incluido en cada uno de ellos. A continuación, se indican las referencias utilizadas para realizar los capítulos de introducción, estado del arte y metodología, así como los apartados de resultados adicionales y discusión de resultados:

Abdul-Wahab, S.A., 2006. Impact of fugitive dust emissions from cement plants on nearby communities. Ecol. Modell. 195, 338-348. doi:10.1016/j.ecolmodel.2005.11.044.

Abril, G.A., Diez, S.C., Pignata, M.L., Britch, J., 2016. Particulate matter concentrations originating from industrial and urban sources: Validation of atmospheric dispersion modeling results. Atmos. Pollut. Res. 7, 180-189. doi:10.1016/j.apr.2015.08.009.

Abril, G.A., Wannaz, E.D., Mateos, A.C., Pignata, M.L., 2014. Biomonitoring of airborne particulate matter emitted from a cement plant and comparison with dispersion modelling results. Atmos. Environ. 82, 154-163. doi:10.1016/j.atmosenv.2013.10.020.

Alastuey A., 1994. Caracterización mineralógica y alterológica de morteros de revestimiento en edificios de Barcelona. [Tesis Doctoral].

Alastuey A., Mantilla E., Querol X., Rodríguez S., 2000. Estudio de la evaluación de la contaminación atmosférica por material particulado en España: necesidades derivadas de la propuesta de la directiva del consejo relativa a partículas PM10 y PM2.5 e implicaciones en la industria cerámica. Bol. Soc. Esp. Ceram. Vidr. 39, 135-148.

Alastuey, A., Moreno, N., Querol, X., Viana, M., Artíñano, B., Luaces, J.A., Basora, J., Guerra, A., 2007. Contribution of harbour activities to levels of particulate matter in a harbour area: Hada Project-Tarragona Spain. Atmos. Environ. 41, 6366-6378.doi:10.1016/j.atmosenv.2007.03.015.

Allen, A.G., Nemitz, E., Shi, J.P., Harrison, R.M. and Greenwood, J.C., 2001. Size distributions of trace metals in atmospheric aerosols in the United Kingdom. Atmos. Environ.,35(27), 45814591. doi: 10.1016/S1352-2310(01)00190-X.

Amato, F., 2010. Particulate matter resuspension from urban paved roads: impact on air quality and abatement strategies [PhD Thesis].

Amato, F., Cassee, F.R., Denier van der Gon, H.A.C., Gehrig, R., Gustafsson, M., Hafner, W., Harrison, R.M., Jozwicka, M., Kelly, F.J., Moreno, T., Prevot, A.S.H., Schaap, M., Sunyer, J., Querol, X., 2014. Urban air quality: The challenge of traffic non-exhaust emissions. J. Hazard. Mater. 275, 31-36. doi:10.1016/j.jhazmat.2014.04.053.

Amato, F., Escrig, A., Sanfélix, V., Celades, I., Reche, C., Monfort, E., Querol, X., 2016. Effects of water and CMA in mitigating industrial road dust resuspension. Atmos. Environ. 131, 334-340. doi:10.1016/j.atmosenv.2016.02.018. 
Amato, F., Pandolfi, M., Escrig, A., Querol, X., Alastuey, A., Pey, J., Perez, N., Hopke, P.K., 2009. Quantifying road dust resuspension in urban environment by Multilinear Engine: A comparison with PMF2. Atmos. Environ. 43, 2770-2780. doi:10.1016/j.atmosenv.2009.02.039.

Amato, F., Pandolfi, M., Viana, M., Querol, X., Alastuey, A., Moreno, T., 2008. Spatial and chemical patterns of PM10 in road dust deposited in urban environment. Atmos. Environ. 43, 1650-1659. doi:10.1016/j.atmosenv.2008.12.009.

ANEFA, 2013. Estudio buenas prácticas medioambientales en el sector de los áridos. Proyecto GAP Áridos.

ANEFHOP, 2016. Estadísticas de producción de hormigón preparado. [En línea], consulta 2016-1116, <http://www.anefhop.es>.

ASCER, 2017. El sector en datos. [En línea], consulta 2017-01-09, <http://www.ascer.es>.

Australian Government, 2008. Emission Estimation Technique Manual for Cement Manufacturing. Version 2.1. Department of Sustainability, Environment, Water, Population and Communities.

Australian Government, 2012. Emission Estimation Technique Manual for Mining. Version 3.1. Department of Sustainability, Environment, Water, Population and Communities.

Arya, P., 2001.Introduction to micrometeorology. International Geophysics. Volume 79. Academic Press.

Barad, M.L.,1958. Project Prairie Grass. A Field Program in Diffusion, Geophysics Research Paper no. 59, Cambridge: Geophysics Research Directorate, Air Force Research Center.

Barba A., Feliu C., García-Ten F.J., et al., 2002. Materias primas para la fabricación de soportes de baldosas cerámicas. $2^{a}$ de. Castellón: Instituto de Tecnología Cerámica-Asociación de Investigación de las Industrias Cerámicas.

Barratt, R., 2013. Atmospheric dispersion modelling: an introduction to practical applications. Routledge.

Belot, Y.; Baille, A.; Delmas, J.-L., 1976. Modèle numérique de dispersion des polluants atmosphériques en présence de couverts végétaux: Application aux couverts forestiers, Atmos. Environ. 10, 89-98.

Briggs, G.A., 1973. Diffusion estimation for small emissions. Air Resources Atmospheric Turbulence and Diffusion Laboratory National Oceanic and Atmospheric Administration Oak Ridge, Tennessee.

Buseck, P.R. y Pósfai, M., 1999. Airborne minerals and related aerosol particles: Effects on climate and the environment. Proceedings of the National Academy of Sciences,96(7), 3372-3379. 
Calder, K.L., 1977. Multiple-Source Plume Models of Urban Air Pollution - The General Structure. Atmos. Environ., 11, $403-414$.

Castro, M., González, R., Portela, A., 1991. Parametrización de la capa límite atmosférica en los modelos numéricos de pronóstico meteorológico. Física de la Tierra, №3, 103-138. Universidad Complutense de Madrid.

Celades López, I., 2013. Caracterización física, mineralógica y morfológica del material particulado emitido por focos canalizados de la industria de baldosas y fritas cerámicas. [Tesis Doctoral].

Churg, A. y Brauer, M., 1997. Human lung parenchyma retains PM2.5. Am. J. Respir. Crit. Care Med., 155(6), 2109-2111. doi:10.1164/ajrccm.155.6.9196123.

Cimorelli, A.J.; Perry, S.G.; Venkatram, A.; Weil, J.C.; Paine, R.J.; Wilson, R.B.; Lee, R.F.; Peters, W.D.; Brode, R.W., 2005. AERMOD: A dispersion model for industrial source applications. Part I: General model formulation and boundary layer characterization. J. Appl. Meteor. 44, 682693. doi:10.1175/JAM2227.1.

Cowherd, C., Axetell, K., Guenther, C.M., Jutze, G.A., 1974. Development of Emission Factors for Fugitive Dust Sources. Technical Report EPA-450/3-74-037. US Environmental Protection Agency.

Cowherd, C., Bohn, R., Cuscino, T., 1979. Iron and Steel Plant Open Source Fugitive Emission Evaluation. Technical Report EPA-600/2-79-103. US Environmental Protection Agency.

Draxler, R.R., 1976. Determination of atmospheric diffusion parameters. Atmos. Environ. 10, 99105. doi:10.1016/0004-6981(76)90226-2.

Eckman, R.M., 1994. Re-examination of empirically derived formulas for horizontal diffusion from surface sources. Atmos. Environ. 28, 265-272. doi: 10.1016/1352-2310(94)90101-5.

EEA, 2013. Climate change and air. Our climate is changing. European Environment Agency. (https://www.eea.europa.eu/signals/signals-2013/articles/climate-changeand-air).

EEA, 2015. Air quality in Europe - 2015 report. European Environment Agency. ISBN 978-92-9213702-1.

EEA, 2016. Air quality in Europe - 2016 report. European Environment Agency. ISBN 978-92-9213824-0.

Efron, B., Tibshirani, R.J., 1993. An Introduction to the Bootstrap. Chapman \& Hall, Boca Raton.

Ehrlich, C., Noll, G., Kalkoff, W.-D., Baumbach, G., Dreiseidler, A., 2007. PM10, PM2.5 and PM1.0Emissions from industrial plants-Results from measurement programmes in Germany. Atmos. Environ. 41, 6236-6254. doi:10.1016/j.atmosenv.2007.03.059. 
EMEP/EEA, 2016. EMEP/EEA Air Pollutant Emission Inventory Guidebook. Technical Report. European Environment Agency.

EPA, 1993. A Review of Methods for Measuring Fugitive PM10 Emission Rates. Environmental Protection Agency.

EPA, 1996. Air Quality Criteria for Particulate Matter (Final Report). U.S. Environmental Protection Agency, Washington, D.C., EPA 600/P-95/001.

Ermak, D.L., 1977. An analytical model for air pollutant transport and deposition from a point source. Atmos. Environ. 11, 231-237.

EU, 2013. Comunicación de la Comisión al Parlamento Europeo, al Consejo, al Comité Económico y Social Europeo y al Comité de las Regiones. Programa «Aire Puro» para Europa. $\operatorname{COM}(2013) 918$.

Garratt, J., 1992. The atmospheric boundary layer. Cambridge atmospheric and space science series. Cambridge Univ. Press.

Generalitat de Catalunya, 2014. Càlcul d'emissions fugitives de partícules en activitats extractives amb o sense planta de tractament de productes minerals associada i operacions similars. $1^{\underline{a}}$ Edició. Direcció General de Qualitat Ambiental.

Generalitat Valenciana, 2008. "Plan de Mejora de la Calidad del Aire de la zona ES 1003: MijaresPenyagolosa (A. Costera) y Aglomeración ES 1015: Castelló” Zona cerámica de Castellón. Conselleria de Medi Ambient, Aigua, Urbanisme i Habitatge, Generalitat Valenciana.

Gifford, F. A., 1961. Use of Routine Meteorological Observations for Estimating Atmospheric Dispersion. Nuclear Safety, 2, 47-51.

Gifford, F.A., 1976. Turbulent diffusion-typing schemes: a review. Nucl. Saf., v. 17, no. 1, pp. 68-86.

Gobierno Vasco, 2012. Guía para la Prevención de Emisiones Difusas de Partículas. Departamento de Medio Ambiente, Planificación Territorial, Agricultura y Pesca. Dirección de Planificación Ambiental. Gobierno Vasco.

Gómez, E.T., Álvarez, C., Jordán, M. M., et al., 1999. Influencia de la industria cerámica en la composición del material particulado atmosférico. Técnica Cerámica, 271, 280-289.

Hanna, S.R.; Briggs, G.A.; Deardorff, J.; Egan, B.A.; Gifford, F.A.; Pasquill, F., 1977. AMS workshop on stability classification schemes and sigma curves—summary of recommendations. Bull. Am. Meteorol. Soc. 58, 1305-1309.

Hernández, D., Gómez, E.T., Sanfeliu, T., Vicente, A.B., 2001. Particulate matter PM2.5 and PM10 in an industrial ceramic area. En: Jornadas sobre material particulado. Madrid: Ministerio de Medio Ambiente. 
Hinds, W.C., 1999. Aerosol Technology: Properties, Behaviour, and Measurement of Airbone Particles. 2nd Edition. New York: Wiley-Intercience. ISBN: 978-0-471-19410-1.

Holtslag, A.A.M., de Bruin, H.A.R., van Ulden, A.P., 1981. Estimation of the sensible heat flux from standard meteorological data for stability calculations during daytime. In: Air Pollution Modeling and its Application I, 401-407.

Holtslag, A.A.M., van Ulden, A.P., 1983. A simple scheme for daytime estimates of the surface fluxes from routine weather data. J. Clim. Appl. Meteorol. 22, 517-529.

Hosseini, B., Stockie, J.M., 2016. Bayesian estimation of airborne fugitive emissions using a Gaussian plume model. Atmos. Environ. 141, 122-138. doi: 0.1016/j.atmosenv.2016.06.046.

HISPALYT, 2015. Estadísticas del sector. [En línea], consulta 2017-01-09, <http://www.hispalyt.es>.

IARC, 2013. Outdoor air pollution a leading environmental cause of cancer deaths. Press Release № 221. International Agency for Research on Cancer (http://www.iarc.fr/en/mediacentre/ iarcnews/pdf/pr221_E.pdf).

IPCC, 2007. Climate Change 2007: Impacts, Adaptation and Vulnerability. IPCC. Cambridge University Press.

IPTS, 2006. European Commission. Reference Document on Best Available Techniques on Emissions from Storage of bulk or dangerous materials. (http://eippcb.jrc.es).

IPTS, 2003. European Commission. Reference Document on the General Principles of Monitoring. (http://eippcb.jrc.es).

IPTS, 2007. European Commission. Reference Document on Best Available Techniques in the Ceramic Manufacturing Industry. (http://eippcb.jrc.es).

IPTS, 2013a. European Commission. Best Available Techniques (BAT) Reference Document for Iron and Steel Production. (http://eippcb.jrc.es).

IPTS, 2013b. European Commission. Best Available Techniques (BAT) Reference Document for the Production of Cement, Lime and Magnesium Oxide. (http://eippcb.jrc.es).

IPTS, 2015. European Commission. Best Available Techniques (BAT) Reference Document for the Refining of Mineral Oil and Gas. (http://eippcb.jrc.es).

IPTS, 2016. European Commission. Best Available Techniques (BAT) Reference Document for Large Combustion Plants. (http://eippcb.jrc.es).

Irwin, J.S.,1983. Estimating plume dispersion: a comparison of several sigma schemes. J. Clim. Appl. Met. 22, 92-114. 
Kulkarni, P., Baron P., Willeke K., 2011. Aerosol Measurement: Principles, Techniques and Applications. 3rd Edition. New York: John Wiley \& Sons. ISBN: 978-0-470-38741-2.

Langner J. y Rodhe H., 1992. A global three-dimensional model of the tropospheric sulphate. J. Atmos. Chem. 13, 225-263. doi:10.1007/BF00058134.

Leopold, J.G. y Gough, J., 1957. The centrilobular form of hypertrophic emphysema and its relation to chronic bronchitis. Thorax, 12(3), 219-235.

Lin, J.S.; Hildemann, L.M., 1996. Analytical solutions of the atmospheric diffusion equation with multiple sources and height-dependent wind speed and eddy diffusivities. Atmos. Environ. 30, 239-254. doi: 0.1016/1352-2310(95)00287-9.

López-Lilao, A., Juárez, M., Sanfélix Forner, V., Mallol Gasch, G., Monfort Gimeno, E., 2017. Efecto del procesado de materias primas sobre su poder de emisión de polvo. Boletín la Soc. Española Cerámica y Vidr. doi:10.1016/j.bsecv.2016.12.001.

López-Lilao, A., Escrig, A., Sanfélix, V., Monfort, E., Mallol, G., 2014. Determinación del poder de emisión de polvo de materias primas empleadas en el sector cerámico. XIII Congreso Mundial de la Calidad del Azulejo y del Pavimento Cerámico. QUALICER 2014. Castellón.

Llewelyn, R.P., 1983. An analytical model for the transport, dispersion and elimination of air pollutants emitted from a point source. Atmos. Environ. 17, 249-256. doi:10.1016/00046981(83)90040-9.

MAGRAMA, 2013. Plan Nacional de Calidad del Aire y Protección de la Atmósfera 2013-2016. Plan Aire. Dirección General de Calidad y Evaluación Ambiental y Medio Natural.

Marta, S., Viana, A., Garcia, S., Miranda, A.I., 2013, Contribution of Fugitive Emissions for PM10 Concentrations in an Industrial Area of Portugal. In EGU General Assembly Conference Abstracts, 15, 10851.

Martín, F., González, C., Bailador, A., Sánchez, E., Palomino, I., Palacios, M., Crespí, S.N., Gorostiza, C., 2002. SICAH: an automatic system for control and prevention of air pollution in Huelva (Spain). International Journal of Environmental Pollution 16, 1-6.

Martín, F., Pujadas, M., Artiñano, B., Gómez-Moreno, F., Palomino, I., Moreno, N., Alastuey, A., Querol, X., Basora, J., Luaces, J.A., Guerra, A., 2007. Estimates of atmospheric particle emissions from bulk handling of dusty materials in Spanish Harbours. Atmos. Environ. 41, 63566365. doi:10.1016/j.atmosenv.2006.12.003.

McElroy J. L. and Pooler F., 1968. St. Louis dispersion study volume II-analysis. National Air Pollution Control Administration Publication No. AP-53 Arlington, VA. 
McKenna, J.D., Turner,J.H., McKenna, J.P., 2008. Fine Particle (2.5 microns) Emissions: Regulations, Measurement and Control. Hoboken, New Jersey: John Wiley \& Sons. ISBN: 9780-471-70963-3.

Mészáros, E., 1999. Fundamentals of atmospheric aerosol chemistry, Akadémiai Kiadó, Budapest. ISBN 963-05-7624-4.

Minguillón Bengochea, M.C., 2007. Composición y fuentes del material particulado atmosférico en la zona cerámica de Castellón. Impacto de la introducción de las Mejores Técnicas Disponibles. [Tesis Doctoral].

Minguillón, M.C., Monfort, E., Escrig, A., Celades, I., Guerra, L., Busani, G., Sterni, A., Querol, X., 2013. Air quality comparison between two European ceramic tile clusters. Atmos. Environ. 74, 311-319. doi:10.1016/j.atmosenv.2013.04.010.

Minguillón, M.C., Monfort, E., Querol, X., Alastuey, A.S., Celades, I., Miró, J.V., 2009. Effect of ceramic industrial particulate emission control on key components of ambient PM 10. J. Environ. Manage. 90, 2558-2567. doi:10.1016/j.jenvman.2009.01.016.

Minguillón, M.C., Querol, X., Alastuey, A., Monfort, E., Mantilla, E., Sanz, M.J., Sanz, F., Roig, A., Renau, A., Felis, C., Miró, J.V., Artíñano, B., 2007a. PM10 speciation and determination of air quality target levels. A case study in a highly industrialized area of Spain. Sci. Total Environ. 372, 382-396. doi:10.1016/j.scitotenv.2006.10.023.

Minguillón, M.C., Querol, X., Alastuey, A., Monfort, E., Vicente Miró, J., Mantilla, E., Ruiz, C.R., Artíñano, B., Salvador, P., Sánchez, M., Santos, S.G. Dos, Garraleta, M.D.H., FernandezPatier, R., Moreno-Grau, S., Minguillón, M.C., Monfort, E., Sanz, M.J., Palomo-Marín, R., Pinilla-Gil, E., Cuevas, E., 2007b. PM sources in a highly industrialised area in the process of implementing PM abatement technology. Quantification and evolution. J. Environ. Monit. 9, 1071. doi:10.1039/b705474b.

Ministerio de Industria, Energía y Turismo, 2014. Estadística Minera de España 2014. Secretaría General Técnica. Ministerio de Industria, Energía y Turismo.

Ministry for the Environment, 2004. Good Practice Guide for Atmospheric Dispersion Modelling. Air Quality Technical Report 27. New Zealand.

Monfort, E., Celades, I., Mestre, S., Sanz, V., 2004. PMx data processing in ceramic tile manufacturing emissions. Key Engineering Materials. 264-268, 2453-2456. doi:10.4028/www.scientific.net/KEM.264-268.2453.

Monfort, E., López-Lilao, A., Sanfélix V.; Escrig A., Celades I., Mantilla E., Querol X., 2014. Libro blanco sobre emisiones difusas de material particulado: cuantificación, control y minimización. Instituto de Tecnología Cerámica. 
Monin, A.S., Obukhov, A.M., 1954. Basic laws of turbulent mixing in the surface layer of the atmosphere. Tr. Akad. Nauk SSSR Geofiz. Inst. 24, 163-187.

Moreno, N., Alastuey, A., Querol, X., Artiñano, B., Guerra, A., Luaces, J.A., Lorente, A., Basora, J., 2007. Characterisation of dust material emitted during harbour operations (HADA Project). Atmos. Environ. 41, 6331-6343. doi:10.1016/j.atmosenv.2007.03.028.

Muleski, G.E., Cowherd, C., Englehart, P., 1987. Update of Fugitive Dust Emission Factors in AP42 Section 11.2. Technical Report. Midwest Research Institute, Kansas City, MO.

Muleski, G.E., Cowherd, C., Kinsey, J.S., 2005. Particulate emissions from construction activities. J. Air \& Waste Manag. Assoc. 55, 772-783.

Nicholson, K.W, 2001. A critique of empirical emission factor models: a case study of the AP-42 model for estimating PM10 emissions from paved roads. Atmos. Environ. 35, 185-186.

Nieuwstadt F.T.M.; van Ulden A.P., 1978. A numerical study of the vertical dispersion of passive contaminants from a continuous source in the atmospheric surface layer. Atmos. Environ. 12, 2119-2124.

Nieuwstadt, F.T.M., Duynkerke, P.G., 1996. Turbulence in the atmospheric boundary layer. Atmos. Res. 40, 111-142.

OECD, 2012. OECD Environmental Outlook to 2050. OECD Publishing. doi:10.1787/9789264122246-en.

OFICEMEN, 2016. Memoria anual 2014. [En línea], consulta 2016-11-16 <http://www.oficemen.es>.

Pasquill, F., 1974. Atmospheric Diffusion, 2nd ed., Nueva York: J. Wiley \& Sons.

Pasquill, F.,1961. The estimation of dispersion of windborne material. Meteorol. Mag. 90, 33-49.

Pasquill, F., Smith, F.B., 1983. Atmospheric Diffusion: Study of the Dispersion of Winborne Material from Industrial and Other Sources, third ed. John Wiley \& Sons, New York.

Pérez, N., Pey, J., Reche, C., Cortés, J., Alastuey, A. and Querol, X., 2016. Impact of harbour emissions on ambient PM10 and PM2.5 in Barcelona (Spain): Evidences of secondary aerosol formation within the urban area. Sci. Total Environ., 571, 237-250. doi: 10.1016/j.scitotenv.2016.07.025.

Perry, S.G., Cimorelli, A.J., Paine, R.J., Brode, R.W., Weil, J.C., Venkatram, A., Wilson, R.B., Lee, R.F., Peters, W.D., 2005. AERMOD: A Dispersion Model for Industrial Source Applications. Part II: Model Performance against 17 Field Study Databases. J. Appl. Meteorol. 44, 694-708. doi:10.1175/JAM2228.1. 
Puertos del Estado, 2012. Memoria de sostenibilidad del sistema portuario de interés general. Año 2012. Ministerio de Fomento.

Puertos del Estado, 2015. Guía de Buenas Prácticas en manipulación y almacenamiento de Graneles Sólidos en Instalaciones Portuarias. Ministerio de Fomento.

Putaud, J.P., Raes, F., Van Dingenen, R., Brüggemann, E., Facchini, M.C., Decesari, S., Fuzzi, S., Gehrig, R., Hüglin, C., Laj, P., Lorbeer, G., Maenhaut, W., Mihalopoulos, N., Müller, K., Querol, X., Rodriguez, S., Schneider, J., Spindler, G., Brink, H. ten, Tørseth, K., Wiedensohler, A., 2004. A European aerosol phenomenology-2: chemical characteristics of particulate matter at kerbside, urban, rural and background sites in Europe. Atmos. Environ. 38, 2579-2595. doi:10.1016/j.atmosenv.2004.01.041.

Qian, W.; Venkatram, A., 2011. Performance of steady-state dispersion models under low windspeed conditions. Bound. Layer Meteor. 138, 475-491. doi:10.1007/s10546-010-9565-1.

Querol, X., Alastuey, A., Moreno, T., Viana, M.M., Castillo, S., Pey, J., Rodríguez, S., Artiñano, B., Salvador, P., Sánchez, M. and Dos Santos, S.G., 2008. Spatial and temporal variations in airborne particulate matter (PM10 and PM2.5) across Spain 1999-2005. Atmos. Environ. 42(17), 3964-3979. doi: 10.1016/j.atmosenv.2006.10.071.

Querol, X., Alastuey, A., Rodriguez, S., Plana, F., Mantilla, E., Ruiz, C.R., 2001a. Monitoring of PM10 and PM2.5 around primary particulate anthropogenic emission sources. Atmos. Environ. 35, 845-858. doi:10.1016/S1352-2310(00)00387-3.

Querol, X., Alastuey, A., Rodríguez, S., Plana, F., Ruiz, C.R., Cots, N., Massagué, G., Puig, O., 2001b. PM10 and PM2.5 source apportionment in the Barcelona Metropolitan Area, Catalonia, Spain. Atmospheric Environment 35, 6407-6419. doi:10.1016/S1352-2310(01)00361-2.

Querol, X., Alastuey, A., Rodríguez, S., Viana, M.M., Artínano, B., Salvador, P., Mantilla, E., do Santos, S.G., Patier, R.F., de La Rosa, J., de la Campa, A.S., Menéndez, M., Gil, J.J., 2004. Levels of particulate matter in rural, urban and industrial sites in Spain. Sci. Total Environ. 334335, 359-376. doi:10.1016/j.scitotenv.2004.04.036.

Querol, X., Alastuey, A., Rosa, J. de la, Sánchez-de-la-Campa, A., Plana, F., Ruiz, C.R., 2002. Source apportionment analysis of atmospheric particulates in an industrialised urban site in southwestern Spain. Atmos. Environ. 36, 3113-3125. doi:10.1016/S1352-2310(02)00257-1.

Querol, X., Minguillón, M.C., Alastuey, A., Monfort, E., Mantilla, E., Sanz, M.J., Sanz, F., Roig, A., Renau, A., Felis, C., Miró, J.V., Artíñano, B., 2007a. Impact of the implementation of PM abatement technology on the ambient air levels of metals in a highly industrialized area. Atmos. Environ. 41, 1026-1040. doi:10.1016/j.atmosenv.2006.09.013. 
Querol, X., Viana, M., Alastuey, A., Amato, F., Moreno, T., Castillo, S., Pey, J., de la Rosa, J., Sánchez de la Campa, A., Artíñano, B., Salvador, P., García Dos Santos, S., Fernández-Patier, R., Moreno-Grau, S., Negral, L., Minguillón, M.C., Monfort, E., Gil, J.I., Inza, A., Ortega, L.A., Santamaría, J.M., Zabalza, J., 2007b. Source origin of trace elements in PM from regional background, urban and industrial sites of Spain. Atmos. Environ. 41, 7219-7231. doi:10.1016/j.atmosenv.2007.05.022.

Querol, X., Viana, M., Moreno, T., Alastuey, A. (eds), 2012. Bases científico-técnicas para un Plan Nacional de Mejora de la Calidad del Aire. Consejo Superior de Investigaciones Científicas.ISBN: 978-84-00-09475-1.

Runca, E.; Sardei, F., 1975. Numerical treatment of time dependent advection and diffusion of air pollutants. Atmos. Environ. 9, 69-80.

Sánchez de la Campa, A.M., de la Rosa, J.D., González-Castanedo, Y., Fernández-Camacho, R., Alastuey, A., Querol, X., Pio, C., 2010. High concentrations of heavy metals in PM from ceramic factories of Southern Spain. Atmos. Res. 96, 633-644. doi:10.1016/j.atmosres.2010.02.011.

Sánchez de la Campa, A.M., Moreno, T., de la Rosa, J., Alastuey, A., Querol, X., 2011. Size distribution and chemical composition of metalliferous stack emissions in the San Roque petroleum refinery complex, southern Spain. J. Hazard. Mater. 190, 713-722. doi:10.1016/j.jhazmat.2011.03.104.

Schauer, J.J., Lough, G.C., Shafer, M.M., Christensen, W.F., Arndt, M.F., DeMinter, J.T., Park, J.S., 2006. Characterization of metals emitted from motor vehicles. Res. Rep. Health. Eff. Inst. 176-88.

Schmidt, W., 1925. Der Massenaustausch infreier Luft und verwandte Erscheinungen, Henri Grand Verlag, Hamburg.

Scire, J.S.; Strimaitis, D.G.; Yamartino, R.J., 2000. A user's guide for the CALPUFF dispersion model. Version 5, Earth Tech, Inc. Concord, MA.

Seinfeld, J. H. and Pandis, S. N., 2006. Atmospheric chemistry and physics: From air pollution to climate change, 2nd Edition. 1232 pp., ISBN: 978-0-471-72018-8.

Singer, I.A., Frizzola, J.A., Smith Meteorologists, M.E., 1966. A Simplified Method of Estimating Atmospheric Diffusion Parameters. Journal of the Air Pollution Control Association, 16:11, 594596.

Smith, F.B., 1957. The diffusion of smoke from a continuous elevated point-source into a turbulent atmosphere. J. Fluid Mech. 2, 49-76.

Stull, R.B., 1988. An Introduction to Boundary Layer Meteorology. Kluwer Academic Publishers. doi:10.1007/978-94-009-3027-8. 
Taylor, G.I.,1921. Diffusion by continuous movements. Proc. Lond. Math. Soc. 20, 196-212.

TNO, 2009. Development of a mechanistic model for the Advanced REACH Tool. TNO Report, V8667.

Torres, J., Ricardo, Romieu, I., Gutiérrez H.J., 1991. Modelos de dispersión en la atmósfera. Curso básico sobre contaminación del aire y riesgos para la salud. ECO.

Turner D.B.,1970. Workbook of Atmospheric Dispersion Estimates. USEPA AP-26.

Umbría, A., Gervilla, J., Galán, M., Valdés, R., 1999. Caracterización de partículas. Consejería de medio Ambiente. Junta de Andalucía.

US EPA, 1993. Emission factor documentation for AP-42. Section 13.2.1, Paved Roads. US Environmental Protection Agency. Office of Air Quality Planning and Standards.

US EPA, 1995. Compilation of air pollutant emission factors In: Stationary Point and Area Sources, fifth ed., vol. I. US Environmental Protection Agency. Office of Air Quality Planning and Standards. (http://www.epa.gov/ttn/chief/ap42/ch13/final/ c13s02.pdf).

US EPA, 2006a. Emission factor documentation for AP-42. Section 13.2.4, Aggregate Handling and Storage Piles. US Environmental Protection Agency. Office of Air Quality Planning and Standards.

US EPA, 2006b. Emission factor documentation for AP-42. Section 13.2.2, Unpaved Roads. US Environmental Protection Agency. Office of Air Quality Planning and Standards.

US EPA, 2011. Emission factor documentation for AP-42. Section 13.2.1, Paved Roads. US Environmental Protection Agency. Office of Air Quality Planning and Standards.

Usher, C.R., Michel, A.E., Grassian, V.H., 2003. Reactions on Mineral Dust. Chem. Rev. 103, 48834939. doi:10.1021/cr020657y.

van Ulden, A.P., 1978. Simple estimates for vertical diffusion from sources near the ground. Atmos. Environ. 12, 2125-2129.

van Ulden, A.P., Holtslag, A.A.M., 1985. Estimation of atmospheric boundary layer parameters for diffusion applications. J. Clim. Appl. Meteorol., 24, 1196-1207.

Venkatram, A., 2000. A critique of empirical emission factor models: a case study of the AP-42 model for estimating PM10 emissions from paved roads. Atmos. Environ. 34, 1-11. doi:10.1016/S1352-2310(00)00294-6

Venkatram, A., 2004. The role of meteorological inputs in estimating dispersion from surface releases. Atmos. Environ. 38, 2439-2446. doi:10.1016/j.atmosenv.2004.02.005. 
Venkatram, A., 2008. Computing and displaying model performance statistics. Atmos. Environ. 42, 6862-6868. doi:10.1016/j.atmosenv.2008.04.043.

Versteeg, H.K., Malalasekera, W., 1995. An introduction to computational fluid dynamics. The finite volume method. Longman Scientific \& Technical.

Viana Rodríguez, M., 2003. Niveles, composición y origen del material particulado atmosférico en los sectores Norte y Este de la Península Ibérica y Canarias. [Tesis doctoral].

Viana, M., Rivas, I., Querol, X., Alastuey, A., Álvarez-Pedrerol, M., Bouso, L., Sioutas, C. and Sunyer, J., 2015. Partitioning of trace elements and metals between quasi-ultrafine, accumulation and coarse aerosols in indoor and outdoor air in schools. Atmos. Environ.,106, 392-401. doi: 10.1016/j.atmosenv.2014.07.027.

Vicente, A.B., Gómez, E.T., Sanfeliu, T., 2002. Materia particulada atmosférica en el área de la plana de Castellón: procesos de aporte natural y antropogénico. Técnica Cerámica, 301, 413-415.

Vrins, E., van Duuren, H., Janssen-Jurkovicova, M., 1994. Estimation of the emission rates of fugitive dust sources, in: Proceedings of 2nd Air Pollution Conference, Barcelona, Spain, 157-168.

Wang, X., Chancellor, G., Evenstad, J., Farnsworth, J.E., Hase, A., Olson, G.M., Sreenath, A., Agarwal, J.K., 2009. A novel optical instrument for estimating size segregated aerosol mass concentration in real time. Aerosol Sci. Technol. 43:939-950. doi:10.1080/02786820903045141.

Warneck, P., 1988. Chemistry of the natural atmosphere: International geophysical series, Vol. 41. New York Acad.

Watson, J.G., Chow, J.C. and Pace, T.G., 2000a. Fugitive dust emissions. Crops,3(14), 7.

Watson, J.G., Chow, J.C., 2000b. Reconciling Urban Fugitive Dust Emissions Inventory and Ambient Source Contribution Estimates: Summary of Current Knowledge and Needed Research, DRI Document No. 6110.4F.

WBG, 1998. Pollution Prevention and Abatement Handbook 1998: toward cleaner production. The World Bank Group.

WHO, 1987. Air quality guidelines for Europe. World Health Organization Regional Office for Europe Copenhagen.

WHO, 2005. Air quality guidelines for particulate matter; ozone; nitrogen dioxide and sulfur dioxide. Global update 2005. Summary of risk assessment.

WHO, 2008. Health risks of ozone from long-range transboundary air pollution. World Health Organization, Regional Office for Europe. Copenhagen. 
WHO, 2013. Health risks of air pollution in Europe - HRAPIE project: New emerging risks to health from air pollution - results from the survey of experts. World Health Organization, Regional Office for Europe. Copenhagen 

